\title{
A comunidade zooplanctônica de lagos de pesca da Região Metropolitana de São Paulo: aspectos ecológicos e sanitários
}

Maria Ângela de Abreu Cabianca

Tese apresentada ao Programa de PósGraduação em Saúde Pública da Faculdade de Saúde Pública da Universidade de São Paulo para obtenção do título de Doutor em Saúde Pública.

Área de Concentração: Saúde Ambiental Orientador: Prof ${ }^{\mathrm{a}}$. Dr ${ }^{\mathrm{a}}$. Suzana Sendacz

São Paulo 2005

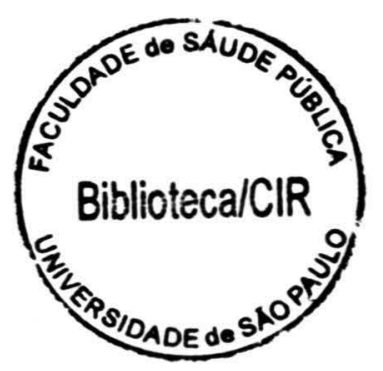


Autorizo exclusivamente para fins acadêmicos e científicos. a reprodução total ou parcial desta tese. por processos fotocopiadores. Ao usá-lo. cite a fonte. Assinatura:

Data:

$$
4608912005 \text { doc }
$$




\section{RESUMO}

Cabianca MAA. A comunidade zooplanctônica de lagos de pesca da Região Metropolitana de São Paulo: aspectos ecológicos e sanitários. São Paulo; 2005 [Tese de Doutorado - Faculdade de Saúde Pública da Universidade de São Paulo].

O presente estudo integra um projeto multidisciplinar que visou elaborar um diagnóstico ecológico-sanitário de 30 pesqueiros da Região Metropolitana de São Paulo. Como o objetivo principal de caracterizar a composição. a estrutura e a dinâmica da comunidade zooplanctônica dos lagos de pesca e suas relações com variáveis bióticas e abióticas destes ecossistemas. foram realizadas coletas de água em dois períodos do ano: estiagem-frio (setembro/outubro de 2001) e chuvoso-quente (fevereiro/março de 2002). Os resultados obtidos evidenciaram que a comunidade zooplanctônica destes ambientes foi semelhante em estrutura e composição à de corpos d'água eutróficos da bacia do Alto Tietê. Verificou-se a dominância de poucos táxons na maioria dos lagos estudados, nos dois períodos amostrados, o que evidencia uma comunidade sujeita a freqüentes instabilidades. As principais características observadas no zooplâncton estiveram possivelmente associadas ao manejo adotado nestes lagos. Este, quando inadequado, pode produzir efeitos indesejáveis do ponto de vista ecológico e sanitário. Tais efeitos associados à localização destes pesqueiros, instalados preferencialmente em áreas de mananciais da Região Metropolitana de São Paulo, podem resultar em riscos ao abastecimento de água dos municípios da região.

Descritores: zooplâncton, eutrofização, qualidade de água, pesqueiros, manejo 


\begin{abstract}
Cabianca MAA. The zooplankton community of fee-fishing systems of the Metropolitan Region of São Paulo: ecological and sanitary aspects. São Paulo: 2005 [Tese de Doutorado - Faculdade de Saúde Pública da Universidade de São Paulo].

This study is part of a multi-institutional project developed with the purpose to provide an ecological and sanitary diagnosis of 30 fee-fishing of the Metropolitan Region of São Paulo. The zooplankton community of the fee-fishing systems and its relation to biotic and abiotic variables was evaluated through analysis of water collected in two seasonal periods: cold and dry (September and October. 2001). and warm and rainy (February and March. 2002). The results showed that the structure and composition of the zooplankton community of these environments is similar to the observed for other eutrophic aquatic systemsof Alto Tietê hydrographic basin; the dominance of few taxa in most of the studied environments, in both periods, reflects a community submitted to frequent instabilities; the zooplankton characteristics reflect mainly the management imposed to these systems; the conditions generated by this inadequate management produce undesirable ecological and sanitary effects. Due to the establishment of the fee fishing mainly in water catchment areas of the Metropolitan Region of São Paulo, they represent a risk in terms of water supply for the municipalities involved.
\end{abstract}

Key words: zooplankton, eutrophication, water quality. fee fishing. management. 


\section{AGRADECIMENTOS}

A Dra. Suzana Sendacz pela orientação, amizade, paciência, carinho e dedicação na concretização deste trabalho. $O$ que houver de meritório nele se atribui. principalmente, à generosidade e valor de seus ensinamentos.

Ao Centro de Pesquisa e Desenvolvimento em Recursos Hídricos do Instituto de Pesca da Secretaria de Agricultura e Abastecimento do Estado de São Paulo, pela infra-estrutura e facilidades concedidas.

Aos senhores proprietários dos estabelecimentos incluídos neste estudo, por haverem colaborado, cedendo sua propriedade para a realização das coletas, fornecendo gentilmente as informações solicitadas e, na maioria das vezes. recebendo-nos com grande cordialidade.

A Dra. Katharina Eichbaun Esteves pela coordenação do projeto "Diagnóstico Ecológico-Sanitário de Pesqueiros da Região Metropolitana de São Paulo", no qual se insere este trabalho e por sua colaboração em diversas etapas de sua realização, sobretudo na sua viabilidade.

A Dra. Cacilda Thais Jason Mercante, chefe do Centro de Pesquisa e Desenvolvimento em Recursos Hídricos, pela amizade, colaboração e apoio material e espiritual em todas as etapas do trabalho.

Às mestrandas do Instituto de Botânica Daniella da Silva e Sandra Vieira Costa pela companhia e cooperação durante as coletas.

À Dra. Maria Helena Matté e sua orientanda Marisa Morita, da Faculdade de Saúde Pública pelas informaç̃̃es e sugestões feitas ao longo do trabalho.

Aos colegas do Centro de Pesquisa e Desenvolvimento em Recursos Hídricos do Instituto de Pesca - o técnico Luis Cláudio dos Santos Evangelista, os pesquisadores Luciana Bezerra de Menezes, Paula Maria Gênova de Castro e sua estagiária Lídia, Adalberto Jose Monteiro Jr. - pela simpática acolhida e constantes contribuições com informações, idéias ou materiais necessários ao desenvolvimento deste trabalho. 
A Dra. Lúcia Sipaúba-Tavares, do Centro de Aquicultura de Jaboticabal da Universidade Estadual Paulista Júlio de Mesquita Filho - UNESP, pela disponibilidade demonstrada na colaboração deste trabalho e pela rica contribuição na discussão dos resultados obtidos.

A Dra. Ana Lúcia Brandimarte do Departamento de Ecologia Geral do Instituto de Biociências da Universidade de São Paulo - USP, pelas sugestões e amizade de sempre.

Aos professores e funcionários da Faculdade de Saúde Pública, em especial aos do Departamento de Saúde Ambiental e Secretaria de Pós-Graduação, pela acolhida e apoio durante todo o andamento do curso de doutorado.

À geógrafa Andréa Presotto pela colaboração no estudo do entorno e na confecção dos mapas.

Aos meus pais, Luiz e Mair, pelo carinho, apoio e confiança que sempre depositaram em mim.

Aos meus sogros, Dr. Lelivaldo, pelo interesse demonstrado pelo meu trabalho e colaboração nas correções do texto, e D. Lourdes pela compreensão das minhas ausências nas reuniões familiares.

Às minhas irmãs e meus irmãos, cunhadas, cunhados, sobrinhas e sobrinhos - a família é imensa, como é imenso o seu apreço e sua importância no embasamento emocional para a realização de todo o trabalho.

Aos meus filhos, Paula e Pedro, pelo apoio que me deram em todos os momentos, colaborando com a rotina da casa, compartilhando comigo o computador doméstico e a satisfação de cada etapa concluída.

Ao Neto, dedicado, generoso, constante, incansável e imprescindível companheiro, por mais esta "viagem" que realizamos juntos. 


\section{ÍNDICE}

1 - INTRODUÇÃO .1

2 - OBJETIVOS

2.1 - Objetivos Gerais 11

2.2 - Objetivos Específicos. .11

3 - MATERIAL E MÉTODOS. .12

3.1 - Variáveis fisicas, quimicas e clorofila $a$ .14

3.2 - Análise qualitativa e quantitativa do zooplâncton .15

3.3 - Análise estatística .16

3.4 - Metodologia para a caracterização do entorno .18

3.5 - Caracterização climatológica. .19

\section{4 - RESULTADOS}

4.1 - Caracterização da área estudada

4.1.1 - Entorno .20

4.1.2 - Características das áreas de localização das bacias hidrográficas. .21

4.1.2 - Características gerais dos lagos estudados .30 
4.3 - Variáveis fisicas e quimicas e concentraçâo de clorofila $a$ 36

4.4 - Comunidade zooplanctônica

4.4.1 - Composição da comunidade.

4.4.2 - Diversidade. riqueza e equitatividade.

4.4.3 - Relação com o estado trófico 56

4.5 - Análise estatistica

4.5.1 - Análise de Componentes Principais das variáveis ambientais e clorofila $a$ .59

4.5.2 - Análise de Componentes Principais da comunidade zooplanctônica

4.5.2.1 - Rotiferos. .62

4.5.2.2 - Crustáceos .65

4.5.3 - Análise de agrupamento (Cluster). .68

\section{5 - DISCUSSÃO}

5.1 - Variáveis fisicas e quimicas e concentração de clorofila $a$ .74

5.2 - Comunidade zooplanctônica

5.2.1 - Composição da comunidade 
5.2.2 - Relação com o estado trófico e com aspectos de interesse sanitário .87

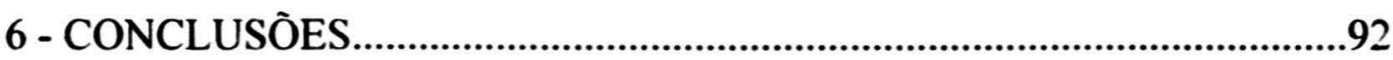

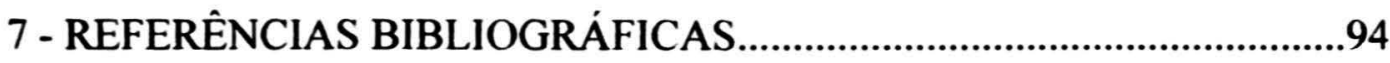




\section{Introdução}

Um dos problemas mais graves da Região Metropolitana de São Paulo (RMSP) é a ameaça aos recursos hídricos desta área que sofre pressão intensa da ocupaçâo nâo planejada e os impactos decorrentes sobre a qualidade e disponibilidade de água para a metrópole.

Os problemas da RMSP têm sido objeto de estudo de diversas áreas do conhecimento pela importância crescente desta região no cenário econômico nacional. por concentrar $10.5 \%$ da produção brasileira e comportar 18.8 milhões de habitantes numa área de $8.051 \mathrm{~km}^{2}$. Esta concentração populacional se intensificou nos últimos anos. gerando problemas que constituem um grande desafio para cientistas. urbanistas. planejadores e politicos.

Segundo MEYER et al. (2004) o "padrão predatório de expansão urbana“ - loteamentos ilegais. irregulares e clandestinos. invasões e favelas de periferia localizados em áreas impróprias à urbanização - produz impactos negativos sobre os principais mananciais que alimentam os sistemas produtores de água. Os autores mencionam também as distorções da legislação vigente, em especial a que visa a proteção das áreas de mananciais. como co-responsáveis ao processo de degradação ambiental observado.

Embora as situações mais criticas de ocupaçâo sejam verificadas nas bacias Guarapiranga e Billings. o "padrão predatório" de ocupação tende a se reproduzir em outros sistemas produtores de água como as sub-bacias de drenagem do Alto Tietê (Cabeceiras) e da Cantareira.

A presença dos estabelecimentos conhecidos como "pesque-pague" tornou-se um elemento comum na paisagem da região nos últimos dez anos, tendo surgido como uma alternativa de geração de renda aos pequenos proprietários rurais e como opção de lazer aos moradores da zona urbana. carente de áreas verdes e espaços livres. Segundo informações de fornecedores de produtos e prestadores de serviços aos pescadores e proprietários destes estabelecimentos, calcula-se que existam cerca de 1500 pesqueiros na RMSP. 
O termo "pesque-pague“ tem sido usado. tanto na imprensa quanto por órgãos governamentais, para designar um estabelecimento onde se paga pelo direito de pescar. Existem algumas modalidades destes estabelecimentos. conforme a modalidade de pagamento e destino do produto: pesque e pague (paga-se por peso ou por unidade de peixe), pague e pesque (paga-se por tempo de permanência. com direito ao produto da pesca), pesque e solte. entre outras.

KUBITZA (1997) divide os pesqueiros em duas classes. de acordo com a estratégia comercial e o tipo de manejo adotado para os estoques de peixes: os pesqueiros de concessão (aluguel) de pesca, prática mais comum nos Estados Unïdos do que no Brasil. e os do tipo pesque-pague ou pague-pesque. Neste trabalho empregaram-se os termos pesque-pague ou pesqueiro. indiferentemente à modalidade do estabelecimento de pesca.

A denominação de "lago" dada a estes ecossistemas aquáticos de natureza tão variável é controvertida. A finalidade. no entanto. é única: manter o peixe, já adulto, em condições adequadas e favoráveis a sua captura pelos pescadores que procuram o estabelecimento. Optou-se neste estudo pelo emprego da expressão "lago de pesca" para se referir especificamente a estes ambientes que contemplam diversas de origens. formas, presença ou ausência de revestimento. apresentando em comum apenas a finalidade da prática de pesca esportiva.

SIPAÚBA-TAVARES (1994) definiu como viveiros "os corpos d’água construídos pelo homem por represamento e/ou escavação do terreno natural" e tanques. os corpos d’água "menores. construídos de alvenaria. concreto ou outro material adequado".

KUBITZA (1997) empregou o termo "tanques de pesca", mencionando que represas e lagos disponiveis nas propriedades podem ser adaptados para o sistema de pesca.

LOPES (2000) chamou de lagos de pesca os ambientes aquáticos onde se pratica a pesca esportiva. 
Por sua pouca profundidade poderiam ser classificados como lagoas. mas o fato de não apresentarem uma zona eufótica que corresponda a toda a coluna d’água nem apresentarem macrófitas aquáticas em toda a sua extensâo. conforme a definição de lagoa contida em ESTEVES (1988), poderiam se situar melhor na categoria de lagos artificiais como a maioria das represas e açudes. A ausência de macrófitas aquáticas neste sistema pode estar relacionada aos constantes esvaziamentos e preenchimentos a que são submetidos os lagos. com o objetivo de renovar a água para o recebimento de novas cargas de peixe. o que implica num tempo de residência mais curto que o de outros ambientes lênticos.

De modo geral. os proprietários de pesque-pague referem-se a diversos "lagos de pesca” em suas propriedades e atendem. ainda que intuitivamente. a recomendaçào feita por KUBITZA (1997) de disponibilizar aos pescadores pelo menos dois lagos de pesca em seu pesqueiro. permitindo a eles que escolham em qual pescar. A utilização do termo "lago de pesca" vem se integrando à linguagem dos proprietários e freqüentadores de pesqueiros e seu significado torna-se cada vez mais familiar aos que visitam ou trabalham neste setor de atividades.

A procura por corpos d’água de boa qualidade. que garantam uma imagem de "ambiente saudável" para os freqüentadores faz com que estes empreendedores procurem áreas próximas às nascentes e rios pouco impactados pela ocupaçâo urbana. Como conseqüência. a grande concentração destes pesqueiros se dá próximo ou dentro de áreas de mananciais. sobretudo nas imediações das represas Billings. Guarapiranga e nos reservatórios do sistema Cantareira.

Em todo o Estado de São Paulo. onde se tornou uma importante alternativa de renda para muitos agricultores e pecuaristas. calcula-se a existência de mais de 3.000 pesqueiros que, só na bacia do rio Piracicaba. segundo KITAMURA et al. (1999), geram uma renda de US\$ 60 milhōes para os empreendedores. Estes autores afirmam que um problema crítico nos pesqueiros estudados é a qualidade da água e recomendam um estudo mais cuidadoso neste sentido. Tal medida visa não só aumentar a rentabilidade dos pesqueiros como também evitar problemas mais sérios à saúde da população que os freqüenta e consome seus peixes. Deve-se ressaltar a 
importáncia desta atividade na diversificação da economia. principalmente na possibilidade de combinações da aqüicultura. indústria e comércio. já que muitos dos estabelecimentos mantêm. além dos tanques de pesca. uma estrutura capaz de atender aos visitantes. com restaurantes e atrativos para o turismo rural. Segundo relatório da EMBRAPA (2003). estas contribuições devem gerar impactos positivos para o desenvolvimento de comunidades locais mas podem produzir impactos ambientais se não houver adequação do manejo.

Sobre a opção da implantação de piscicultura para povoamento de represas BRANCO \& ROCHA (1977) afirmam que nâo há compatibilidade da qualidade da água exigida para o abastecimento com a água para a produção de peixes. que requer certo grau de eutrofização para garantir sua produtividade.

VINATEA ARANA (2004) elenca os principais impactos que aqüicultura provoca no ambiente circundante: modificação da vazão e da temperatura da água: aumento da concentração de nitrogênio. fósforo. sólidos em suspensão. demanda quimica de oxigênio: diminuição da concentração de oxigênio dissolvido: contaminação por substâncias químicas e antibióticos: produção de sedimentos ricos em matéria orgânica: floração de algas em águas eutrofizadas: modificação do índice biótico (comunidades de invertebrados) e modificação do índice de integridade biótica (populaçôes de peixes): poluição e erosâo genéticas: aumento do risco de disseminação de enfermidades.

O estudo realizado por pesquisadores da EMBRAPA (2003) sobre pesque-pagues do interior de São Paulo aponta como impactos negativos da atividade os efeitos sobre a paisagem (com alteração do padrâo de drenagem de micro-bacias e aumento do risco de erosão), a deterioração da qualidade da água com a utilização excessiva de rações e restos de alimentos e o aumento na concentração de coliformes fecais pela presença de animais domésticos nas imediações.

A localização de lagos destinados à pesca esportiva à montante de reservatórios de abastecimento representa, portanto, uma preocupação a mais em relação aos cuidados necessários à garantia da qualidade da água dos efluentes produzidos por esta atividade. 
A avaliaçào e o controle da qualidade da água dos lagos de pesca são imprescindiveis não apenas para garantir a rentabilidade do empreendimento a médio e longo prazo. como também na tentativa de evitar o comprometimento da saúde da população que frequienta e consome seus peixes.

Muitos relatos. tanto de proprietários. usuários ou técnicos que visitam eventualmente os pesqueiros. mencionam a ocorrência de "águas esverdeadas". mortalidade de peixes por razôes desconhecidas. ou ainda a presença de peixes com características morfológicas alteradas. Além disso. irregularidades ocorrem em muitos destes ambientes em virtude da falta de fiscalização por órgão competente. da preocupação preponderante em maximizar a produçâo de peixes através de fertilização dos lagos. da ausência de cuidados com relação ao esgoto ou lixo produzidos nas imediaçōes. entre outras causas.

Também é preocupante o impacto causado pelos efluentes provenientes de lagos de pesca comercial que muitas vezes são encaminhados. sem qualquer tipo de tratamento. para corpos d’água estratégicos ao abastecimento de alguns municipios.

Estudos realizados por ELER \& ESPÍNDOLA (2003) ressaltam os impactos negativos associados à operação dos pesque-pagues. Dentre eles, os mais significativos são a produção de efluentes eutrofizados e a introdução de espécies exóticas nas bacias de drenagem.

As caracteristicas destes lagos de pesca apresentam algumas peculiaridades: de modo geral são lagos rasos. com tempo de residência mais reduzido e variável que de outros lagos. determinado principalmente pela disponibilidade de água. freqūência de chuvas ou pela necessidade de "renovar" 0 ambiente para receber novo lote de peixes. Há casos em que a renovação da água é feita duas vezes ao dia.

Diferentemente dos sistemas convencionais de piscicultura. os peixes são colocados já adultos nos lagos. onde são alimentados intensivamente para atingir peso e tamanho atraente para os pescadores. Os estágios anteriores de 
desenvolvimento. como larvas e alevinos. são considerados indesejáveis e freqüentemente descartados.

Torna-se, portanto. dificil prever o mojelo de funcionamento deste ecossistema tâo manipulado e constantemente alterado.

A associação que se estabelece entre a saúde humana e a saúde dos ecossistemas é tratada por NIELSEN (2001) que ressalta que "a promoção da saúde humana deve incluir a busca pela saúde do ecossistema“. $\mathrm{O}$ autor reconhece como sendo de grande utilidade o conhecimento de diferentes comunidades que podem se tornar em seu conjunto. importantes indicadores da saúde do ecossistema.

Conforme o conceito proposto por FORATINI (1992). "a saúde é resultante. em nivel de organismo. do desempenho fisiológico. traduzido pela ausência de desabilidade funcional". Se tal conceito é transposto a um outro nivel organizacional dos seres vivos, ou seja. se ao invés de considerarmos o organismo. consideramos o ecossistema, poderemos considerá-lo saudável se seus aspectos funcionais operarem plenamente (saúde plena) ou satisfatoriamente (saúde relativa).

A análise das comunidades planctônicas possibilita a compreensâo das condições existentes no ambiente aquático, pois as espécies que as constituem representam sensores precisos das propriedades do manancial (BRANCO. 1991).

A estrutura e dinâmica do plâncton respondem rapidamente às mudanças do ambiente, podendo funcionar como indicadores ecológicos e auxiliar no entendimento da dinâmica do ecossistema (NOGUEIRA \& MATSUMURATUNDISI, 1996).

O zooplâncton, por representar um dos elos da cadeia alimentar estabelecida em ambientes aquáticos. ocupa importante papel na estrutura trófica das comunidades aquáticas, proporcionando a ligação entre produtores e consumidores. Deste modo, a herbivoria exercida por alguns grupos do zooplâncton pode regular a densidade e diversidade do fitoplâncton, promovendo o desenvolvimento de microalgas coloniais ou filamentosas ou reduzindo o fitoplâncton menor e mais 
consumivel (LAMPERT. 1982).

A diversidade de hábitos alimentares dos grupos que compõem a comunidade possibilita que se façam inferências sobre o papel destes organismos como indicadores da qualidade da água.

A influência controladora reciproca exercida pelas comunidades aquáticas e as fontes alimentares disponiveis no ambiente é discutida por CAIRNS et al. (1993): variações no aporte de nutrientes influem na quantidade e qualidade do alimento disponivel (efeito "bottom-up"). enquanto este é controlado pela predação (efeito "top-down").

Segundo MORIARTY (1997). o microzooplâncton exerce importante papel também na ciclagem de nutrientes de lagos de aqüicultura como mineralizador de nitrogênio ao se alimentar de bactérias.

PINTO COELHO (2000) afirma que as bactérias pequenas e de crescimento rápido podem ser a principal fonte de alimento de muitos rotíferos $\mathrm{e}$ cladóceros do zooplâncton tropical. $\mathrm{O}$ autor reforça ainda a importância do zooplâncton na remineralização de nutrientes (pela excreçâo de amônia e ortofosfato), papel que anteriormente era atribuido prioritariamente às bactérias.

As novas metodologias de estudo das bactérias permitiram diferenciá-las mais. tanto em relação a sua taxonomia, quanto aos diferentes papéis e interações que desempenham nos ecossistemas. A melhor compreensão das 'rotas tróficas alternativas" por onde fluem matéria e energia possibilita a identificação de outras fontes de alimento e energia e de diferentes relações tróficas entre os organismos das comunidades aquáticas. $\mathbf{O}$ zooplâncton, que apresenta várias espécies consumidoras de bactérias associadas ou não a flagelados e ciliados, tem sido considerado o principal agente remineralizador na zona pelágica de mares e grandes lagos (PINTO COELHO , op. cit.).

Há ainda a possibilidade de algumas espécies do zooplâncton estarem associadas a bactérias patogênicas, como as do gênero Vibrio o que aumenta a 
importância de seu controle do ponto de vista sanitário. ARAÚJO et al. (1996) estudaram a influência do copépode Mesocylops longisetus na sobrevivência de Vibrio cholerae em água doce. constatando a associação da bactéria ao copépode. Em HUQ \& COLWELL (1995) e HUQ et al. (1996) tal associaçâo é registrada com freqüência seja em ambiente marinho ou de água doce.

VENKATESWARA et al. (1989) ressaltam que o aumento da concentração de nutrientes. originado principalmente pelo lançamento de esgotos. estimula a proliferação deste patógeno. A presença de crustáceos planctônicos favorece o desenvolvimento destas bactérias mas nâo sâo responsáveis por sua ocorrência nos corpos d’água

A escassez de informaçôes sobre os ambientes constituídos pelos pesqueiros e a possibilidade destes virem a produzir meios propicios às florações de cianobactérias constitui um outro problema a ser avaliado devido à gravidade da situação representada pelos efeitos nocivos causados por estas aos organismos aquáticos e à população envolvida.

Estudos realizados em outros paises sugerem que a eutrofizaçâo é um problema sério enfrentado em tanques de criação de peixes, podendo ser causada por diversos fatores. entre eles o uso de fertilizantes quimicos na agricultura, bem como produtos compostos por polifosfatos que podem ser desencadeadores de um processo de enriquecimento artificial em diversos ecossistemas aquáticos. Este processo produz mudanças na qualidade da água, incluindo a reduçâo de oxigênio dissolvido. perda das qualidades cênicas, aumento do custo de tratamento, morte extensiva de peixes e aumento de incidências de floraçôes de microalgas e cianobactérias (AZEVEDO. 1998).

Florações de cianobactérias sâo comuns em lagos ou tanques de cultivo, especialmente em regiões tropicais, onde as altas temperatura: pequena circulação da água $\mathrm{e}$ altos teores de nutrientes criam condições favoráveis para o desenvolvimento deste grupo.

Na cidade de São Paulo MATSUZAKI (2002) E MATSUZAKI et al. 
(2004) realizaram estudos abordando aspectos ecológicos e sanitários da comunidade fitoplanctônica de um pesqueiro e constataram a presença de cianobactérias potencialmente tóxicas.

Os efeitos das cianotoxinas sobre o zooplâncton podem ser de caráter inibitório. onde a formação de colônias ou filamentos interfere na filtração e o alimento disponivel é de baixo valor nutritivo e pouco digerivel. ou toxicológico. Este caso é verificado na ocorrência de cepas tóxicas de cianobactérias. cujas causas não são ainda bem determinadas. mas sabe-se que compostos secundários. como as microcistinas. são produzidos por cianobactérias e seu efeito sobre os invertebrados não é tão bem conhecido como em mamíferos.

Dentre os estudos realizados no Hemisfério Norte que abordam interaçôes entre o zooplâncton e cianobactérias. destacam-se os DE MOTT et al. (1991). FULTON \& JONES (1991). HANAZATO (1991), HENNING et al. (1991), HIETALA et al. (1996). JUNGMANN et al. (1991 e 1994), KOTAK et al. (1996), VASCONCELOS (1990 e 1999), entre outros.

No Brasil os efeitos tóxicos de Microcystis aeruginosa sobre cladóceros na lagoa de Jacarepaguá (RJ) foram avaliados por FERRÃO FILHO, (1998) e FERRÃO FILHO et al. (2000). Outros grupos de pesquisadores brasileiros têm acompanhado a ocorrência de florações de algas tóxicas e avaliado seu potencial de toxicidade em São Paulo (ZAGATTO. 1995) e no Rio Grande do Sul (MATTHIENSEN et al.. 1999. WERNER et al., 2000).

Outro aspecto a ser considerado no estudo da comunidade zooplanctônica de lagos de pesca é a própria estrutura da comunidade que aí se estabelece, levandose em conta o curto tempo de residência decorrente da alta taxa de renovação e circulação de água, com a finalidade de promover oxigenação e eliminação de “substâncias indesejáveis".

Deve-se considerar, ainda, a possivel influência sobre a composição da comunidade zooplanctônica constante introdução de peixes trazidos de diferentes regiões do país (Paraná e Mato Grosso, principalmente), juntamente com a água 
procedente do local de cultivo. levando a supor que inúmeras espécies do zooplâncton possam estar sendo transportadas entre diferentes bacias hidrográficas. Torna-se importante que se realizem investigaçōes sobre estas ações e suas conseqüências para a biodiversidade. sobretudo para os organismos de água doce.

Os trabalhos sobre a qualidade da água e as comunidades aquáticas dos lagos de pesca ainda sâo pouco numerosos. podendo-se citar os que vêm sendo desenvolvidos pela EMBRAPA (2003) no interior do estado de São Paulo e pelo grupo de pesquisadores do CHREA- USP. coordenados por ELLER \& ESPINNDOLA (2003). com pesqueiros da bacia do rio Mogi-Guaçu: como também são raros os estudos que enfocam a saúde de peixes procedentes de pesque-pague. como o realizado por VARGAS et al. (2003). KUBITZA (1997) propõe algumas recomendaçôes para os sistemas de pesca recreativa que incluem os cuidados com a infra-estrutura básica e a manutenção da qualidade da água. baseada num programa de adubação e no controle de aspectos físicos e químicos, principalmente oxigênio dissolvido. transparência. $\mathrm{pH}$. amônia e nitrito. além de alguns aspectos relacionados ao estoque de peixes nos tanques de pesca. Um aprofundamento sobre as condições limnológicas dos lagos de pesca. incluindo as comunidades aquáticas. pode representar uma contribuição importante à compreensão dos aspectos funcionais e dinâmicos destes ecossistemas.

Este estudo fez parte do projeto: Diagnóstico Ecológico-Sanitário de Pesqueiros da Região Metropolitana de São Paulo. financiado pela FAPESP e desenvolvido por pesquisadores do Instituto de Pesca - Secretaria de Agricultura e Abastecimento. Instituto de Botânica - Secretaria do Meio Ambiente, e do Departamento de Microbiologia da Faculdade de Saúde Pública - USP. O objetivo do projeto foi de realizar um levantamento das condições ecológicas e sanitárias em que funcionam estes pesqueiros. a partir da análise física, química e biológica da água e dos aspectos biológicos e sanitários dos peixes encontrados nos lagos de pesca. 


\section{OBJETIVOS}

\section{1 - Objetivo geral}

- Conhecer a estrutura e dinâmica da comunidade zooplanctônica dos lagos de pesque-pague da Região Metropolitana de São Paulo. contribuindo com subsidios para o diagnóstico ecológico-sanitário dos lagos de pesca da Regiâo Metropolitana de São Paulo

\section{1 - Objetivos específicos}

- Avaliar a influência do manejo dos lagos de pesque-pague na composiçâo da comunidade zooplanctônica.

- Estabelecer relaçôes entre a comunidade zooplanctônica e outras variáveis bióticas e abióticas destes ambientes.

- Avaliar os efeitos da introdução de espécies exóticas de peixes sobre a composição da comunidade zooplanctônica da bacia hidrográfica estudada.

- Avaliar a influência exercida pelas florações de algas na comunidade zooplanctônica destes lagos.

- Oferecer informações que subsidiem um plano de manejo para os lagos de pesque-pague. visando obter melhores condições ecológicas e sanitárias. garantindo a boa qualidade do ambiente e da saúde da população. 


\section{Material e Métodos}

- Área de estudada

Foram selecionados 30 pesqueiros na Região Metropolitana de São Paulo. levando-se em conta as condições de acesso ao local e disponibilidade do proprietário em participar do levantamento. Para os pesqueiros onde se realizou o estudo foi definido um código numérico (por razões éticas o nome do estabelecimento não foi mencionado bem como suas coordenadas geográficas). A distribuição por municípios resultou da seguinte forma: 2 pesqueiros no municipio de Santa Isabel: 1 no município de Arujá; 3 no município de Mairiporã; 3 no município de Santana do Parnaiba: 1 no municipio de Itapecerica da Serra: 2 no municipio de Vargem Grande Paulista: 1 no municipio de São Lourenço da Serra: 6 na região de Santo Amaro. municipio de São Paulo. 2 no municipio de Mauá: 3 no município de Suzano: 1 no municipio de Ribeirão Pires: 1 no município de São Bernardo do Campo; 1 no municipio de Mogi das Cruzes e 3 no município de Cotia (figura 1).

- Periodo de Amostragem

Foram feitas duas séries de coletas nos lagos de pesca dos pesqueiros, uma no final do período estiagem/frio (setembro/outubro de 2001) e outra no final periodo chuvoso/quente (fevereiro/março de 2002). Foi amostrado um lago de cada estabelecimento. em geral localizado à jusante do sistema de lagos. Devido a grande variação da morfometria dos lagos estudados, optou-se amostrar em todos eles um ponto onde a profundidade variasse entre $1 \mathrm{~m}$ e $1,5 \mathrm{~m}$, sendo amostrada toda a coluna d'água para as amostras de zooplâncton e a sub-superficie para as demais variáveis. 


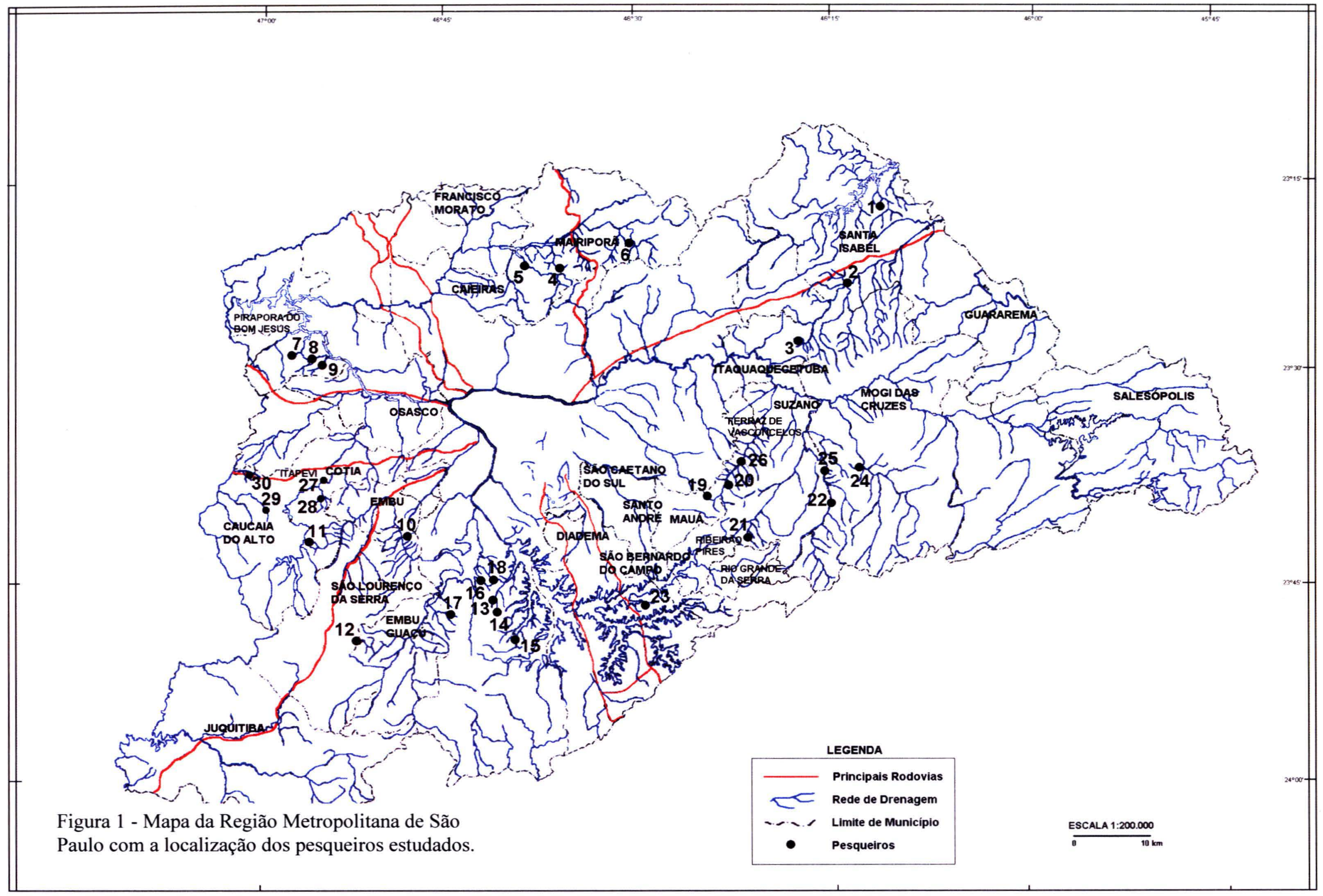




\section{1 - Variáveis fisicas, químicas e clorofila-a.}

Para a determinação feita em campo das variáveis como temperatura da água $\left({ }^{\circ} \mathrm{C}\right)$, oxigênio dissolvido $(\mathrm{mg} / \mathrm{L})$. pH. turbidez (UNT) e condutividade elétrica $(\mu \mathrm{S} / \mathrm{cm})$ empregou-se uma sonda multiparâmetros da marca Horiba. modelo U22. A transparência da água foi determinada utilizando-se um disco de Secchi.

As análises das amostras de clorofila-a. sólidos totais em suspensão. nitrogênio inorgânico e fósforo total foram realizadas no Centro de Pesquisa e Desenvolvimento em Recursos Hidricos do Instituto de Pesca (Secretaria de Agricultura e Abastecimento do Estado de São Paulo). As amostras para a determinação destas variáveis foram filtradas com auxílio de bomba a vácuo. através de filtro Milipore AP 20. de $4.5 \mu \mathrm{m}$ de porosidade e. posteriormente. congeladas. A metodologia empregada na determinação é descrita a seguir:

- Clorofila-a $(\mu \mathrm{g} / \mathrm{L})$ - determinada pelo método de extração por etanol, conforme MARKER et al. (1980)

- Sólidos totais em suspensão (mg/L): técnica gravimétrica descrita em WETZEL e LIKENS (1991).

- Nitrogênio inorgânico (mg/L): obtido da soma das concentraçôes de nitrato. nitrito (determinadas pelo método de Griess modificado (GINÉ et al., 1980)) e nitrogênio amoniacal (determinada pelo método de Nessler (APHA. 1979)).

- Fósforo total (mg/L): técnica descrita em SRICKLAND \& PARSONS (1960) - para esta determinação não se empregou a etapa da filtragem. 


\section{2 - Análise qualitativa e quantitativa do zooplâncton}

A partir de amostras coletadas com rede de plâncton de malha de $60 \mu \mathrm{m}$. onde. com o auxilio da bomba de sucção submergivel. marca Rule. modelo 1500/2000 GPH. acoplada a uma bateria de 12 volts: foi filtrado um volume de $100 \mathrm{~L}$ de água $\mathrm{e}$ acondicionado em frascos de $200 \mathrm{~mL}$. As amostras foram fixadas em soluçâo de formalina a $4 \%$.

Foi feita a identificação e quantificação dos organismos zooplanctônicos com o auxílio de microscópio óptico e estereoscópico e bibliografia especializada. empregando-se as técnicas de sub-amostragem diferenciadas para rotíferos e microcrustáceos.

Para a quantificação dos rotíferos foram contadas aliquotas de $1 \mathrm{ml}$ da amostra. em lâmina de Sedgewick-Rafter sob microscópio óptico (contou-se um número de aliquotas necessário a atingir $\mathbf{3 0 0}$ individuos deste grupo).

A quantificaçâo dos crustáceos foi feita a partir da contagem de subamostras contidas em quadrantes de uma placa de Petri de aproximadamente $10 \mathrm{~cm}$ de diâmetro: quando se verificaram densidades muito baixas de organismos zooplanctônicos. a amostra foi contada em sua totalidade.

Algumas amostras apresentaram grande abundância de protozoários que nâo foram incluidos neste estudo por requererem técnicas especificas de coleta $e$ identificação.

Para a caracterização da estrutura da comunidade foram determinados:

- a - Densidade Numérica: número de organismos por metro cúbico, a partir da förmula $D=N / V$, onde $D$ é a estimativa da densidade expressa em indivíduos por metro cúbico (ind/m3), $\mathrm{N}$ o número de indivíduos capturados e $\mathrm{V}$ o volume filtrado pela rede: 
- b - Abundância Relativa: porcentagem de individuos pertencentes a um grupo taxonômico em relação ao número total de organismos da amostra:

- c-Riqueza (S): somatória dos táxons presentes na amostra:

- d - Diversidade $\left(\mathrm{H}^{\circ}\right)$ : calculada através do İndice de Shannon-Weaver (1949 apud ODUM. 1985) através da fórmula

$$
H=-\sum_{i=1} \frac{N i}{N} \log _{2} \frac{N i}{N}
$$

onde s é o número de espécies: $\mathrm{Ni}$ o número de indivíduos em cada espécie e $\mathrm{N}$ o número total de individuos.

- e - Equitatividade ou uniformidade (E): calculada através da expressão de PIELOU (1975 apud ODUM, 1985), utilizando a fórmula $E=$ H'/H'max, onde $\mathrm{H}^{\prime}$ é a diversidade de espécies obtida pelo indice de Shannon-Weaver e H'max. a diversidade de espécies sob condições de máxima equitatividade.

\section{3- Análise estatística}

- "Box-Plot"

Para a análise dos resultados das variáveis físicas e quimicas e de clorofila- $a$, foram elaborados gráficos do tipo Box-Plot, que possibilitam a observação da faixa de variação dos dados e a deteç̧ão de valores extremos. Cada conjunto de dados é apresentado em quatro áreas: um retângulo (“box") que compreende $50 \%$ dos dados , dividido em duas partes pela mediana daquele conjunto de dados; a média é representada por uma cruz. $O$ gráfico resultante representa de modo diagramático 5 números sumários: os valores mínimo e máximo, os quartis inferior e superior e a mediana. 
- Análise multivariada

Foram elaboradas para os lagos estudados matrizes de covariânica dos valores obtidos para as variáveis ambientais e clorofila- $a$. transformados em $\log (x+1)$ para normalização: aplicou-se a Análise de Componentes Principais (ACP). técnica estatística multivariada que trabalha com a estrutura interna de matrizes e consiste em um método de fracionar uma matriz de associação em um conjunto de eixos ortogonais (perpendiculares) ou componentes (LUDWIG e REYNOLDS. 1988).

Esta análise foi aplicada também para os táxons mais freqüentes do zooplâncton (com freqüência de ocorrência superior a $70 \%$ das amostras). sendo elaboradas matrizes de correlação entre os valores de densidades numéricas. Foi também aplicada a análise de agrupamento ("cluster analysis") que tem como objetivo evidenciar as associações entre espécies, ou seja. reconhecer entre as mesmas um grau de similaridade suficiente para reuni-las em um mesmo conjunto. visando descrever. da maneira clara e sintética, a estrutura de um corpo d'água. determinando a composição e a extensão das suas unidades funcionais (VALENTIN. 2000).

Esta análise foi aplicada também com a intenção de agrupar os pesqueiros estudados, conforme sua similaridade em relação aos táxons mais freqüentes do zooplâncton. Foi empregado o método de aglomeração de Wards (variância mínima) que, segundo VALENTIN (op. cit). é considerado o mais eficiente, embora não apresente o melhor coeficiente cofenético (o coeficiente cofenético mede o grau de distorção de um dendrograma). Neste método, um grupo será reunido a um outro se essa reunião proporcionar o menor aumento da variância intragrupo. Utilizou-se como medida de distância o coeficiente de correlaçâo de Pearson.

O programa estatístico empregado para estas análises é o PC-ORD, versão 3.0 para Windows (McCUNE \& MEFFORD, 1997). 


\section{4 - Metodologia para a caracterização do entorno}

Utilizando o mapa da Região Metropolitana de São Paulo contendo a localização dos pesqueiros estudados. carta base da Região Metropolitana de São Paulo (1979). em escala de 1:100000. e com informações adicionais sobre a UGRHI 6 (Unidade de Gerenciamento de Recursos Hídricos $\mathrm{n}^{\mathbf{0}} 6$ - Alto Tietê) , realizou-se a divisão dos pesqueiros por sub-bacias. Também foram extraidas destas fontes as informações sobre a drenagem. uso do solo, geologia. geomorfologia e clima da área abrangida pelas sub-bacias do Alto Tietê.

Foram utilizadas também as informações contidas em mapas temáticos elaborados pelo Laboratório de Informática Geológica do Instituto de Geociências USP. do projeto Banco de Dados Espaciais para a Bacia Hidrográfica do Alto Tietê (IG USP. 1999).

Em relação à bacia do rio Paraíba do Sul foi feita uma caracterização geral (www.sigrh.sp.gov.br), havendo apenas um pesqueiro estudado nesta área e localizado muito próximo à bacia adjacente (Alto Tietê - Sub-bacia Cabeceiras).

O levantamento realizado nos pesqueiros contribui para parte das análises ambientais necessárias que devem ser utilizadas no planejamento e manutenção de tal atividade.

Para todos os pesqueiros visitados foram levantadas, com o auxílio de GPS (Global Position System), suas coordenadas geográficas e altitudes, posteriormente localizadas no mapa em gabinete. Com a carta base da Região Metropolitana de São Paulo (1979), foram projetadas as coordenadas geográficas, gerando um mapa com a localização dos pesqueiros (figura 1). Tal localização, pela escala utilizada (1:100.000), apresenta distorções e nâo é precisa no nivel dos cursos d'água, porém para efeito de análise, pode ser considerada com maior precisão no nivel da divisão de bacias hidrográficas proposta pela CETESB (1999). 
O levantamento em campo realizado nos pesqueiros levou em consideração aspectos passiveis de serem detectados por meio de observação das condições gerais do local. Para tanto. uma ficha com o levantamento das caracteristicas foi confeccionada especialmente para dar suporte ao trabalho de campo (anexo 1).

\section{5 - Dados climatológicos}

Os dados climatológicos foram obtidos no site do IAG-USP (2004), de onde foram extraidas as temperaturas minimas. médias e máximas mensais e volume de precipitação mensal dos anos de 2001 e 2002 


\section{RESULTADOS}

\section{1 - Caracterização da Área Estudada}

\subsection{1 - Entorno}

A área do estudo concentrou-se quase que em sua totalidade na bacia hidrográfica do Alto Tietê (figura 1), com exceção de um pesqueiro localizado na bacia hidrográfica do rio Paraíba do Sul. O mapa resultante do estudo de localização dos pesqueiros na Regiâo Metropolitana de São Paulo (RMSP) está representado na figura 1.

A tabela 1 mostra a altitude dos pesqueiros amostrados e algumas caracteristicas observadas na área de entorno ao lago estudado.

Dentre os pesqueiros levantados. $76.6 \%$ apresentavam cobertura vegetal do tipo grama e 6,6\% não apresentavam cobertura alguma. Associada a presença de grama, $13,3 \%$ apresentavam solo exposto e $16,6 \%$ apresentavam outro tipo de vegetação e apenas $6,6 \%$ demonstravam cuidados de ajardinamento, buscando cumprir funções relacionadas à estética em espaços livres'.

Em relação aos topos de morro. que são áreas de preservação permanente. segundo a Lei $4.771 / 65$ do Código Florestal Brasileiro. em $16.6 \%$ dos pesqueiros eles estão desmatados ou estão ocupados com atividades agricolas; $36.6 \%$ dos pesqueiros visitados, apresentavam reflorestamento com espécies de Eucaliptus ou Pinus no topo de morro, concomitante com áreas de mata.

Em 56,6\% dos pesqueiros, a mata nativa do entorno encontra-se pouco modificada, ou seja, não houve desmatamento. Em apenas 3,3\% a mata do entorno dos pesqueiros foi desmatada, reforçando a idéia de que a conservação da mata pode se associar a tal atividade.

\footnotetext{
1 A soma das percentagens pode, em alguns casos. ultrapassar $100 \%$, uma vez que os pesqueiros apresentam caracteristicas associadas.
} 
Outra presença frequentemente observada no entorno dos pesqueiros são as áreas de nascente. que estão presentes em $36.6 \%$ deles. também consideradas de preservação permanente.

Dentre eles. $36.6 \%$ apresentam algum tipo de agricultura. Em $33.3 \%$ foram observadas atividades relacionadas à criação de animais domésticos (gado, porcos e aves). A grande maioria (80\%). não apresentava sinais de erosão em seu entorno.

\subsection{2 - Características das áreas de localização das Bacias Hidrográficas}

Para o gerenciamento das bacias hidrográficas o Sistema de Gerenciamento de Recursos Hidricos é composto por duas instâncias consultivas e deliberativas: o Conselho Estadual de Recursos Hidricos e os Comitês de Bacia Hidrográfica, criados a partir da Lei 7.663/91 e implantados em 1997. Para o Comitê de Bacias, existem representantes estaduais. municipais. das universidades e institutos de ensino e pesquisa, do ministério público e também da sociedade civil organizada. Para o Alto Tietê, foram criados sub-comitês de Bacia Hidrográfica. num total de 5 sub-comitês da Região Metropolitana e têm como finalidade principal elaborar. implantar e gerenciar a nova legislaçâo de proteção aos mananciais da RMSP (Região Metropolitana de São Paulo).

A Bacia Hidrográfica do Alto Tietê corresponde à área drenada pelo Rio Tietê a montante da Barragem de Pirapora, até as suas nascentes em Salesópolis (35 municípios - a maioria dos municípios integrantes da RMSP); apresenta grande complexidade da dinâmica urbana e sócio-econômica, assim como de suas características hidráulicas e hidrológicas, alteradas pela ocupação antrópica (FUSP, 2001). Devido a sua geologia, a Bacia do Alto Tietê possui muitos pontos de recarga de aqüifero (alimentação das águas subterrâneas). Segundo HIRATA \& FERREIRA (2001), a recarga é feita por dois mecanismos distintos: a natural. com águas de precipitação que infiltram no solo e atingem o aqüifero, $\mathbf{e}$ a induzida, representada por águas provenientes de fugas das redes 
de água e esgoto. Por este motivo também. ou seja, pela necessidade de reabastecer o aqüifero. a Bacia do Alto Tietê deveria sofrer menor impacto por atividades incompativeis com sua importância, principalmente no abastecimento.

Quanto a sua geomorfologia. a região está inserida no Planalto Atlântico (região de terras altas. constituida predominantemente por rochas cristalinas pré-cambrianas e cambro-ordovicianas. cortadas por intrusivas básicas e alcalinas mesozóicas. e pelas coberturas das bacias sedimentares de São Paulo e Taubaté) (IPT. 1981). O intervalo altimétrico vai de $600 \mathrm{~m}$, predominantemente na área ao sul da bacia. a $1.400 \mathrm{~m}$; altitudes entre 1.150 a $1.400 \mathrm{~m}$ correspondem às áreas de maior elevação. localizadas no extremo leste da bacia. contiguas à Serra do Mar e em alguns pontos ao norte. identificados na regiāo da Serra da Cantareira (IG-USP. 1999).

A maior parte da área urbana do Alto Tietê está assentada sobre terrenos sedimentares (Cenozóica). relevo de colinas, compreendendo os depósitos terciários da Bacia Sedimentar de São Paulo $\left(1.452 \mathrm{~km}^{2}\right)$ e as coberturas aluviais mais recentes (Quaternário), desenvolvidas ao longo dos principais rios que drenam a região. A planicie aluvial ampla. onde se encontra a calha do rio Tietê era originalmente recoberta por vegetação de várzea (FUSP, 2001).

Os terrenos cristalinos contornam as áreas sedimentares e configuram praticamente toda a borda da RMSP, concentrando-se neles as áreas de cobertura vegetal e de mananciais hídricos de superficie (CEPAS, 1994; apud FUSP, op. cit.). Entre as elevações maiores. destacam-se as serras do ltapety e da Cantareira, recobertas com significativos remanescentes florestais, ambas sob proteção legal. (FUSP, op. cit.).

Na Bacia Hidrográfica do Alto Tietê verifica-se a presença de quatro domínios de solos com a predominância das seguintes classes de solos (FUSP, op. cit.).:

1) Cambissolo álico. A moderado, textura argilosa (C): 
2) Podzólico Vermelho Amarelo álico, A moderado, textura média/argilosa e argilosa/muito argilosa (PV);

3) Latossolo Vermelho Amarelo álico, A moderado, textura argilosa (LV); e

4) Solos Hidromórficos (HO).

Em relação ao clima, a bacia do Alto Tietê apresenta clima situado no limite da zona Cfb (sem estação seca, verões tépidos) com a zona Cwb (inverno seco), segundo a classificação de Köppen, com total de chuvas entre 30 e $60 \mathrm{~mm}$ para o mês mais seco.

Os pesqueiros visitados e localizados no mapa (figura 1) pertencem às seguintes bacias e sub-bacias:

\section{Bacia do Rio Paraíba do Sul}

A figura 2 mostra o trecho da Região Metropolitana de São Paulo pertencente à bacia do rio Paraíba do Sul, onde está localizado o pesqueiro de código 01 .

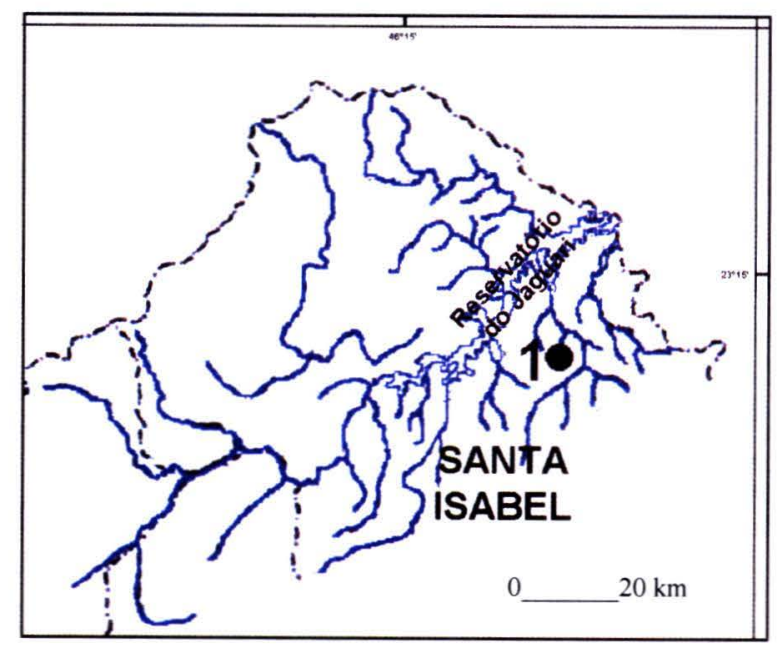

Figura 2: Trecho da RMSP pertencente à bacia do rio Paraíba do Sul 
A área total de drenagem da bacia do Rio Paraíba do Sul é de 14.547 km2 (a área estudada está a montante do reservatório de Jaguari), com terrenos cristalinos Cenozóico.

Os principais problemas na área são: o tratamento insuficiente de esgoto (<30\%) e disposição inadequada de lixo, segundo o Comitê de Bacia do Rio Paraíba do Sul.

\section{Sub-Bacia do rio Tietê Alto - Cabeceiras}

A figura 3 mostra a área pertencente à sub-bacia do rio Tietê Alto - Cabeceiras, onde estão localizados os pesqueiros de código 02, 03, 22, 24 e 25.

A área total de drenagem desta sub-bacia é de $1889 \mathrm{~km} 2$ (nascente do rio Tietê até a divisa com Itaquaquecetuba - $74 \mathrm{~km}$ ).

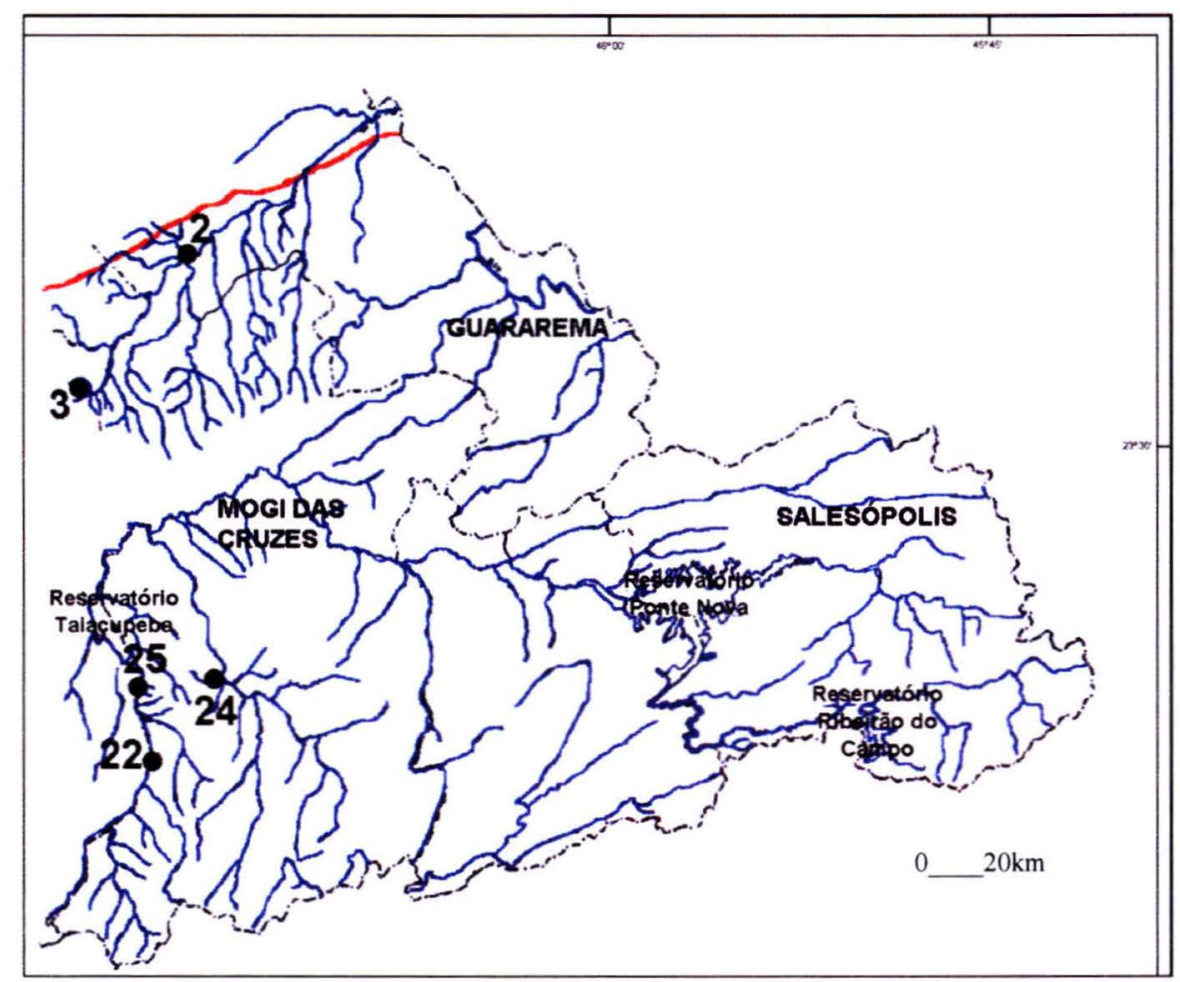

Figura 3: -Bacia do rio Tietê Alto - Cabeceiras 
Uso predominante do solo desta área apresenta atividades conflitantes (hortifrutigranjeiras, pastagens naturais e cultivadas nas zonas rurais dos municípios de Mogi das Cruzes, Suzano e Itaquaquecetuba, industrialização significativa, próximo à capital e a Mogi das Cruzes; extração mineral, principalmente areia) (CETESB, 2001).

\section{Sub-Bacia do Reservatório Billings}

A figura 4 mostra a área pertencente à sub-bacia do Reservatório Billings, onde estão localizados os pesqueiros de código 13, 14, 15, 19, 20, 21, 23 e 26.

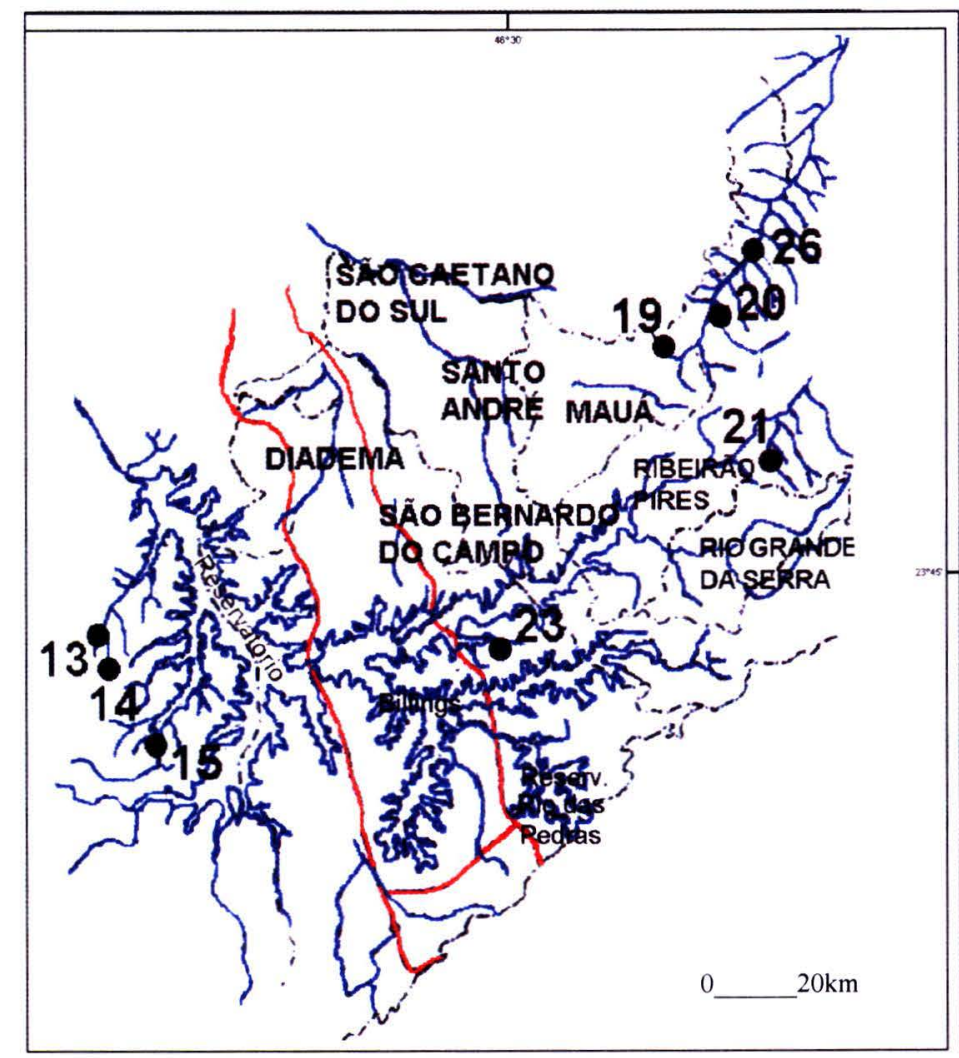

Figura 4: Sub-Bacia do Reservatório Billings

A área de drenagem desta sub-bacia é de $560 \mathrm{~km}^{2}$ (abrange os reservatórios Billings e do Rio Grande e Rios Grande, Pequeno, Bororé e Taquacetuba, entre outros). 
O Reservatório Billings pode receber as águas do Rio Pinheiros, por meio dos bombeamentos na Estação Elevatória de Pedreira.

O uso do solo na área é de substituição da vegetação natural e da pequena atividade agricola por um processo de intensa urbanização. Apesar das condições físicas desfavoráveis. que acabam ocasionando problemas como escorregamento. erosão e assoreamento e da existência da Lei da Proteção aos Mananciais. a ocupação da área vem se acelerando.

A regiâo atualmente caracteriza-se por grandes contrastes, associando chácaras de recreio com favelas e loteamentos irregulares e clandestinos (CETESB. 2001).

\section{Sub-Bacia do Reservatório Guarapiranga}

A figura 5 mostra a área pertencente à sub-bacia do reservatório Guarapiranga. onde estão localizados os pesqueiros de código 10. 12. 16. 17 e 18.

A área correspondente a esta sub-bacia é ocupada com chácaras de recreio, loteamentos com baixa densidade ou ainda não ocupados e áreas rurais (ltapecerica da Serra e Embu-Guaçu) (CETESB, 2001). A área de drenagem é de $631 \mathrm{~km}^{2}$ (Rio Guarapiranga e seus afluentes: Lavra. Santa Rita. Embu-Guaçu. Embu-Mirim e outros 17 córregos de menor extensão). Existem ai quatro áreas com urbanização intensa (Bororé. Riviera. Embu e Itapecerica da Serra) e áreas com ocupação esparsa (Parelheiros. Cipó e Embu-Guaçu) 


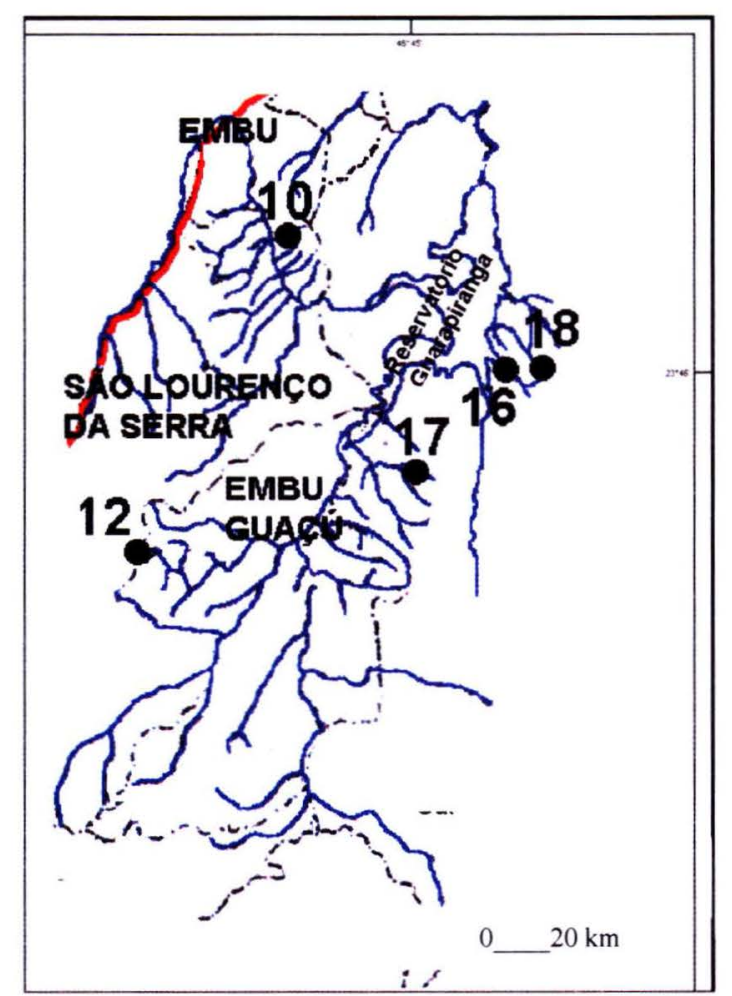

Figura 5: Sub-Bacia do reservatório Guarapiranga

\section{Sub-Bacia do Rio Cotia}

A figura 6 mostra a área pertencente à sub-bacia do rio Cotia, onde estão localizados os pesqueiros de código 11, 27, 28, 29 e 30. 


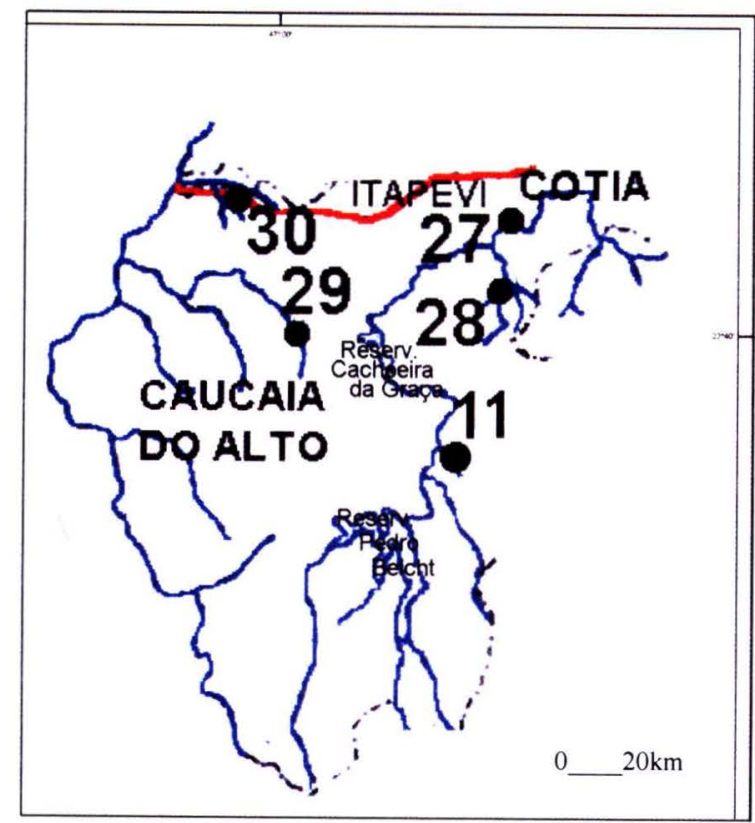

Figura 6: Sub-Bacia do Rio Cotia

A área de drenagem desta sub-bacia é de $250 \mathrm{~km}^{2}$ (Rio Cotia). O rio Cotia Alto, a montante do município de Cotia, tem suas águas represadas em dois reservatórios (Pedro Beicht e Cachoeira da Graça) e área coberta por matas naturais da Reserva Estadual de Morro Grande.O rio Cotia Baixo apresenta urbanização com cerca de 400 indústrias e trechos reflorestados (CETESB, 2001).

\section{Sub-Bacia do Rio Tietê Alto - Zona Metropolitana}

A figura 7 mostra a área pertencente à sub-bacia do rio Tietê Alto - Zona Metropolitana, onde estão localizados os pesqueiros de código 4, 5, 6, 7, 8 e 9 . 


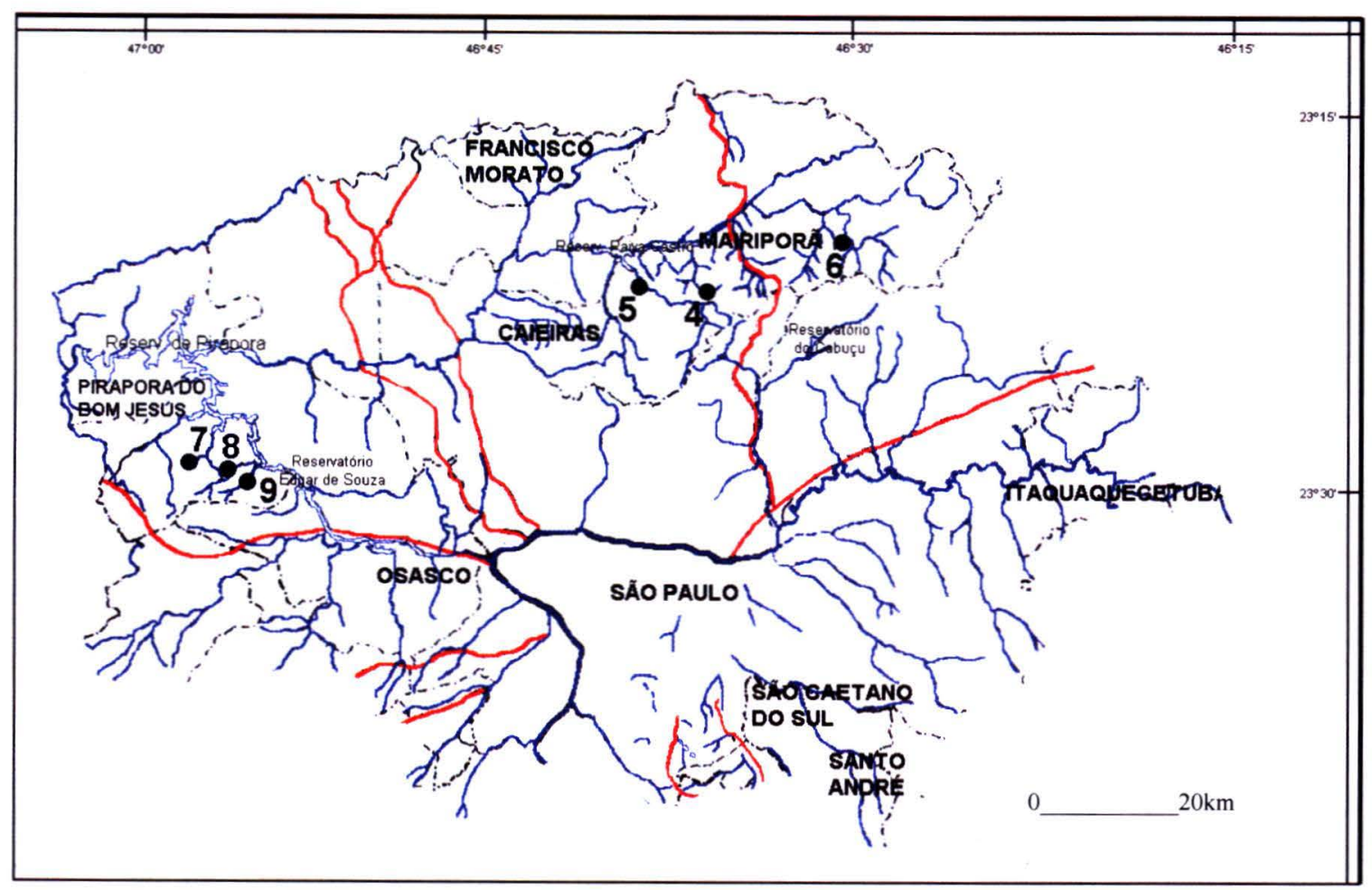

Figura 7: Sub-Bacia do Rio Tietê Alto - Zona Metropolitana

A área de drenagem desta sub-bacia é de $3.327 \mathrm{~km}^{2}$ (Rio Tietê desde a sua entrada na cidade de São Paulo, na divisa com o município de Itaquaquecetuba, até a barragem de Pirapora, numa extensão de 86 km e Rios Baquirivu-Guaçu, Guarapira, Tamanduateí, Pinheiros e Juqueri, e córregos Aricanduva e Cabuçu de Baixo). Esta é uma área conurbada, com amplo e dinâmico complexo urbano-industrial - regiões do $\mathrm{ABCD}$, Guarulhos e Osasco, além do setor de prestação de serviços. A sub-bacia do Rio Juqueri apresenta áreas de vegetação natural e de reflorestamentos, pastagens naturais e cultivadas, e atividades hortifrutigranjeiras. As principais indústrias são metalúrgica, mecânica, química e alimentícia (CETESB, 2001). 


\subsection{3 - Características gerais dos lagos estudados}

Os lagos de pesca estudados apresentaram características muito variáveis tanto quanto à sua gênese quanto à sua morfometria. De modo geral são formados pelo represamento de riachos ou córregos pertencentes à área de drenagem da bacia do Alto Tietê. Alguns possuíam margens ajardinadas ou revestidas com concreto. Outros sofreram algumas intervenções na área de inundação, como escavações para ampliação do espelho d'água, não apresentando áreas muito extensas, o que tornaria mais difícil o manejo requerido. Em geral, estes lagos foram formados em terrenos com predominância de colinas, resultando num formato quase retangular, onde se distinguem a área da barragem e a direção do curso d'água formador. Há, portanto um aproveitamento da topografia do terreno, o que evita que se façam grandes movimentos de terra para escavação dos lagos.

Muitas propriedades possuem mais de um lago de pesca, situados em cascata, ou ainda paralelos, quando mais de um córrego atravessa o terreno.

Algumas imagens dos lagos estudados são apresentadas nas figuras 8 a 12 .

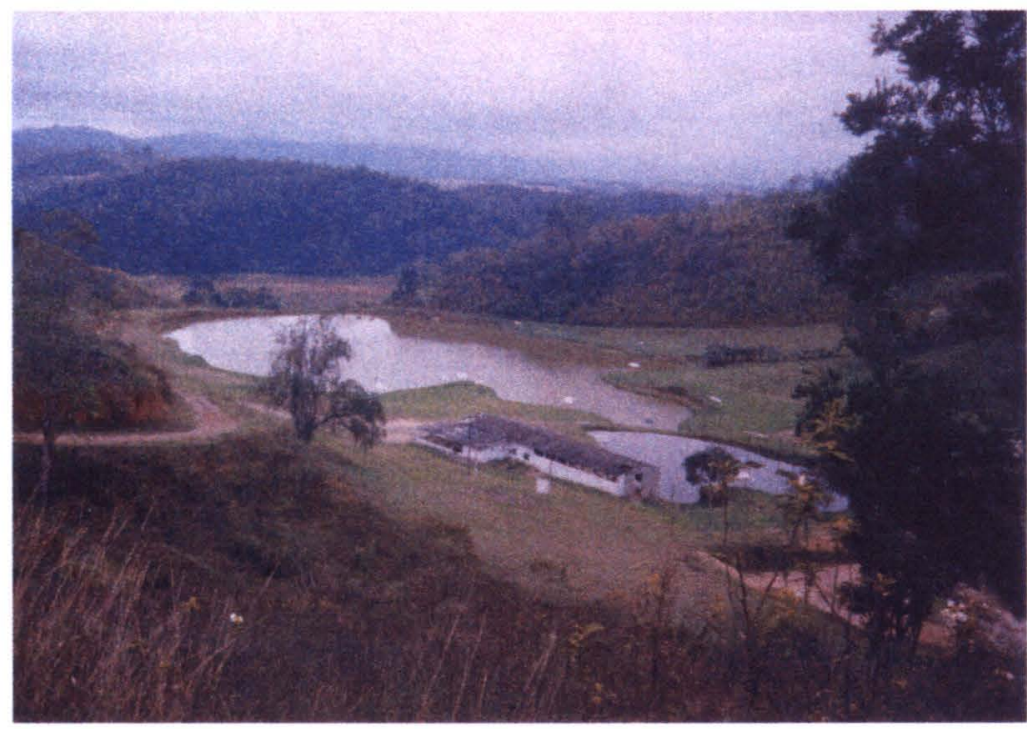

Figura 8: Pesqueiro 1, localizado à montante da Represa de Santa Isabel 


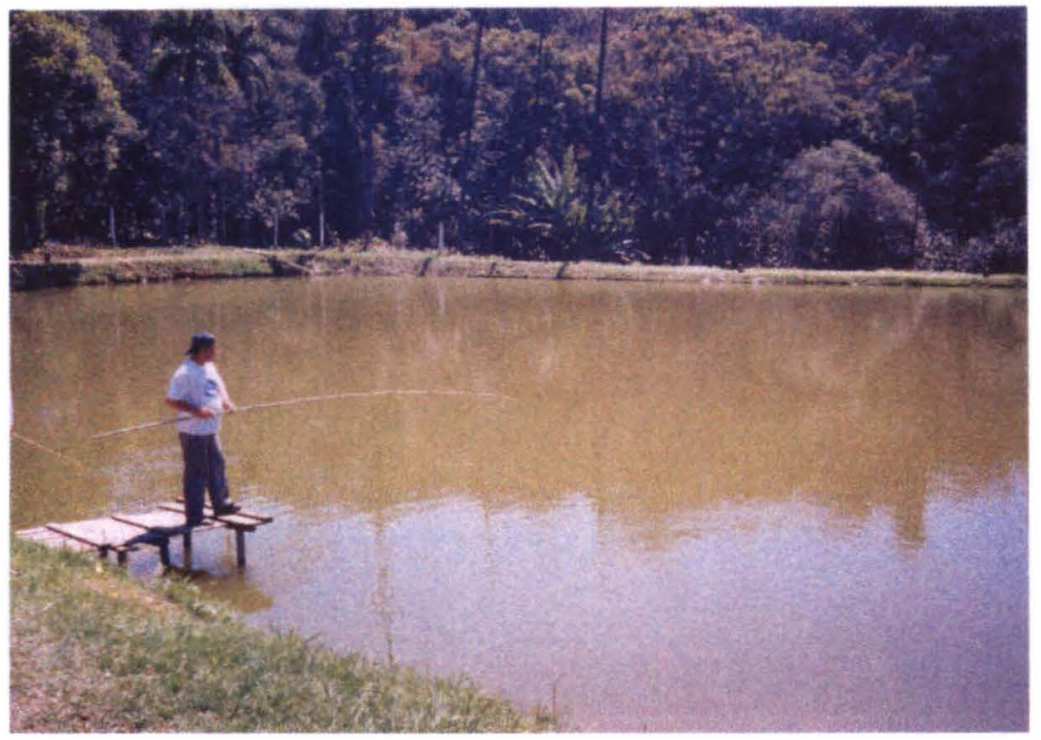

Figura 9: Pesqueiro 8, localizado o município de Santana do Parnaíba

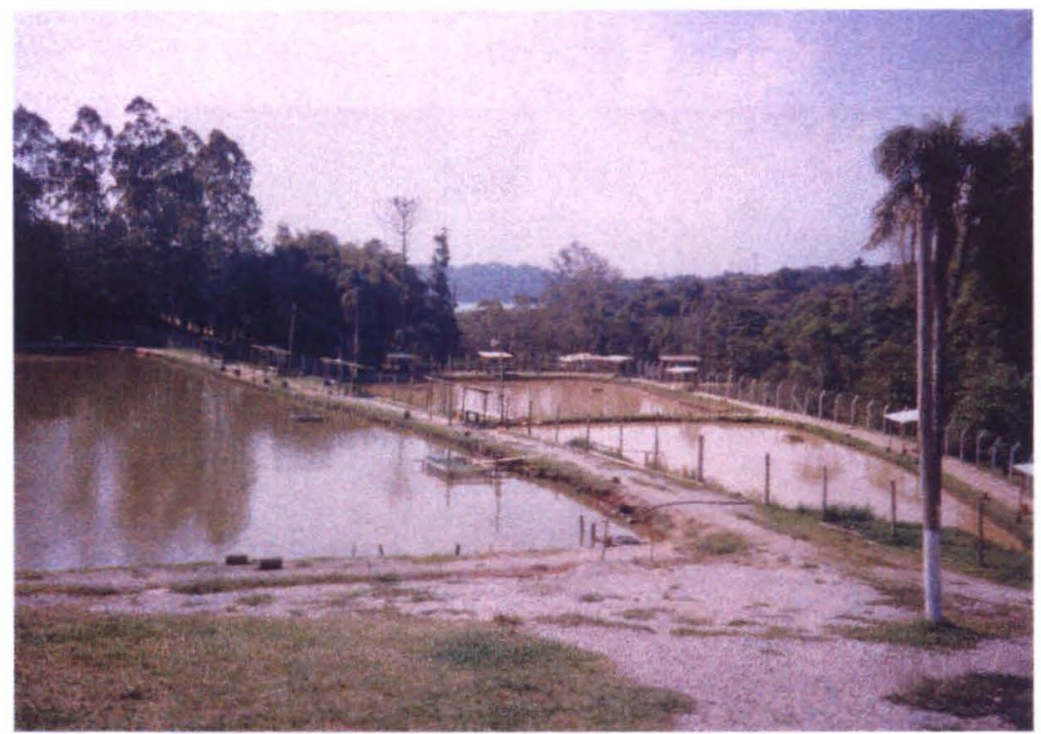

Figura 10: Pesqueiro 15, localizado à montante da represa Billings. 


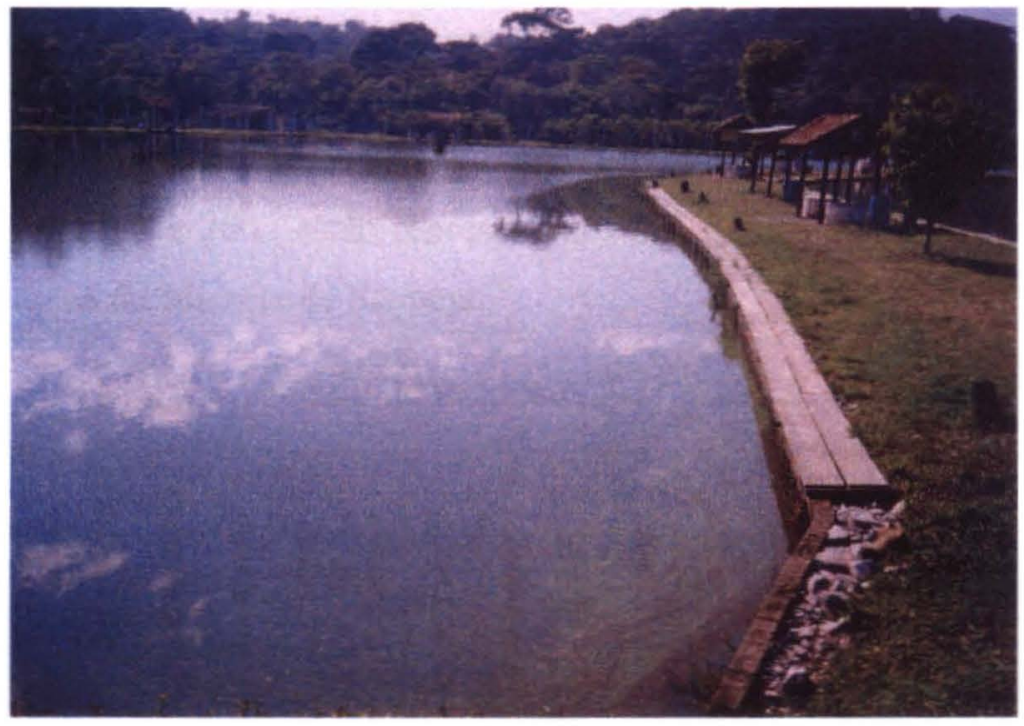

Figura 11: Pesqueiro 25, localizado no município de Suzano.

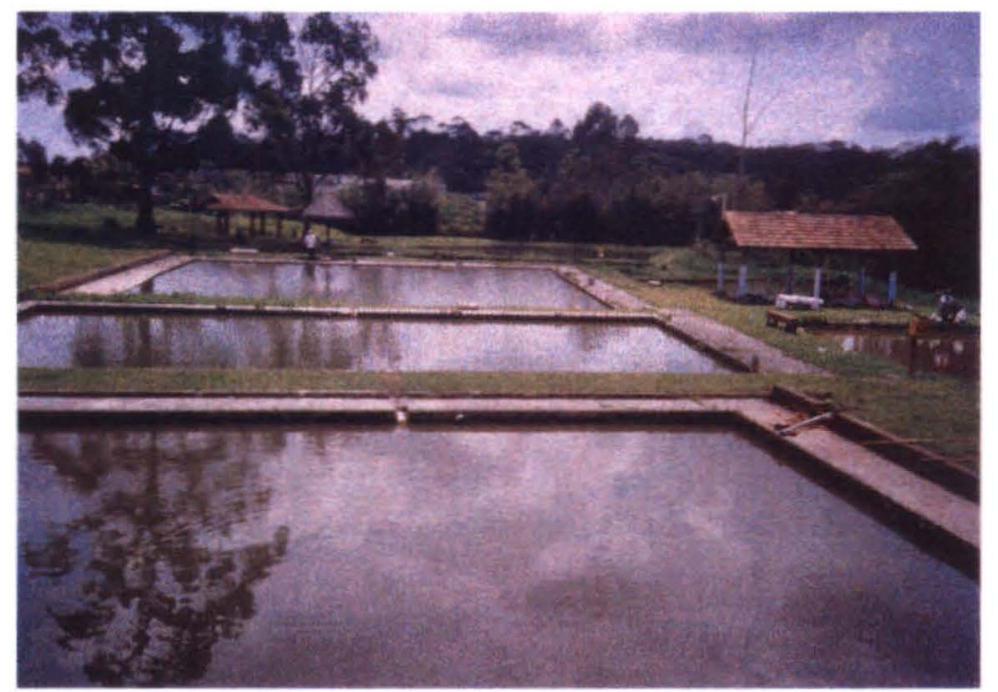

Figura 12: Pesqueiro 29, localizado no município de Cotia. 


\subsection{Caracterização climatológica do período estudado}

As temperaturas mínimas, médias e máximas mensais e o volume de precipitação mensal dos anos de 2001 e 2002 estão representados nas figuras 13 e 14, obtidas pela Estação Meteorológica do Mirante de Santana.

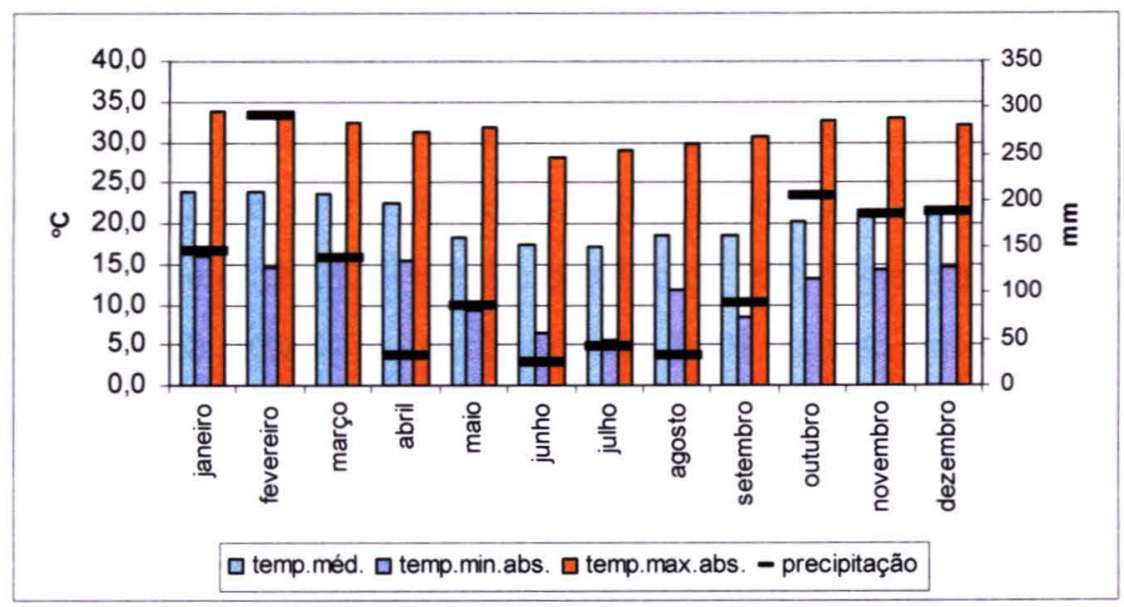

Figura 13: Variação das temperaturas médias, máximas e mínimas e do volume de precipitação durante o ano de 2001, no Mirante de Santana - São Paulo.

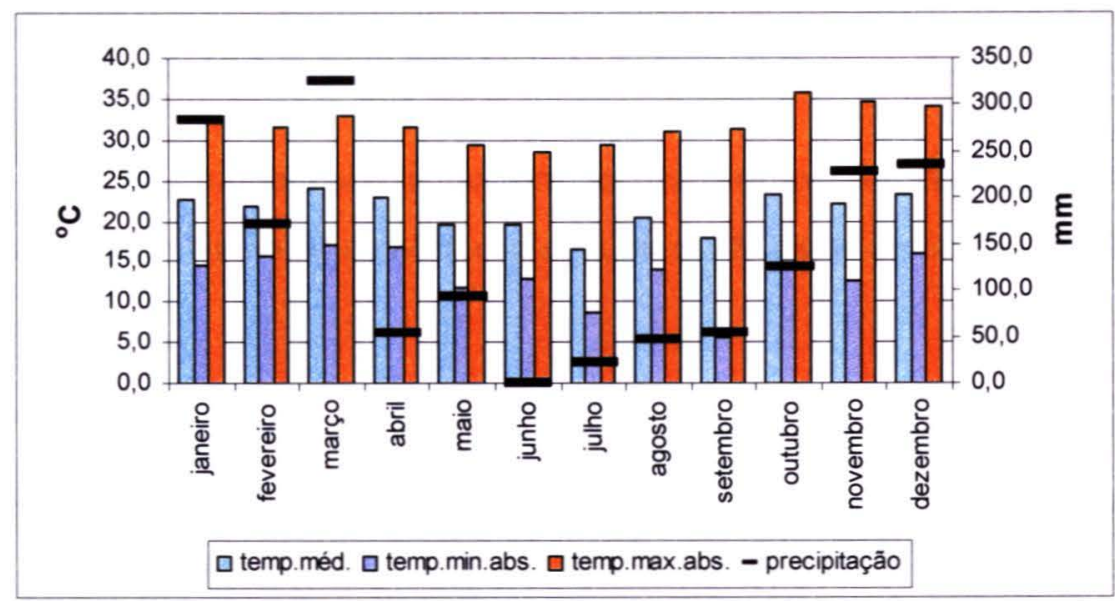

Figura 14: Variação das temperaturas médias, máximas e mínimas e do volume de precipitação durante o ano de 2002, no Mirante de Santana - São Paulo. 
O período em que se realizou este estudo foi caracterizado por baixos índices de precipitação não só na Região Metropolitana de São Paulo, como em todo o país, ocorrendo escassez de água em várias represas de geração de energia elétrica, o que obrigou o governo federal a iniciar uma campanha para o uso racional de energia, com o risco de haver racionamento em algumas regiões durante os meses de menor volume de chuvas. Comparando os dados climatológicos deste período com os dados das normais climatológicas determinadas entre 1961 e 1999 (figura 15) pelo Instituto Nacional de Meteorologia (INMET), notou-se um volume muito baixo de chuvas nos anos de $2001 \mathrm{e}$ 2002. O ano de 2002 apresentou um volume de precipitação maior nos meses de verão quando comparado ao de 2001. O mês de outubro de 2001 registrou volume elevado de precipitação, tanto em relação ao verificado em 2002, quanto em comparação com a série de normais climatológicas de 1961 a 1999.

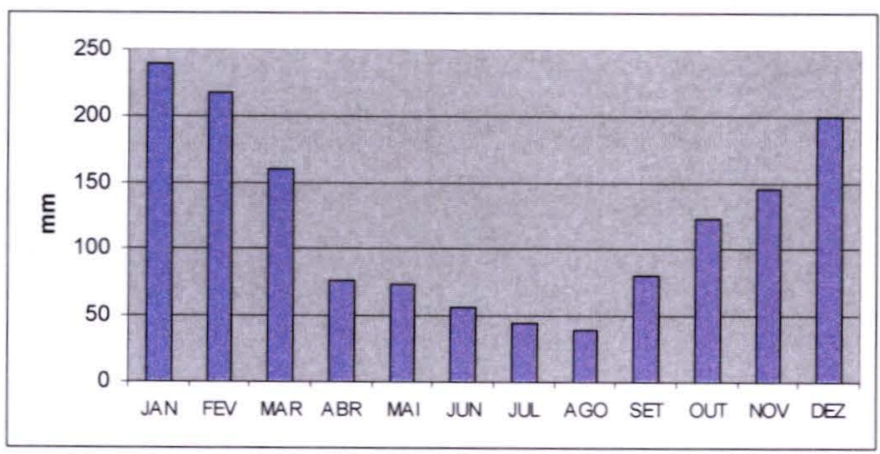

Figura 15: Precipitação total da série de normais climatológicas determinadas entre 1961 e 1999 pelo Instituto Nacional de Meteorologia para o Mirante de Santana - São Paulo SP

A situação também foi crítica em relação ao nível dos reservatórios de abastecimento da Região Metropolitana, sempre prestes a sofrer um possível racionamento de água.

Em relação às áreas estudadas, segundo relatos dos proprietários e freqüentadores dos pesqueiros, os córregos e nascentes que abastecem os lagos de pesca 
apresentaram um volume de água muito abaixo do normal, sobretudo no periodo estiagem/frio, o que impedia que fosse feita a renovação da água do lago com a freqüência habitual. Deste modo, o tempo de residência dos lagos. embora não tenha sido determinado, pode ter sido consideravelmente mais longo durante este periodo.

Em relação à temperatura atmosférica. o mês de setembro de 2001 quando foi iniciada a primeira série de amostragens, foi registrada temperatura mínima consideravelmente baixa $\left(8,5^{\circ} \mathrm{C}\right.$ ) para este período (a normal determinada pelo INMET na série citada é de $13,9^{\circ} \mathrm{C}$ ). As temperaturas máximas obtidas nos meses amostrados não apresentam variação significativa. As temperaturas médias variaram em torno de $18^{\circ} \mathrm{C}$ nos meses de setembro e outubro de 2001 e de $23^{\circ} \mathrm{C}$ em fevereiro e março de 2002. 


\section{3 -Variáveis físicas e químicas da água e concentração de clorofila-a}

Os dados referentes às variáveis fisicas e quimicas da água e concentração de clorofila- $a$ são apresentados na tabela 2 para o periodo estiagem/frio e na tabela 3 para 0 periodo chuvoso/quente.

A transparência da água variou entre $0.10 \mathrm{~m}(03)$ e $0.60 \mathrm{~m}(06)$ no periodo seco e entre $0.15 \mathrm{~m}$ (22) e $0.80 \mathrm{~m}$ (10) no periodo chuvoso (tabelas 2 e 3 . figura 16). Os sólidos totais em suspensão variaram de $12.00 \mathrm{mg} / \mathrm{L} \mathrm{(06)} \mathrm{a} 140,00 \mathrm{mg} / \mathrm{L} \mathrm{(23)} \mathrm{no} \mathrm{período} \mathrm{seco} \mathrm{e}$ de $9.14 \mathrm{mg} / \mathrm{L}$ (11) a $144.00 \mathrm{mg} / \mathrm{L}$ (23) no periodo chuvoso (tabelas 2 e 3 ).

Os menores valores de condutividade elétrica foram registrados no pesqueiro 03 tanto no periodo seco quanto no período chuvoso $(20.0 \mu \mathrm{S} / \mathrm{cm})$ : os maiores valores ocorreram no pesqueiro $23(390 \mu \mathrm{S} / \mathrm{cm})$ no período seco e no pesqueiro 10 no período chuvoso $(470 \mu \mathrm{S} / \mathrm{cm})$ (Tabelas 2 e 3$)$. $\mathrm{O}$ pH variou entre 5.8 (26) e 8.10 (30) no periodo seco e entre 5,3 (03) e 8,10 (30) no periodo chuvoso (tabelas 2 e 3 ).

As concentrações de oxigênio dissolvido apresentaram variação de $5,20 \mathrm{mg} / \mathrm{L}$ (25) a $12,40 \mathrm{mg} / \mathrm{L}$ (30) no período seco e de $3,5 \mathrm{mg} / \mathrm{L}$ (19) a $14,60 \mathrm{mg} / \mathrm{L}$ (18) no período chuvoso. A turbidez da água dos lagos variou entrell NTU (18) e 270 NTU (23) no período seco e entre 17 NTU (11) e $200 \mathrm{NTU}$ (23) no período chuvoso. O fósforo total presente na água variou entre $0.04 \mathrm{mg} / \mathrm{L}(22)$ a $0.28 \mathrm{mg} / \mathrm{L}$ (30) no periodo seco e entre $0,03 \mathrm{mg} / \mathrm{L}(18)$ e $0,35 \mathrm{mg} / \mathrm{L}(10)$ no periodo chuvoso. A concentração de nitrogênio inorgânico $\left(\mathrm{NO}_{2}, \mathrm{NO}_{3}\right.$ e $\left.\mathrm{NH}_{4}\right)$ variou de $0.21 \mathrm{mg} / \mathrm{L}$ (07) a $2.56 \mathrm{mg} / \mathrm{L}$ (23) no período seco e de $0,20 \mathrm{mg} / \mathrm{L}$ (22) a $1,74 \mathrm{mg} / \mathrm{L} \mathrm{(24)} \mathrm{no} \mathrm{periodo} \mathrm{chuvoso} \mathrm{(tabelas} 2$ e 3).

A concentração de clorofila- $a$ variou entre 0 (17 e 19) e $0,17 \mathrm{mg} / \mathrm{L}(28)$ no período seco e entre $0(03,06,15$ e 24$)$ e $0,43 \mathrm{mg} / \mathrm{L}$ (30) no período chuvoso (tabelas 2 e 3).

A figura 16 representa os gráficos do tipo Box-Plot da variação da transparência, turbidez, temperatura, $\mathrm{pH}$, condutividade elétrica e sólidos totais em suspensão na água, 
nos dois periodos estudados. Observou-se pouca variação seco e chuvoso para os valores de transparência. pH. turbidez, sólidos totais em suspensão e condutividade elétrica. A temperatura da água apresentou uma maior variação entre os dois periodos e uma amplitude maior de variação entre os pesqueiros no período chuvoso.

A figura 17 representa os gráficos do tipo box-plot das variações das concentraçôes de clorofila- $a$. oxigênio dissolvido, fósforo total e nitrogênio inorgânico $(\mathrm{mg} / \mathrm{L})$ e do Índice de Estado Trófico da água. nos dois períodos estudados. Os valores médios de concentração de clorofila- $a$ mantiveram a mesma amplitude de variação nos dois periodos estudados. mas no periodo chuvoso registrou-se um valor máximo muito superior ao observado no período seco: o pesqueiro 30 apresentou concentração de 0.43 $\mathrm{mg} / \mathrm{L}$ de clorofila- $a$. enquanto o máximo observado no periodo seco foi de $0.17 \mathrm{mg} / \mathrm{L}$. As concentrações de oxigênio dissolvido também variaram mais no período chuvoso. 0 IET variou entre 44 e 71 (pesqueiros 14 e 28. respectivamente) no periodo seco e entre 50 e 81 (pesqueiros 3 e 30) no período chuvoso. No período seco observaram-se valores máximos e mínimos inferiores aos obtidos no período chuvoso. A amplitude de variação dos valores médios foi semelhante nos dois periodos. Nos dois períodos os índices obtidos são correspondentes aos de ambientes eutróficos. 

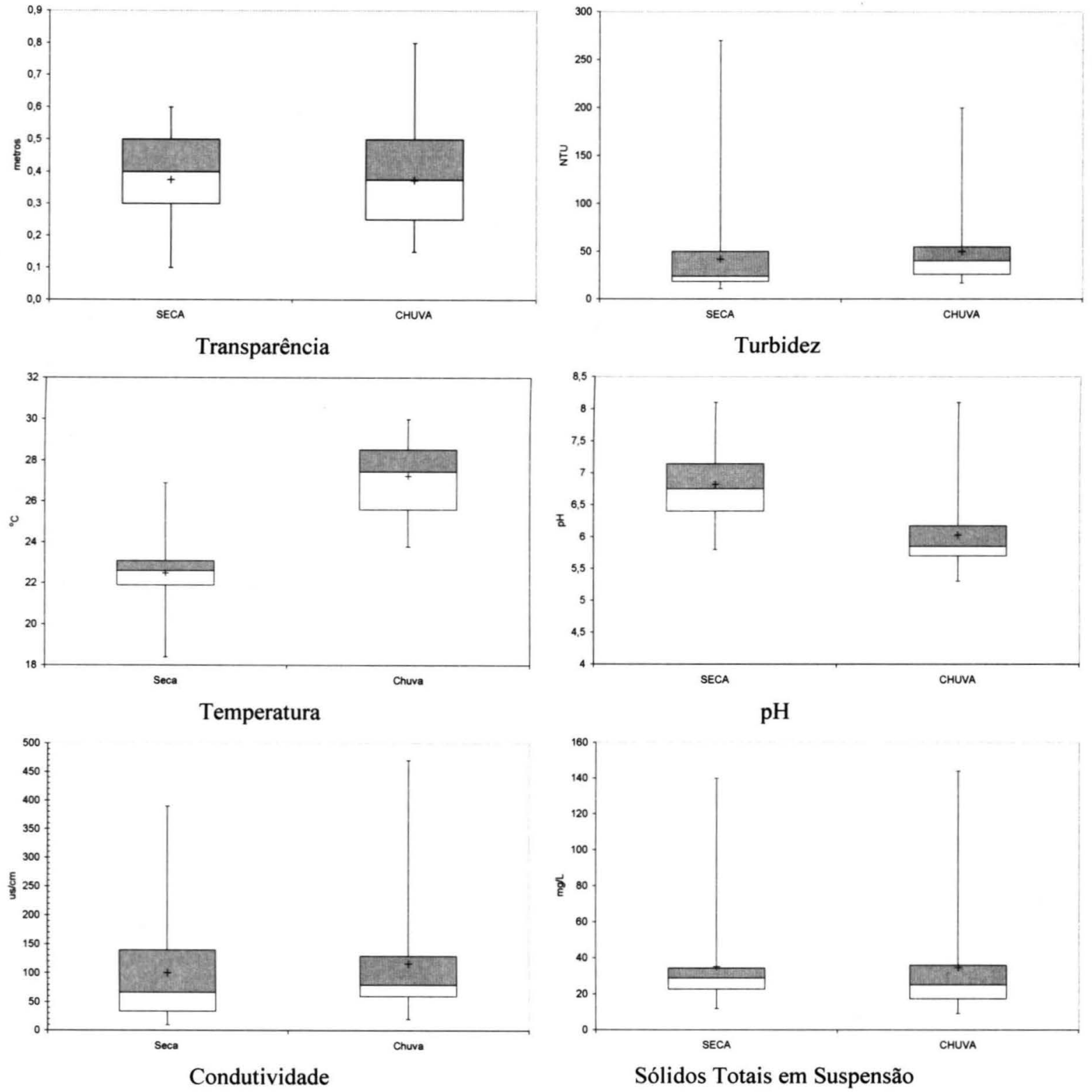

Figura 16: Box Plot das variações da transparência (metros), turbidez (NTU), temperatura $\left({ }^{\circ} \mathrm{C}\right), \mathrm{pH}$, condutividade elétrica $(\mathrm{uS} / \mathrm{cm})$ e sólidos totais em suspensão (mg/L) na água, nos dois períodos estudados 

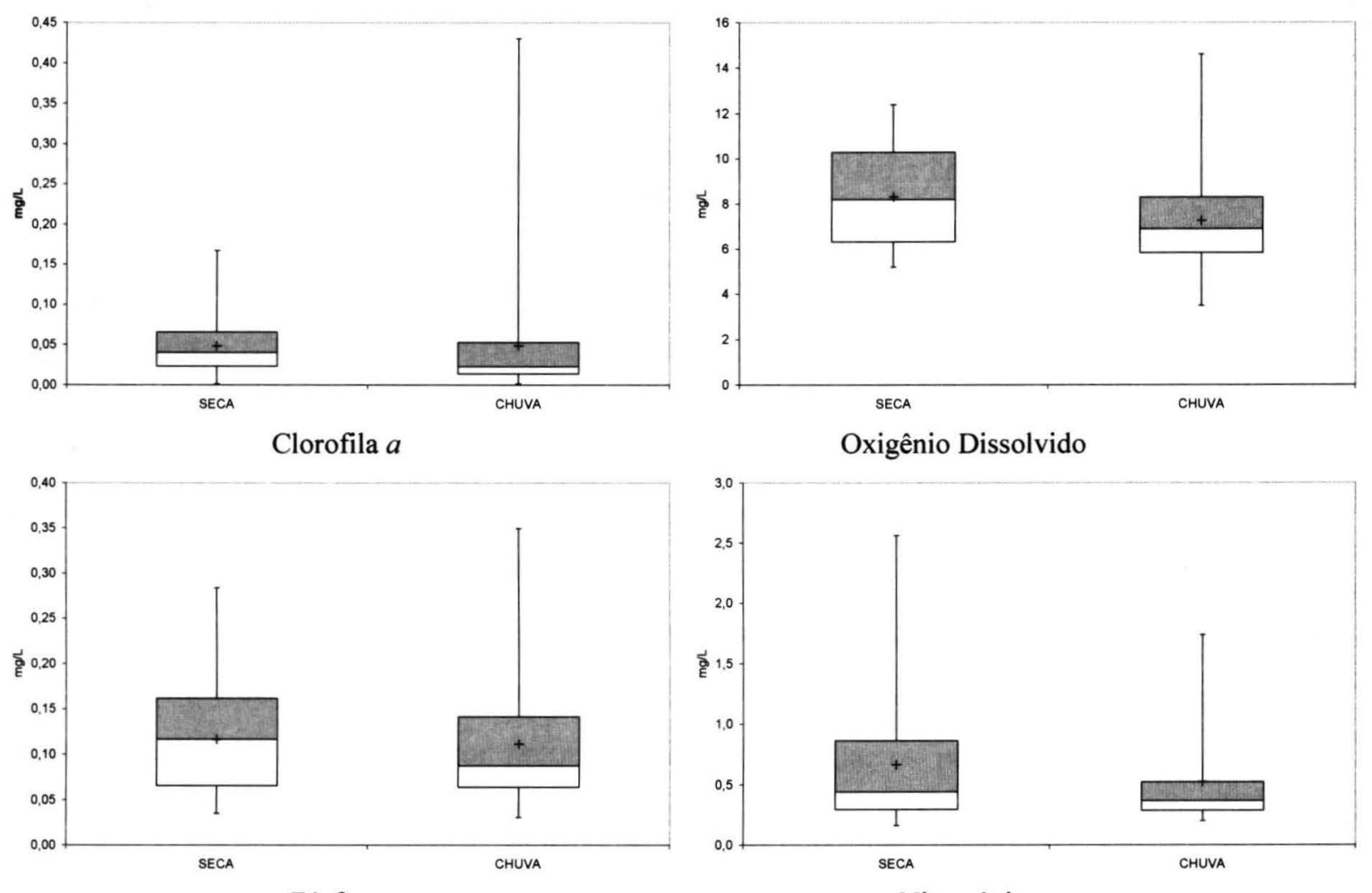

Oxigênio Dissolvido
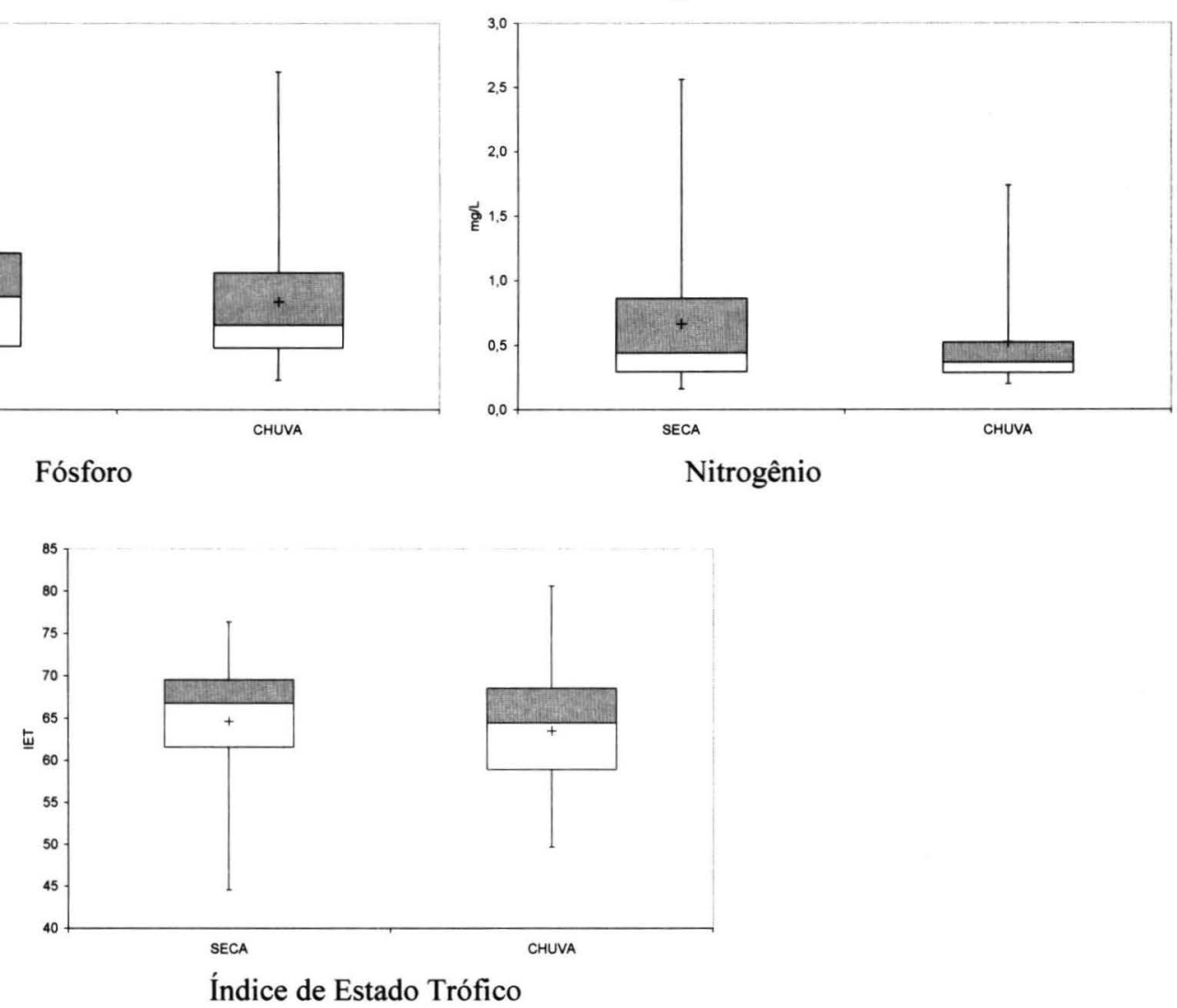

Figura 17: Box Plot das variações das concentrações de clorofila- $a$, oxigênio dissolvido, fósforo total e nitrogênio inorgânico $(\mathrm{mg} / \mathrm{L})$ e do Índice de Estado Trófico da água, nos dois períodos estudados. 


\section{4 - Comunidade zooplanctônica}

\subsection{1 - Composição da comunidade}

As tabelas 4 e 5 mostram a densidade numérica e a abundância relativa dos rotíferos presentes nas amostras obtidas no periodo estiagem/frio e chuvoso/quente. Nas tabelas 6 e 7 são apresentadas as densidades numéricas e as abundâncias relativas dos crustáceos planctônicos e de organismos considerados como não euplanctônicos presentes nas amostras obtidas no periodo estiagem/frio e chuvoso/quente.

As densidades numéricas totais obtidas no periodo seco, conforme se observa na tabela 6 e figura 18 apresentaram-se com valores muito variáveis: 15 pesqueiros com densidade total de organismos zooplanctônicos de até 500.000 indivíduos por metro cúbico; 8 pesqueiros com densidade total de organismos zooplanctônicos variando entre 500.000 e 1.000 .000 indivíduos por metro cúbico; 6 pesqueiros com densidade total superior a 1.000 .000 indivíduos por metro cúbico, sendo que os pesqueiros 20 e 25 registraram densidades acima de 2.500 .000 indivíduos por metro cúbico.

No período chuvoso a variação da densidade total de organismos zooplanctônicos (figura 19 e tabela 7) foi menor que a obtida no período seco: 12 pesqueiros com densidade total menor que 200.000 indivíduos por metro cúbico; 17 pesqueiros com densidade total entre 200.000 e 400.000 indivíduos por metro cúbico; 1 pesqueiro (de número 20 ) com densidade total acima de 1.800 .000 indivíduos por metro cúbico. 


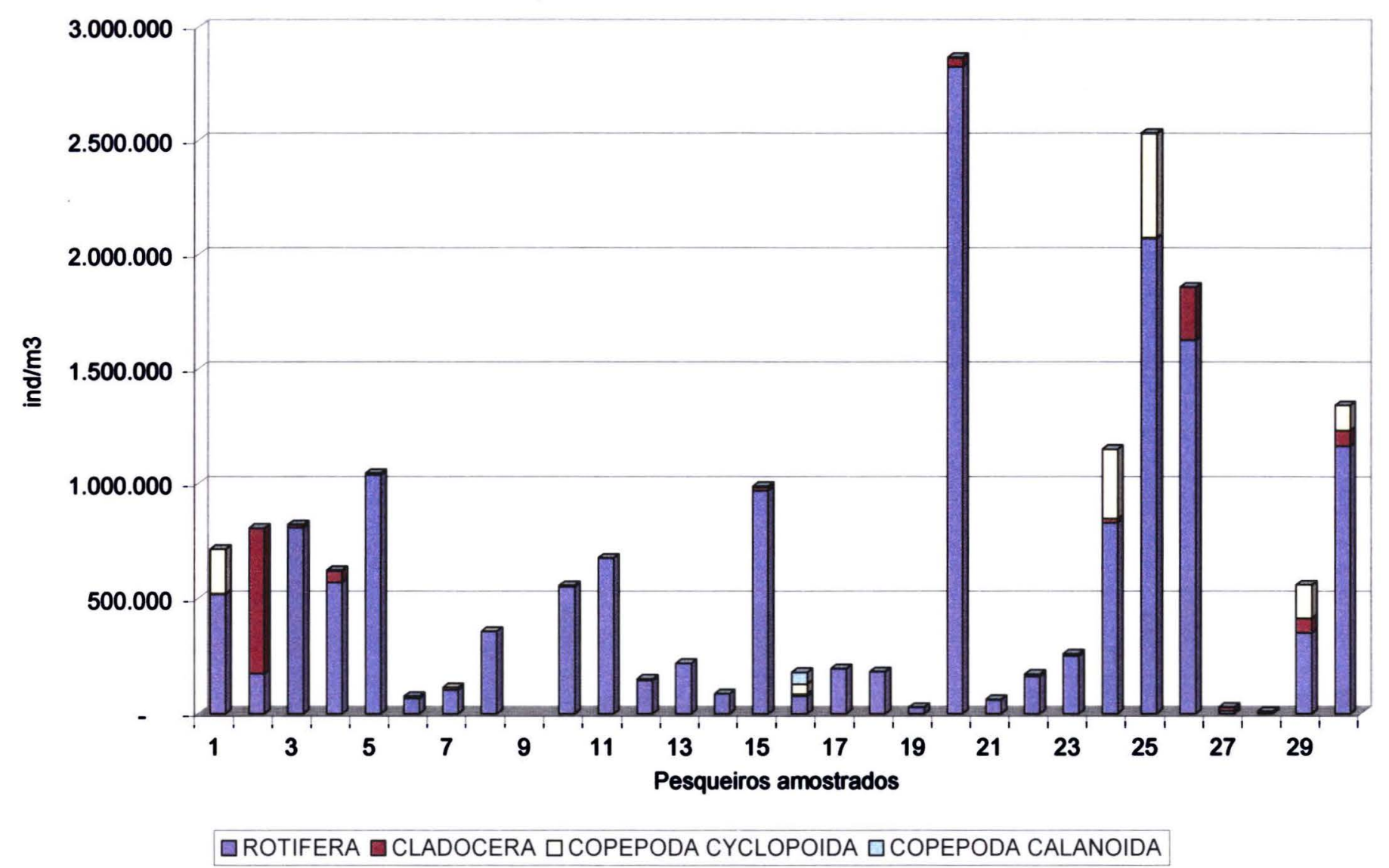

Figura 18: Densidades numéricas (em número de indivíduos por metro cúbico) dos grupos que compõem a comunidade zooplanctônica nos lagos de pesca estudados durante o período estiagem/frio. 


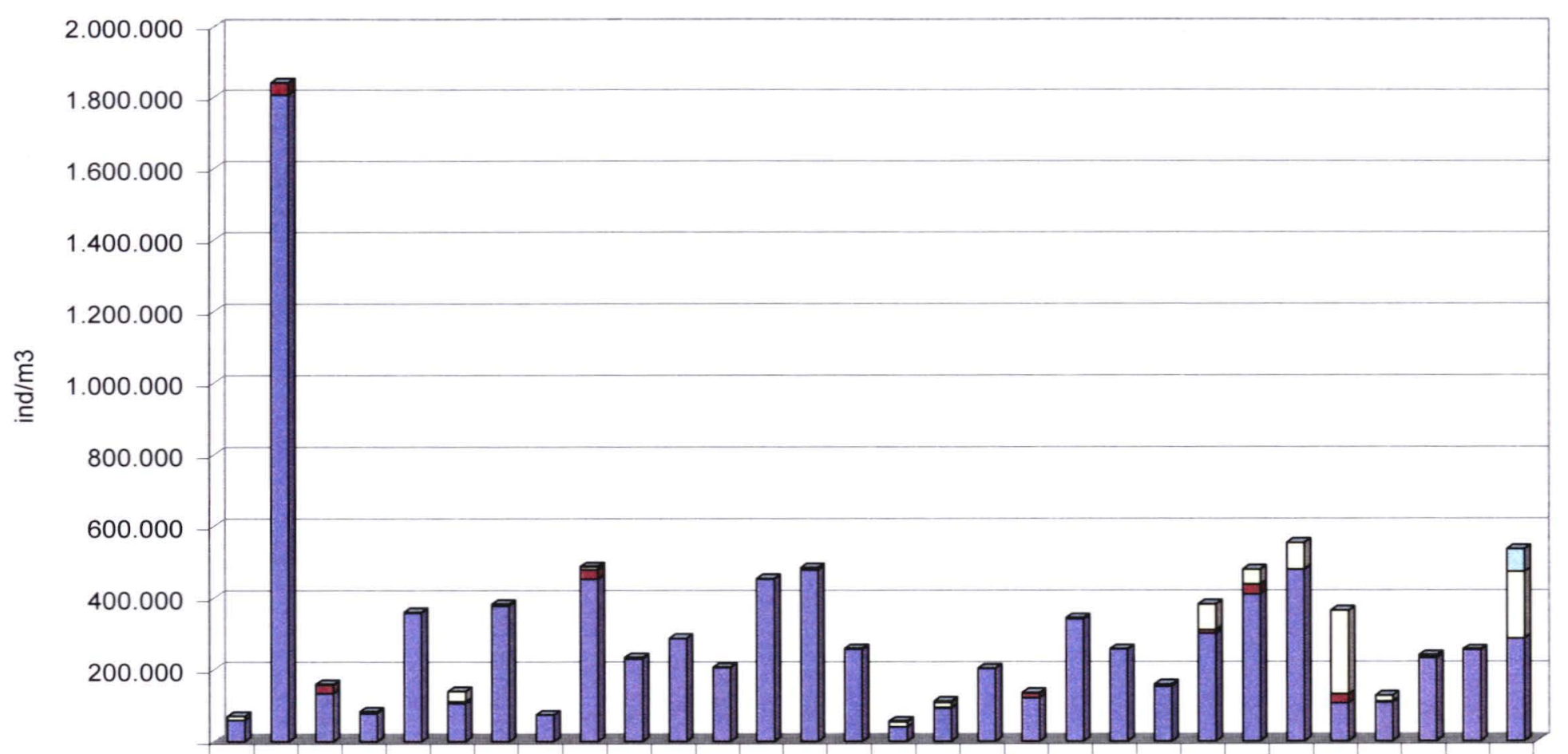

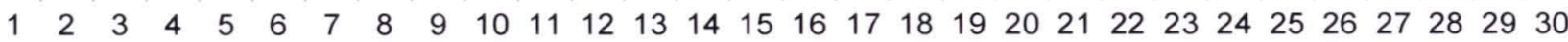
pesqueiros amostrados

$\square$ ROTIFERA $\square$ CLADOCERA $\square$ COPEPODA CYCLOPOIDA $\square$ COPEPODA CALANOIDA

Figura 19: Densidades numéricas (em número de indivíduos por metro cúbico) dos grupos que compõem a comunidade zooplanctônica nos lagos de pesca estudados durante o período chuvoso/quente. 
No primeiro período a densidade total de organismos zooplanctônicos variou entre $9650 \mathrm{ind} / \mathrm{m} 3(28)$ e $2865640 \mathrm{ind} / \mathrm{m}^{3}(20)$, com média de $913.447 \mathrm{ind} / \mathrm{m}^{3}$. Foram registradas neste período 82 espécies de rotíferos, 19 espécies de cladóceros, 9 espécies de copépodes ciclopóides e uma espécie de copépode calanóide.

No segundo período a densidade total variou entre $56.328 \mathrm{ind} / \mathrm{m}^{3}$ (02) e 1.863.121 ind $/ \mathrm{m}^{3}$ (15). com média de $390.180 \mathrm{ind} / \mathrm{m}^{3}$. A comunidade zooplanctônica neste período esteve representada por 67 espécies de rotíferos. 16 espécies de cladóceros. 6 espécies de copépodes ciclopóides e 2 espécies de copépodes calanóides.

Foram freqüentes nas amostras organismos não tipicamente planctônicos (larvas de inseto como Chaoboridae. Chiromidae. Plecoptera, além de Oligochaeta. Nematoda e Ostracoda) em baixas densidades.

Verificou-se a ocorrência de copépodes parasitas (Poecilostomatoida), principalmente nos estágios de náuplio e copepodito, em $40 \%$ dos pesqueiros na estação seca e $70 \%$ destes na estação chuvosa.

$\mathrm{Na}$ tabela 8 são apresentados os táxons presentes nas amostras do período estiagem/frio e chuvoso quente. $O$ número de táxons (riqueza) presentes no primeiro período (143) foi superior ao obtido no segundo período (111).

Conforme se vê na figura 20 o grupo dos rotíferos foi dominante em $96 \%$ dos pesqueiros estudados durante o período estiagem/frio. Apenas no pesqueiro 02 houve dominância de cladóceros (predominantemente Bosminopsis deitersi). No pesqueiro 16, apesar do predomínio de rotíferos, houve uma porcentagem maior de copépodes calanóides e ciclopóides do que a que se verificou em outros pesqueiros. A amostra correspondente ao pesqueiro 9 do período estiagem/frio apresentou problemas com a preservação e foi inutilizada, razão pela qual não foram incluídos os seus resultados. 


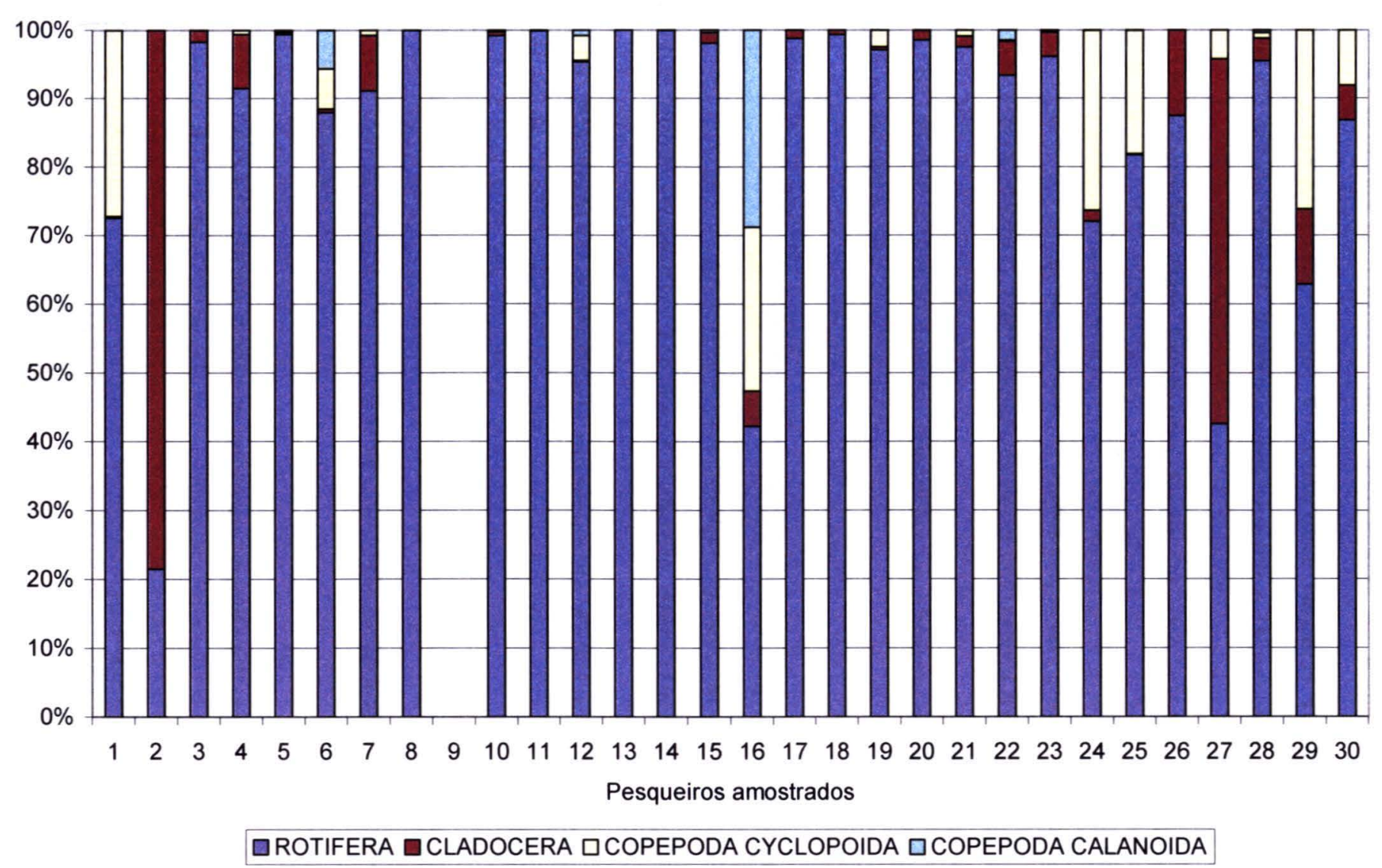

Figura 20: Abundâncias relativas (porcentagens) dos principais grupos zooplanctônicos no período estiagem/frio 
As espécies de rotíferos mais abundantes no primeiro periodo foram Brachionus angularis. Keratella americana e Polvarthra vulgaris (tabela 4). Entre os cladóceros dominaram Moina minuta. Bosmina longisrostris e Diaphanosoma birgei (tabela 6).

Os copépodos mais freqüentes foram os ciclopóides, quase sempre nos estágios larvais, sendo comum a presença de uma única espécie em cada lago estudado; as espécies mais freqüentes deste grupo foram Thermocylops decipiens. Metacyclops mendocinus. Eucyclops pseudoensifer. Thermocyclops inversus (tabela 6).

No periodo chuvoso/quente. conforme se observa na figura 21 . houve dominância de rotíferos em $97 \%$ dos lagos estudados.

Neste período as espécies dominantes de rotíferos variaram mais entre os lagos, sendo mais abundantes Kellicottia bostoniensis, Synchaeta pectinata. Keratella cochlearis tecta, Brachionus angularis . Trichocerca pusilla, entre outros (tabela 5).

No pesqueiro 02 a densidade numérica de Kellicottia bostoniensis foi responsável por $66 \%$ da densidade total de organismos zooplanctônicos da amostra (tabela 5).

Os cladóceros ocorreram em porcentagens mais baixas no periodo chuvoso do que no período seco. sendo os mais freqüentes Bosmina longirostris e Diaphanosoma birgei em ambos os periodos.

Os copépodes foram pouco numerosos, ocorrendo predominantemente em estágios jovens (náuplios e copepoditos). As espécies que apresentaram maior freqüência de ocorrência no periodo chuvoso foram Thermocyclops decipiens e Eucyclops pseudoensifer . entre os ciclopóides e Notodiaptomus cf. henseni, entre os calanóides. 


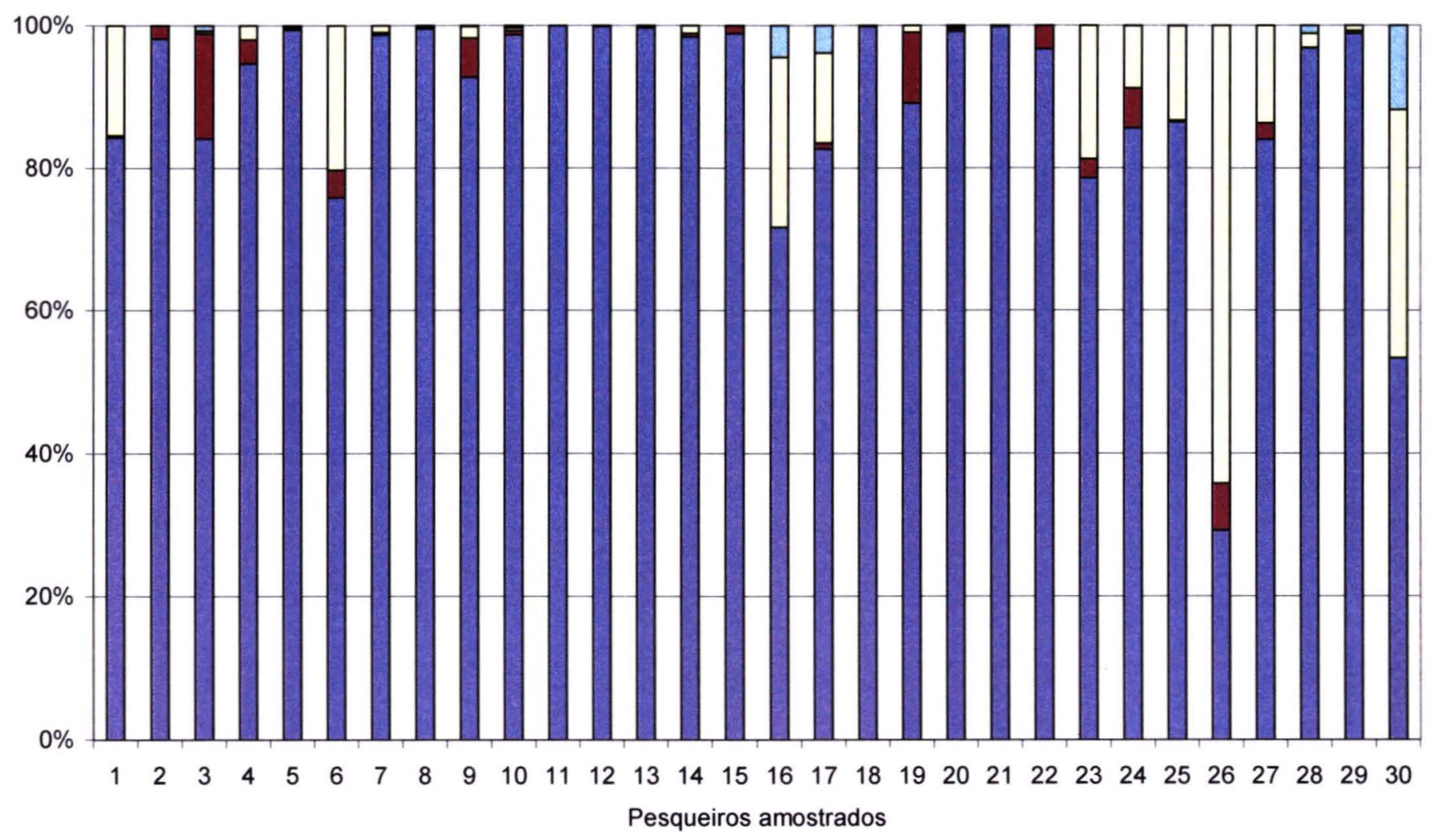

๑ROTIFERA —CLADOCERA QCOPEPODA CYCLOPOIDA ICOPEPODA CALANOIDA

Figura 21: Abundâncias relativas (porcentagens) dos principais grupos zooplanctônicos no período chuvoso/quente. 
De modo geral, cladóceros e copépodes calanóides estiveram presentes em maiores proporções que copépodes ciclopóides na maioria dos pesqueiros durante o período seco. Já no período chuvoso. os copépodes ciclopóides foram mais importantes em termos de abundância relativa que cladóceros e copépodes calanóides. Nos dois períodos estudados foram observadas algumas espécies cuja ocorrência é recente nesta bacia. como o rotífero Filinia cornuta brachiata e o copépode ciclopóide Acanthocyclops robustus. 


\subsection{2 - Diversidade, riqueza e equitatividade}

Os índices de riqueza, diversidade e equitatividade da comunidade zooplanctônica obtidos no periodo estiagem/frio estão representados na tabela 9 e figura 22.

0 pesqueiro 5 apresentou 0 maior índice de riqueza (35 táxons), enquanto os pesqueiros 14, 16 e 28 apresentaram o menor indice de riqueza no período ( 21 táxons). A diversidade de espécies foi maior nos pesqueiros 7 e 18 (3,7 bits/indivíduo) e menor no pesqueiro 8 (1.5 bits/individuo). 0 maior indice de equitatividade no periodo foi obtido no pesqueiro 07 (0.22) e o menor no pesqueiro $08(0.08)$.

Para o período chuvoso estes índices estão representados na figura 23 e tabela 10 . Neste período o maior índice de riqueza foi obtido para o pesqueiro 2 (43 táxons) e o menor nos pesqueiros 6 e 16 (24 táxons). 0 pesqueiro 7 apresentou 0 maior índice de diversidade (3,98 bits/indivíduos) e o pesqueiro 30 o menor (1,97 bits/indivíduos). A equitatividade foi maior os pesqueiros 3 e $7(0,23)$ e menor nos pesqueiros 2 e $30(0,10)$. 


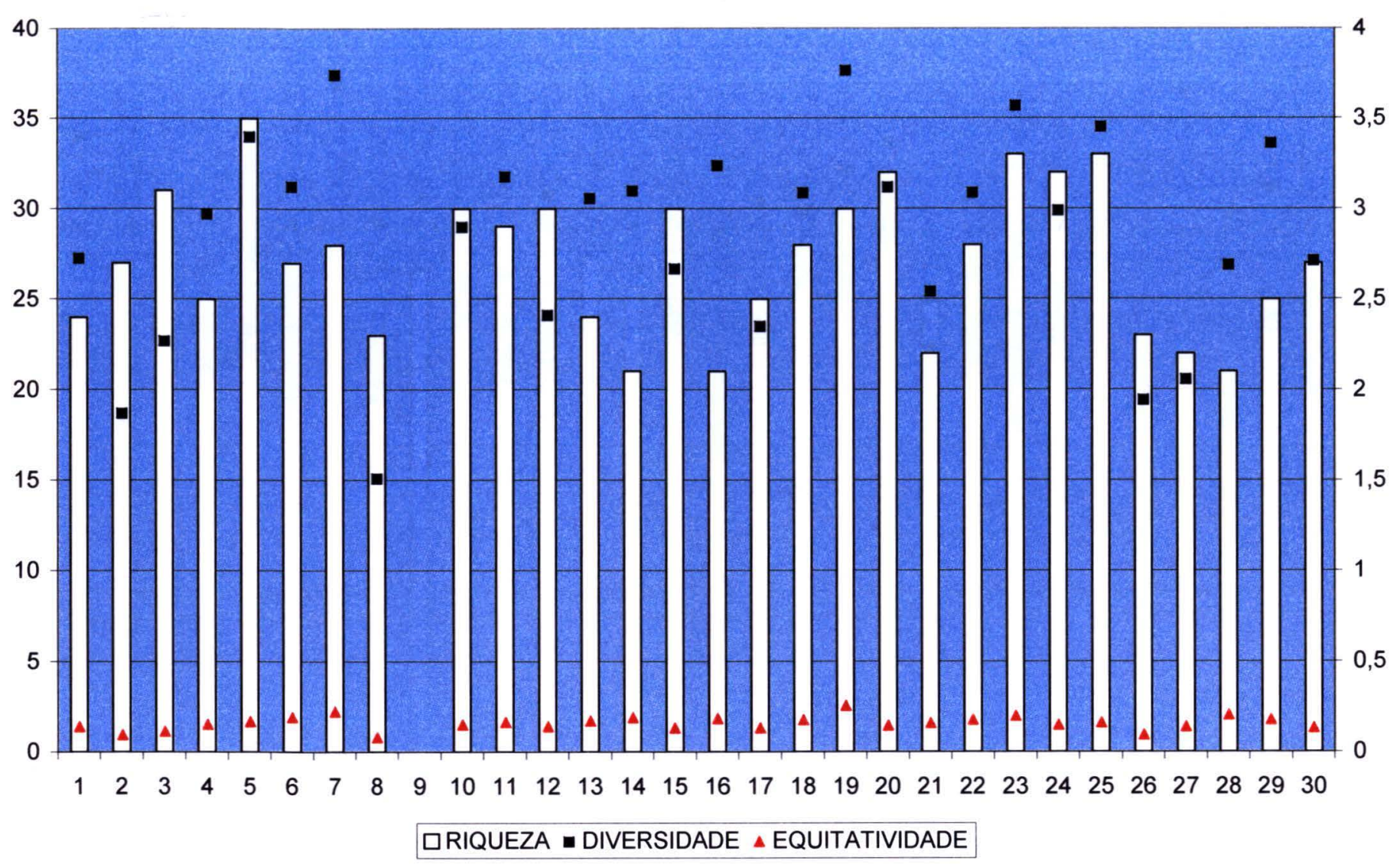

Figura 22: Variação dos índices de riqueza, equitatividade e diversidade $\left(\mathrm{H}^{\prime}\right)$ nos pesqueiros estudados, no período estiagem/frio. 


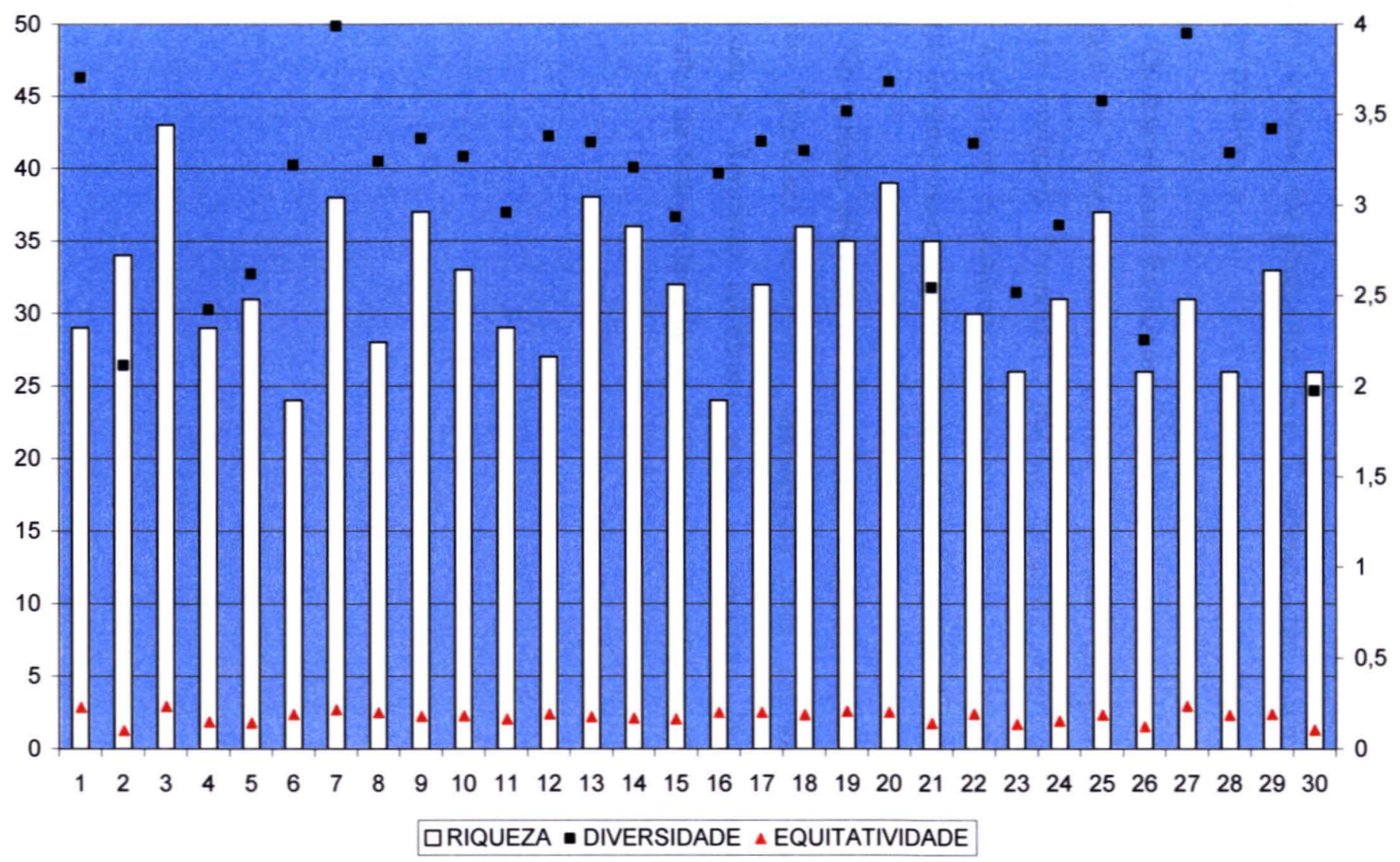

Figura 23: Variação dos índices de riqueza, equitatividade e diversidade (H') nos pesqueiros estudados, no período estiagem/frio. 
A comparação entre os índices de diversidade e riqueza nos dois periodos estudados está representada nas figuras 24 e 25 . Houve aumento de diversidade em $76 \%$ dos lagos de pesca estudados, e de riqueza em $87 \%$ dos lagos, do período seco para o período chuvoso. Os pesqueiros 23 e 30 apresentaram maior diversidade e riqueza no primeiro período.

Os táxons mais freqüentes (freqüência de ocorrência maior que $70 \%$ dos lagos) nos lagos de pesca estudados durante o período estiagem/frio foram os rotíferos Polyarthra vulgaris, Trichocerca pusilla, Keratella americana, Keratella cochlearis tecta. Kellicottia bostoniensis. Anuraeopsis fissa. os cladóceros Moina minuta e Bosmina longirostris e náuplios e copepoditos de ciclopóides (figura 26).

No período chuvoso os táxons mais freqüentes foram os rotíferos Polyarthra vulgaris, Epiphanes macrourus, Anuraeopsis fissa, Trichocerca pusilla, Keratella americana e Keratella cochlearis tecta, o cladócero Moina minuta, náuplios e copepoditos de ciclopóides e larvas de Chironomidae (figura 27). 


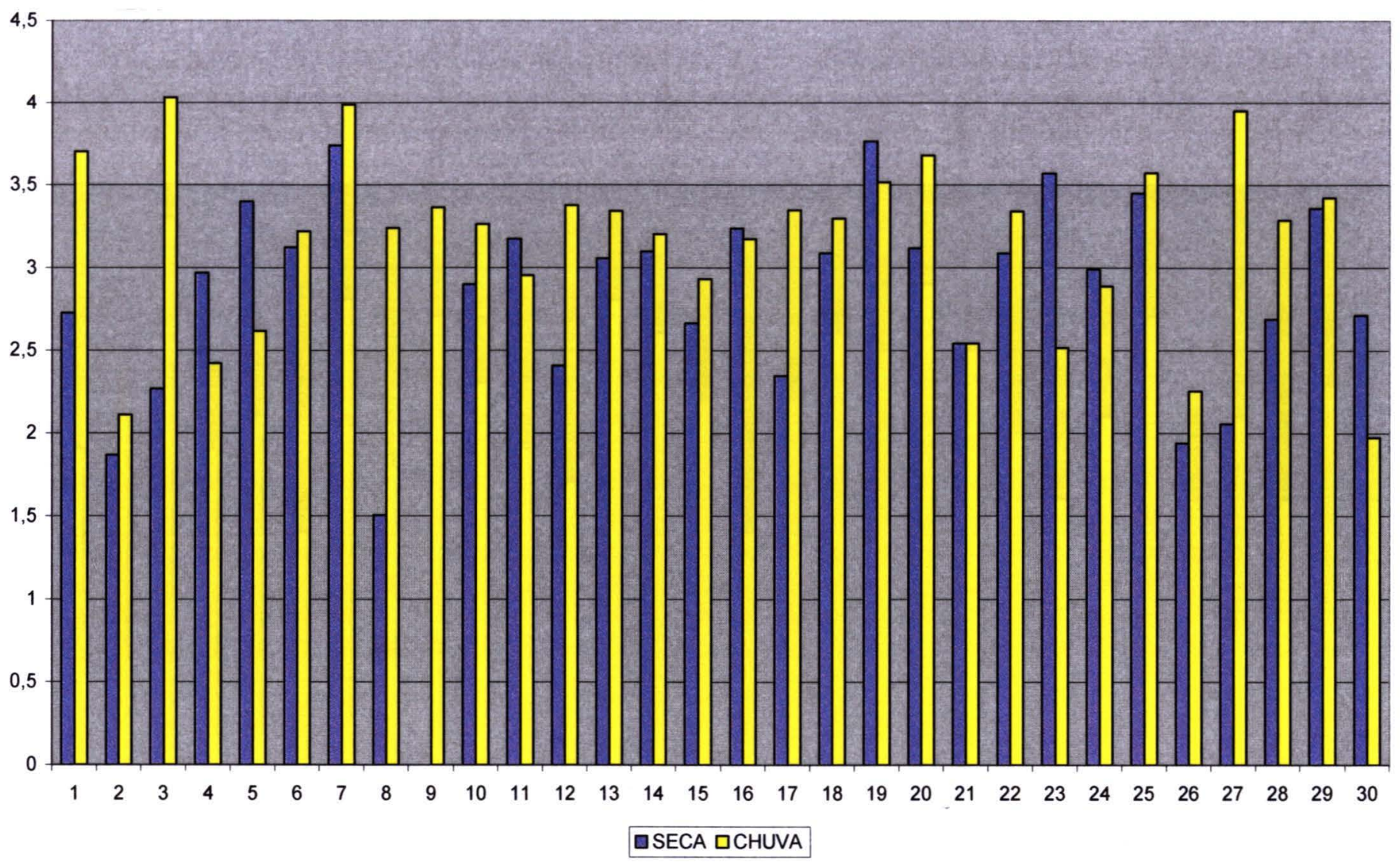

Figura 24: Comparação entre os índices de diversidade obtidos nos períodos estiagem/frio e chuvoso/quente. 


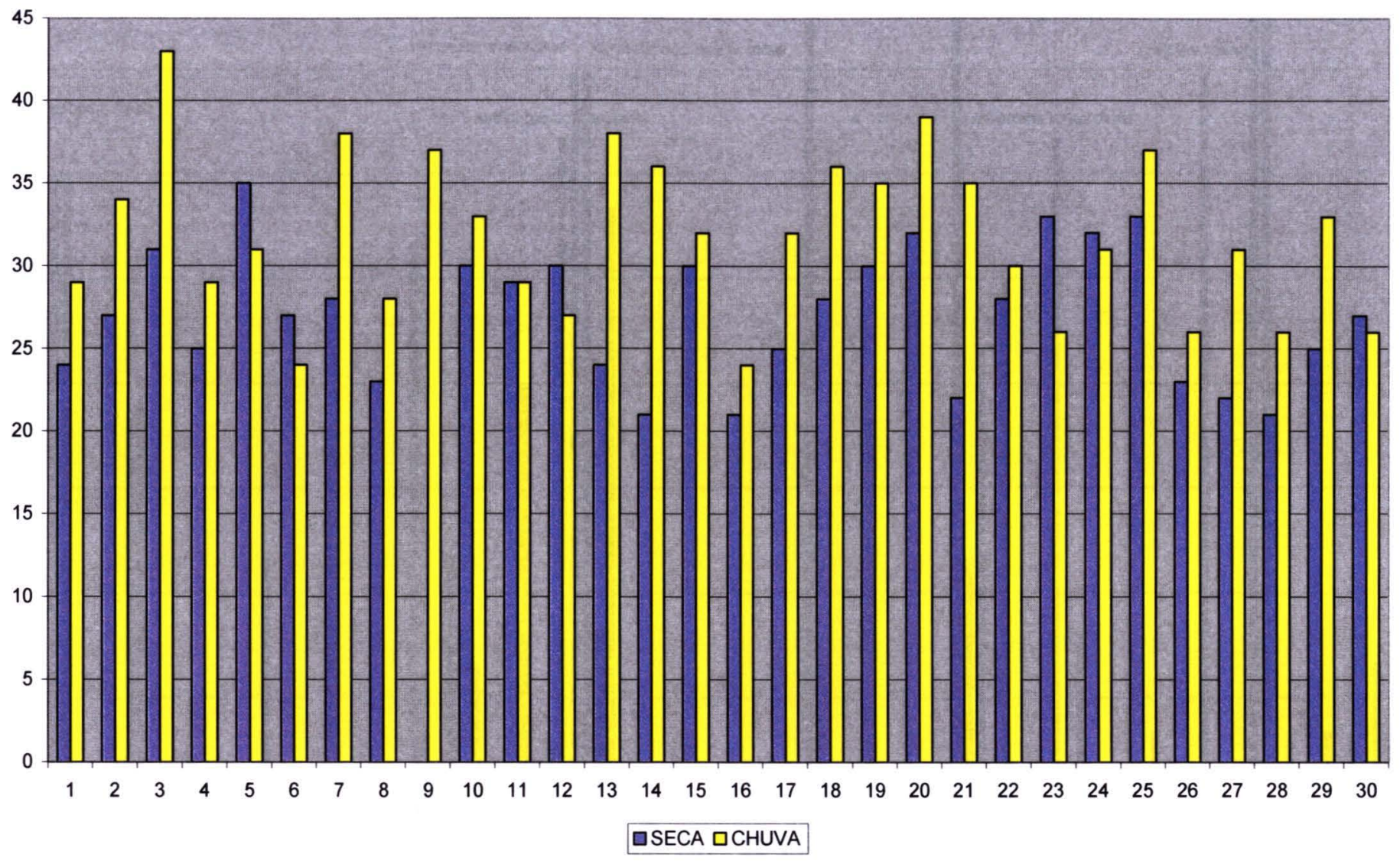

Figura 25: Comparação entre os índices de riqueza obtidos nos períodos estiagem/frio e chuvoso/quente chuvoso/quente. 


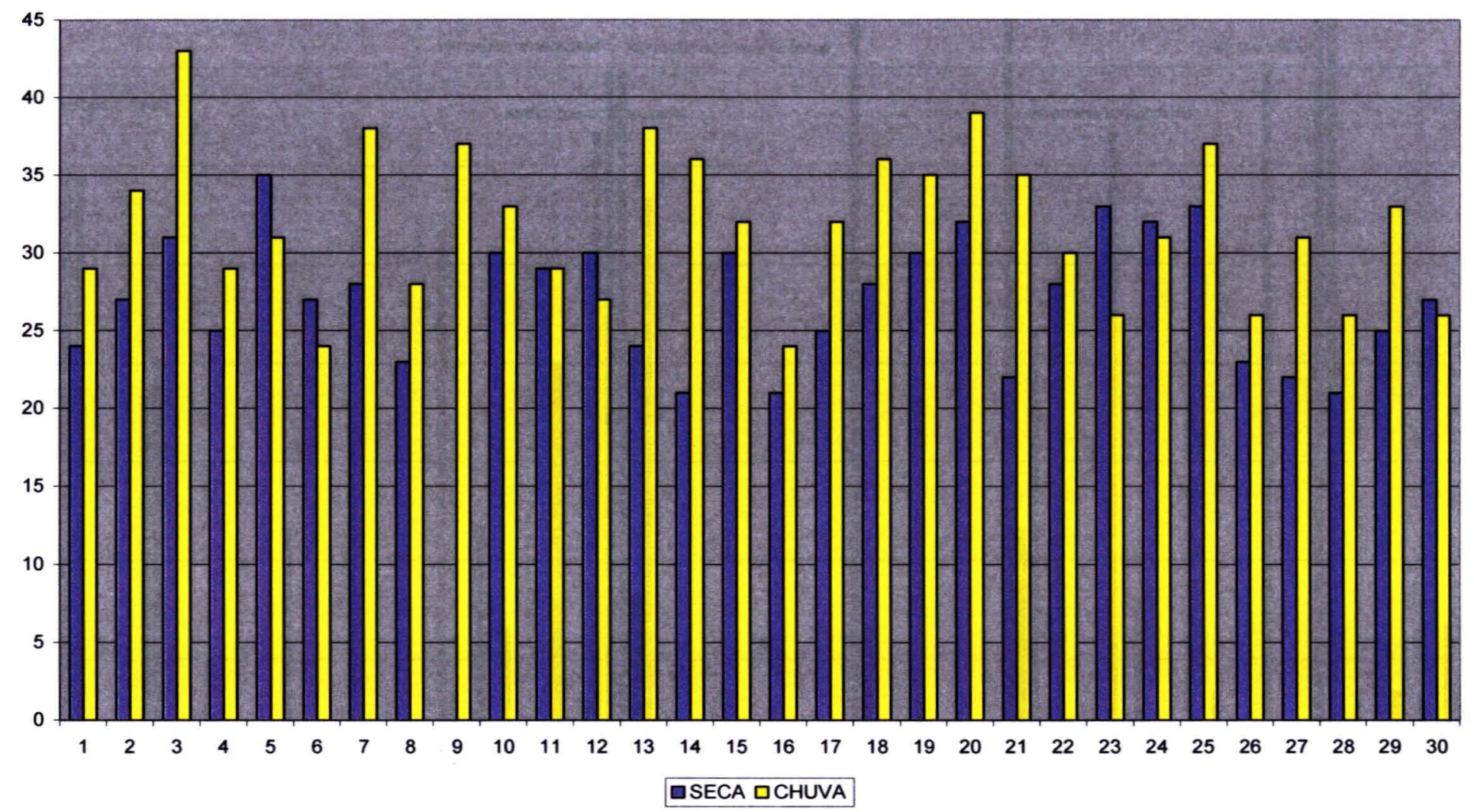

Figura 25: Comparação entre os índices de riqueza obtidos nos períodos estiagem/frio e chuvoso/quente chuvoso/quente. 


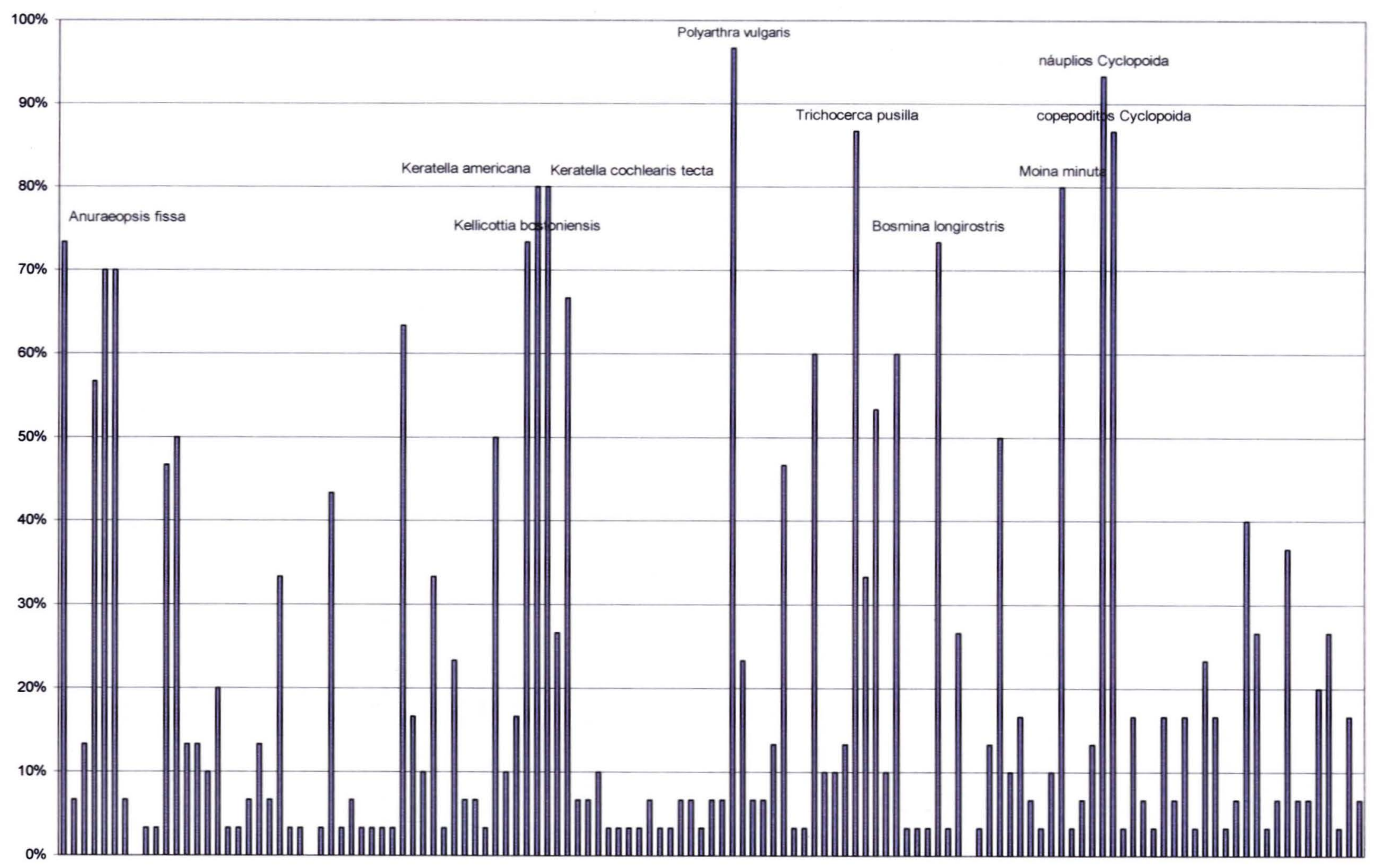

Figura 26: Variação da freqüência de ocorrência das espécies nos lagos estudados no período estiagem/frio 


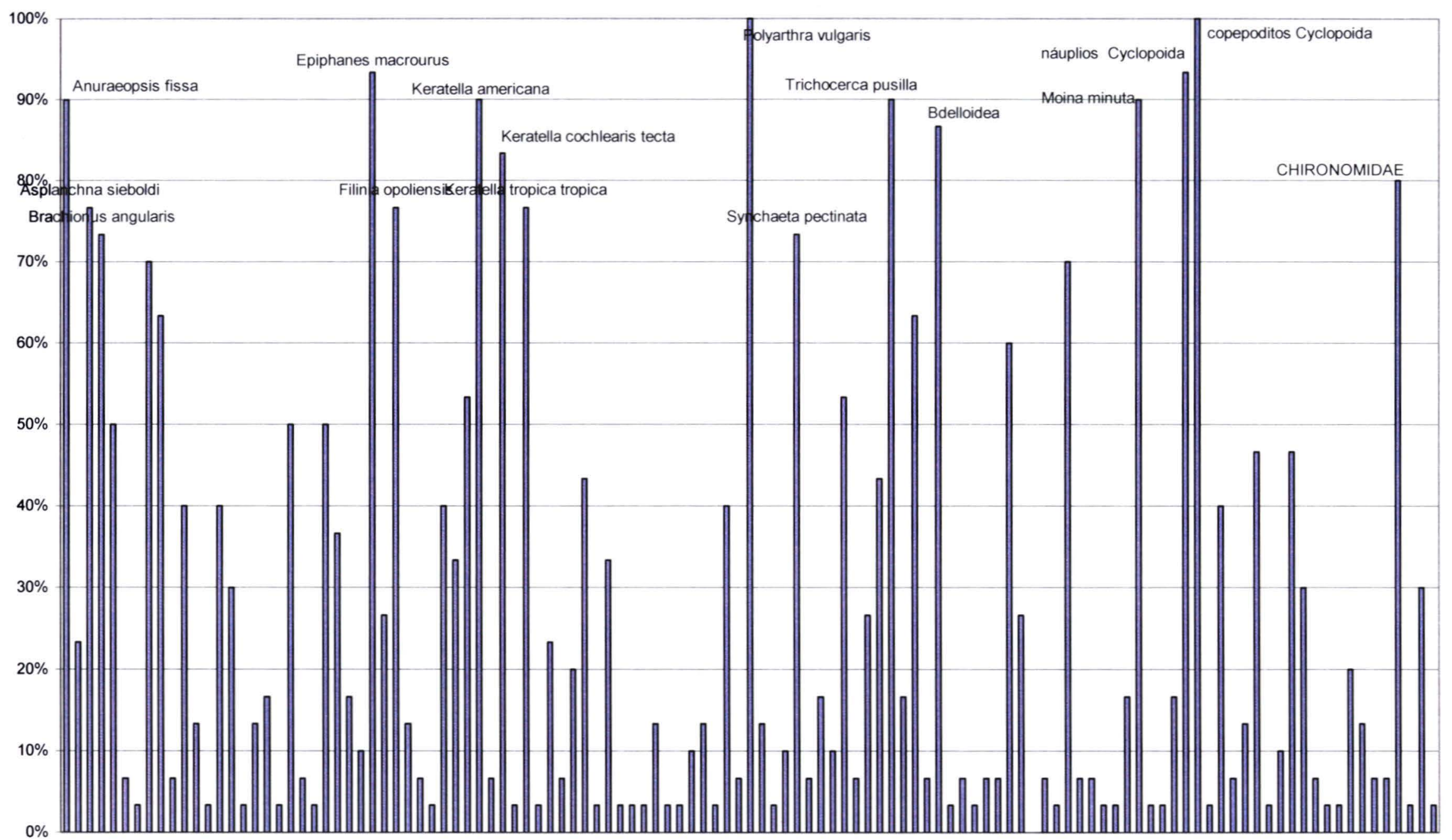

Figura 27: Variação da freqüência de ocorrência das espécies nos lagos estudados no período chuvoso/quente 


\subsection{3 - Relação com o estado trófico}

As figuras 28 e 29 mostram a variação das densidades do zooplâncton em função das concentrações de clorofila- $a$ e fósforo total, indicadores do estado trófico do corpo d'água. nos periodos estiagem/frio e chuvoso/quente. respectivamente.

A amplitude de variação das concentrações de fósforo total e clorofila- $a$ foram maiores no período estiagem/frio na maioria dos pesqueiros, quando comparada ao periodo chuvoso/quente. No primeiro periodo. os pesqueiros 20 e 25 , que apresentaram as maiores densidades totais de organismos, estão situados entre concentrações de 0.02 e $0.08 \mathrm{mg} / \mathrm{L}$ de clorofila- $a$. e 0.10 e $0.15 \mathrm{mg} / \mathrm{L}$ de fósforo total (figura 28 ).

No segundo período, a maior densidade total de organismos foi apresentada pelo pesqueiro 02 , situado numa variação entre 0,0 e $0,3 \mathrm{mg} / \mathrm{L}$ de clorofila- $a$ e 0,05 e 0,1 $\mathrm{mg} / \mathrm{L}$ de fósforo total, juntamente a outros 11 pesqueiros (figura 29). Neste período a variação da densidade total de organismos zooplanctônicos foi menor entre os pesqueiros na mesma faixa de variação da concentração de clorofila-a obtida no primeiro período.

O pesqueiro 30 apresentou-se distanciado dos demais na figura 28 por apresentar uma concentração mais elevada de clorofila- $a$ e não consta da figura 29 por ter apresentado uma concentração de $0,43 \mathrm{mg} / \mathrm{L}$ de clorofila- $a$ e a escala adotada não incluiu este valor. A densidade total de organismos zooplanctônicos neste pesqueiro, no entanto foi de $535344 \mathrm{ind} / \mathrm{m} 3$, o que resultaria num círculo com área semelhante à dos pesqueiros 9 e 14, localizado no gráfico entre os pesqueiros 5 e 28 pela sua concentração de fósforo total. Em ambos os períodos, portanto, este pesqueiro apresentou valores mais elevados de clorofila- $a$ em relação dos demais pesqueiros. 


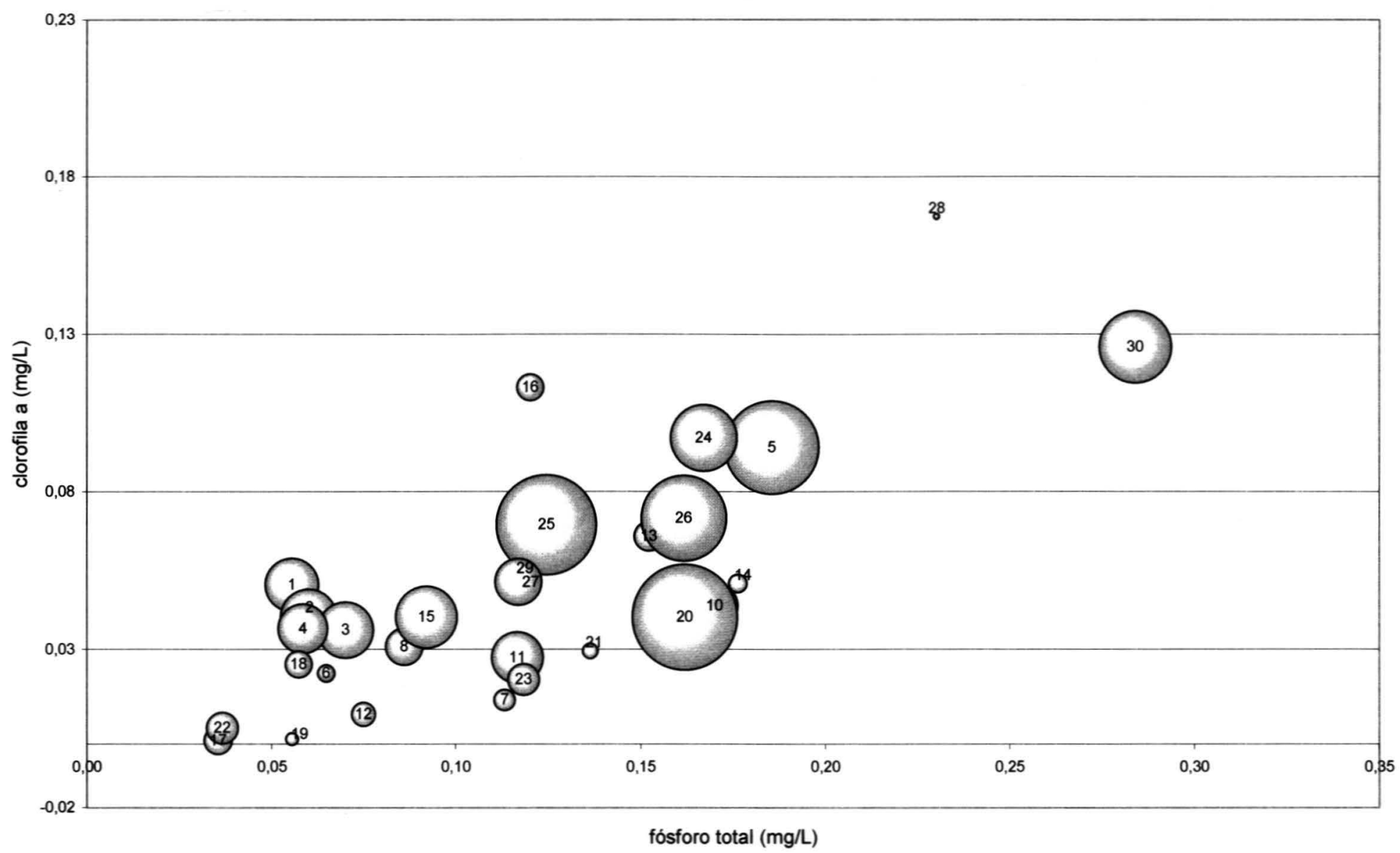

Figura 28: Dispersão da densidade total de organismos zooplanctônicos (com áreas proporcionais à densidadde total de organismos na amostra) em relação ao estado trófico indicado pelas concentrações de fósforo total $(\mathrm{mg} / \mathrm{L})$ e clorofila- $a(\mathrm{mg} / \mathrm{L})$ (período estiagem/frio). 


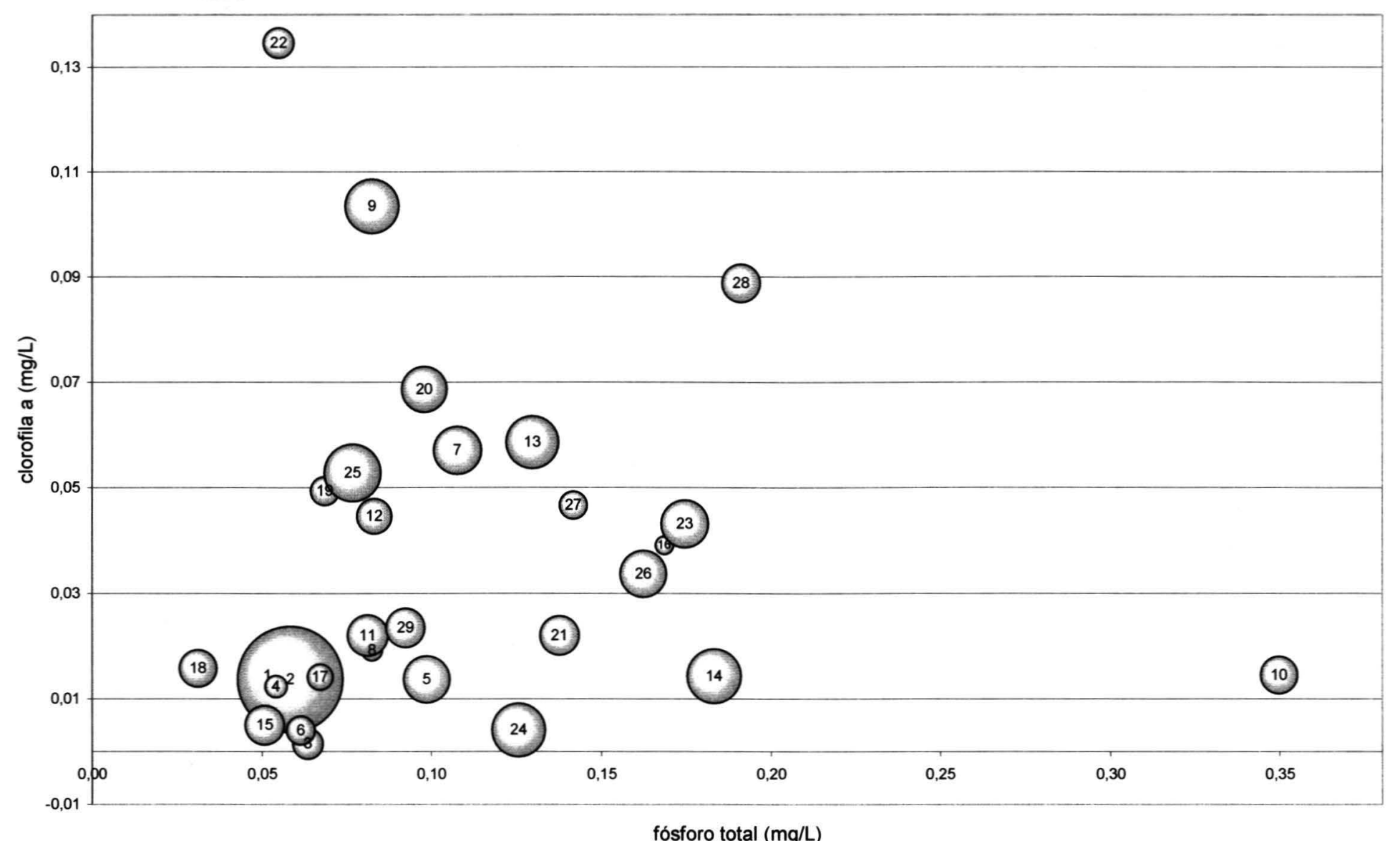

Figura 29: Dispersão da densidade total de organismos zooplanctônicos (com áreas proporcionais à densidade total de organismos na amostra), em relação ao estado trófico indicado pelas concentrações de fósforo total $(\mathrm{mg} / \mathrm{L})$ e clorofila- $a(\mathrm{mg} / \mathrm{L})$ (período chuvoso/quente). 


\section{5 - Análise estatística}

\subsection{1 - Análise de Componentes Principais das variáveis ambientais e clorofila-a}

A análise de componentes principais aplicada às variáveis ambientais e clorofila- $a, \mathrm{pH}$. transparência (TRANSP), oxigênio dissolvido (OD), nitrogênio inorgânico ( $\mathrm{N}$ inorg), fósforo total (P tot), sólidos totais em suspensão (STS), condutividade elétrica (COND) e clorofila- $a$ $(\mathrm{CHL})$ no periodo estiagem - seco resultou no gráfico apresentado na figura 30.

O eixo 1, que representa $34,2 \%$ de variância explicada dos dados, esteve associado negativamente aos pesqueiros 10.16 e 28 . em relação a sólidos totais em suspensão $(r=-0.47)$. clorofila- $a(r=-0.41)$. fósforo total $(r=-0,48)$, nitrogênio inorgânico $(r=-0.38)$ e condutividade elétrica $(r=-0,38)$ (tabela 11). Tais variáveis estão relacionadas às condições tróficas e à disponibilidade alimentar do zooplâncton. O eixo 2 , representado $21,1 \%$ de variabilidade explicada dos dados, esteve associado positivamente ao $\mathrm{pH}(\mathrm{r}=0,59)$, concentração de oxigênio dissolvido $(r=0,56)$ e transparência $(r=0,48)$ (tabela 11). O coeficiente de correlação obtido para a temperatura da água foi baixo em relação aos dois eixos, motivo pelo qual esta variável não foi nem representada no gráfico.

Na figura 31 é apresentado o gráfico resultante da análise de componentes principais das variáveis ambientais e clorofila- $a$ no periodo chuvoso/quente.

O eixo 1 do gráfico referente ao período chuvoso/quente apresentou $38 \%$ de variância explicada e esteve associado negativamente à transparência $(r=-0,45)$, e positivamente a sólidos totais em suspensão $(r=0,44)$, fósforo total $(r=0,44)$ e condutividade elétrica $(r=0,41)$, evidenciando a oposição existente entre os valores transparência da água e as variáveis relacionadas ao estado trófico. As concentrações de oxigênio dissolvido $(r=0,65)$ e a temperatura da água $(\mathrm{r}=0,45)$, como foi observado também para o periodo seco estiveram associadas positivamente ao eixo 2 , com $19 \%$ de variância explicada dos dados (tabela 12) . 
Em relação à distribuição dos pesqueiros no gráfico, verificou-se uma maior concentração destes no lado negativo dos eixos 1 e 2, associados aos valores mais elevados de transparência e condições de menor eutrofização que as demais.

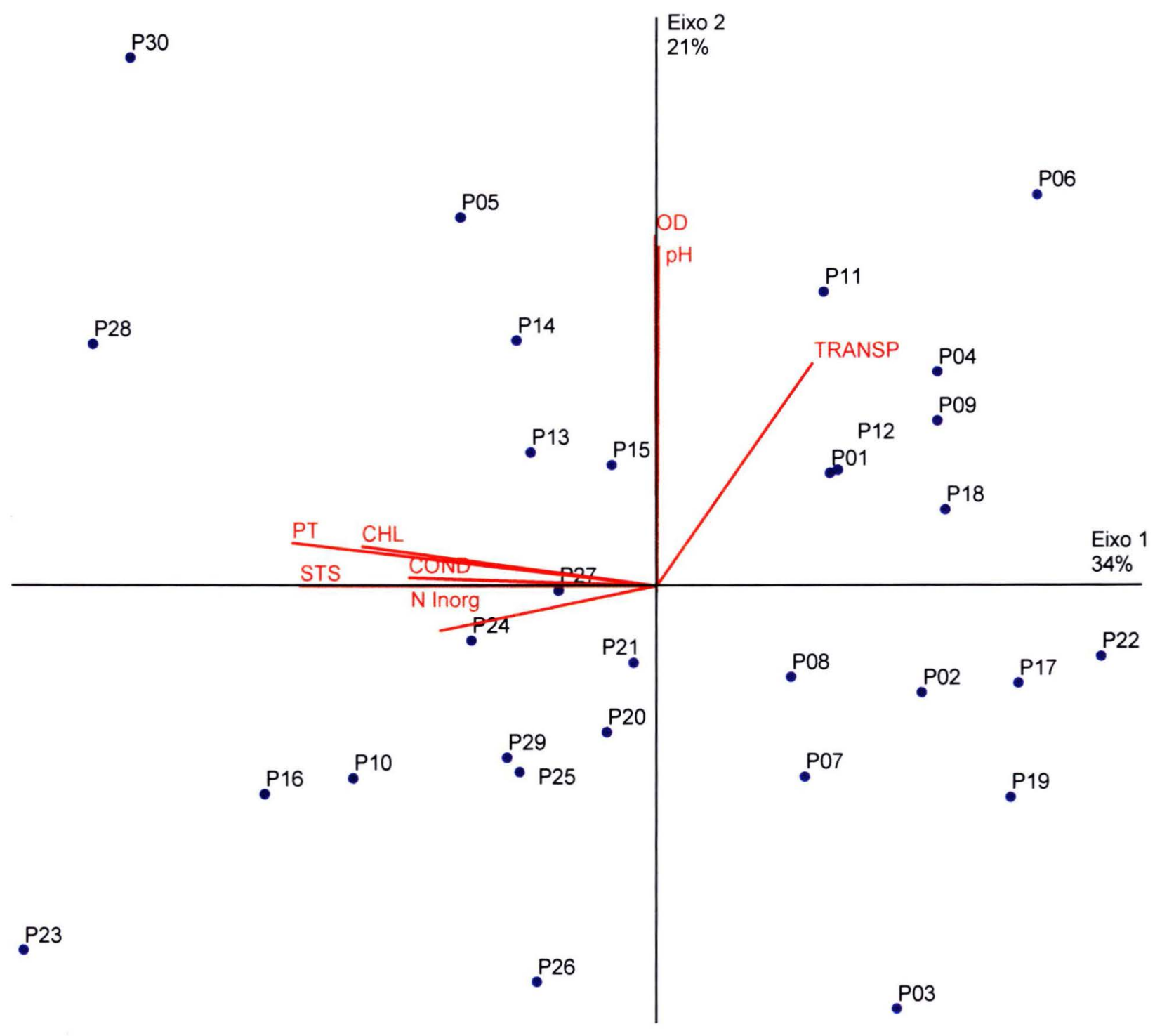

Figura 30: Biplot da análise de componentes principais para as variáveis ambientais dos lagos de pesca no período estiagem/frio. 


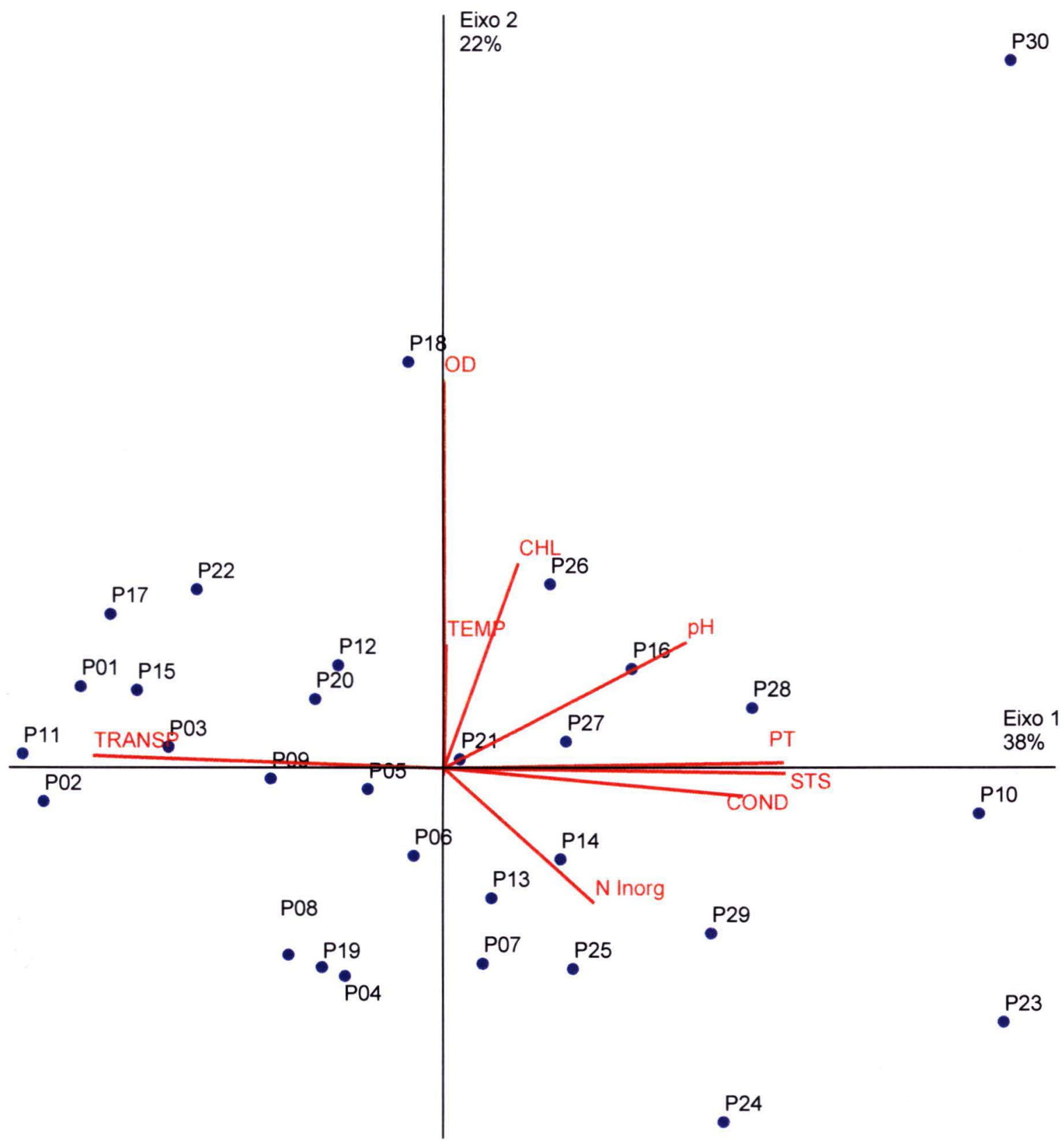

Figura 31: Biplot da análise de componentes principais para as variáveis ambientais dos lagos de pesca no período chuvoso quente 


\subsection{2 - Análise de Componentes Principais da comunidade zooplanctônica}

\subsubsection{1 - Rotíferos}

A análise de componentes principais aplicada às densidades numéricas de rotíferos, no período estiagem/frio. apresentou $20,7 \%$ de variância explicada. representada pelos eixos 1 e 2 (figura 32). Apesar da baixa explicabilidade e correlação com o eixo. nota-se que espécies de rotiferos tais como Keratella tropica $(\mathrm{r}=0,31)$, Brachionus angularis $(\mathrm{r}=0,28)$, Keratella cochlearis tecta $(\mathrm{r}=0.26)$. Anuraeopsis fissa $(\mathrm{r}=0,25)$ e Polvarthra vulgaris $(\mathrm{r}=0.22)$ estão associadas positivamente ao eixo 1 e poderiam estar relacionadas a condições mais eutróficas (tabela 13).

Os pesqueiros estão agrupados, considerando as espécies de rotiferos, predominantemente ao lado positivo do eixo 1, numa possível associação ao maior grau de eutrofização.

A figura 33 representa a análise de componentes principais das densidades numéricas de rotíferos no período chuvoso quente. A variância explicada dos dados foi de $19,7 \%$, sendo de $10,6 \%$ para o eixo 1 e $9.1 \%$ para o eixo 2 . Estas porcentagens são consideradas muito baixas para uma boa explicabilidade dos resultados, porém. é possivel verificar algumas tendências apresentadas por estes dados, como a relação negativa existente entre o eixo $1 \mathrm{e}$ as espécies de Brachionus quadridentatus $(\mathrm{r}=-0,28)$, B. calyciflorus $(\mathrm{r}=-0,27)$ e $B$. caudatus $(\mathrm{r}=-$ 0,23), Keratella tropica $(\mathrm{r}=-0,26)$ e Trichocerca pusilla $(\mathrm{r}=-0,22)$ e entre o eixo 2 e Trichocerca stylata $(\mathrm{r}=-0,32)$ e Synchaeta oblonga $(\mathrm{r}=0,27)$ (tabela 14). 


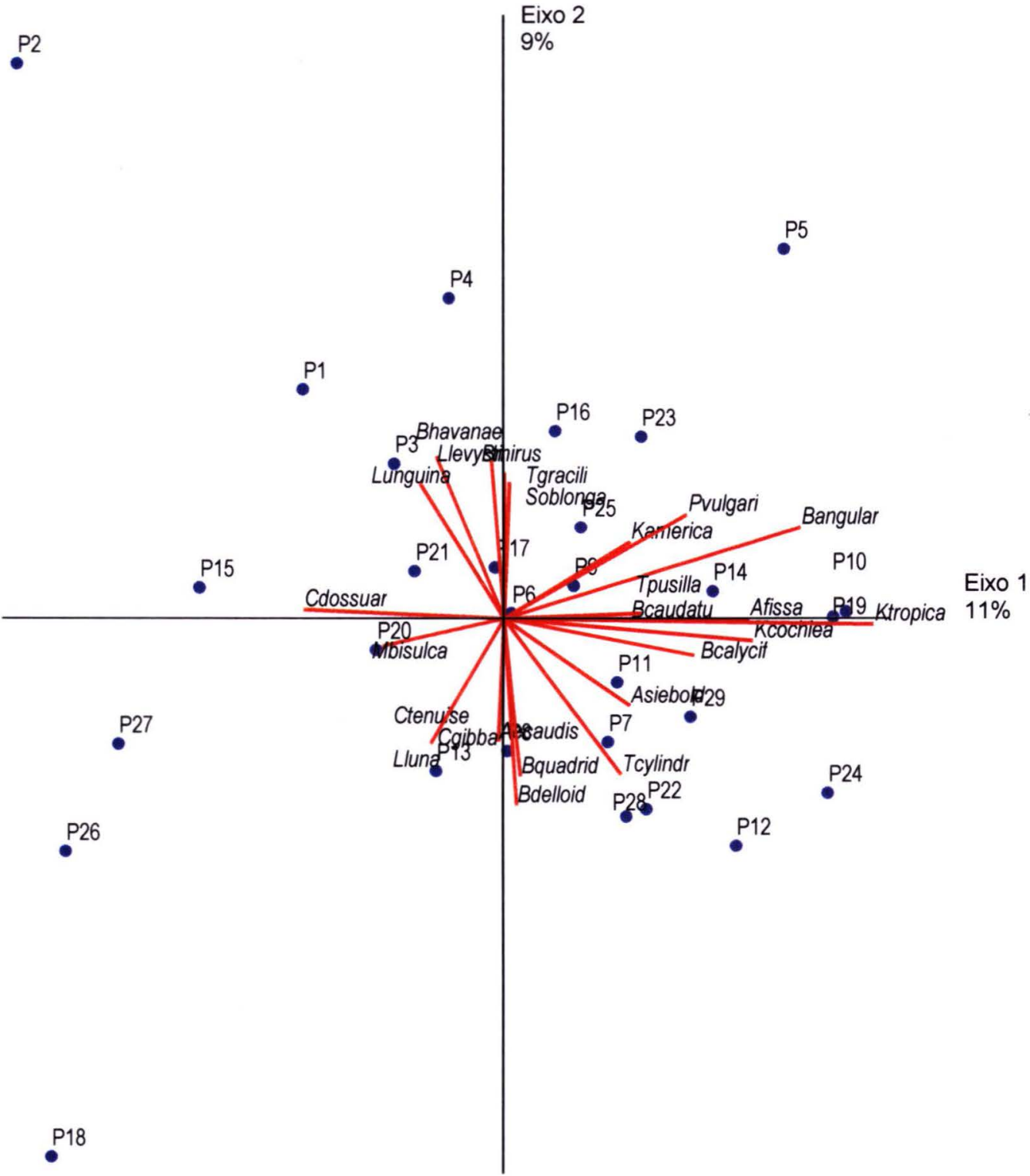

Figura 32: Biplot da análise de componentes principais para as densidades numéricas de rotíferos dos lagos de pesca no período estiagem/frio. 


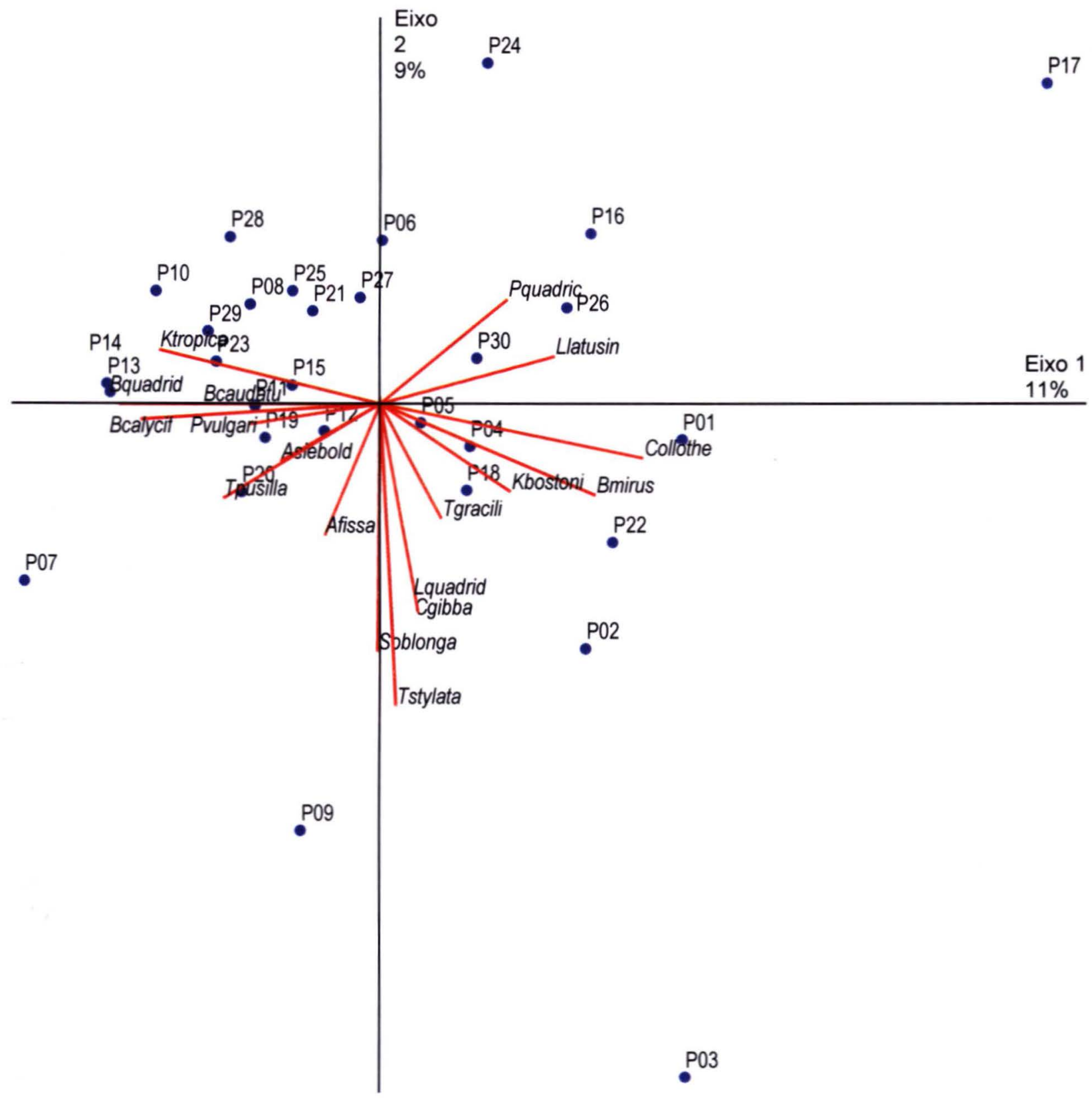

Figura 33: Biplot da análise de componentes principais para as densidades numéricas de rotíferos dos lagos de pesca no período chuvoso/quente. 


\subsubsection{2- Crustáceos}

A figura 34 representa a análise de componentes principais aplicada às densidades numéricas de crustáceos planctônicos do periodo estiagem/frio. A variância explicada nesta análise foi de $29,4 \%$, sendo de $16.3 \%$ para o eixo 1 e $13,1 \%$ para o eixo 2 .

O eixo 1 esteve associado negativamente a Bosmina hagmanni. Daphnia ambigua, Alonella sp $(\mathrm{r}=-0.38)$, Thermocyclops decipiens $(\mathrm{r}=-0.37)$ e Thermocyclops inversus $(\mathrm{r}=-0,33)$. táxons que apresentaram baixas densidades nos lagos de pesca estudados. $O$ eixo 2 esteve associado positivamente a táxons mais abundantes: Bosmina longirostris $(\mathrm{r}=0.35)$, copepoditos de ciclopóides $(r=0.349)$. náuplios de ciclopóides $(r=0.259)$ e náuplios de calanóides $(r=0,253)$ (tabela 15). Os pesqueiros encontram-se agrupados predominantemente ao lado positivo do eixo 1 e negativo do eixo 2 , evidenciando a pequena representatividade de crustáceos nos pesqueiros estudados.

$\mathrm{Na}$ figura 35 está representada a análise de componentes principais aplicada às lensidades numéricas de crustáceos dos lagos estudados no período chuvoso/quente.

O eixo 1 esteve associado positivamente a Diaphanosoma breviremme $(\mathrm{r}=0,34)$, Jiaphanosoma birgei $(\mathrm{r}=0,31)$, Alona poppei $(\mathrm{r}=0,313)$, náuplios $(\mathrm{r}=0,263)$ e copepoditos $\mathrm{r}=0,236$ ) de calanóides (tabela 16)). Como verificado no período seco, os pesqueiros no reríodo chuvoso situaram-se em direções opostas aos vetores representativos dos crustáceos, lenotando baixas densidades dos táxons pertencentes a este grupo nestes ambientes. 


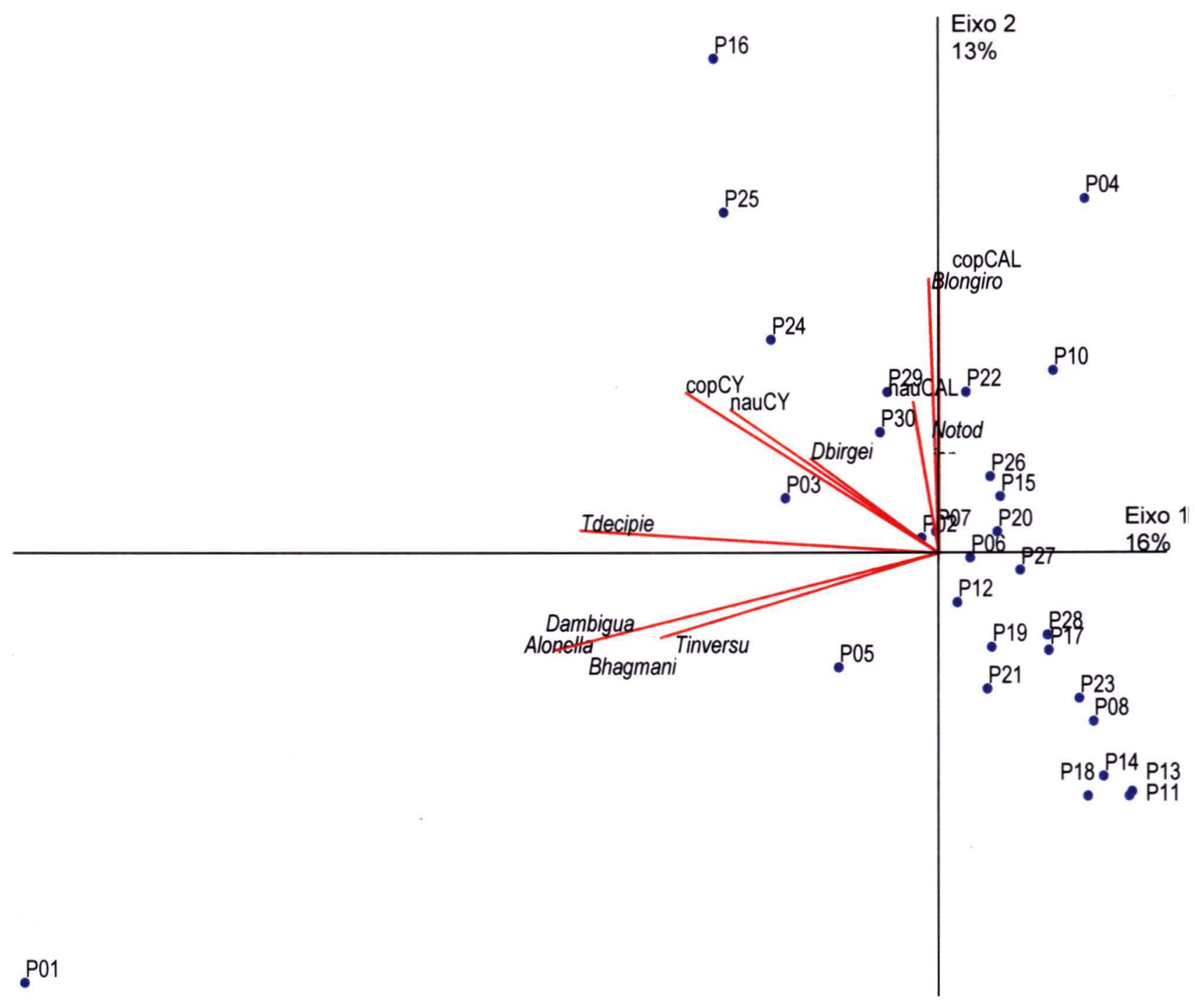

Figura 34: Biplot da análise de componentes principais para as densidades numéricas de crustáceos dos lagos de pesca no período estiagem/frio. 


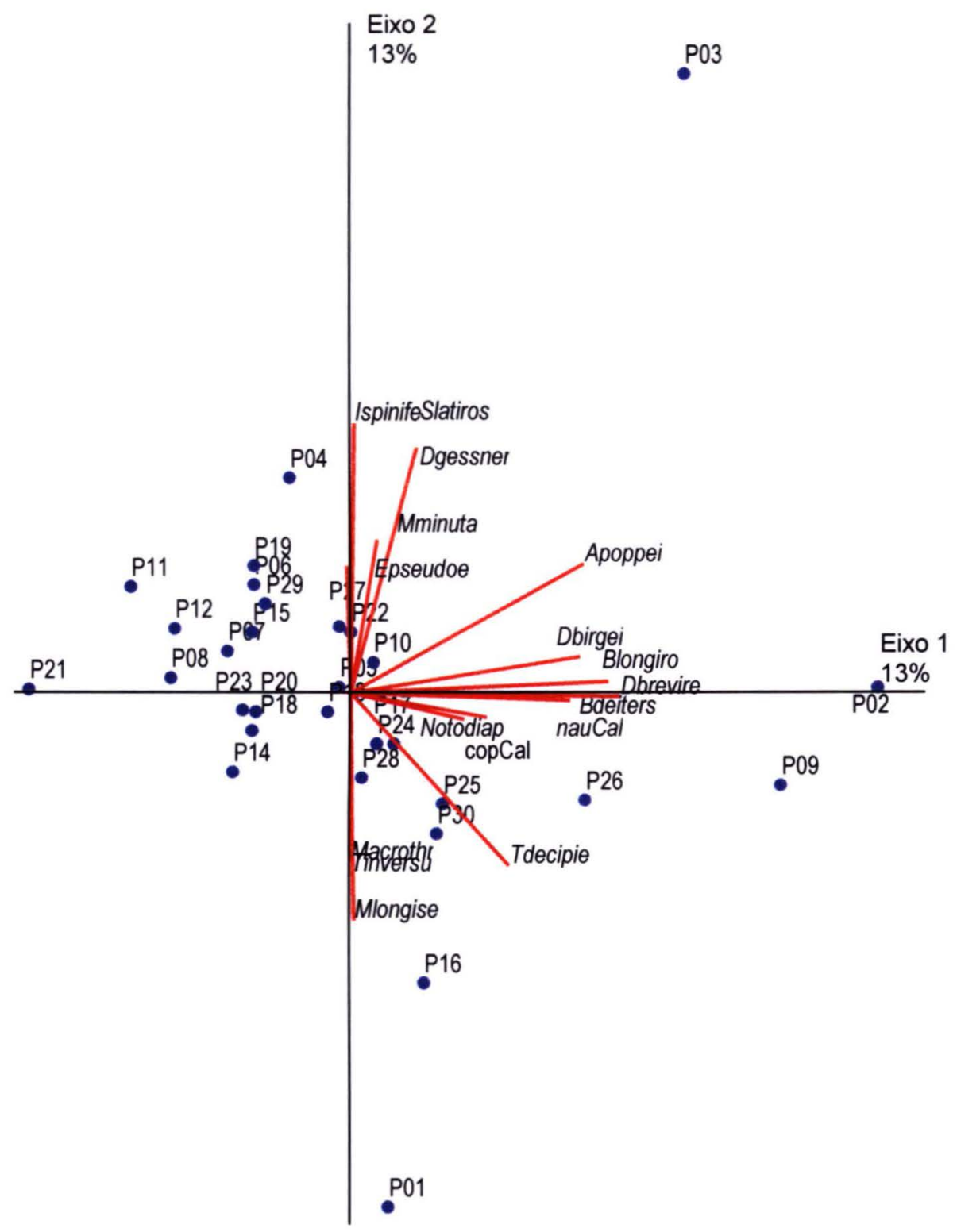

Figura 35: Biplot da análise de componentes principais para as densidades numéricas de crustáceos dos lagos de pesca no período chuvoso/quente. 


\subsection{3 - Análise de agrupamento (Cluster)}

O resultado da análise de agrupamento aplicada aos táxons mais freqüentes (freqüência de ocorrência maior que $70 \%$ ) do periodo estiagem/frio está representado na figura 36 e evidencia quatro grupos com maiores afinidades ecológicas nos lagos estudados, num nível de $50 \%$ de similaridade:

Grupo A: Anuraeopsis fissa (Afissa), Keratella cochlearis (Kcochlea). náuplios (nauCY) e copepoditos (copdtCY) de ciclopóides

Grupo B: Kellicottia bostoniensis (Kbostoni) e Moina minuta (Mminuta)

Grupo C: Keratella americana (Kamerica), Polyarthra vulgaris (Pvulgari) e Bosmina longirostris (Blongiro)

O grupo 1 e o grupo 3 caracterizam-se por se constituirem de táxons freqüentes representados por densidades numéricas elevadas. Os do grupo 2, apresentam em comum elevada freqüência de ocorrência nos lagos estudados, mas densidades numéricas mais baixas.

O resultado desta análise para o período chuvoso/quente está representado na figura 49 , constituindo-se os seguintes grupos, num nivel de $50 \%$ de similaridade:

Grupo A: Anuraeopsis fissa (Afissa) e náuplios de ciclopóides (nauCY)

Grupo B: Asplanchna sieboldi (Asiebold), Synchaeta pectinata (Spectina), Filinia opoliensis (Fopolien) e Trichocerca pusilla (Tpusilla)

Grupo C: Brachionus angularis (Bangular), Keratella americana (Kamerica), Moina minuta (Mminuta), copepodito de ciclopóides (copdtCY), Filinia opoliensis (Fopoliens) e Polyarthra vulgaris (Pvulgari)

Grupo D: Keratella cochlearis (Kcochlea), Keratella tropica (Ktropica) e larvas de Chironomidae (CHIRON). 
Grupo F: Epiphanes macrourus (Emacrour) e Bdelloidea (Bdelloid)

Grupo G: Keratella cochlearis (Kcochlea). Keratella tropica (Ktropica) e larvas de Chironomidae (CHIRON)

Os grupos 1 e 3 são constituídos por táxons com frequiências de ocorrência acima de $90 \%$ e densidades numéricas mais elevadas. Os grupos 2 e 4 contem os táxons com freqüência de ocorrência entre 70 e $90 \%$.

No primeiro e no segundo periodo estão associados num mesmo grupo náuplios de ciclopóides e Anuraeopsis fissa e em outro grupo Keratella americana e Polyarthra vulgaris.

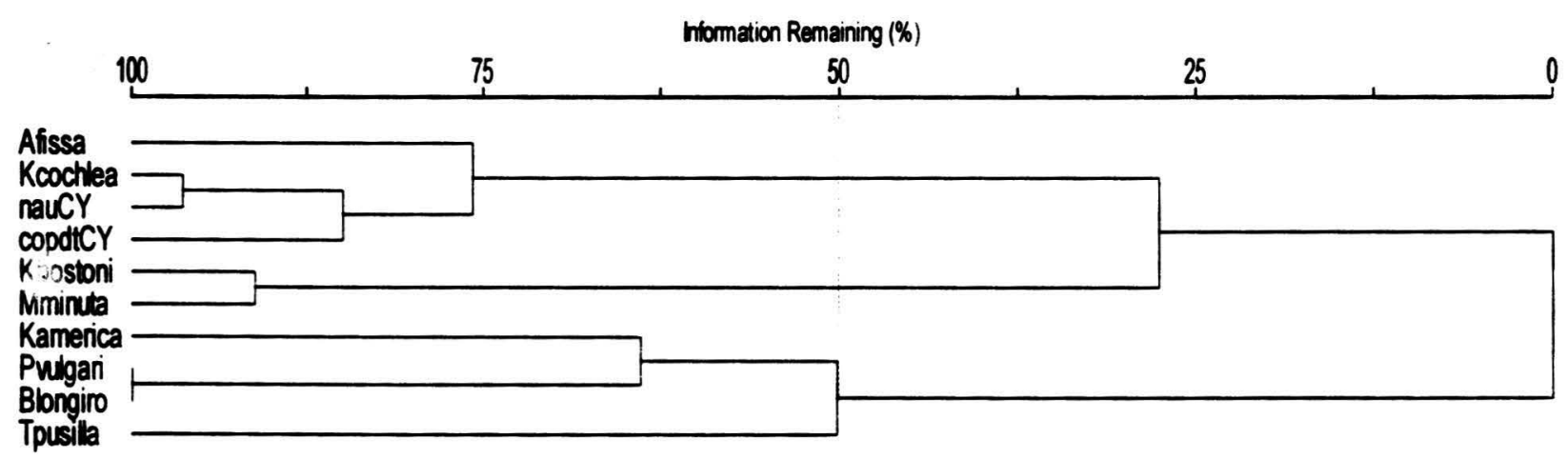

Figura 36: Dendrograma da análise de agrupamento dos táxons mais freqüentes no zooplâncton dos pesqueiros no periodo estiagem/frio 


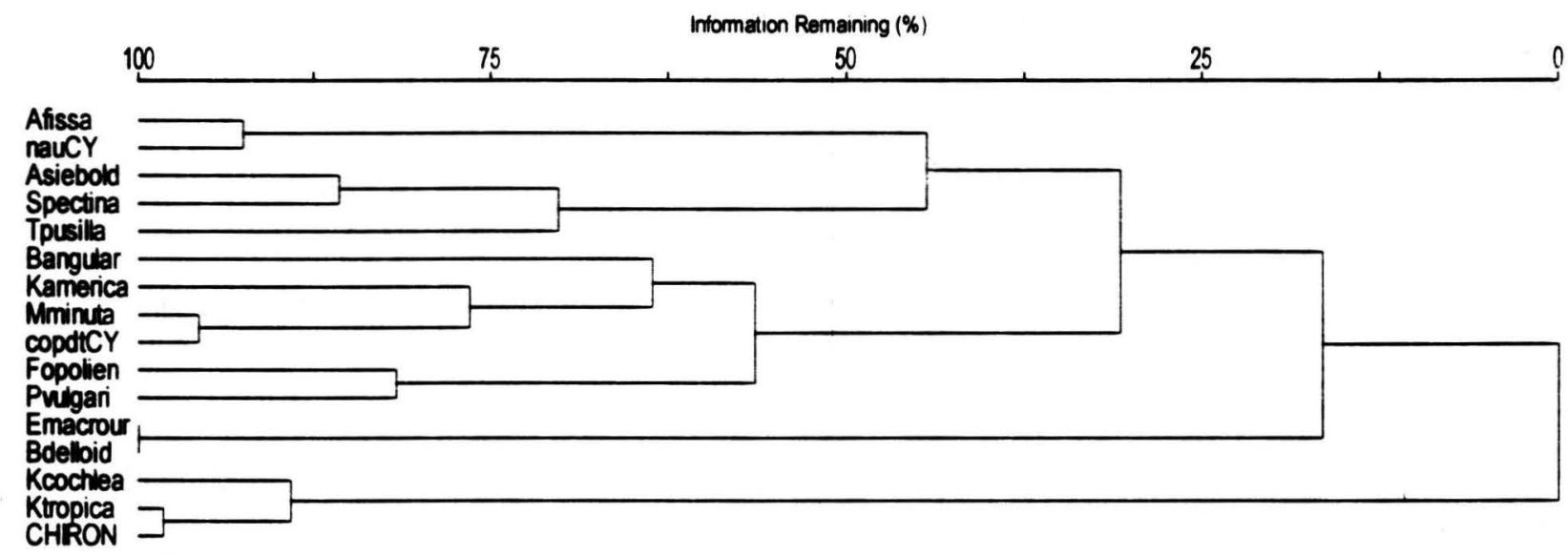

Figura 37: Dendrograma da análise de agrupamento dos táxons mais freqüentes no zooplâncton dos pesqueiros no periodo chuvoso/quente.

A análise de agrupamento aplicada aos pesqueiros estudados, baseada na densidade numérica das espécies mais freqüentes, para o período estiagem/frio, está representada na figura 38.

Constituiram-se a partir da na análise dois grupos de pesqueiros, com um nível de $75 \%$ de similaridade:

Grupo A: 1 e 16

Grupo B: 4, 21, 23, 8, 5, 19

Grupo C: 24, 25, 29

Grupo D: 2, 6, 10, 11, 12, 14, $15,17,20,22,26,28,30$

Grupo E: 3, 7, 8, 13 
Levando-se em conta que estes grupos se formaram a partir dos táxons mais freqüentes do zooplâncton. o grupo A caracterizou-se pela presença destes mesmos táxons em densidades mais baixas do que os pesqueiros dos grupos B. C. D. E. Os pesqueiros 1 e 16 que formaram o grupo A são também os que se encontram mais afastados dos demais na análise de componentes principais (figura 37).

Para o período chuvoso/quente, o agrupamento dos pesqueiros, baseado nos táxons mais freqüentes do zooplâncton, com um nível de $75 \%$ de similaridade. constituiu os seguintes grupos (figura 42):

Grupo A: 1. 25. 23

Grupo B: 4.8 e 28

Grupo C: 4, 20, 24, 11, 22. 19

Grupo D: 2, 3, 15

Grupo E: 16, 17, 26

Grupo F: 5, 13, 14

Grupo G: 6, 7, 10.27

Grupo H: 9, 21, 29, 12, 18

Um número maior de grupos neste período reflete o aumento da diversidade, comentada anteriormente. 


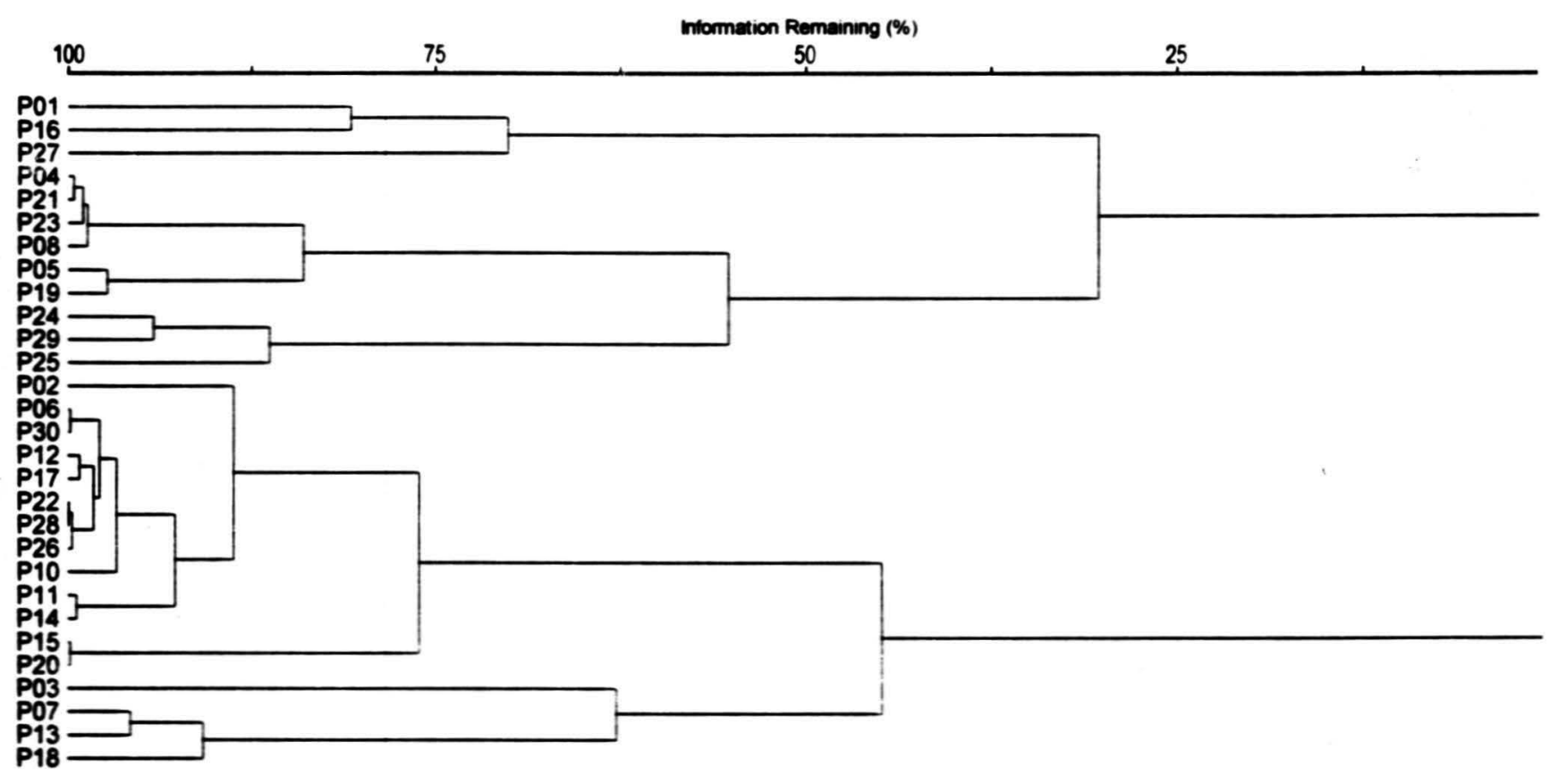

Figura 38: Dendrograma da análise de agrupamento dos lagos de pesca no período estiagem/frio, baseado nas espécies mais freqüentes do zooplâncton ( $75 \%$ de similaridade). 


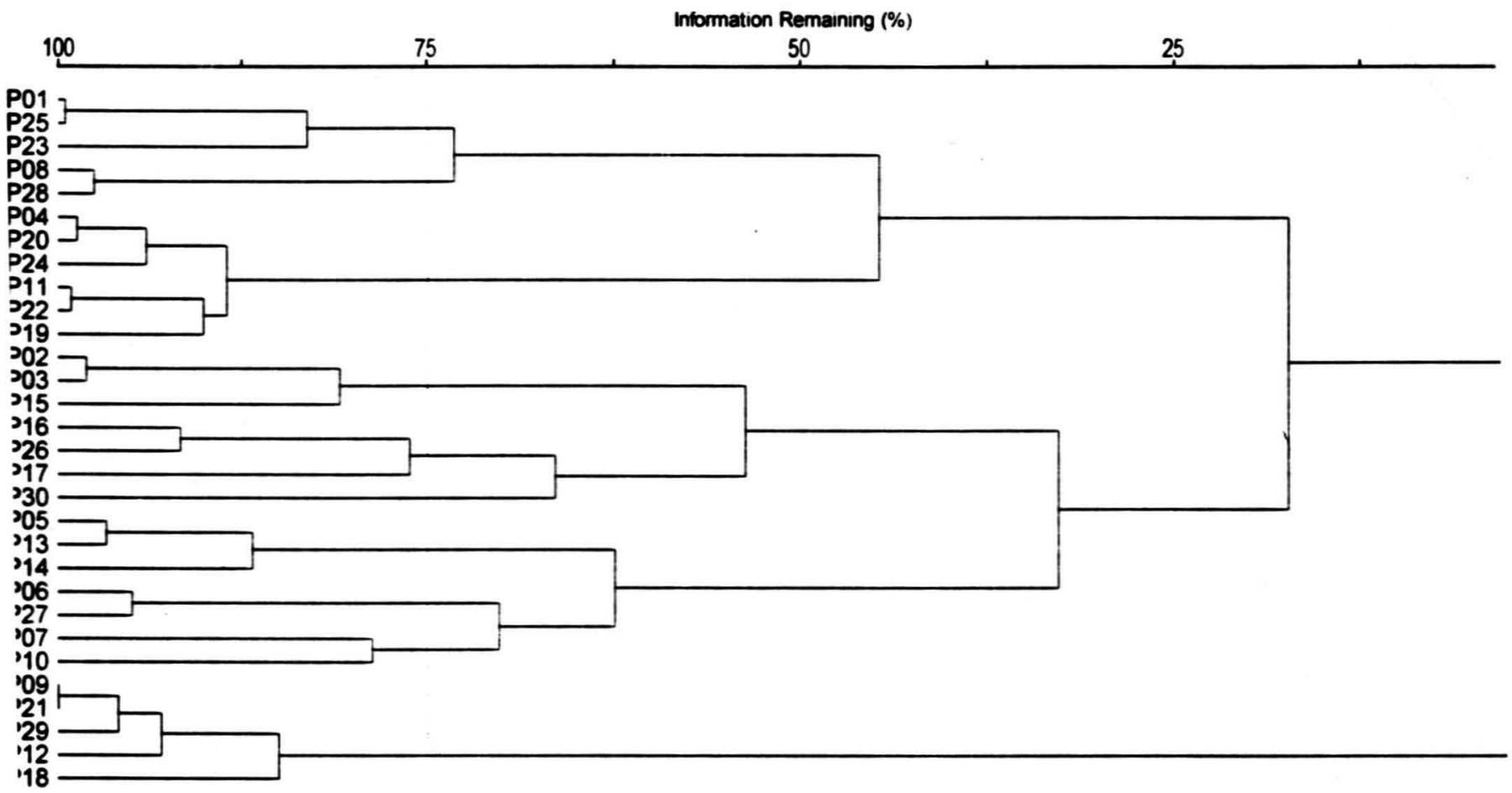

Figura 39: Dendrograma da análise de agrupamento dos lagos de pesca no período chuvoso/quente, baseado nas espécies mais freqüentes do zooplâncton ( $75 \%$ de similaridade). 


\section{5 - DISCUSSÃO}

\section{1 - Variáveis físicas e químicas da água}

Os resultados referentes às características físicas e químicas da água demonstraram haver variabilidade entre os lagos estudados. sendo a amplitude de variação maior no período chuvoso/quente que no período estiagem/frio.

No período chuvoso. o efeito diluidor da chuva e o tempo de residência mais curto podem ter sido responsáveis pela variação observada.

A transparência da água. relacionada diretamente à concentração de sólidos totais em suspensão, apresentou no período chuvoso valores mais altos que no período seco. Este resultado contraria a expectativa de que, havendo maior aporte de material alóctone carreado pela chuva, os valores de transparência seriam menores e os de sólidos em suspensão maiores durante o período chuvoso. Tal fato evidencia a influência exercida pelo manejo dos lagos sobre as variáveis ambientais, reduzindo a ação da sazonalidade que naturalmente atua nestes ambientes.

Os valores de transparência apresentaram uma amplitude de variação correspondente ao recomendável - entre 0,25 e $0,70 \mathrm{~m}$ - por SIPAÚBA-TAVARES (1994) para tanques de piscicultura. $O$ pesqueiro 23 , no entanto. apresentou transparência inferior a $0,20 \mathrm{~m}(0,10 \mathrm{~m}$ no período seco e $0,15 \mathrm{~m}$ no período chuvoso) e os valores mais elevados de sólidos totais em suspensão nos dois períodos estudados. Considerando que a água de abastecimento do lago vem diretamente de nascente, que não há solo exposto na área de entorno, há indícios de que esteja havendo um manejo pouco adequado, com excesso de material sendo adicionado à água do lago.

Os lagos estudados, embora pertencentes a sub-bacias diferentes quanto às suas características geológicas, geomorfológicas e de uso e ocupação do solo, apresentaram semelhantes amplitudes de variação das características físicas e químicas estudadas. GREEN \& BOYD (1995), consideram a adição de fertilizantes e rações como 
responsável pelo maior aporte de nitrogênio e fósforo em lagos de piscicultura. enquanto a chuva e o escoamento superficial representam uma entrada menor destes nutrientes. Os referidos autores verificaram que não há diferença sazonal significativa das variáveis abióticas da água de lagos de piscicultura.

Estas observações levam a supor que o manejo é direcionado a estabelecer um ambiente onde todas as variáveis sejam controladas no sentido de prover nutrientes aos peixes e as boas condições para sua sobrevivência, ainda que intuitivamente por parte de alguns proprietários. A oxigenação da água através de aeradores mecânicos é muito empregada na maioria dos pesqueiros, o que indica uma grande preocupação em não comprometer os estoques de peixe pela falta de oxigênio na água. Uma possível estratificação em decorrência do aquecimento superficial diário. principalmente no periodo seco, pode ter ocorrido em virtude da maior amplitude térmica observada nesta época. o que poderia provocar redução do oxigênio dissolvido em parte da coluna d'água. Com a intervenção que promove a movimentação da água por mecanismos artificiais, ou ainda, devido a pouca profundidade dos lagos que favorece a circulação da água pela ação de ventos, é pouco provável observar situação de anoxia no fundo, embora seja grande o volume de matéria orgânica em decomposição aí acumulado.

Segundo SIPAÚBA-TAVARES (1995) a qualidade da água é um fator limitante em tanques de piscicultura e a renovação da água costuma ser usada para a eliminação de resíduos alimentares e metabólicos, já que um dos principais problemas destes lagos é decorrente da grande quantidade de alimento que não é utilizado pelos peixes e acaba ficando disponivel para o crescimento de algas e bactérias.

A temperatura da água, apresentou uma variação mais significativa que as demais variáveis entre os períodos estudados. Supõe-se que esta variável possa atuar como um fator isolado, sem influenciar diretamente as demais variáveis que seriam controladas pela ação do manejo adotado - $97 \%$ dos lagos estudados são submetidos a manejo, conforme informaram seus proprietários. A necessidade, segundo estes, é de controlar o pH da água, promover oxigenação e, principalmente, adicionar alimentos e 
nutrientes complementares aos peixes, introduzindo rações e fertilizantes. Estas ações se dão muitas vezes de forma empírica, sendo poucos os que contam com assessoria técnica para definir a quantidade e qualidade adequada de produtos a serem adotados. $\mathrm{A}$ preocupação predominante é proporcionar saúde e vigor aos peixes oferecidos aos pescadores, sendo negligenciados os aspectos referentes à qualidade da água e dos efluentes produzidos na atividade.

Em relação à eutrofização promovida. MERCANTE et al. (2004) verificaram que não houve diferença significativa entre os períodos seco e chuvoso para as variáveis que definem o grau de trofia dos lagos estudados. ressaltando que todos eles apresentaram concentrações de fósforo total pelo menos dez vezes acima do recomendado pela resolução CONAMA 20 (1986) - valores preconizados para a Classe II, que estabelece os limites para águas destinadas à aqüicultura natural ou intensiva. Segundo os autores supracitados os valores obtidos para o IET classificariam estes lagos como ambientes eutróficos a hipereutróficos.

Os resultados da análise de componentes principais evidenciaram a importância das variáveis relacionadas ao processo de eutrofização nos dois períodos estudados. Os valores de temperatura e transparência da água foram menos variáveis no período chuvoso entre os lagos estudados em conseqüência de características climáticas deste período (menor amplitude térmica e maior umidade relativa do ar). As variáveis relacionadas às demais características físicas e quimicas da água, entretanto, foram mais dependentes do manejo dos lagos. Assim sendo, a dinâmica das variáveis ambientais fica condicionada pelo manejo, que consiste prioritariamente na alimentação dos peixes por adubação orgânica, rações (cuja adição fica condicionada à transparência da água), ceva (muito empregada tanto pelos proprietários quanto pelos pescadores) oxigenação por aeradores e calagem dos tanques para o controle do pH (Relatório FAPESP, 2003). Além disso, há ainda o recurso de se esgotar o lago e tornar a enchê-lo no caso de ocorrer algum problema não solucionado pelos mecanismos acima, dependendo apenas da disponibilidade de água para realizá-lo. Alguns proprietários mencionam recorrer a este recurso, principalmente em época de introduzir nova carga de peixes nos lagos. 
PEREIRA et al. (2004) verificaram que o fluxo de água em tanques de piscicultura influenciou as características físicas e químicas, bem como a comunidade zooplanctônica presente: os sistemas com menor fluxo de água apresentaram maior concentração de nutrientes, material em suspensão e clorofila- $a$. enquanto os sistemas com maior fluxo de água apresentaram redução da densidade e biomassa de organismos, sendo que a variável mais impactada pelo fluxo contínuo de água foi a concentração de oxigênio dissolvido. No presente estudo, a maior variação da concentração de oxigênio dissolvido observada no período chuvoso leva a supor que o maior fluxo de água nos lagos de pesca produzido pelo aumento das precipitações e pela maior disponibilidade de água para a renovação dos lagos, também influencia de modo significativo esta variável. 


\section{2 - Comunidade zooplanctônica}

\subsection{1 -Composição da comunidade}

As densidades numéricas totais da comunidade zooplanctônica observadas nos dois periodos amostrados comparam-se às que foram obtidas em diversos reservatórios da bacia do Alto Tietê em estudo realizado por COELHO-BOTELHO et al. (2001).

Observou-se que, no periodo seco, vários pesqueiros apresentaram densidades numéricas acima de 500000 indivíduos por metro cúbico. enquanto no periodo chuvoso, densidades superiores a esta se verificaram em um único pesqueiro (pesqueiro 02). Como neste periodo a maior disponibilidade de água permite que seja feita uma renovação mais freqüente da água dos lagos, supõe-se que o tempo de residência seja menor neste periodo. $\mathrm{O}$ tempo de residência maior do periodo estiagem/frio tem papel importante no estabelecimento de comunidades zooplanctônicas, acarretando densidades numéricas mais elevadas neste periodo.

A temperatura da água, dentre as variáveis avaliadas, foi a única cuja amplitude de variação foi grande entre os dois períodos e menor entre os pesqueiros no período chuvoso - mesmo padrão de variação observado na densidade numérica total dos organismos. A temperatura influencia o crescimento, as taxas de filtração e a reprodução de organismos zooplanctônicos (GEIGER, 1983), sobretudo em regiões temperadas. Num ambiente onde as características ambientais são muito influenciadas pelo manejo exercido, a variação da temperatura - uma variável dificilmente manipulada nos lagos de pesca - pode passar a exercer uma influência maior sobre os organismos.

No entanto, a influência exercida pelo aumento da temperatura sobre o zooplâncton (modificação das taxas metabólicas, aceleração da reprodução,GEIGER, 1983) pode ter sido compensada pelo efeito diluidor da chuva e da renovação da água dos lagos, uma vez que as densidades numéricas totais foram mais baixas no período chuvoso/quente. A perda de biomassa planctônica (efeito wash-out) foi observada por PEREIRA (2003) nas represas do Médio e Baixo Tietê, e resultou de uma interação de 
processos operacionais das usinas hidrelétricas, pluviosidade e consumo elétrico. Este efeito promove. segundo o autor. o transporte das espécies planctônicas para outros corpos d'água a jusante da represa em questão.

No caso dos lagos de pesca, a variação da vazão se dá em função da necessidade de renovação da água. como já se mencionou anteriormente. medida que pode ser adotada mais de uma vez ao dia, dependendo da chegada de nova carga de peixes. Além disso, pode haver um manejo de peixes entre os lagos de um mesmo estabelecimento com a finalidade de aumentar sua capturabilidade, o que pode influenciar algumas variáveis ambientais. sobretudo o oxigênio dissolvido. como menciona LOPES (2000).

Em represas consideradas eutróficas as densidades do zooplâncton são. em geral. mais baixas durante o periodo chuvoso/quente, em conseqüência da diminuição de nutrientes devido à diluição da água superficial (CALEFFI 1994; WISNIEWSSKI 1998; PIVA-BERTOLETTI 2001). No caso dos lagos de pesca, considerados eutróficos ou hipereutróficos, a diluição se dá pela ação direta da água da chuva ou pela maior taxa de renovaçâo da água do lago.

PEREIRA et al. (2004) verificaram que mudanças significativas da estrutura da comunidade zooplanctônica de tanques de piscicultura estiveram associadas ao fluxo de água nos tanques, além de disponibilidade alimentar, variações físicas e químicas do ambiente e interações biológicas tais como predação e competição. Segundo estes autores, a densidade de peixes nos tanques afeta a dinâmica das comunidades zooplanctônicas, o que distingue os sistemas constituídos pelos tanques de piscicultura dos lagos de pesca. Nestes últimos os peixes são introduzidos já adultos, em geral, com hábitos alimentares que não incluem organismos do zooplâncton e, portanto, exercendo uma influência menor sobre esta comunidade. Embora não tenha sido avaliada experimentalmente a influência da predação de peixes sobre o zooplâncton, esta não pode ser descartada. 
Segundo ESTEVES (em preparação) os peixes mais freqüentes nos pesqueiros estudados foram as tilápias das espécies Tilapia rendalli e Oreochromus niloticus. Segundo LAZZARO (1987), estas espécies são consideradas planctívoras, alimentandose, de cladóceros e copépodos, de onde se poderia pressupor que a predação fosse também um fator importante no controle das populações zooplanctônicas deste ambiente. No entanto. ESTEVES (op. cit.) menciona que a análise do conteúdo estomacal dos indivíduos destas espécies, coletados nos lagos estudados, continha predominantemente ração e detritos.

ESTEVES (1988) afirma que em regiões tropicais, onde as águas possuem maior concentração de material em suspensão, as algas e zooplâncton são geralmente de menor porte o que favorece a ocorrência de peixes planctófagos onívoros.

As diversas espécies de peixes que são introduzidas nos lagos de pesca não apresentam, como se pode concluir, um hábito alimentar restritivo, sendo consideradas mais generalistas. Isto reduz a intensidade do impacto produzido pela predação sobre o zooplâncton nos lagos de pesca, onde o alimento para os peixes é artificial e abundante.

Em relação à composição da comunidade zooplanctônica as espécies registradas nos lagos são, de modo geral, as que vêm sendo verificadas nos últimos estudos realizados em corpos d'água da bacia do Alto Tietê (PIVA-BERTOLETTI 2001; LUCINDA et al. 2004).

Algumas destas espécies foram introduzidas recentemente, como Kellicottia bostoniensis e Brachionus havanaensis, constando apenas nos últimos estudos realizados em represas do Alto e Médio Tietê e sua dispersão para outras áreas de ocorrência estaria relacionada a ações antropogênicas (SENDACZ, 2002).

Kellicottia bostoniensis vem sendo registrada em trabalhos recentes em outras bacias hidrográficas como a que faz parte o reservatório de Furnas em Minas Gerais (LANDA et al., 2002), nos reservatórios do Médio Tietê (LUCINDA, 2003), sendo o 
seu primeiro registro no Brasil feito por LOPES et al. (1997) no reservatório mesotrófico de Segredo (Paraná). LANDA et al. (opus. cit.) acreditam que os organismos desta espécie são favorecidos pelo processo de eutrofização dos corpos d'água e tendem a se expandir nas regiões tropicais, onde foram introduzidas - seriam originalmente de regiões temperadas. mais especificamente da América do Norte.

Atividades como introdução de peixes originários de outras bacias em represas, tanques de piscicultura ou lagos de pesca podem ser responsáveis pela ocorrência de espécies do zooplâncton que não eram observadas antes da intervenção. A comunidade fitoplanctônica, do mesmo modo, tem sido incrementada por espécies de registros recentes nestes ambientes (SANT'ANNA, comunicação pessoal). No presente estudo verificou-se em vários lagos de pesca a presença do rotífero Filinia cornuta brachiata, cuja ocorrência só havia sido registrada em lagos do Hemisfério Norte.

Uma causa provável da ocorrência de espécies não registradas anteriormente nestas bacias poderia ser investigada através de um levantamento mais acurado sobre a água utilizada no transporte de peixes dos tanques de criação, onde se dá a reprodução e desenvolvimento das fases iniciais, até chegarem aos lagos de pesca. Informações fornecidas pelos proprietários fazem referência a trocas de água dos tanques de transporte durante o percurso, captando muitas vezes água em fontes ou riachos à beira da estrada.

O copépode ciclopóide Acanthocyclops robustus, presente em alguns pesqueiros estudados também teria sua dispersão associada à ação antropogênica. Segundo ROCHA \& COELHO-BOTELHO (1998) esta espécie é considerada cosmopolita e tem sido observada em represas e lagos artificiais do Peru, Uruguai, Argentina e Brasil. $\mathrm{O}$ primeiro registro em uma represa do estado de São Paulo foi em 1998, na represa Billings (CETESB, 1999), tendo ocorrido também na represa de Barra Bonita (PEREIRA, 2003) onde foi associada ao processo de eutrofização observado naquele ambiente. Estudo realizado por PIASECKI (2000) demonstrou que os organismos desta espécie podem constituir importantes predadores de larvas de peixes em tanques de 
cultivo, onde encontrem boas condições de desenvolvimento e possam se tornar dominantes no zooplâncton. Nos lagos estudados a abundância relativa desta espécie foi pequena. o que não deve representar ameaça aos peixes. sobretudo porque estes são introduzidos nos lagos já adultos, quando não são mais predados por este ciclopóide.

ROCHA (2000) alerta que a importância médica dos copépodes ciclopóides vem sendo negligenciada nos estudos do zooplâncton, lembrando que estes organismos são comprovadamente portadores de vermes que podem trazer prejuizos à saúde humana. além de parasitar peixes, causando grandes perdas à aqüicultura.

A presença de copépodes da ordem Poecilostomatoida. constituída por espécies predadoras de peixes. foi verificada nestes lagos e pode estar relacionada à introdução de água dos tanques de criação juntamente com os peixes nos lagos de pesca. Estes copépodes são também predadores de peixes e podem comprometer sua saúde. No entanto, foram verificados em densidades muito baixas, sem representar um comprometimento ao estoque de peixes dos lagos de pesca no período estudado.

Grande parte das espécies de organismos zooplanctônicos que foram observadas neste estudo evidencia a importância da influência exercida pela freqüente renovação da água sobre a comunidade zooplanctônica, pois são comumente associadas a ambientes lóticos (como rotíferos do gênero Lecane e o cladócero Bosminopsis deitersi, por exemplo). Isto demonstra a importância da contribuição de nascentes, córregos e riachos, principais formadores da maioria dos lagos de pesca estudados, para a composição da comunidade zooplanctônica nestes ecossistemas.

A maioria das espécies de rotíferos verificadas nos lagos de pesca tem sido registrada nos estudos realizados nos reservatórios desta bacia, sendo as mais comuns, segundo LUCINDA et al. (2004), Conochilus unicornis, Keratella cochlearis, Lecane bulla, Polyarthra vulgaris e Trichocerca similis. Todas estas são consideradas no referido estudo como espécies cosmopolitas. Segundo estes autores, algumas espécies observadas têm sua ocorrência relacionada ao grau de trofia do corpo d'água, como 
Brachionus angularis, Brachionus calyciflorus, Brachionus havanaensis havanaensis, Filinia opoliensis, Kellicottia bostoniensis, Keratella cochlearis var. tecta e Trichocerca capucina multicrinis. Estas espécies foram freqüentes e abundantes na maioria dos lagos de pesca estudados, o que evidencia as características eutróficas destes ambientes. PIVA-BERTOLETTI (2001) recomenda, no entanto, que espécies como Conochilus unicornis, Keratella americana, Keratella cochlearis e Polyarthra vulgaris não sejam utilizadas como indicadoras da qualidade da água porque estas ocorrem na maioria dos corpos d'água do Estado de São Paulo, independentemente do estado trófico.

O agrupamento dos táxons mais freqüentes nos lagos do pesca evidenciou grupos com associações de Keratella americana e Polyarthra vulgaris. tanto no periodo seco quanto no chuvoso, o que pode significar uma similaridade do ponto de vista ecológico entre as duas espécies. Nos dois periodos também participaram do mesmo grupo Anuraeopsis fissa e náuplios de ciclopóides. A diversificação de táxons mais freqüentes no período chuvoso e a constituição de um maior número de grupos com menor número de táxons, pode ser resultante de condições mais homogêneas entre os lagos, possivelmente em decorrência do maior volume de chuvas neste periodo.

Foi comum a dominância de uma única espécie de rotífero na comunidade zooplanctônica dos lagos estudados, como se observou por exemplo com Brachionus angularis em muitos dos lagos nos dois períodos e ainda com Kellicottia bostoniensis no pesqueiro $2(66 \%)$ e Synchaeta pectinata no pesqueiro 21 (58\%) no periodo chuvoso. $O$ alto grau de dominância de espécies pode indicar, segundo GREEN (1993), distúrbios ambientais, responsáveis por gerar instabilidade no sistema, favorecendo a espécie mais apta a se adaptar a eles. Tal fato também foi observado com cladóceros como Bosmina longirostris que representou $53 \%$ da comunidade zooplanctônica do pesqueiro 27 e Bosminopsis deitersi que representou $65 \%$ da comunidade zooplanctônica no pesqueiro 02 , durante o período seco.

Em relação às abundâncias relativas dos grupos zooplanctônicos, houve predomínio de rotíferos sobre os microcrustáceos na maioria dos lagos estudados, nos 
dois períodos amostrados. A dominância de rotíferos é comum em sistemas lênticos de regiões tropicais e subtropicais e é relativamente previsivel em ambientes sujeitos a instabilidade, como é o caso dos lagos de pesca, por sua característica de maior oportunismo em comparação a outros grupos do zooplâncton. ciclo de vida mais curto, reprodução partenogenética, sem estágios larvais, produção de ovos de repouso, tolerância a baixos teores de oxigênio dissolvido, hábito alimentar seletivo em relação ao tamanho das partículas (STEMBERGER \& GILBERT 1987; MIRACLE \& VICENTE 1983; PAGGI \& PAGGI 1990; GILBERT \& BOGDAN 1981).

Os rotíferos seriam ainda favorecidos pela presença de bactérias, fitoflagelados e protozoários que se encontram comumente associados a cianobactérias (SENDACZ. 2000).

Segundo SANT'ANNA (em preparação) o grupo das cianobactérias foi predominante no fitoplâncton dos lagos estudados, com abundâncias relativas muito semelhantes às verificadas para os rotíferos.

PIVA-BERTOLETTI (2001) concluiu em seu estudo dos lagos do Parque Estadual das Fontes do Ipiranga que nestes ambientes 0 predomínio do microzooplâncton (rotíferos e náuplios) independe do estado trófico.

As baixas densidades de microcrustáceos obtidas neste estudo indicam que o manejo dos lagos é desfavorável a estes organismos, seja pela constante renovação da água que promove sua remoção sem que completem seu ciclo reprodutivo, seja pela adição de elementos químicos (fertilizantes, rações, medicamentos) que alteram as condições físicas e químicas da água, modificando de maneira adversa seus habitats.

Uma grande variabilidade do tempo de residência destes lagos que é presumível a partir do relato de proprietários sobre manejo adotado, parece ser um dos fatores mais importantes na composição das comunidades planctônicas. A mesma observação foi feita por PEREIRA (2003) para os reservatórios do Médio e Baixo Tietê, onde o tempo 
de residência influenciou o padrão de circulação da água e a distribuição das comunidades aquáticas.

As variações observadas nos índices de diversidade e riqueza entre o primeiro e o segundo período de estudo levam a supor que a maior disponibilidade de água propiciada pelas chuvas aumente também o fluxo de água nos lagos, já que vários proprietários admitem esta forma de manejo para limpeza dos tanques e descarte de pequenos peixes sem valor comercial. Tal procedimento, ainda que promova uma melhoria da qualidade da água do lago sob aspecto sanitário, para a comunidade zooplanctônica. especialmente, tem impacto negativo. Tanto as densidades numéricas quanto os índices de diversidade obtidos evidenciam uma comunidade mais numerosa $\mathrm{e}$ diversificada no período estiagem/frio do que no chuvoso/quente. sendo que nos dois periodos a riqueza foi fortemente influenciada pelos rotiferos.

A redução na diversidade e riqueza da comunidade, bem como a maior riqueza de rotíferos nos dois períodos, também foi observada por MACEDO (2004) em viveiros de peixes.

Na tabela a seguir é apresentada a comparação entre o número de táxons obtidos pelo autor supracitado e os obtidos neste estudo:

\begin{tabular}{|c|c|c|c|c|}
\hline \multirow{2}{*}{$\begin{array}{l}\text { Grupo de organismos } \\
\text { (número de thxons) }\end{array}$} & \multicolumn{2}{|c|}{$\begin{array}{l}\text { Viveiros de poixes } \\
\text { (MACEDO, 2004) }\end{array}$} & \multicolumn{2}{|c|}{ Pesqueiros da RMSP } \\
\hline & seca & chuva & seca & chuva \\
\hline Rotiferos & 42 & 35 & 80 & 64 \\
\hline Cladóceros & 11 & 7 & 17 & 17 \\
\hline Copépodes & 3 & 3 & 14 & 12 \\
\hline Total & 56 & 45 & 111 & 93 \\
\hline Riqueza média & 32 & 44 & 27 & 32 \\
\hline Equitatividade módia & 0,77 & 0,77 & 0,12 & 0.18 \\
\hline Diversidade média & 3,75 & 2.01 & 2,11 & 3,15 \\
\hline
\end{tabular}

Se comparados os índices de riqueza média obtidos nos dois estudos, entretanto, nota-se que houve aumento do índice de riqueza nos lagos de pesca estudados do 
período seco para o período chuvoso. Isto decorre do fato de que no estudo realizado em viveiros há maior equitatividade nos ambientes estudados - 6 viveiros dispostos em sequiência, com fluxo contínuo de água - enquanto a água dos lagos dos pesqueiros tem origem diversificada. A baixa equitatividade observada nestes lagos evidencia uma distribuição heterogênea dos organismos nos táxons, além de indicar dominância de um táxon sobre os demais.

Os indices de diversidade também apresentaram uma situação diferente entre os ambientes constituídos pelos viveiros de peixes e os dos lagos de pesca, nos periodos estudados. Nos primeiros a diversidade foi maior no periodo seco, diminuindo no período chuvoso. enquanto nos lagos de pesca ocorreu o inverso. Estes resultados podem evidenciar mais uma vez a contribuição dos corpos d'água formadores dos lagos de pesca para a comunidade zooplanctônica ai estabelecida.

LUCINDA et al. (2004) em seu estudo sobre reservatórios da bacia do Alto Tietê observaram que a maior riqueza de rotíferos (30 táxons) ocorreu na represa de Cachoeira das Graças, pertencente à sub-bacia do rio Cotia, sendo que os menores índices ocorreram na represa Pedro Beicht, também nesta sub-bacia, e no lago Rodrigo Pires, sub-bacia do reservatório Billings. No presente estudo não há evidências de que a riqueza da comunidade zooplanctônica varie tanto de um lago de pesca para outro (entre 21 e 35 no período seco e 24 e 43 no período chuvoso), o que pode ser mais uma das influências do manejo sobre a comunidade, que acaba conferindo condições mais homogêneas a todos estes ambientes. LUCINDA et al. (op. cit.) obtiveram riquezas variando entre 7 e 30 (apenas para o grupo dos rotíferos) nas represas do Alto Tietê.

A análise de agrupamento aplicada aos pesqueiros resultou num número maior de grupos no período seco do que no chuvoso. Tal fato pode ser decorrente de uma possivel homogeneização dos lagos propiciada pelo aumento do volume de chuvas, permitindo aceleração nas taxas de renovação e redução no tempo de residência dos lagos, como já se inferiu baseado nos resultados do agrupamento dos táxons mais freqüentes do zooplâncton. 


\subsection{2 - Relação com o estado trófico e com aspectos de interesse sanitário}

Observou-se neste estudo um aumento das densidades numéricas totais do zooplâncton proporcional ao aumento nas concentrações de fósforo total e clorofila- $a$. Esta relação foi mais nítida no período estiagem - frio. onde se observaram densidades mais elevadas, na faixa de variação entre 0,10 e $0,20 \mathrm{mg} / \mathrm{L}$ de fósforo total e entre 0,03 e $0,10 \mathrm{mg} / \mathrm{L}$ de clorofila- $a$. No período chuvoso - quente verificou-se uma faixa mais estreita de variação das concentrações de fósforo total e clorofila-a. Esta diferença entre os dois periodos está, possivelmente, relacionada ao efeito diluidor da chuva associado à maior renovação da água do lago e menor tempo de residência. A faixa de variação no periodo chuvoso (entre 0,05 e $0,15 \mathrm{mg} / \mathrm{L}$ de fósforo total e 0.01 e $0,05 \mathrm{mg} / \mathrm{L}$ de clorofilaa), embora mais restrita que no período seco, ainda situa os pesqueiros entre eutróficos a hipereutróficos quanto ao grau de eutrofização.

ROCHA et al. (1997), relacionando a comunidade zooplanctônica com o grau de eutrofização de dez sistemas lacustres brasileiros, observaram uma faixa de variação semelhante da concentração de fósforo total e clorofila- $a$ (entre 0,01 e $0,10 \mathrm{mg} / \mathrm{L}$ ), onde a densidade média do zooplâncton variou entre $150.000 \mathrm{ind} / \mathrm{m}^{3}$ (lago oligotrófico) a $9.900 .000 \mathrm{ind} / \mathrm{m}^{3}$ (lago hipereutrófico). Estes autores verificaram que as densidades são baixas em lagos oligotróficos mas não obedecem a uma seqüência proporcional ao grau de eutrofização; outros fatores, como efeito "washout", escoamento superficial em áreas agrícolas contribuindo com a entrada no corpo d'água de substâncias tóxicas e, principalmente, o sistema operacional das represas intervêm na composição das comunidades fitoplanctônica e zooplanctônica.

SENDACZ et al. (no prelo), comparando duas represas com diferentes estados tróficos, obtiveram densidades totais de zooplâncton 10 vezes mais elevadas na represa Guarapiranga classificada como eutrófica (com $677.500 \mathrm{ind} / \mathrm{m}^{3}$ ) que na represa Ponte Nova, classificada como oligotrófica $\left(69.000 \mathrm{ind} / \mathrm{m}^{3}\right)$. Neste estudo os autores também 
verificaram uma redução nas concentrações de nutrientes e clorofila- $a$ durante o período chuvoso - quente. resultante da diluição na água superficial.

PIVA-BERTOLETTI (2003) também obteve densidades totais de zooplâncton proporcionalmente mais elevados em relação ao Índice de Estado Trófico em três lagos estudados do Parque Estadual das Fontes do Ipiranga.

Segundo CULVER (1991) a variação das quantidades de nitrogênio e fósforo disponiveis afeta a composição dos fitoplâncton: altas taxas de fósforo favorecem as cianobactérias com menor importância na alimentação de organismos zooplanctônicos que as algas verdes e diatomáceas ao zooplâncton.

Os estudos de CULVER (op. cit.) concluem que o excesso de nutrientes pode resultar em efeitos prejudiciais para o zooplâncton e os peixes, acarretando problemas na qualidade da água tais como baixas concentrações de oxigênio dissolvido e/ou de amônia ionizada associadas a alto pH e altas concentrações de nitrogênio.

O estudo realizado por SANT'ANNA et al. (em preparação) verificou que o nitrogênio e o fósforo não são limitantes para a comunidade fitoplanctônica dos lagos de pesca e que a variação do $\mathrm{pH}$, turbidez e transparência da água teriam influência mais determinante sobre ela, já que não seria controlada pela baixa disponibilidade destes nutrientes.

Tais variáveis ambientais, através da comunidade fitoplanctônica, podem exercer um efeito indireto sobre o zooplâncton. Um dos possíveis efeitos está relacionado às condições ambientais favoráveis às florações de cianobactérias, cujo predomínio no fitoplâncton tem grande importância na qualidade do alimento disponível ao zooplâncton.

Houve dominância de cianobactérias nas comunidades fitoplanctônicas estudadas, o que, segundo SANT'ANNA et al. (op. cit.), resultou do enriquecimento da água promovido através do arraçoamento, iscas e ceva para atrair os peixes. Estudos 
realizados durante o período chuvoso - quente demonstraram que em $60 \%$ dos pesqueiros havia a presença de microcistinas na água do lago (MERCANTE et al., em preparação). Para que se estabeleçam relações entre a presença de microcistina na água e a composição da comunidade zooplanctônica há a necessidade de estudos laboratoriais e bioensaios que avaliem a natureza e a intensidade dos efeitos que estas toxinas podem promover nos diferentes organismos do zooplâncton.

FERRÃO-FILHO (1998) verificou que os rotiferos da espécie Brachionus calyciflorus são mais sensiveis a neurotoxinas do que a hepatotoxinas que são produzidas por Microcystis aeruginosa e que foram comuns nos pesqueiros estudados. Isto indica que os efeitos sobre as diferentes espécies do zooplâncton podem variar em função da espécie de cianobactéria presente e do tipo de toxina produzida. Além disso, fatores como a temperatura podem influenciar indiretamente na sensibilidade dos organismos às toxinas produzidas por cianobactérias (GILBERT, 1996).

Para os cladóceros o baixo valor das cianobactérias como alimento se deve a uma combinação de vários fatores, tais como as suas características bioquimicas, a capacidade de interferir mecanicamente no processo de filtração de partículas e a pouca digestibilidade das colônias ou filamentos, o que resulta em impactos negativos sobre seu desenvolvimento e em suas taxas de reprodução (FERRÃO-FILHO, op. cit.).

O aumento da eutrofização dos corpos d'água produzido pelas atividades ligadas à piscicultura estimulam também a produção de grande diversidade e densidade de bactérias. Segundo MORIARTY (1997), as cadeias alimentares microbianas são parte fundamental de todos os sistemas de aqüicultura e têm impacto direto na produtividade, mesmo quando praticada a alimentação artificial intensiva. $\mathrm{O}$ autor afirma que, onde se adiciona matéria orgânica, as bactérias tornam-se componentes essenciais da cadeia trófica. 
O processo de mineralização da matéria orgânica autóctone ou alóctone na massa de água resulta em biossintese de proteina particulada. composta pela célula bacteriana que, por sua vez, constitui excelente alimento para o zooplâncton.

A grande diversidade de bactérias no ambiente aquático compreende também aquelas potencialmente patogênicas. MORIARTY (op. cit.) e VINATEA-ARANA (2004) chamam a atenção para um dos principais impactos produzidos pela aqüicultura que é o da dispersão de organismos patógenos pelos corpos d'água.

Alguns autores. como HUQ \& COLWELL (1995), HUQ et al. (1996), TAMPLIN et al. (1990), estudaram a relação de Vibrio cholerae com crustáceos planctônicos em ambientes com diferentes salinidades.

ARAÚJO et al. (1996) analisaram a influência do copépode Mesocyclops longisetus na sobrevivência desta bactéria, o que consiste num grave problema de saúde, sobretudo em paises pobres.

VENKATESWARA et al. (1989) salientam que a associação de Vibrio cholerae ao zooplâncton se dá pela fixação da bactéria à carapaça de custáceos planctônicos, preferencialmente às exúvias de copépodes. Segundo este autor a ocorrência da doença está associada a condições ambientais onde prevalecem deficiências sanitárias, que implicam em eutrofização e contaminação, aliadas à presença de crustáceos planctônicos.

Os estudos realizados por MORITA et al. (em preparação) nos lagos de pesca da Região Metropolitana de São Paulo detectaram a presença de Escherichia coli em concentrações que estão acima dos padrões previstos na legislação (CONAMA nº 20, 1986), e também de Salmonela spp nas amostras de água. Em relação à presença de Aeromonas, os autores observaram grande diversidade de espécies deste gênero, tanto nas amostras de água quanto nos peixes analisados, muitas delas com potencial patogênico. 
AZEVEDO et al. (2002) estudando a ocorrência de Aeromonas spp e Vibrio cholerae nestes lagos de pesca, verificaram que o gênero Aeromonas esteve presente em $\mathbf{8 7 \%}$ dos peixes coletados e $\mathbf{9 7 \%}$ das amostras de água, enquanto Vibrio cholerae não foi detectado na água nem nos peixes coletados.

A presença destas bactérias estaria relacionada a condições inadequadas de manuseio dos peixes, iscas e rações, além da precariedade de algumas instalações sanitárias presentes nas proximidades dos lagos.

As baixas densidades de crustáceos planctônicos verificadas neste estudo poderiam representar um dos fatores responsáveis pela ausência de Vibrio cholerae nos pesqueiros estudados, porém não é suficiente para explicá-la.

Cabe ainda ressaltar que, mesmo pertencendo a sub-bacias com diferentes características geológicas, geomorfológicas e de uso e ocupação do solo, diversas variáveis ambientais e biológicas apresentaramm concentrações e dinâmicas muito semelhantes, sendo comum a todos os ambientes apenas a ação preponderante do manejo adotado e o controle que este exerce sobre todas as variáveis. Até mesmo na colonização do ambiente pelos organismos aquáticos essa influência é perceptível através da introdução e estabelecimento, ainda que acidental, de espécies de outras bacias que melhor se adaptariam à instabilidade destes sistemas. 


\section{6 - CONCLUSÕES}

- A comunidade zooplanctônica dos lagos de pesca é constituída por espécies observadas em outros corpos d’água da bacia do Alto Tietê. havendo uma maior semelhança com as comunidades zooplanctônicas verificadas nos reservatórios mais eutrofizados.

- Os rotíferos constituem o grupo dominante nos lagos de pesca e é freqüente a dominância de uma única espécie. revelando a instabilidade destes ecossistemas. evidenciada também pelos indices de diversidade $\mathrm{e}$ equitatividade obtidos

- Há grande contribuição das espécies procedentes de córregos e nascentes formadores dos lagos de pesca para a composição da comunidade zooplanctônica, mas ocorrem também espécies que podem estar sendo introduzidas através de ações ligadas a atividades de piscicultura (introdução de espécies de diferentes bacias) e o transporte de peixes.

- Considerando que a maior disponibilidade de água no período chuvoso, permitindo o aumento da taxa de renovação de água, pode trazer para os lagos novas espécies para colonizar o ambiente, pode-se inferir que o aumento da diversidade estaria relacionado às condições climáticas, especificamente as pluviométricas, e ao manejo.

- O tempo de residência do corpo d'água é um fator determinante para a comunidade zooplanctônica. cujo estabelecimento, por sua vez, constitui um componente desejável em ecossistemas aquáticos saudáveis. Sabendo-se que um tempo de residência mais prolongado é um dos fatores a favorecer as florações de cianobactérias (um problema cada vez mais freqüente e preocupante em grande parte dos ecossistemas aquáticos), deve haver uma preocupação em determinar um tempo de residência que concilie o controle das condições ambientais e sanitárias do corpo d'água e favoreça o estabelecimento de uma comunidade planctônica diversificada. 
- A composição e a estrutura da comunidade zooplanctônica verificada nos lagos de pesca. associada às caracteristicas fisicas e quimicas da água. evidenciam um ambiente que vem sofrendo um intenso processo de eutrofização que pode significar uma exportação significativa de nutrientes para os corpos d’água à jusante. Uma atenção maior deve ser direcionada a estes estabelecimentos é à regulamentação desta atividade. A conscientização dos proprietários e freqüentadores de pesque-pagues sobre a importância dos cuidados com a água que abastece e deriva dos tanques de pesca é fundamental para minimizar os impactos observados neste estudo. 


\section{7 - REFERÊNCIAS BIBLIOGRÁFICAS}

APHA - American Public Health Association. Standard Methods for the Examination of Water and Wastewater. $14^{\text {th }}$ ed.. Washington. p. 412-415. 1979.

Araújo DB. Martins SC. Albuquerque LMB. Hofer E. Influence of the copepod Mesocyclops longisetus (Crustacea: Cyclopidae) on the survival of Vibrio cholerae O1 in fresh water. Cad. Saúde Pub. 1996: 12 (4): 551-554.

Azevedo S.M.F.O. Toxinas de Cianobactérias: Causas e conseqüèncias para a Saúde Pública. Méd. on line [periódico online]. 1998. I (3). Disponivel em: http://www.medonline.com.br/med_ed/med3/microcis. [2004 Dez 30].

Azevedo VM. Morita. M Dropa M. Cabianca MAA. Esteves KE. Matté GR. Matté MH. Ocorrência de Aeromonas spp. e Vibrio cholerae em pesque pagues da Região Metropolitana de São Paulo. [Apresentado ao Il Simpósio de Segurança Alimentar e Saúde do Estado de São Paulo: 2002; Set 24; São Paulo (BR)].

Branco CWCC. A comunidade planctônica e a qualidade da água no lago Paranoá, Brasilia, DF, Brasil. Brasília. 1991 [Dissertação de Mestrado - Departamento de Ecologia - UFB].

Branco SM. Rocha AA, Poluị̧ão, Proteção e Usos Múltiplos de Represas. São Paulo.

Ed. Edgard Blücher, 1977.

Cairns J, McCormock PV, Niederlehner BR A proposed framework for developing indicators of ecosystem health. Hydrobiol, 1993, 263: 1-44. 
Caleffi S. A Represa de Guarapiranga: estudo da comunidade zooplanctônica e aspectos da eutrofização. São Paulo. 1994 [Dissertação de Mestrado Departamento de Saúde Ambiental - Faculdade de Saúde Pública - USP].

CETESB. Monitoramento Integrado - Bacias do Alto e Médio Tietê. Avaliação da Qualidade - Ȧgua, Sedimento e Peixes. Aditamento do Contrato 20. Relatório Final. São Paulo: CETESB/SABESP. 1999.

CETESB. Relatório de qualidade das águas interiores do estado de São Paulo 2000 / CETESB. São Paulo : CETESB. 2001.

Coelho-Botelho MJ. Cabianca MAA. Sendacz. S. Alteraçōes na Comunidade Zooplanctônica em Represas do Alto e Médio Tietê. (Estado de São Paulo). São Paulo (SP): CETESB. Relatório técnico: 2001.

Conselho Nacional do Meio Ambiente - CONAMA. Resolução n. 20. de 18 de junho de 1986. Classificação das águas doces, salobras e salinas do Território Nacional. Disponivel em: http://www.lei.adv.br/020-86.htm [2002 Mar 12].

Culver DA. Effects of the $\mathrm{N}: \mathrm{P}$ ratio in fertilizer form fish hatchery ponds. Verh. Internat. Verein. Limnol. 1991: 24: 1503-7.

De Mott WR. Moxter F. Foraging on Cyanobacteria by Copepods: Responses to Chemical defenses and resource abundance. Ecology 1991; 72 (5): 1820-34.

Eler, MN. Espíndola, EG. Estudo de caso: impactos ambientais de tanques de pesque-e-pague no estado de São Paulo. [Apresentado no World Aquaculture; 2003; Mai 20, Salvador (BR)].

EMBRAPA. Avaliação de impacto ambiental de atividades produtivas em estabelecimentos familiares do Novo Rural - Boletim de Pesquisa e Desenvolvimento. Jaguariúna (SP) 2003. Disponível em: http://www.cnpma.embrapa.br/download/boletim_17.pdf - [2004 Dez 21]. 
Esteves. FA. Fundamentos de Limnologia. Rio de Janeiro: Interciência FINEP: 1988.

FAPESP. Diagnóstico ecológico-sanitário de pesqueiros da Regiâo Metropolitana de São Paulo. Relatório Final. 2003.

Ferrão Filho. AS. Influências das floraçōes de cianobactérias na dinâmica de populações zooplanctônicas da Lagoa de Jacarepaguá (RJ): efeitos tóxicos de Microcystis aeruginosa sobre cladóceros. Rio de Janeiro. 1998 [Tese de Doutorado. Instituto de Biofisica/ UFRJ].

Ferrão Filho AS. Azevedo SMFO. De Mott WR. Effects of toxic and non-toxic cyanobacteria on the life history of tropical and temperate cladocerans. Fresh. Biol. 2000: $45: 1-9$

Foratini. PO. Ecologia, Epidemiologia e Sociedade São Paulo. Artes Médicas. EDUSP. 1992

Fulton RS. Jones RC. Growth and Reproductive Responses of Daphnia to Cyanobacterial Blooms on the Potomatic River, Int. Revue ges. Hydrobiol. 1991: 76: 5-19.

FUSP (Fundação de Apoio à Universidade de São Paulo). Plano da Bacia do Alto Tietê Relatório de Situação dos Recursos Hídricos - Revisão I. FUSP. Comitê da Bacia Hidrográfica do Alto Tietê. 2001. Disponivel em: http://www.sigrh.sp.gov.br/sigrh/ARQS/RELATORIO/CRH/CBH-AT/478/05 [2003 Set 12].

Geiger JG. A review of pond zooplankton production and fertilization for the culture of larval and fingerling striped bass. Aquaculture. 1983; 35: 353-69.

Gilbert JJ. Effect of temperature on the response of planktonic rotifers to a toxic cyanobacteria. Ecology. 1996; 77(4): 1174-80.

Gilbert JJ, Bogdan KG. Selectivity of Polyarthra and Keratella for flagellate and aflagellate cells. Verh. Internat. Verein. Limnol. 1981; 21: 1515-21. 
Giné H. Bergamin H. Zagatto EAG. Reis BF. Simultaneous determination of nitrate and nitrite by flow injection analisys. Anal.Chim. Acta. 1980: 114: 191-7.

Green J. Diversity and dominance in planktonic rotifers. Hydrobiol. 1993: 255/256: 34552.

Green . BW. Boyd C. Chemical Budgets for Organically Fertilized Fish Ponds in Dry Tropics. J Aquacult Soc. 1995: 26 (3): 284-96.

Hanazato T. Interrelations between Microcystis and Cladocera in the Highly Eutrophic Lake Kasumigaura. Japan. Int Revue ges Hydrobiol. 1991: 76: 21-36.

Henning M. Hertel H. Wall H. Johannes-Günter K. Strain-specific Influence of Microcystis aeruginosa on Food Ingestion and Assimilation of some Cladocerans and Copepods. Int Revue ges Hydrobiol. 1991: 76: 37-45.

Hietala J, Laurën-Maata C. Wall M. Sensitivity of Daphnia to toxic cyanobacteria: effects of genotype and temperature. Fresh Biol. 1996: 37: 299-306.

Hirata R, Ferreira LMR. Os aqüiferos da Bacia Hidrográfica do Alto Tietê: disponibilidade hidrica e vulnerabilidade à poluição. Rev Bras Geociênc. 2001; 31.

Huq A. Colwell.RR. Vibrios in the marine and estuarine environments. J. Mar. Biotechnol. 1995; 3: 60-3.

Huq A, Xu B, Chowdury MAR, Islam MS, Montilla, R, Colwell RR. A Simple Filtration Model to Remmove Plankton-Associated Vibrio cholerae in Raw Water Supplies in Developing Countries. Ap Environ Microbiol. 1996; 62 (7): 2508-12.

IAG USP (Instituto de Astronomia, Geofísica e Ciências Atmosféricas da Universidade de São Paulo). Relatórios 2001-2002. Disponível em: http://www.grec.iag.usp.br/grec_relatorios.html.[2004 Jul 13]. 
IG USP (Instituto de Geociências da Universidade de São Paulo). Banco de Dados Espaciais da Bacia do Alto Tietê, Região Metropolitana de São Paulo. Coord. Prof. Arlei Macedo. Instituto de Geociências - USP. 1999.

IPT (Instituto de Pesquisas Tecnológicas do Estado de São Paulo) Mapa Geomorfológico do Estado de São Paulo. 1.P.T.- Divisão de Minas e Geologia Aplicada. São Paulo. (Série Monografias. 5). 1981: vol. 1.

Jungmann D. Henning M. Friedrich J. Are the Same Compounds in Microcystis Responsible for Toxicity to Daphnia an Inhibition of its Filtering Rate? Int. Revue ges. Hydrobiol. 1991: 76: 47-56.

Jungmann. D. Benndorf. J. Toxicity to Daphnia of a compound extracted from laboratory and natural Microcystis spp.. and the role of microcystins. Fresh Biol. 1994: 32: 13-20.

Kitamura PC. Lopes RB, Castro-Júnior FG, Queiroz. JF. Avaliação ambiental e econômica dos lagos de pesca esportiva na bacia do rio Piracicaba. B. Indústr. Anim. 1999; 56: 95-107.

Kotak BG. Zurawell EEP, Holmes CFB. Microcystin-LR concentration in aquatic food web from lakes of varying trophic status. Can. Fish. Aquat. Sci. 1996: 53: 1974-1985.

Kubitza. F. Sistema de Pesca Recreativa. Cuiabá. SEBRAE/MT. 1997.

Lampert. W. Further studies on the inhibitory effect of toxic blue-green Microcystis aeroginosa on the filtering rate of zooplankton. Arch. für Hydrobiol, 1982; 95: 207-20.

Landa GG, Aguila LR, Pinto-Coelho, RM. Distribuição espacial e temporal de Kelicottia bostoniensis (Rousselet, 1908) (Rotifera) em um grande reservatório tropical (reservatório de Furnas), Estado de Minas Gerais, Brasil. Acta Scienc. 2002; 24 (2): 313-19. 
Lazzaro X. A review of planktivorous fishes: Their evoluation. feeding behaviors. seletivities and impcts. Hydrobiol. 1987: 97-167.

Lopes RM. Lansac-Tôha FA. Vale R. Serafim Jr M. Comunidade zooplanctônica do reservatório de Segredo. In: Agostinho AA \& LC Gomes editores Reservatório de Segredo: bases ecológicas para o manejo. Editora da Universidade Maringá. Maringá (PN). 1997; p. 39-60.

Ludwig JA. ReynoldsJF. Statistical ecology: a primer on methods and computing. New York (USA): John Wiley \& Sons. Inc.: 1988.

Lucinda I. Moreno IH. Melão MGG. Matsumura-Tundisi T. Acta Limnol Bras. 2004: 16 (3): $203-24$.

Macedo CF. Qualidade da água em viveiros de criação de peixes com sistema de fluxo continuo. Jaboticabal (SP) 2004 [Tese de Doutorado. Centro de Aqüicultura UNESP].

Marker AFH. Nusch H, Rai H, Riemann B. The measurement of photosynthetic pigments in freshwaters and standartization of methods: conclusion and redomendations. Arch Hydrobiol Beith. 1980: 14: 91-106.

Matthiensen A. Yunes JS. Codd G.A. Ocorrência. distribuição e toxicidade de cianobactérias no estuário da Lagoa dos Patos. RS. Rev Bras Biol. 1999; 59: 36176.

Matsuzaki M. A comunidade fitoplanctônica de um pesqueiro na cidade de São Paulo. São Paulo 2002 [Dissertação de Mestrado - Departamento de Saúde Ambiental Faculdade de Saúde Pública - Universidade de São Paulo].

Matsuzaki M, Mucci JLN, Rocha AA. Comunidade fitoplanctônica de um pesqueiro na cidade de São Paulo. Rev Saúde Publica. 2004: 38 (5): 679-86.

Cune B, Mefford M J. PC-ORD. Multivariate analysis of ecological data, version 3.0. 
Oregon: MjM Software Design: 1997.

Mercante CTJ. Cabianca MAA. Silva D. Costa SV. Esteves KE. Water quality in feefishing ponds located in the metropolitan region of São Paulo city. Brazil: an analysis of the eutrophication process. Acta Limnol Brasil. 2004: 16 (1): 95-102.

Meyer R, Grostein M.D. Biderman C. São Paulo Metrópole. Edusp: São Paulo. 2004.

Miracle MR; Vicente E. Vertical distribution and rotifer concentrations in the chemocline of meromitic lakes. Hydrobiol. 1983; 104: 259-67.

Moriarty DJW. The Role of Microorganisms in Aquaculture Ponds. Aquacult. 1997; 151: $333-49$.

Nielsen NO. Ecosystem approaches to human health. Cad. Saúde Pública. 2001: 17: 6975.

Nogueira MG, Matsumura-Tundisi T. Limnologia de um sistema artificial raso (Represa do Monjolinho - São Carlos. SP). Dinâmica das populações planctônicas. Acta Limnol Brasil. 1996; 8: 149-68.

Odum, E.P. Ecologia. Rio de Janeiro: Interamericana; 1985.

Paggi JC. Paggi S. Zooplancton de ambientes lóticos e lênticos do rio Paraná Médio. Acta Limnol Brasil. 1990; 3: 685-719.

Pereira RHG. Análise da distribuição, densidade e diversidade de Copepoda Calanoida e Cyclopoida nos reservatórios e tributários do Médio e Baixo rio Tietê e sua relação com as características limnológicas do sistema. São Carlos (SP) 2003 [Tese de Doutorado. Depto. de Hidráulica e Saneamento - USP. São Carlos]

Pereira RHG, Espindola ELG, Eler MN. Limnological variables and their correlation with water flow in fishponds. Acta Limnol Brasil. 2004; 3 (16): 263-71.

Piasecki WG. Attacks of Cyclopoid Acanthocyclops robustus (Sars) on Newly Hatched 
Cyprinids. Eletr J Pol Agricult. 2000: 3 (1). Disponivel em: http:// www.ejpau.media.pl/series/volume3/issuel/fisheries [2004 Dez19].

Pinto-Coelho. R.M. Fundamentos em Ecologia. la Edição. Porto Alegre: Ed. Artes Médicas Sul: 2000.

Piva-Bertolleti. S.A. Zooplâncton dos lagos do Parque Estadual das Fontes do Ipiranga (SP) e relações entre espécies zooplanctônicas e estado trófico em corpos d'água do Estado de São Paulo. São Paulo. 2001 [Tese de Doutorado. Faculdade de Saúde Pública. USP].

Região Metropolitana de São Paulo. Carta de Classes de Declividade da RMSP. EMPLASA (1:100000). 1979.

Rocha O. Perfil do conhecimento de biodiversidade em águas doces no Brasil. 2000.

Disponivel em: http:// www.mma.gov.br/port/sbf/chm/doc/aguadoce.doc [2004 Dez 25]

Rocha O, Matsumura-Tundisi T. Sampaio EV. Phytoplankton and zooplankton comunity structure and production as related to trophic state in some Brazilian lakes and reservoirs. Verh. Internat. Verein. Limnol. 1997: 26: 599-604.

Rocha CEF. Coelho-Botelho MJ. Maxillopoda - Copepoda Cyclopoida. Relatório. 1998. Disponivel em: http://acd.ufrj.br/mndi/Carcinologia/hp/Text/Cyclopoida.htm [2004 Dez 19].

Sendacz, S. Principais variáveis biológicas em Aqüicultura. $\underline{\text { In: I }}$ workshop sobre qualidade da água em aqüicultura. 2000. Pirassununga. 25-36.

Sendacz. S. Estimativa da biomassa de organismos zooplanctônicos em represas de diferentes condições tróficas do sistema Alto Tietê (São Paulo, Brasil). 2002. Relatório FAPESP.

Sendacz S, Caleffi, S, Santos-Soares J. Zooplannkton biomass of reservoirs of different 
trophic state conditions of São Paulo State. Brazil. Brazil J Biol. no prelo.

Sipaúba Tavares LH. Limnologia Aplicada à Aquicultura. Jaboticabal: FUNEP. 1994.

Sipaúba Tavares LH. Variação de alguns parâmetros limnológicos em um viveiros de piscicultura em função da luz. Acta Limnol Brasil. 1995: 7: 138-50.

Stemberger RS. Gilbert JJ. Defenses of planktonic rotifers against predators. In: Kerfoot WC. Sih A. Predation: direct and indirect impacts on aquatic communities. Universitiy Press of New England. 1987.

Strickland JDH. Parsons TR. A mannual of sea water analysis. Bull of the Fish Res Board Can. 1960: 125: 1-185.

Tamplin ML. Gauzens AL. Huq A, Sack DA. Colwell RR. Attachment of Vibrio cholerac Serogroup 01 to Zooplankton and Phytoplankton of Bangladesh Waters. Applied Envir Microbiol. 1990: 56 (6):1977-80.

Toledo Jr AP. Talarico M. Chinez SJ. Agudo EG. A aplicação de modelos simplificados para a avaliação de processo de eutrofização em lagos e reservatórios tropicais. In: Anais do $1^{\circ}$ Congresso Brasileiro de Engenharia Sanitária e Ambiental. Camboriú (SC). 1983: 1-34.

Valentin JL. Ecologia Numérica. Uma introdução à análise multivariada de dados ecológicos. Rio de Janeiro: Interciência. 2000.

Vargas L, Faria RHS, Ribeiro RP, Merlini LS, Moreira HLM, Toninato JC. Ocorrência sazonal de ectoparasitos em tilápias do Nilo (Oreochromis niloticus) em um pesquepague de Umuarama, Paraná. Arq. Ciênc. Vet. Zool. 2003; 6 (1): 61-66.

Vasconcelos VM. Preliminary results of a study on the impact of toxic and non-toxic cyanobacteria on some freshwater microcrustacean species. Crustaceana. 1990; 59: 316-318. 
Vasconcelos VM. Cyanobacterial toxins in Portugal: effects on aquatic animals and risk for human health. Braz. J. Med. Biol. Res. 1999; 32 (3): 249-254.

Venkateswara K. Takai T. Navarro IM. Nakano H. Hashimoto H. Siebeling RJ. Ecology of Vibrio cholerae Non-01 and Salmonella spp and Role of Zooplankton in Their Seasonal Distribution in Fukuyanma Coastal Waters. Japan. Applied Environ Microbiol. 1989: 55 (6): 1591-98.

Vinatea-Arana L. Principios químicos da água em aqüicultura: uma revisão para peixes e camarões. $2^{\text {a }}$ ed. Florianópolis: Ed. da UFSC. 2004.

Werner VR. Torgan LC. Yunes JS. Cunha MT. Ocorrência de Floração de Cianoficea (Cianobctéria) Tóxica na Represa de Itaúba. Rio Grande do Sul. Brasil. In: Seminário Internacional do Broa - Resumos. 2000 Dez 10. São Carlos (SP).

Wetzel RG. Limnology. 2a ed.Saunders College Publishing. 1983

Wetzel RG. Likens GE. Limnological Analysis. 20a ed. NY: Spring-Verlag; 1991.

Wisniewski MJS. Distribuição espacial e produção secundária da comunidade zooplanctônica do Reservatório de Barra Bonita, SP. São Carlos (SP); 1998 [Tese de Doutorado - Universidade Federal de São Carlos].

Zagatto P. Avaliação ecotoxicológica do reservatório do Guarapiranga-SP, Brasil. com ênfase à problemática das algas tóxicas e algicidas. França; 1995. (Tese de Doutorado - Université de Metz, Centre des Sciences de L'Environment). 
Tabela 1: Altitude dos pesqueiros amostrados, características da área de entorno dos lagos de pesca e do curso d água que os abastece.

\begin{tabular}{|c|c|c|c|c|c|c|c|c|c|c|}
\hline $\begin{array}{l}\text { Pesquei- } \\
\text { ro }\end{array}$ & $\begin{array}{l}\text { Altitude } \\
\text { (m) }\end{array}$ & $\begin{array}{l}\text { Cobertura vegetal da } \\
\text { area vizinha ao lago }\end{array}$ & $\begin{array}{l}\text { Cobertura vegetal do } \\
\text { topo de morro }\end{array}$ & $\begin{array}{c}\text { Cobertura vegetal da } \\
\text { área marginal ao curso } \\
\text { d'agua }\end{array}$ & Agricultura & Pecuária & $\begin{array}{l}\text { Declivid. } \\
\text { predom. }\end{array}$ & Sinais de erosăo & $\begin{array}{c}\text { Curso } \\
\text { d'água } \\
\text { formador }\end{array}$ & $\begin{array}{c}\text { Area à montante do } \\
\text { lago }\end{array}$ \\
\hline 1 & 701 & gramado & Eucalip/mata secund. & parcialm. preservada & reflorest. & gado & $>450$ & enrug. do morro & nascente & agricola/reflorest. \\
\hline 2 & 665 & gramado & mata secund. & parcialm. preservada & milho & gado & $\sim 300$ & enrug, á jusante & nascente & área cultivada \\
\hline 3 & 696 & sem cobertura & desmatado * & resto de mata ciliar & năo há & năo há & -300 & solo exposto & nascente & resto de mata ciliar \\
\hline 4 & 920 & sem cobertura & Eucalip/mata secund. & parcialm. preservada & năo há & não há & $>450$ & ausente & córrego & pouco modificada \\
\hline 5 & 796 & gramado & campo & parcialm. preservada & năo há & năo há & -300 & ausentes & córrego & pouco modificada \\
\hline 6 & 830 & gramado & campolPinus/Eucal. & sem mata ciliar & năo há & cavalos & -450 & sulcos nas vert. & corrego & desmatada \\
\hline 7 & 767 & jardim (gramado) & campo & sem mata ciliar & năo há & aves & $\sim 300$ & ausente & córr.canaliz. & área cultivada \\
\hline 8 & 765 & gramado & mata secund. & mata ciliar preservada & hortaliças & năo há & -150 & ausente & nascente & pouco modificada \\
\hline 9 & 757 & gramado/solo exposto & mata/cana-de-acúcar & mata ciliar preservada & năo há & năo há & $\sim 450$ & ausente & córrego & pouco modificada \\
\hline 10 & 786 & mata/gramado & Eucaliptus/agricult. & parcialm. preservada & hortaliças & nāo hà & -300 & desliz barragem & córrtpoço & pouco modificada \\
\hline 11 & 842 & gramado/solo exposto & mata parc. preserv. & parcialm. preservada & năo há & não há & -300 & ausente & nascente & pouco modificada \\
\hline 12 & 766 & jardim (gramado) & mata preservada & mata ciliar preservada & hortaliças & năo há & $\sim 300$ & ausente & nascente & mata natural \\
\hline 13 & 778 & gramado & Eucaliptus/campo & sem mata ciliar & hortaliças & gado & -300 & ausente & córrego & pouco modificada \\
\hline 14 & 788 & gramado/Eucaliptus & mata secund. & parcialm. preservada & não há & năo há & $\sim 150$ & ausente & córrego & pouco modificada \\
\hline 15 & 783 & gramado/solo exposto & Eucalip/mata secund. & parcialm. preservada & não há & gado & $\sim 450$ & sulcos na área & córrego & pouco modificada \\
\hline 16 & 788 & gramado/solo exposto & mata preservada & mata/reflor. Eucaliptus & não há & năo há & $\sim 450$ & ausente & córrego & pouco modificada \\
\hline 17 & 800 & gramado & Pinus/Eucal./mata & parcialm. preservada & năo há & não há & -300 & ausente & córrego & algumas casas \\
\hline 18 & 798 & gramado & mata/campo & parcialm. preservada & hortaliças & não há & $\sim 300$ & ausente & nascente & pouco modificada \\
\hline 19 & 796 & gramado/campo & Eucalip/mata secund. & parcialm. preservada & hortaliças & gado & -300 & ausente & córrego & pouco modificada \\
\hline 20 & 787 & gramado & mata/horta & parcialm. preservada & hortaliças & năo há & -450 & ausente & córrego & pouco modificada \\
\hline 21 & 801 & gramado & reflorest. Eucaliptus & parcialm. preservada & năo há & não há & $\sim 150$ & ausente & córrego & pouco modificada \\
\hline 22 & 784 & gramado & Pinus/Eucal./mata & parcialm. preservada & não há & não há & -150 & ausente & córrego & pouco modificada \\
\hline 23 & 805 & gramado & campo & parcialm. preservada & hortaliças & aves/porcos & $\sim 300$ & ausente & nascente & pouco modificada \\
\hline 24 & 785 & gramado & mata/Pinus & parcialm. preservada & nåo há & não há & -300 & ausente & córrego & loteamento/agric. \\
\hline 25 & 805 & gramado & mata & parcialm. preservada & năo há & não há & $\sim 450$ & ausente & córrego & preservada \\
\hline 26 & 773 & mata/gramado & mata & mata ciliar preservada & não há & gado & $\sim 300$ & ausente & nascente & preservada \\
\hline 27 & 804 & mata Secundária & preparado para plantio & parcialm. preservada & hortaliças & não há & $\sim 150$ & ausente & córrego & pouco modificada \\
\hline 28 & 800 & mata & mata & mata ciliar preservada & năo há & não há & $\sim 150$ & ausente & nascente & preservada \\
\hline 29 & 922 & gramado & Eucalip/mata secund. & parcialm. preservada & agricultura & não há & $\sim 300$ & ausente & córrego & algumas casas \\
\hline 30 & 952 & gramado & mata & mata ciliar preservada & não há & aves & $\sim 300$ & ausente & nasc/cór. & preservada \\
\hline
\end{tabular}

${ }^{*} O$ lago se situa em uma antiga calha de extração de areia.

Abreviações empregadas: decliv. predom. - declividade predominante reflorest. - reflorestamento enrug - enrugamento

córr.canaliz. - córrego canalizado

Eucalip. - Eucaliptus mata secund - mata secundária parcialm - parcialmente desliz - deslizamento nasc - nascente 
Tabela 2: Variáveis físicas e químicas e concentração de clorofila $a$ na água observadas durante o período estiagem-frio

\begin{tabular}{|c|c|c|c|c|c|c|c|c|c|c|c|}
\hline Cód. & Temp. & Cond. & pH & OD & turbidez & transparência & STS & N Tot & P tot & CHL & IET \\
\hline unidades & ${ }^{\circ} \mathrm{C}$ & $\mathrm{uS} / \mathrm{cm}$ & & $\mathrm{mg} / \mathrm{L}$ & NTU & $\mathrm{m}$ & $\mathrm{mg} / \mathrm{L}$ & $\mathrm{mg} / \mathrm{L}$ & $\mathrm{mg} / \mathrm{L}$ & $\mathrm{mg} / \mathrm{L}$ & \\
\hline 1 & 22,80 & 52,70 & 7,16 & 8,90 & 19,00 & 0,40 & $*$ & 0,29 & 0,06 & 0,05 & 62 \\
\hline 2 & 22,00 & 19,50 & 6,61 & 6,30 & 27,00 & 0,50 & $*$ & 0,42 & 0,06 & 0,04 & 62 \\
\hline 3 & 22,60 & 10,20 & 6,20 & 6,10 & 120,00 & 0,10 & $*$ & 0,26 & 0,07 & 0,04 & 67 \\
\hline 4 & 20,40 & 37,80 & 7,68 & 10,40 & 24,00 & 0,40 & 22,00 & 0,21 & 0,06 & 0,04 & 62 \\
\hline 5 & 22,80 & 74,50 & 7,35 & 11,80 & 21,00 & 0,40 & 44,00 & 0,31 & 0,19 & 0,09 & 72 \\
\hline 6 & 25,30 & 67,80 & 7,59 & 10,60 & 12,00 & 0,60 & 12,00 & 0,25 & 0,06 & 0,02 & 59 \\
\hline 7 & 19,50 & 66,00 & 6,89 & 5,90 & 13,00 & 0,30 & 27,00 & 0,21 & 0,11 & 0,01 & 62 \\
\hline 8 & 19,20 & 87,00 & 6,95 & 6,60 & 23,00 & 0,40 & 31,00 & 0,31 & 0,09 & 0,03 & 64 \\
\hline 9 & 21,70 & 55,00 & 6,96 & 10,30 & 11,00 & 0,50 & 18,00 & 0,35 & 0,09 & 0,01 & 59 \\
\hline 10 & 18,40 & 200,00 & 7,11 & 6,00 & 37,00 & 0,25 & 55,00 & 1,00 & 0,17 & 0,04 & 70 \\
\hline 11 & 19,70 & 32,30 & 7,69 & 10,60 & 19,00 & 0,60 & 31,60 & 0,74 & 0,12 & 0,03 & 63 \\
\hline 12 & 23,30 & 53,20 & 7,09 & 9,40 & 15,00 & 0,50 & 26,00 & 0,85 & 0,07 & 0,01 & 57 \\
\hline 13 & 22,40 & 82,90 & 7,47 & 7,80 & 19,00 & 0,40 & 32,67 & 0,86 & 0,15 & 0,07 & 70 \\
\hline 14 & 24,60 & 124,00 & 7,39 & 8,50 & 15,00 & 0,50 & 30,86 & 0,93 & 0,18 & 0,05 & 69 \\
\hline 15 & 26,90 & 44,80 & 7,05 & 8,20 & 50,00 & 0,50 & 55,33 & 1,04 & 0,09 & 0,04 & 45 \\
\hline 16 & 22,70 & 26,50 & 6,50 & 7,90 & 60,00 & 0,20 & 68,46 & 1,96 & 0,12 & 0,11 & 72 \\
\hline 17 & 25,80 & 25,00 & 6,34 & 7,60 & 18,00 & 0,50 & 18,75 & 0,74 & 0,04 & 0,00 & 64 \\
\hline 18 & 23,10 & 32,00 & 6,51 & 11,00 & 11,00 & 0,40 & 23,50 & 0,16 & 0,06 & 0,03 & 60 \\
\hline 19 & 21,50 & 65,50 & 6,95 & 5,60 & 13,00 & 0,30 & 12,38 & 0,26 & 0,06 & 0,00 & 50 \\
\hline 20 & 21,90 & 100,00 & 6,30 & 6,40 & 24,00 & 0,40 & 26,66 & 0,66 & 0,16 & 0,04 & 68 \\
\hline 21 & 21,90 & 110,00 & 6,50 & 8,20 & 36,00 & 0,30 & 29,00 & 0,42 & 0,14 & 0,03 & 67 \\
\hline 22 & 22,10 & 30,00 & 6,00 & 9,50 & 39,00 & 0,50 & 17,00 & 0,22 & 0,04 & 0,01 & 51 \\
\hline 23 & 23,90 & 390,00 & 6,10 & 8,60 & 270,00 & 0,10 & 140,00 & 2,56 & 0,12 & 0,02 & 68 \\
\hline 24 & 22,70 & 140,00 & 6,40 & 6,20 & 38,00 & 0,40 & 32,14 & 0,43 & 0,17 & 0,10 & 72 \\
\hline 25 & 22,80 & 250,00 & 6,60 & 5,20 & 60,00 & 0,30 & 27,00 & 0,49 & 0,12 & 0,07 & 68 \\
\hline 26 & 21,90 & 30,00 & 5,80 & 6,10 & 78,00 & 0,20 & 24,00 & 0,93 & 0,16 & 0,07 & 72 \\
\hline 27 & 22,50 & 230,00 & 6,40 & 8,30 & 23,00 & 0,40 & 35,00 & 0,45 & 0,12 & 0,05 & 68 \\
\hline 28 & 24,50 & 270,00 & 6,50 & 11,20 & 56,00 & 0,30 & 38,18 & 0,68 & 0,23 & 0,17 & 76 \\
\hline 29 & 22,60 & 140,00 & 6,40 & 7,70 & 58,00 & 0,30 & 21,87 & 1,57 & 0,12 & 0,05 & 68 \\
\hline 30 & 23,10 & 170,00 & 8,10 & 12,40 & 49,00 & 0,30 & 54,16 & 0,44 & 0,28 & 0,13 & 76 \\
\hline $\min$ & 18,40 & 10,20 & 5,80 & 5,20 & 11,00 & 0,10 & 12,00 & 0,21 & 0,04 & 0,00 & 45 \\
\hline média & 22,49 & 100,56 & 6,82 & 8,31 & 41,93 & 0,38 & 35,32 & 0,64 & 0,12 & 0,05 & 64 \\
\hline máx & 26,90 & 390,00 & 8,10 & 12,40 & 270,00 & 0,60 & 140,00 & 2,56 & 0,28 & 0,17 & 76 \\
\hline
\end{tabular}


Tabela 3: Variáveis físicas e químicas e concentração de clorofila $a$ na água observadas durante o período chuvosoquente.

\begin{tabular}{|c|c|c|c|c|c|c|c|c|c|c|c|}
\hline Cód. & Temp. & Cond. & pH & OD & turbidez & transparência & STS & N Tot & P tot & CHL & IET \\
\hline unidades & ${ }^{\circ} \mathrm{C}$ & $\mathrm{uS} / \mathrm{cm}$ & & $\mathrm{mg} / \mathrm{L}$ & NTU & $\mathbf{m}$ & $\mathrm{mg} / \mathrm{L}$ & $\mathrm{mg} / \mathrm{L}$ & $\mathrm{mg} / \mathrm{L}$ & $\mathrm{mg} / \mathrm{L}$ & \\
\hline 1 & 28,30 & 40,00 & 5,50 & 7,90 & 22,00 & 0,50 & 12,14 & 0,21 & 0,05 & 0,01 & 57 \\
\hline 2 & 26,60 & 30,00 & 5,60 & 5,90 & 20,00 & 0,70 & 17,50 & 0,29 & 0,06 & 0,01 & 56 \\
\hline 3 & 29,40 & 20,00 & 5,30 & 7,40 & 38,00 & 0,35 & 23,27 & 0,41 & 0,06 & 0,00 & 50 \\
\hline 4 & 23,80 & 40,00 & 5,40 & 6,80 & 96,00 & 0,20 & 41,50 & 0,44 & 0,05 & 0,01 & 59 \\
\hline 5 & 28,60 & 90,00 & 5,80 & 6,60 & 28,00 & 0,40 & 22,00 & 0,50 & 0,10 & 0,01 & 61 \\
\hline 6 & 26,20 & 70,00 & 5,80 & 8,50 & 110,00 & 0,30 & 34,18 & 0,78 & 0,06 & 0,00 & 54 \\
\hline 7 & 25,30 & 80,00 & 6,10 & 3,90 & 48,00 & 0,30 & 30,67 & 0,48 & 0,11 & 0,06 & 68 \\
\hline 8 & 24,20 & 100,00 & 6,10 & 4,40 & 34,00 & 0,50 & 17,50 & 0,30 & 0,08 & 0,02 & 60 \\
\hline 9 & 25,10 & 70,00 & 5,90 & 6,10 & 26,00 & 0,50 & 14,50 & 0,38 & 0,08 & 0,10 & 67 \\
\hline 10 & 25,30 & 470,00 & 6,80 & 7,00 & 55,00 & 0,20 & 52,00 & 0,35 & 0,35 & 0,01 & 70 \\
\hline 11 & 25,20 & 60,00 & 5,60 & 7,90 & 17,00 & 0,80 & 9,14 & 0,27 & 0,08 & 0,02 & 59 \\
\hline 12 & 27,40 & 60,00 & 5,70 & 9,50 & 41,00 & 0,40 & 36,00 & 0,30 & 0,08 & 0,04 & 64 \\
\hline 13 & 24,90 & 110,00 & 5,80 & 5,50 & 40,00 & 0,25 & 28,00 & 0,32 & 0,13 & 0,06 & 69 \\
\hline 14 & 25,40 & 130,00 & 6,10 & 6,10 & 30,00 & 0,25 & 27,33 & 0,28 & 0,18 & 0,01 & 66 \\
\hline 15 & 27,40 & 50,00 & 5,80 & 8,40 & 19,00 & 0,55 & 16,40 & 0,25 & 0,05 & 0,00 & 52 \\
\hline 16 & 28,00 & 50,00 & 6,30 & 8,30 & 86,00 & 0,20 & 62,00 & 0,42 & 0,17 & 0,04 & 70 \\
\hline 17 & 28,60 & 60,00 & 5,60 & 9,80 & 19,00 & 0,60 & 13,09 & 0,22 & 0,07 & 0,01 & 57 \\
\hline 18 & 29,00 & 60,00 & 7,60 & 14,60 & 42,00 & 0,40 & 24,57 & 0,31 & 0,03 & 0,02 & 55 \\
\hline 19 & 27,50 & 100,00 & 5,70 & 3,50 & 26,00 & 0,40 & 16,00 & 0,52 & 0,07 & 0,05 & 64 \\
\hline 20 & 29,60 & 80,00 & 5,70 & 5,80 & 22,00 & 0,40 & 17,50 & 0,23 & 0,10 & 0,07 & 67 \\
\hline 21 & 26,90 & 180,00 & 6,10 & 7,50 & 29,00 & 0,40 & 19,43 & 0,36 & 0,14 & 0,02 & 65 \\
\hline 22 & 27,80 & 60,00 & 5,70 & 7,70 & 27,00 & 0,50 & 13,50 & 0,20 & 0,05 & 0,13 & 66 \\
\hline 23 & 27,20 & 380,00 & 6,30 & 5,00 & 200,00 & 0,15 & 144,00 & 1,24 & 0,17 & 0,04 & 71 \\
\hline 24 & 26,90 & 120,00 & 6,10 & 4,20 & 98,00 & 0,20 & 47,50 & 1,74 & 0,13 & 0,00 & 59 \\
\hline 25 & 27,60 & 160,00 & 6,20 & 5,20 & 47,00 & 0,40 & 26,00 & 1,68 & 0,08 & 0,05 & 65 \\
\hline 26 & 30,00 & 30,00 & 5,60 & 11,00 & 72,00 & 0,20 & 94,00 & 0,35 & 0,16 & 0,03 & 69 \\
\hline 27 & 29,20 & 200,00 & 6,20 & 6,10 & 41,00 & 0,30 & 22,00 & 0,42 & 0,14 & 0,05 & 69 \\
\hline 28 & 29,40 & 280,00 & 6,30 & 7,30 & 47,00 & 0,30 & 31,33 & 0,83 & 0,19 & 0,09 & 73 \\
\hline 29 & 28,20 & 190,00 & 6,10 & 6,40 & 53,00 & 0,30 & 79,50 & 1,33 & 0,09 & 0,02 & 63 \\
\hline 30 & 28,30 & 130,00 & 8,10 & 13,60 & 65,00 & 0,25 & 49,33 & 0,39 & 0,23 & 0,43 & 81 \\
\hline $\min$ & 23,80 & 20,00 & 5,30 & 3,50 & 17,00 & 0,15 & 9,14 & 0,20 & 0,03 & 0,00 & 50 \\
\hline média & 27,24 & 116,67 & 6,03 & 7,26 & 49,93 & 0,37 & 34,73 & 0,53 & 0,11 & 0,05 & 64 \\
\hline máx & 30,00 & 470,00 & 8,10 & 14,60 & 200,00 & 0.80 & 144.00 & 1,74 & 0.35 & 0.43 & 81 \\
\hline
\end{tabular}


Tabela 4 - Densidades numéricas (ind $/ \mathrm{m}^{3}$ ) dos rotíferos planctônicos nos pesqueiros amostrados no período estiagem-frio.

\begin{tabular}{|c|c|c|c|c|c|c|c|c|c|c|c|c|c|c|c|c|c|c|}
\hline & 1 & & 2 & & 3 & & 4 & & 5 & & 6 & & 7 & - & 8 & 3 & 10 & \\
\hline & ind. $/ \mathrm{m} 3$ & x & ind./m3 & 3 & ind./m3 & 8 & ind. $/ \mathrm{m} 3$ & 2 & ind./m3 & $\%$ & ind./m3 & $\%$ & ind./m3 & $\%$ & ind. $/ \mathrm{m} 3$ & $\%$ & ind. $/ \mathrm{m} 3$ & $\%$ \\
\hline Anuraeopsis fissa & 648 & 28 & & & 16167 & 19.6 & & & 466 & 24 & 4 & 0.5 & 24 & 3.0 & 2 & ox & 566 & 1. \\
\hline \multicolumn{19}{|l|}{ Ascomorpha sp } \\
\hline \multicolumn{19}{|l|}{ A. ecaudis } \\
\hline Asplanchna sieboldi & & $\mathbb{1}$ & & & & & & $\mathbb{N}$ & 1 & 10 & 72 & 0.0 & 656 & 6.7 & 2 & 3 & 2 & 3. \\
\hline Brachionus angularis & 192429 & 288 & 7165 & 0,8: & 33 & 0.5 & 666 & 17 & 26866 & 258 & 136 & 1,8 & 16 & 1,4 & 66 & 3 & 434 & 08 \\
\hline B. angularis $\mathrm{f}$ chelonis & 121 & 0,2 & & & & & & & 266 & 93 & 24 & 0,3 & 48 & 0.4 & 366 & 1 & 134 & 18 \\
\hline B. angularis $f$ pudolabra & 56113 & 78 & 335 & 0.4 & & & & & & & & & & & & $\mathbb{3}$ & & \\
\hline \multicolumn{19}{|c|}{ B. bidentata f testudinarius } \\
\hline \multicolumn{19}{|c|}{ B. budapestinensis f lineatus } \\
\hline B. calyciflorus & & 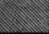 & & & & & & & 14 & 13 & & 13 & & 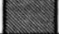 & 34 & 38 & 16 & 28 \\
\hline B. calyciflorus $\mathrm{f}$ amphic & & & & & & & & & 14 & 18 & 664 & 8,7 & 168 & 14,7 & 166 & 36 & 7666 & 138. \\
\hline \multicolumn{19}{|c|}{ B. calyciflorus $f$ anuraeiformis } \\
\hline B. caudatus caudatus & & $\mathbb{3}$ & & & & & & & 158 & 18.6 & & 2 & 336 & 29 & & $\mathbb{3}$ & & 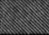 \\
\hline \multicolumn{19}{|l|}{ B. caudatus $f$ personatus } \\
\hline \multicolumn{19}{|c|}{ B. caudatus $\mathrm{f}$ austrogenitus } \\
\hline \multicolumn{19}{|l|}{ B. caudatus $\mathrm{f}$ vulgatus } \\
\hline \multicolumn{19}{|l|}{ B. falcatus falcatus } \\
\hline \multicolumn{19}{|l|}{ B. havanaensis } \\
\hline \multicolumn{19}{|l|}{ B. mirus } \\
\hline B. minus $f$ angustus & & 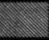 & & $\mathbb{N}$ & 38 & 0.5 & & & 88 & 85 & 8 & 0.1 & & r & & $\mathbb{Z}$ & 334 & 28 \\
\hline B. mirus ftypicus & & & 4165 & 0.5 & & & & & & & & & & 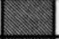 & & 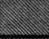 & & 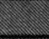 \\
\hline B. quadridentatus quad & & 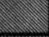 & & & & & & & & & & & 16 & 0,1 & & $\mathbb{3}$ & & $\$$ \\
\hline Cephalodella sp & & & & ? & & & & & & & & & & & & & & 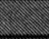 \\
\hline Collotheca sp & 1377 & 18 & 35 & 81 & 767 & 0.9 & & & & 80 & & & 48,0 & 0.4 & 34,0 & की & & 3 \\
\hline Conochilus dossuarius & & & 17835 & 28 & & & & & & 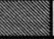 & & & & & & & & $\$$ \\
\hline C. unicomis & & & & $\mathbb{1}$ & & & & & 66 & 0,0 & & & & & & $\mathbb{8}$ & & s \\
\hline Epiphanes macrourus & & & 5 & 9.6) & & & & & 4 & 0.4 & & & & & & 3 & & ) \\
\hline Filinia longispina longis, & & & & & & & & & & 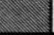 & & & & & 34,0 & 68 & & 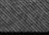 \\
\hline F. opoliensis & 526 & 07 & 165 & 0,2 & 633 & 0,8 & & 8 & 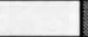 & 3 & 456,0 & 8, 영 & 1264,0 & 11,4 & & 80 & 1,0 & 02 \\
\hline F. longita f limnetica & & & & & & & & & 86 & 2,2 & & 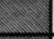 & & 8 & & 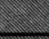 & & 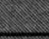 \\
\hline Hexarthra intermedia & & & & & & & 2466 & 3,8 & & 3 & & 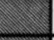 & & 2 & & s & & 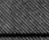 \\
\hline H. mira mira & & & & 3 & & & 15 & 2.5 & & 3 & & 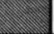 & & 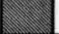 & & 3 & 1566,0 & 28 \\
\hline Kellicottia bostoniensis & & & & 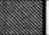 & 11167 & 1369 & 66 & 62 & 466 & 04 & 24,0 & 0.85 & & 3 & & m & 366,0 & 37 \\
\hline Keratella americana & 182712 & 264 & 12665 & 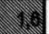 & & 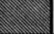 & 4334 & 60\% & 1332 & 31 & 24,0 & 0.3 & 768,0 & (6) & 34,0 & 3 & 5334,0 & 35 \\
\hline K. cochlearis tecta & & 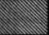 & & 3 & 66 & 0.6 & 24366 & $398:$ & 4732 & 14 & 544,0 & 7.1 & 352,0 & 37 & 24434,0 & 62 & & 8 \\
\hline K. lenzi & & 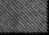 & & & 411 & 49.96 & 534 & 0,0 & 188 & 180.0 & 328,0 & 43 & 16,0 & 1,4 & & 3 & & 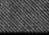 \\
\hline K. tropica tropica & & 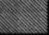 & & 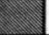 & & & 3866 & 0.2 & 16 & 1,5 & 72,0 & 0.9 & 1472,0 & 12,9 & 66,0 & 32 & 17,0 & 34 \\
\hline Lecane aculeata & & & & & & & & & & 3 & & & & 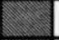 & & 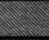 & & 3 \\
\hline L. bulla bulla & & & & & & & & & 66 & 0.8 & & & & 8 & & & & \\
\hline L. curvicomis & & & & : & & & & & 66 & 0.6 & & 28 & & 2 & & & & \\
\hline L. levystila & & & 335 & 0,4 & & & & & & 3 & & & & 2 & & & & 8 \\
\hline L. Iunaris lunaris & & & 165 & 0.2 & & & & $\$$ & & & & & & $\mathbb{2}$ & & 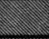 & & 8 \\
\hline L. unguinata & & \& & 165 & 32 & & & & 3 & & 3 & & 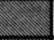 & & 3 & & m & & 8 \\
\hline Polyarthra vulgaris & 15223 & 21 & 19665 & 13. & 1767 & 21 & 11266 & 83 & 3732 & 3 & 56,0 & Q7. & 1152,0 & 10 & 2734,0 & 18 & 14334,0 & 27 \\
\hline P. vulgaris f longiremis & & & & $\mathbb{2}$ & & & & 3 & & 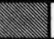 & 3352,0 & 4.0. & & 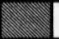 & & m & & $\infty$ \\
\hline Pompholix sp & & & & & & & & 3 & 34 & 32 & & 3 & & 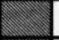 & & $n^{2}$ & & \\
\hline Synchaeta oblonga & 121 & 0.2 & & & & & 66 & 0,2 & 66 & 0.8 & & 10 & & 8 & & 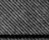 & & 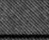 \\
\hline S. pectinata & & & & & & & & & & & 144,0 & 1,0 & 96,0 & 0.8 & 6734,0 & 1388 & 3234,0 & 58 \\
\hline Trichocerca cylindrica & & & & & & & & & & & & 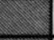 & 28,0 & 1,8 & 1,0 & 0.3 & 34,0 & 0.7 \\
\hline T. dixon-nutalli & & & & & & & 334 & 0.6 & & 2 & & 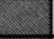 & & - & & sis & & 8 \\
\hline T. gracilis & & & 1335 & 02 & & & & 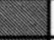 & 6 & 064 & & 1 & & 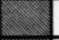 & & 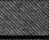 & 5,0 & 08 \\
\hline T. pusilla & 45 & 0.5 & 7335 & 10 & 28 & 3,4 & 134 & 0.2 & 166 & 12 & 24,0 & 3,1 & 1536,0 & 18,4 & 566,0 & 18 & & 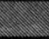 \\
\hline T. similis grandis & 45 & 06 & 4835 & 0.6 & 33 & 0,5 & 1466 & 23 & 8 & 02 & 8,0 & 0,1 & & $x^{3}$ & & $x^{2}$ & & \\
\hline T. stylata & & & & & 13 & 1,6 & & $\approx$ & & 3 & & 3 & & 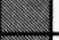 & & ? & & $\$$ \\
\hline Bdelloidea & & & & 50 & & 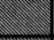 & & 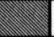 & & & 56,0 & 07 & 176,0 & 1.3 & & m & 166,0 & 20 \\
\hline Subtotal & 52484 & 726 & 174 & 21.6 & 8846 & 68.2 & 5713 & 94,4 & 1399 & 281 & 6712,0 & 320 & 1432,0 & 01,2 & 3582,0 & 98 & 55368,0 & 981 \\
\hline
\end{tabular}


Tabela 4 - Densidades numéricas (ind $/ \mathrm{m}^{3}$ ) dos rotíferos planctônicos nos pesqueiros amostrados no período estiagem-frio (contin.).

\begin{tabular}{|c|c|c|c|c|c|c|c|c|c|c|c|c|c|c|c|c|c|c|c|c|}
\hline & 11 & & 12 & & 13 & 4 & 14 & & 15 & & 16 & & 17 & & 18 & & 19 & m & 20 & $S_{1}$ \\
\hline & ind. $/ \mathrm{m} 3$ & $\%$ & ind./m3 & $\%$ & ind./m3 & $\%$ & ind. $/ \mathrm{m} 3$ & $*$ & ind. $/ \mathrm{m} 3$ & $x$ & ind./m3 & $\%$ & ind./m3 & 8 & ind./m3 & $x$ & ind./m3 & $x$ & ind. $/ \mathrm{m} 3$ & ж \\
\hline Anuraeopsis fissa & 166 & 0,2 & & D. & 166 & 0.8 & & 5 & 1 & 1.1 & & 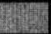 & 2434 & 123 & 1434 & 78 & 2 & 0.7 & 3866 & 1,3 \\
\hline Ascomorpha sp & 1 & 1,5 & & & & 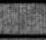 & & 30 & & 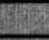 & & 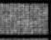 & & 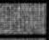 & & 4 & & 5 & & 8 \\
\hline A. ecaudis & & - & & 5 & 66 & 0,3 & 1 & 1,1 & & 8 & & 5 & & 5 & & 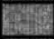 & 24 & 0.8 & & 5 \\
\hline Asplanchna sieboldi & 2 & 0,3 & 1 & 0.7 & 1334 & 6.5 & 334 & 3.8 & 3 & 0,3 & & 8 & & 7 & & 6 & 12 & 42 & 2666 & 10,0 \\
\hline Brachionus angularis & 16166 & 23.8 & & 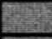 & 336 & 1,5 & 34 & 0,4 & 34 & 0.3 & & 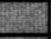 & & 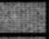 & 34 & 02 & & 5 & 2474 & 0,9 \\
\hline B. angularis $f$ chelonis & 334 & 0,5 & 126 & 0,8 & & - & 166 & 1,9 & 2666 & 2.7 & & 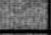 & 6 & 3,4 & 2866 & 15.6 & & 5 & 4932 & 1,7 \\
\hline B. calyciflorus & 2266 & 3,3 & 15 & 1,0 & 68 & 3,9 & 466 & 5,4 & & 4 & & 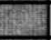 & & 5 & & 5 & & 5 & 66 & 02 \\
\hline B. calyciflorus f amphiceros & 434 & 0,8 & 426 & 28 & 1134 & 5,1 & 1834 & 2,9 & 3 & 0,3 & & 8 & & 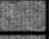 & & 2 & & sis & 2666 & 0,9 \\
\hline B. calyciflorus $f$ dorcas & & 28 & & +8 & & 8? & & 8 & & 5 & 366 & 17,0 & 1 & 0,6 & & 5 & & 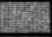 & & 5 \\
\hline B. caudatus caudatus & 266 & 0,4 & & 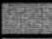 & & 5 & & 4 & & 8 & & 5 & & 5 & & E & & 5 & & 5 \\
\hline B. caudatus $\mathrm{f}$ personatus & & 18 & & 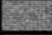 & & 86 & & 8 & 3434 & 3,5 & & & & 2 & & 5 & & 50 & & 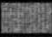 \\
\hline B. caudatus $\mathrm{f}$ austrogenitus & 43 & 6,3 & 1 & 0,7 & & P्य & & $\overline{5}$ & & ? & & 5 & & 15 & & 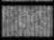 & & $\sqrt{13}$ & 5866 & 25 \\
\hline B. caudatus $\mathrm{f}$ vulgatus & & 3 & & 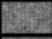 & 466 & 2,1 & & 4 & & 5 & & 5 & & 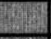 & & 8 & & 5 & & 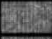 \\
\hline B. falcatus falcatus & & 4 & & 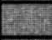 & & +4 & 34 & 0,4 & & 8 & & if & & at & & +2 & & 5 & & 2 \\
\hline B. minus & & & 26 & 0,2 & & sin & & tests & & 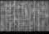 & & (5) & & ty & & 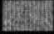 & & 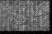 & & Shat \\
\hline B. minus $f$ angustus & & 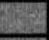 & & 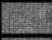 & & 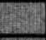 & & 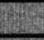 & & 5 & & 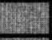 & 466 & 2,4 & 34 & 0,2 & 2 & 0.7 & & Ests \\
\hline B. minus f laticaudatus & & 65 & & 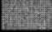 & & 58 & & 45 & & 48. & 8 & 44 & & 8 & & 6 & & 5 & & 28 \\
\hline B. patulus petulus & & & & 5 & & 298 & & 8 & & 5 & & Pente & 2 & 0,1 & & We & & nist & & ats \\
\hline B. quadridentatus quadridentat & & 4 & 76 & 0,5 & 1 & 0.5 & & $\sqrt{20}$ & & 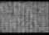 & 66 & 0,4 & & 28 & & 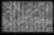 & 32 & 11,1 & 266 & 0,9 \\
\hline Cephalodella gibba & & - & & 5 & & 5 & & 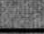 & & +4 & & 3 & & + & & Ek & 48 & 1,7 & & 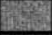 \\
\hline C. cf tenuita & & 5 & & - & & 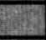 & & 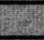 & & 5 & & (5) & & 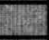 & & 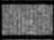 & 296 & 1,3 & & 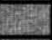 \\
\hline Cephalodella sp & & 6 & & I & 34 & 0,2 & & 5 & & 5 & & 5 & & 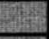 & & 6 & & 5 & & 5 \\
\hline Collothece sp & & A & 76,0 & 0,5 & & 4h14 & 866,0 & 9,9 & 166,0 & 0,2 & 1. & 0,6 & & II & 1266 & 6,9 & 48 & 17 & 66 & 0,2 \\
\hline Conochilus coenobasis & & 5 & & 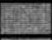 & & 5 & & 5 & & 8 & & 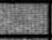 & & 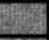 & 34 & 0.2 & 24 & 0,8 & & 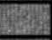 \\
\hline Conochilus dossuanius & & 7 & & 11 & & 4 & & +3 & & 5 & 34 & 0,2 & & 4 & & +5 & 14 & 3,8 & & Dis \\
\hline C. unicomis & 66,0 & 1,0 & & 5 & 34,0 & 0.2 & & 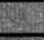 & & 34 & & +4 & 66 & 0,3 & 66 & 0,4 & & 3 & & 5 \\
\hline Epiphanes macrounus & & 5 & & - & & - & & 5 & & E. & & 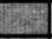 & & +5 & & 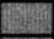 & & 5 & 68734 & 24,0 \\
\hline Filinia comuta v brachiata & & 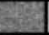 & & 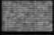 & & ti & & 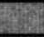 & & 5 & & 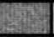 & & 5 & & 8 & & $\sqrt{25}$ & 8 & 0,3 \\
\hline F. longispina longispina & & 8 & & 4 & & - & & 2 & & 5 & & 5 & & 5 & & 5 & 128 & 4,4 & & 58: \\
\hline F. opoliensis & 934,0 & 1,4 & 26,0 & 0,2 & 34,0 & 0,2 & & 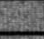 & & 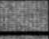 & 2166 & 12,0 & 166 & 0,8 & & 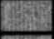 & & 5 & 34 & 0,1 \\
\hline H. mira mira & 5,0 & 0,7 & 26,0 & 0,2 & & 5 & & 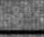 & 434,0 & 0,4 & & 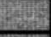 & & 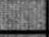 & & 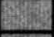 & & Fis & & tive \\
\hline Kellicottia bostoniensis & & 5 & 195,0 & 129 & 66,0 & 0,3 & 66,0 & 0,8 & 37,0 & 31,2 & 66 & 0,4 & 1634 & 8,3 & 134 & 5,6 & 48 & 17 & 56666 & 19,8 \\
\hline Keratella americana & 4,0 & 5,9 & 476,0 & 3,1 & 734,0 & 3,3 & & + & 67,0 & 6,8 & & 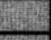 & 234 & 1,2 & 2266 & 12,3 & 2 & 0.7 & 2666 & 0.9 \\
\hline K. cochlearis tecta & 634,0 & 0,9 & 1276,0 & 8,4 & 734,0 & 3,3 & 134,0 & 1,5 & 1866,0 & 19 & & 5 & 1 & 0,6 & 34 & 0.2 & 28 & 72 & 3866 & 1,3 \\
\hline K. lenzi & & 8 & & 7 & & 8 & & 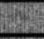 & 72,0 & 73 & 66 & 0,4 & & 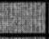 & & 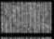 & & 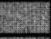 & 17266 & 6,3 \\
\hline K. tropica tropica & 12566,0 & 18,5 & 126,0 & 0,8 & 63,0 & 28.6 & 1,0 & 1,1 & 28,0 & 2,8 & & 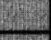 & 66 & 0,3 & & +5 & & 5 & 13734 & 4,8 \\
\hline Lecane aculeata & 34,0 & 0,5 & 26,0 & 0.2 & & + & & 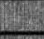 & & 8 & & +4 & & 4 & & 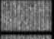 & & 5 & & 8 \\
\hline L. bulla styrax & & 8 & & 5nt & & 5 & & 3 & & 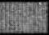 & & 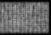 & & 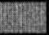 & & Din & 2 & 0,7 & & $\sqrt{2 x}$ \\
\hline L. luna & & 85 & & 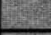 & & 67 & & 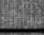 & & 5 & & 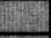 & & 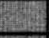 & & 5 & 2 & 0.7 & & End \\
\hline L. cf scutata & & 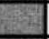 & & 5 & & 5 & & $\overline{4}$ & & 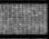 & & 3 & & 5 & 34 & 0,2 & & 5 & & 5 \\
\hline L. patella patella & & 3 & & E & & 5 & & 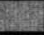 & & 5 & & 5 & & 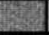 & & 5 & 2 & 0.7 & & S? \\
\hline Monommata sp & & 73 & & 5 & & 5 & & 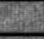 & & 5 & & 4 & 34 & 0,2 & & 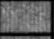 & & 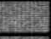 & & $E$ \\
\hline Polyarthra vulgaris & 142,0 & 2.9 & 8826,0 & 58,3 & 134,0 & 4,7 & 2534,0 & 28.9 & 36534,0 & 36,9 & 12 & 6,6 & 19 & 55,3 & 2466 & 13,5 & 288 & 1,2 & 63466 & 22,1 \\
\hline P. vulgaris f longiremis & & - & & 48 & & 8 & & 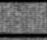 & 234,0 & 2,5 & & 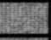 & 234 & 1,2 & & 7 & & 5 & 666 & 0.2 \\
\hline Pompholix complanate & & - & & $\sqrt{2}$ & & 5 & & 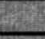 & & 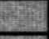 & & 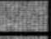 & & 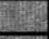 & & 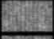 & & 5 & 566 & $1,8$. \\
\hline Pompholix Sp & & +3 & & - & 234,0 & 1,6 & & 5 & & 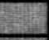 & & (1) & & 5 & & 50 & & 5 & & 7 \\
\hline Synchaeta oblonga & & - & & - & & 3 & & 8 & & 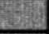 & & 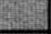 & & 5 & & $E=$ & & 5itis & & 5 \\
\hline S. pectinate & 234,0 & 0,3 & 16,0 & 0,8 & 266,0 & 1,3 & & 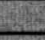 & & 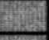 & & 5 & 234 & 13 & 34 & 0,2 & 184 & 6.4 & & 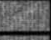 \\
\hline Trichocerca bicristata & & & & ty & & 5 & & 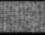 & & 5 & & 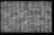 & 2 & 0,1 & & 25: & & 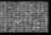 & & 5 \\
\hline Trichocerca cylindrica & 17,0 & 2,6 & 76,0 & 0.5 & 766,0 & 3.5 & 166,0 & 19 & 6,0 & 0,7 & & 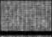 & & 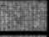 & 4566 & 24.8 & 12 & 42 & 6 & 0,3 \\
\hline T. cylindrica chattoni & & - & & 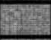 & & 8 & & 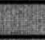 & & 5 & & 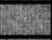 & & 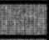 & 1 & 0.5 & & 5 & & \\
\hline T. dixon-nutalli & & 80 & & 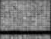 & & 3 & 34,0 & 0.4 & & 5 & & 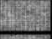 & & 3 & & 28 & -1 & 3 & 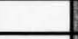 & 5 \\
\hline T. pusilla & 61,0 & 9,0 & 226,0 & 1,5 & 1166,0 & 5,3 & 1234,0 & 14,5 & 5,0 & 0,6 & 34 & 0,2 & 3 & 1,5 & 1834 & 10,0 & 8 & 2,8 & 22 & 0,8 \\
\hline T. similis & & 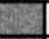 & & 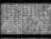 & & 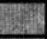 & & 8 & & 4 & 34 & 0,2 & 1 & 0,6 & 166 & 0.8 & 8 & 28 & 66 & 0,2 \\
\hline T. similis grandis & 134,0 & 1.5 & 1,0 & 0,7 & 1,0 & 0.5 & 4,0 & 4,6 & 3,0 & 0,3 & & 5 & & 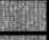 & & 4 & & +1 & & 52 \\
\hline T. stylata & 734,0 & 1,8 & 5,0 & 0,3 & & 58 & & 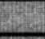 & & 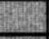 & & 5 & & 48 & & 5 & & +2 & & 5 \\
\hline Bdelloidea & 66,0 & 1,0 & 5,0 & 0,3 & 1,0 & 0,5 & 266,0 & 3,3 & 66,0 & 0.7 & & 5 & & 4 & & 5 & 656 & 22,8 & & P. \\
\hline Subtotal & 67754,0 & 99,9 & 1442,0 & 95,3 & 224,0 & 99,9 & 8768,0 & 99,8 & 9794,0 & 98,9 & 7632 & 42,2 & 19472 & 98,8 & 18268 & 99,3 & 2788 & 96,9 & 28244 & 98,5 \\
\hline
\end{tabular}


Tabela 4 - Densidades numéricas (ind $/ \mathrm{m}^{3}$ ) dos rotíferos planctônicos nos pesqueiros amostrados no período estiagem-frio (contin.).

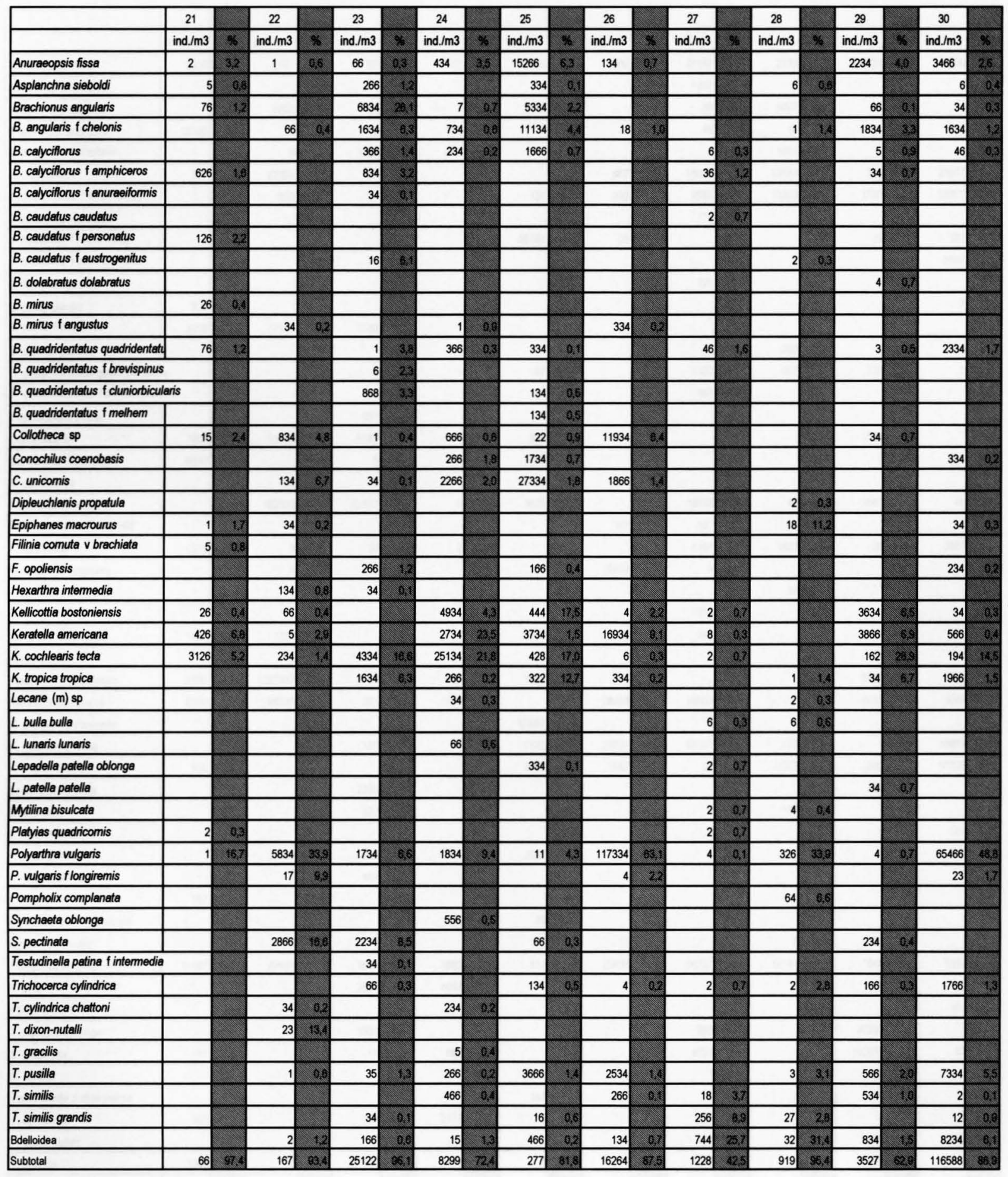


Tabela 5 - Densidades numéricas (ind $/ \mathrm{m}^{3}$ ) dos rotíferos planctônicos nos pesqueiros amostrados no período chuvoso-quente.

\begin{tabular}{|c|c|c|c|c|c|c|c|c|c|c|c|c|c|c|c|c|c|c|c|c|}
\hline & 1 & & 2 & & 3 & & 4 & & 5 & & 6 & & 7 & & 8 & & 9 & & 10 & \\
\hline & ind./m3 & x & ind. $/ \mathrm{m} 3$ & $x$ & ind./m3 & 6 & ind./m3 & $\%$ & ind. $/ \mathrm{m} 3$ & \% & ind. $/ \mathrm{m} 3$ & $x$ & & $\%$ & ind./m3 & $x^{2}$ & ind./m3 & 3 & ind. $/ \mathrm{m} 3$ & 5 \\
\hline Anuraeopsis fissa & 2500 & 3.5 & 2667 & 01 & 7167 & 4.5 & 1167 & 14 & 4833 & 13 & 1500 & 3 & 41167 & 1027 & 2333 & 32. & 6333 & 13 & 1500 & 0.5 \\
\hline Ascomorpha ecaudis & & & & & & & & 1 & & & & & 1167 & 0,3 & & & & $\$$ & & \\
\hline Asplanchna sieboldi & & & 2333 & or & 167. & 61 & 5 & 36 & 2233 & 0.8 & & & 25 & 07 & 1667 & 22 & 11 & 23 & & 15 \\
\hline Brachionus angularis & 12000 & 178 & & 10 & 5 & 03 & 167 & 02 & & & & & 45 & 12 & 15 & 22 & & $\mathbb{Z}$ & 12 & 5.1 \\
\hline B. angularis $\mathrm{f}$ chelonis & & & 6 & 28 & 2833 & 18 & 667 & 08 & & & & & & 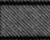 & 1667 & 132 & & 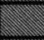 & & \\
\hline B. calyciflorus & 167 & 02 & 22333 & $\sqrt{12}$ & 167. & a? & & 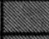 & & & 667 & 3 & 18667 & 48 & 13167 & 178 & 333 & 07 & 23667 & 1.1 \\
\hline B. calycillorus f amphiceros & & & 333 & 02 & & 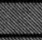 & & & 124 & 34 & 333 & 32 & 2583 & 27 & 13333 & 178 & 1333 & 208 & 33333 & 142 \\
\hline B. caudatus caudatus & & & & & & 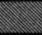 & & & & & & $n^{n}$ & 175 & 16 & & 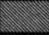 & & 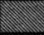 & & 3 \\
\hline B. caudatus f personatus & & & & & & & & & 85167 & 236 & 25 & 3 & & 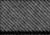 & & & 19 & 13 & 167 & 10, \\
\hline B. caudatus $\mathrm{f}$ austrogenitus & & & & & & & & & & & & & & 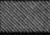 & & & & 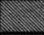 & 5667 & 24 \\
\hline B. falcatus falcatus & & $\mathbb{8}$ & & & & 3 & & 50 & & & & (150) & 125 & 3.3 & & 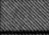 & & 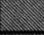 & & 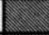 \\
\hline B. havanaensis & 500 & 107 & & & & 3 & & & & & & & & 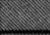 & & & & 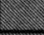 & 7 & 30 \\
\hline B. minus $f$ angustus & 3165 & 45 & 75333 & 4 & 3333 & 28 & & & & & & & & 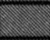 & & 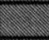 & & $\sqrt{3}$ & & 2 \\
\hline B. patulus patulus & & & & & & 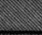 & & & & 1808 & & (1) & & 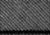 & 333 & 04 & & $\sqrt{3}$ & & 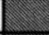 \\
\hline B. quadridentatus quadrident & & & & & & 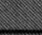 & 1 & 0,1 & 167 & 0.5 & & & 1333 & 0.3 & 667 & 09 & 333 & 07 & 5 & 02 \\
\hline B. quadridentatus $\mathrm{f}$ cluniorbic & & & & & & ב- & & - & & & & & 667 & 0,2 & & & & 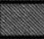 & & $=$ \\
\hline Cephalodella gibba & & & & & 667 & 8.4 & & $\approx$ & & & & & & 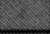 & & & & $=$ & & $=$ \\
\hline Collotheca sp & 7000 & 99 & 53333 & 29 & 5167 & 32 & 1 & 1,2 & 333 & 08 & & $x$ & & 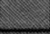 & & 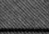 & 1833 & 04 & & $=$ \\
\hline Conochilus coenobasis & 6000 & 0.5 & & & 5 & 0.9 & & 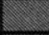 & 167 & 0.5 & & 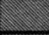 & & 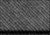 & & & 5 & 61 & & 8 \\
\hline C. dossuarius & & & & & 6 & 3.7 & & , & 3167 & 0,9 & & & & 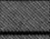 & & 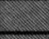 & & $\sum$ & & 8 \\
\hline Epiphanes macrounus & & & 162333 & 87 & 22167 & 138 & 5 & 0,8 & 3833 & 1,6 & & 3 & 18833 & 49 & 45 & 85 & 1667 & 23 & 65 & 28 \\
\hline Filinia comuta $v$ brachiata & & & & 3 & & $\infty$ & & 3 & & 20 & 167 & 81 & 167 & 0.4 & 15 & 22 & & s & & 30 \\
\hline F. opoliensis & 1330 & 18 & 3 & 02. & 25 & 16 & 2 & 24 & & 10 & & 3 & 1264 & 33 & 1833 & 24 & 26 & 53 & 2667 & 1,1 \\
\hline F. longiseta longiseta & & 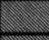 & 2 & 62 & & 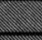 & & 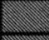 & 25 & 57 & 5333 & 38 & 8 & 28 & & $\int^{3}$ & & 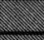 & & 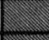 \\
\hline F. longiseta limnetica & & $\mathbb{2}$ & & 1 & & 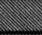 & & $\operatorname{lin}^{2}$ & & $(3$ & & 3 & & 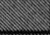 & 34 & 205 & & $\mathbb{3}$ & & 3 \\
\hline Gastropus of minor & & & & 3 & & 3 & & $\mathbb{N}$ & & 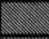 & & 3 & 333 & 30 & & 3 & & $\mathrm{~N}^{2}$ & & 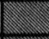 \\
\hline Hexarthra intermedia & 1167 & 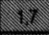 & 1333 & 37 & & 3 & & 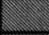 & 1667 & 0,5 & 15 & 1 & 283 & $0 \%$ & & 3 & & $\mathbb{2}$ & & $\sim 3$ \\
\hline H. mira mira & & 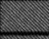 & & 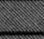 & 14333 & 30 & & 3 & & 10188 & & $\mathbb{2}^{3}$ & & 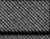 & & $3=$ & 4 & 128 & 5 & 21 \\
\hline Kellicottia bostoniensis & 2830 & 42 & 1227333 & 558 & 5167 & 32. & 167 & 92 & 1667 & 0,5 & & $x^{2}$ & & 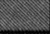 & & 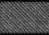 & 5833 & 12 & & 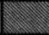 \\
\hline Keratella americana & 6500 & 92 & 96333 & 62 & 265 & 168 & 1667 & 20 & & 10 & 28833 & 27 & 14667 & 38 & & 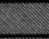 & 4667 & 10 & 3667 & 1.6 \\
\hline K. cochlearis coclearis & & 18 & & & & 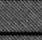 & & & 83667 & 23.2 & & $8=$ & & 2 & & - & & 1 & & 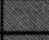 \\
\hline K. cochlearis tecta & & & & & 167 & 81. & & & 7833 & 22 & 23667 & 278 & 53167 & 13,9 & 167 & 02 & & 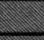 & 16667 & 7,1 \\
\hline K. tropica tropica & 500 & 07 & & 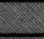 & & 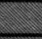 & & & 9167 & 2.5 & 1667 & $7 \%$ & 22 & 5 & 1333 & 18 & 333 & 0.7 & 57333 & 24,6 \\
\hline Lecane bulla bulla & & & & & 2333 & 1.5 & & & & & & 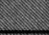 & & I & & $2=$ & 333 & $0 \%$ & & 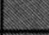 \\
\hline L. lenystila & & & & & 333 & 03 & & & & & & & & s. & 167 & 0.2 & & 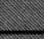 & & 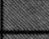 \\
\hline L. lunaris lunaris & & & & & & in: & & & & 8 & & 2 & & 8 & & $\sqrt{3}$ & 5 & 3. & 167. & 0.7 \\
\hline L. papuana & & & 37667 & 22 & 333 & 08 & & & 3167 & 69 & & & & 1 & & 1. & & 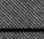 & & - \\
\hline L. quadridentata & & & & 1 & 167 & at. & & & & 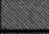 & & 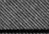 & & 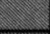 & & $\sqrt{2}$ & & 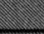 & & 1 \\
\hline L. triloba & 167 & 92 & & 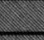 & & 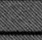 & & & & (I) & & 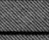 & & 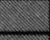 & & 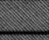 & & 2 & & 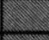 \\
\hline Lepadella patella oblonga & & & & & & 8 & & & 33 & 09 & & 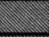 & & 8 & & 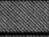 & & 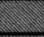 & & I \\
\hline Mytilina bisulcata & & & & 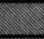 & & & & & & & 15 & 18 & & 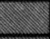 & 5 & 07 & 167 & 23 & & 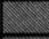 \\
\hline Polyarthra vulgaris & 11167 & 15,9 & 43667 & 23 & 1667 & 67 & 4883 & 58.3 & 833 & 02 & 25833 & 135 & 56167 & 146 & 18167 & 242 & 545 & 112 & 5667 & 21.6 \\
\hline P. vulgaris f longiremis & & no & & & 2833 & 13 & 8667 & 18 & & & & & & 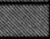 & & & & $\sqrt{3}$ & & m \\
\hline Pompholix sp & & & & & & $\mathbb{3}$ & & 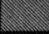 & & & & ses & & 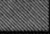 & & 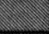 & & 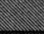 & 167 & 107 \\
\hline Synchaeta oblonga & & & & & 1333 & 68 & & 3 & & & & $n^{2}$ & 283 & 07 & & & 99333 & 23 & & 3 \\
\hline S. pectinata & 167 & 02 & & 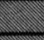 & 15 & 38 & 667 & 38 & & - & & $\mathbb{S}^{2}$ & 4333 & 13 & & & 162667 & 283 & 83 & 04 \\
\hline S. stylate & & & & & & 3 & & 3 & & 2 & & n & 1 & 08 & & 3 & 75 & 13 & & 1 \\
\hline Testudinella patina patina & & & & & & 23 & & 100 & 167 & 03 & & 3 & & 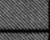 & & 3 & & 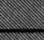 & & $\mathbb{8}$ \\
\hline T. cylindrica & 500 & 07 & & & 667 & 04 & 2167 & 26 & 1 & 03 & & 5 & 5 & 91 & & 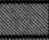 & & $\mathbb{1 0}$ & & 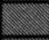 \\
\hline T. dixon-nutalli & & & & & & 3 & & 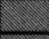 & & 3 & & 3 & 167 & 04 & & 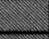 & 2833 & 0,6 & 167 & 07 \\
\hline$T$. gracilis & 1000 & 14 & 4 & 02 & 167 & a. & & 3 & 3 & 8.8 & & 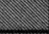 & 15 & 04 & & 3 & 15667 & 33 & & \\
\hline$T$. pusilla & 1500 & 21 & 9333 & 06 & 1167 & 07 & 95 & 11,3 & 667 & 0.2 & 1667 & 12 & 1333 & 27 & 833 & 11 & 18833 & 39 & 667 & 03 \\
\hline T. similis & & & 12 & 06 & & 10 & 667. & 0.8 & & 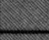 & & 3 & & 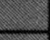 & & - & & 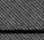 & 667 & 0.3 \\
\hline$T$. similis grandis & & & & & 1667 & 14 & & 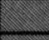 & 167 & 0.5 & 167. & 2: & 3. & 08 & & 2 & 25 & 05 & 1 & 0.4 \\
\hline T. stylata & & & & & 13 & 81 & & & & & & 3 & & 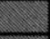 & & 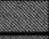 & 1167 & 02 & & $L$ \\
\hline Bdelloidea & 1167 & 17 & 46333 & 2.5 & 1 & 0.8 & 83 & 10 & 1 & 03 & 1333 & 16 & 4 & 14 & 1 & 8,3 & 3333 & 07 & 1 & 0,4 \\
\hline Subtotal & 59327 & 84,3 & 1807664 & 97,2 & 13452 & 84.5 & 79173 & 94.5 & 358435 & 98,4 & 15667 & 75.8 & 378298 & 98.7 & 747 & 58.8 & 452498 & 527 & 231 & 587 \\
\hline
\end{tabular}


Tabela 5 - Densidades numéricas (ind/m3) dos rotíferos planctônicos nos pesqueiros amostrados no período chuvoso-quente (contin.).

\begin{tabular}{|c|c|c|c|c|c|c|c|c|c|c|c|c|c|c|c|c|c|c|c|c|}
\hline & 11 & & 12 & & 13 & & 14 & & 15 & & 16 & & 17 & & 18 & & 19 & & 20 & \\
\hline & ind./m3 & × & ind./m3 & 4 & ind./m3 & 3 & ind./m3 & \& & ind./m3 & $x^{2}$ & ind./m3 & 3 & ind./m3 & 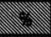 & ind./m3 & 2 & ind./m3 & \& & ind./m3 & 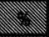 \\
\hline Anuraeopsis fissa & 4000 & $\sqrt{2}$ & 2167 & 13 & 5500 & 3 & 4833 & 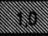 & 6333 & 21 & & 3 & & $\mathbb{2}$ & 75 & 2 & 19667 & 128 & 1333 & 32 \\
\hline Ascomorpha ecaudis & 667 & 3 & & & 167 & 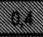 & & & & & & & 167. & 23 & 667 & 3 & & $\mathbb{2}$ & & $\mathbb{3}$ \\
\hline Asplanchna sieboldi & 8167 & 23 & 5 & 2 & 1 & 32 & 12333 & 23 & 333 & 2 & & $\mathbb{N}$ & & $\$$ & 2 & 2 & 25 & 3 & 1333 & 2 \\
\hline Brachionus angularis & 5 & 32 & 125 & 34 & 1167 & 6 & & $\mathbb{N}$ & 2 & 23 & & & & $\mathbb{R}$ & 5 & 2 & 5667 & 23 & 5333 & 3 \\
\hline B. angularis felonis & & & 7167 & 13 & 1333 & 23 & 5 & 23 & 667. & 23 & & & & $\mathbb{N}$ & & $\mathbb{2}$ & 2 & 321 & 1667 & 3 \\
\hline B. calyciflons & 2667 & 3 & 39333 & 38 & 16667 & 3 & 5 & 2 & 29 & 12 & & 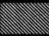 & & $\mathbb{2}$ & 167 & \% & 1 & 3 & & $\mathbb{3}$ \\
\hline B. calyciflorus f amphiceros & 7167 & $2 \times$ & 6 & 10 & 45 & 13 & 8667 & 1 & 333 & 2 & & 30 & & 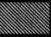 & 167 & 63 & 333 & 3 & 8167 & 21 \\
\hline B. caudatus caudatus & 5833 & 2 & & & & & & & & $\mathbb{S}$ & & & & $\mathrm{N}^{2}$ & & 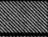 & & 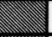 & & $\mathbb{3}$ \\
\hline B. caudetus f personetus & & $\mathbb{N}$ & & & 41167 & 38 & 167 & 23 & 2333 & 13 & & & & 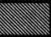 & & 1 & 1333 & 2 & 37667 & 20 \\
\hline B. caudatus f eustrogenitus & & 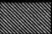 & & & 95 & 38 & 33 & 11 & & $\mathbb{2}$ & & 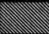 & & ent & & $\mathbb{2}$ & & $\mathbb{2}$ & 2333 & 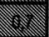 \\
\hline B. dolabratus dolabratus & & & & $\mathbb{N}$ & & $\mathbb{1}$ & & $\mathbb{R}$ & & $\mathbb{2}$ & 333 & 26 & & & & $\mathrm{~s}^{\mathrm{N}}$ & & $\mathbb{1}$ & 1 & $\mathbb{N}$ \\
\hline B. falcetus falcatus & & & & $\mathbb{2}$ & & $\$$ & 333 & 2 & 167 & 3 & 167 & 2 & & $\mathbb{N}$ & 19 & 3 & & $\mathbb{B}$ & 333 & 23. \\
\hline B. hevanaensis & & & & & & 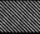 & & 34 & & $\mathbb{1}$ & & 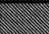 & & $\mathbb{N}$ & & $\mathbb{1}$ & & \$ & 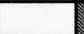 & $\mathbb{2}$ \\
\hline B. minus & & & & & & $\mathbb{2}$ & & $\mathbb{1}$ & & $\mathbb{1}$ & & $\mathbb{2}$ & 333. & 2 & & 3 & & $\mathrm{~s}^{2}$ & & $\mathbb{N}$ \\
\hline B. petulus petulus & & & & & & 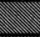 & & 3 & 1 & 3 & & 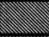 & & $\mathbb{R}$ & & $\mathbb{2}$ & 2 & 3 & & $\mathbb{N}$ \\
\hline B. quadridentatus quadridentath & 167 & 20 & & & 5 & 2 & 167 & 23 & & $\mathbb{1}$ & & $\mathbb{N}$ & & $\mathbb{2}$ & & $\mathbb{1}$ & & $\mathbb{8}$ & 167 & 20 \\
\hline B. quadridentatus f cluniorbicul & & & & & & 2 & & & & $\mathbb{N}$ & & 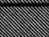 & & 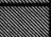 & & $\mathrm{s}^{2}$ & & & & $\mathbb{N}$ \\
\hline Collotheca sp & & & & $\mathbb{N}$ & & ind & & $\mathbb{2}^{2}$ & & $\mathbb{2}$ & 7167 & 2 & 17 & $3 \times$ & 225 & 12 & & & 15 & 20 \\
\hline Conochilus coenobasis & & & & $\mathbb{N}$ & & $\$$ & & $\mathbb{2}$ & 833 & 63 & & 3 & 175 & 32 & & 3 & & $\mathbb{2}$ & 6833 & 2 \\
\hline C. dossuarius & & & & & & $\mathbb{3}$ & & 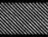 & & $\mathbb{1}$ & & s & & s & 5 & 2. & & s & & $\mathbb{N}$ \\
\hline C. unicomis & & & & & 167 & 3 & & 3 & 9. & 30 & & 3 & 333 & 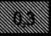 & & $\mathrm{n}^{\mathrm{n}}$ & & 3 & & $\mathbb{2}$ \\
\hline Epiphanes macrourus & 2667 & 20 & 21333 & 138 & 1667 & 28 & 15333 & 3 & 4167 & 12 & 1333 & 21 & 15 . & 3. & 3833 & 32 & 6833 & 301 & 4333 & $3 \times$ \\
\hline Filinia comuta v brachiata & & & & & 833 & 32 & & $\mathbb{1}$ & & $\mathrm{n}^{2}$ & & $\mathbb{N}$ & & $\mathbb{R}$ & 667 . & 32 & & $\mathbb{2}$ & 11333 & 23 \\
\hline F. opoliensis & 15 & 33 & & $\mathbb{N}$ & 1167 & 38 & 667 & 23 & & 3 & 1 & 20 & & $m^{2}$ & 5. & 23 & 833. & 32 & 25333 & 32 \\
\hline F. longiseta limnetica & & & & & & 3 & & s & & 3 & & 3 & & 3 & . & 13 & 24667 & 3 & & $\mathbb{S}^{2}$ \\
\hline Hexarthra intermedia & 89167 & 3 & & & & $\mathrm{n}^{\mathrm{r}}$ & & $\mathrm{n}^{2}$ & & 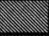 & & $m^{2}$ & 333 & 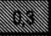 & 167 & 23 & & 3 & & $\mathbb{2}$ \\
\hline H. mira mira & & & 13 & 28 & 16167 & 3 & 2 & 34 & 15 & 23 & & 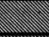 & & 32 & & 3 & 2 & 2 & 1833 . & 20 \\
\hline Kellicottia bostoniensis & 5 & 32 & 3 & 23 & & 3 & & 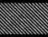 & & $\because$ & 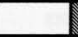 & 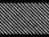 & 1167 & 20 & 333 & 3 & 667. & 3 & 1333 & 2 \\
\hline Keratella americana & 15 & 20 & 6667 & 32 & 235 & 3 & 645 & 13 & 114167 & 20 & 15 & 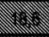 & 15333 & 20 & 27 . & 128 & 15. & 201 & 37167 & 23 \\
\hline K. cochlearis cochlearis & & $\mathbb{N}$ & & $\mathbb{N}$ & & $\mathbb{N}$ & & $\mathrm{s}^{2}$ & & 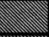 & & $\$$ & & $\mathbb{2}$ & 167 & 30 & & 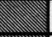 & & $\mathrm{s}^{2}$ \\
\hline K. colearis tecta & 667 & 23 & 7667 & 32 & 137833 & 33 & 119333 & 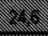 & 5833. & 23 & 4833. & 32 & 115 & a & 5 & 32 & 2333. & 3 & 15. & 28 \\
\hline K. Ienzi & & & & $\mathbb{N}$ & & 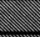 & & $\$$ & & $\mathbb{2}$ & & 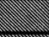 & & 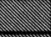 & 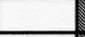 & n & 6997 & 3 & & $\mathbb{2}$ \\
\hline K. tropica tropica & 1167 & 33 & 333 & 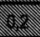 & 45 & 28 & 1275 & 23 & 167 & $3 \times$ & 2667 & $\ldots$ & & 2 & 167 & 20 & 333 & 2 & 9167 & 23 \\
\hline Lecane bulla bulla & & $\mathbb{2}$ & & $\mathbb{N}$ & 167 & 32 & 5 & 4 & & $\mathbb{2}$ & & $\mathbb{R}$ & & s & & $\mathbb{2}$ & & $\mathbb{2}$ & & $\mathbb{N}$ \\
\hline L. hamata & & & & $\mathbb{E}$ & & $\mathbb{2}$ & & $\mathbb{s}$ & & 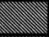 & & $\mathrm{s}^{2}$ & 167 & $2 \times$ & & $\mathbb{2}$ & & $\mathbb{R}$ & & $\mathbb{1}$ \\
\hline L. lenystila & & & & $\mathbb{S}$ & & $\mathbb{N}$ & & $\mathbb{1}$ & & 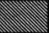 & & $\$$ & 167 & 22 & 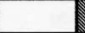 & $\because$ & & $\mathbb{2}$ & 167 & $2 \times$ \\
\hline L. lunaris lunaris & 167. & 20 & & $\mathbb{S}$ & & 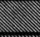 & 833 & 3 & & 3 & & $\mathbb{2}$ & 167 & 23 & & $\mathrm{~m}^{2}$ & & & 833. & 32 \\
\hline L.papuana & 48667 & 230 & 333 & 32 & & 3 & & $\mathbb{1}$ & & $\mathbb{E}$ & & $\$$ & & l & 5. & 32 & & & 48. & 38 \\
\hline$L$ cf remanei & & & & & & $\mathbb{2}^{2}$ & & 3 & & 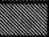 & & $\mathbb{\$}$ & & $\mathbb{N}$ & & 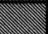 & & & 6333 & 13 \\
\hline L stichaea & & & & & & 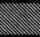 & 167 & 3 & & $\mathbb{1}$ & & $\mathbb{2}$ & & s & 333 & 2 & & & & \\
\hline Lepadella of latusinus & & & & $\mathbb{N}$ & & m & & & & & & $\mathbb{S}$ & 167 & 20 & & $\mathbb{m}$ & & $\mathbb{S}$ & & \\
\hline Lepadella patella oblonga & & & & & & $\mathbb{2}$ & & $\mathbb{2}$ & & $\mathbb{P}$ & & 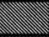 & & & & & & 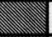 & 2333 . & 3 \\
\hline L. patella patella & & & 167 & 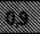 & 333 & 20 & & & & (n) & & $\mathbb{N}$ & 5 & 20 & & $\mathbb{N}$ & & & & \\
\hline Monommata longiseta & & & & & & $\mathbb{3}$ & & & 167. & 32 & & $\$$ & & & & $\sqrt{2}$ & & $\mathbb{1}$ & & \\
\hline Myilina bisulcata & 333 & 2 & & \$ & & 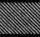 & 167 & 2 & & 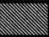 & 167. & 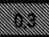 & & m & & $\frac{10}{20}$ & & $\mathbb{2}$ & 167 & $2 \times$ \\
\hline Platyias quadricomis & & & & & & 2 & & & & $\mathbb{2}$ & & & 167 & $2 \times$ & & 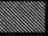 & & & & \\
\hline Polyarthra vulgaris & 54667 & 12 & 21833 & 1 & 89167 & 16 & 5833 & 3 & 26833 & 2 & 167 & 3 & 667 & $2 \times$ & 7 & 20 & 34333 & 3 & 88667 & $2 \%$ \\
\hline$P$. vulgaris f longiremis & & & & & & & & & & & & & & & & & 1667 & 3 & & m \\
\hline S. pectinata & 415 & 14 & 51333 & 28 & 13 & 28 & 6667 & 2 & 8833 & 3 & 167. & 2 & 2 & 178 & 45667 & 32 & 3167 & 3 & 1833 & 20 \\
\hline Testudinella patina patina & & & & & & & & s & & 3 & & $\mathbb{Z}$ & 667. & 30 & & sis & & 3 & & $\$$ \\
\hline Trichocerca capucina & & & & ivis & 3833 & 32 & & $\mathbb{E}$ & & 10 & & $\mathbb{N}$ & 167 & 32 & & & & $\mathbb{\$}$ & & \\
\hline T. cylindrica & 9 & 3 & 833 & 32 & 45 & 38 & 16667 & 3 & 3167 & 2 & 167. & 2 & & & & « & 167 & 3 & & \\
\hline T. cylindrica chattoni & & & & $\mathbb{2}$ & & $\mathbb{2}$ & & $\mathbb{2}$ & & 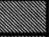 & 5. & 3 & & 3 & & $\$$ & & & 333 & 3 \\
\hline T. dixon-nutalli & & & 45 & $3 \times$ & 333 & 3. & 2667 & 3 & & $\mathbb{2}$ & & & 1167 & 1 & 9667 & 13 & & & & \\
\hline T. gracilis & & $\mathbb{z}$ & & $\mathbb{2}$ & & $\mathbb{1}$ & & $\$$ & 333. & 2 & & & 833 & 2 & 21 & 20 & & & 667 & 2 \\
\hline T. pusilla & 8 & 23 & 25 & 2 & 2833 & 38 & 8667 & 12 & 16333 & 3 & & $\$$ & & $\mathbb{1}$ & 32333 & 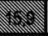 & & 38 & 9833 & 20 \\
\hline T. similis & & & & & & & & $\$$ & & $\$$ & & $\mathbb{2}$ & & $\mathbb{N}$ & & $\mathbb{2}$ & 167. & 3 & 167 & 23 \\
\hline T. similis grandis & 3333 & 22 & & $\mathbb{N}$ & 2 & 34 & 45 & 32 & 5333. & $\$ 2$ & 167. & 3 & 1133. & 30 & 25 & 30 & & 3 & & \\
\hline Bdelloidea & 2667 & 63 & 5 & 22 & 5333 & 62 & 3667 & 30 & 333 & 4 & 1 & 32 & 1667 & 30 & 167 & 201 & 1667 & 32 & 145 & a \\
\hline Subtotal & 28747 & 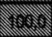 & 26166 & 20 & 452834 & $\%$ & 477168 & 20 & 256175 & $\infty$ & 4335 & 3 & 9282 & 32 & 23522 & 28 & 12851 & 3 & 341498 & 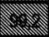 \\
\hline
\end{tabular}


Tabela 5 - Densidades numéricas (ind/m3) dos rotíferos planctônicos nos pesqueiros amostrados no período chuvoso-quente (contin.).

\begin{tabular}{|c|c|c|c|c|c|c|c|c|c|c|c|c|c|c|c|c|c|c|c|c|}
\hline & 21 & & 22 & & 23 & & 24 & & 25 & & 26 & & 27 & & 28 & & 29 & & 30 & \\
\hline & ind./m3 & * & ind. $/ \mathrm{m} 3$ & * & ind./m3 & 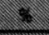 & & $x$ & ind./m3 & $x$ & ind $/ \mathrm{m} 3$ & 4 & ind./m3 & $\%$ & ind./m3 & $\%$ & ind $/ \mathrm{m} 3$ & $x$ & ind./m3 & $\%$ \\
\hline Anuraeopsis fissa & 12667 & 149 & 5833 & 37 & 167 & 04 & & an & 267 & 84 & 3 & 3.3 & 12 & 0.8 & & $=$ & 2 & 178 & 247167 & 48.2 \\
\hline Ascomorpha ecaudis & & & & & & 3 & & 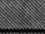 & 2167 & 0.4 & & & & & & & 667 & 103 & & 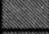 \\
\hline Asplanchna sieboldi & 25 & 18 & 833 & 0.5 & 7667 & 22 & 1667 & 83 & 3. & 05 & 167 & 35 & 4 & 0,3 & & 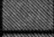 & 1333 & 43 & & $=$ \\
\hline Brachionus angularis & 167 & 0.8 & 5 & 09 & 184333 & 481 & 9667 & 22 & 985 & 178 & & 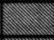 & 6 & 18 & 7 & 28 & 7 & 27 & 333 & 08 \\
\hline B. angularis $\mathrm{f}$ chelonis & & $\mathbb{N}$ & & 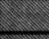 & 833 & 02 & 333 & $9 \%$ & 7 & 1,3 & 19333 & 53 & & 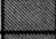 & 33 & 137 & & 1 & & 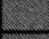 \\
\hline B. bidentata bidentata & 333 & at & & & & & & & 1167 & 02 & & $\mathbb{1}$ & & 18 & & & & 3 & & $=$ \\
\hline B. budapestinensis & & 3 & & & & 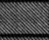 & & 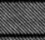 & & 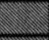 & & 3 & & 3 & & 3 & & 2 & 667 & 21 \\
\hline B. calyciflonus & 1 & 81 & & & 167 & 04 & & 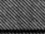 & 5 & 69 & & $\mathbb{N}$ & 4 & 103 & & 3 & 4333 & 12 & 1 & 02 \\
\hline B. calyciflorus f amphiceros & 35 & $\sqrt{14}$ & & & & 3 & & 3 & & (3) & & $\mathbb{2}$ & 2 & 102 & 37667 & $15 ?$ & 1667 & 13.5 & & \\
\hline B. caudatus f personatus & & 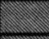 & & 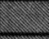 & & 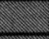 & 6833 & 34 & & 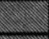 & & 3 & 1 & 3 & 6667 & 28 & 2 & 178 & & 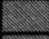 \\
\hline B. falcatus falcatus & 1 & 30 & & 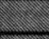 & & 3 & 667 & 9.1 & 99833 & 184. & 12167 & 33 & 44 & 3,5 & 1333 & 0,5 & & 13 & & \\
\hline B. havanaensis & 333 & 0.1 & & 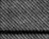 & 167 & 04 & 3833 & 09 & 24667 & 45 & & $\mathbb{N}$ & 184 & 148 & 2667 & 31 & & $=$ & & 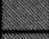 \\
\hline B. mirus f angustus & & & 1167 & 397 & & $\sqrt{3}$ & & 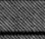 & & & & 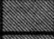 & & & & 3 & & 13 & & L \\
\hline B. patulus petulus & 5 & 02 & & & & 3 & 667 & Q1: & & 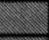 & & 10 & & 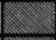 & & 3 & & $=$ & & 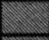 \\
\hline B. patulus v macracanthus & 333 & 0,1 & & & & 3 & & & & 3 & & & & 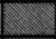 & & 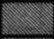 & & $=$ & & - \\
\hline B. quadridentatus quadridentat & 167 & 0.8 & & & 3167 & 08 & & 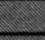 & 167 & 03 & & 2 & & 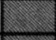 & 667 & 93 & 333 & 92 & & 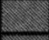 \\
\hline Collotheca sp & & & 5 & 3.1 & & 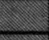 & & 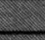 & 3833 & 37 & 5 & 8 & 6 & 0.5 & & 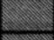 & & 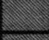 & 5 & 99 \\
\hline Conochilus coenobasis & 167 & 98 & & 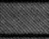 & & - & & 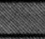 & 5 & 09 & & 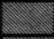 & 2 & 0.2 & & - & 333 & 0.5 & & 8 \\
\hline C. dossuarius & & & 2833 & 19 & & 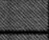 & & 20 & 1. & 02 & & 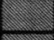 & 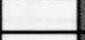 & 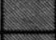 & & 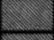 & & 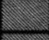 & & 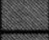 \\
\hline Epiphanes macrourus & 6167 & 24 & 1833 & 12 & 15333 & 43 & 333 & 67 & 7 & 13 & 1 & 33 & 74 & 6,8 & 25 & 1,4 & 14333 & 56 & 35 & 07 \\
\hline Filinia comuta v brachiata & & & & $=$ & & {[} & & 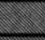 & & 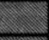 & & 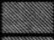 & 2 & 0,2 & & - & 333 & gi. & & E \\
\hline F. opoliensis & 13 & 5.5 & 667 & 04 & 1333 & 02 & 11333. & 24 & 26. & 47 & 167 & 05 & 8 & 03 & 333 & 01 & & 3 & & \\
\hline \multicolumn{21}{|l|}{ F. Iongiseta limnetica } \\
\hline Hexarthra intermedia & 5 & 18 & 345 & 217 & & $\sin ^{3}$ & 155. & 32 & 1167 & 32 & & 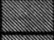 & & 50 & & 3 & & $\mathbb{2}^{3}$ & & De \\
\hline H. mira mira & & & & 3 & & $\mathbb{3}$ & & 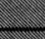 & & 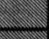 & & 3 & & 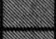 & & 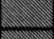 & 4 & 16 & & $n^{\infty}$ \\
\hline Kellicottia bostoniensis & & 2 & 1667 & 15 & & 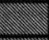 & 2167 & 26 & & 3 & 45 & 2 & & 3 & & 3 & 1 & 12 & & s \\
\hline Keratella americana & 15 & 36 & 7667 & 18 & & 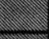 & 124833 & 200. & 75833 & 137 & 61667 & 16 & 1 & 73 & 22 & 22 & 4333 & $\mathbb{1}$ & 333 & 106 \\
\hline K. cochlearis tecta & 4333 & 17 & 5 & 63 & & 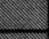 & 4167 & 68 & 16833 & 35 & 333 & 10 & 74 & 159 & 667 & 03 & 15333 & 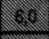 & 167 & 6.3 \\
\hline K. tropica tropica & & & & 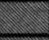 & 833 & 02 & 145 & 33 & 17833 & 32 & & 3 & 14 & 82 & 16 & 67 & 36667 & 114 & 5 & 09 \\
\hline Lecane aculeata & 167 & 0.5 & & 2 & & & & $\otimes$ & & 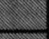 & & 3 & & 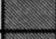 & & 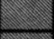 & & $\infty$ & & 1 \\
\hline L. bulla bulla & & & & 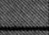 & & 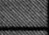 & & 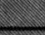 & 1167 & 02 & & 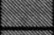 & & 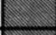 & 667 & 03 & 333 & of & & - \\
\hline L. hamata & & & & & & 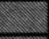 & & 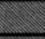 & & $=$ & & 8 & & 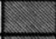 & & 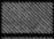 & 333 & 28: & & D \\
\hline L. lewystila & 5 & 02 & & 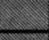 & & 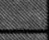 & 167 & 03 & & 28 & & ב & & 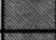 & & 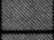 & & 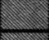 & & 18 \\
\hline L. lunaris lunaris & 1167 & 0.5 & 167 & 0,2 & & s & 167 & 23 & 167 & $0,3$. & 167. & 105 & 6. & os & 667 & 0,3 & & 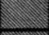 & & - \\
\hline L. (m) pyriformis & & & & 8 & 167 & 24 & & 52 & & 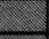 & & 13 & & 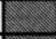 & & 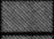 & & 8 & & 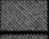 \\
\hline L. papuane & & & & - & & 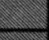 & & - & & 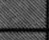 & 333 & 109 & 124 & 87 & 667 & 63 & & $\mathbb{3}$ & & 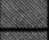 \\
\hline L. cf rotundata & & & & 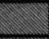 & & & & & & 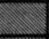 & & 3 & & - & & & & 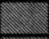 & 5 & 09 \\
\hline L. stichaea & & & 167 & 02 & & & & 3 & & 2 & & 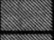 & & $\mathbb{2}$ & & 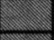 & & 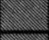 & 167 & 0,3 \\
\hline Lepadella patella oblonga & & & & & & & & 2 & 3833 & 0,7 & & $\sqrt{2}$ & & 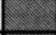 & & 1 & & $s^{2}$ & & 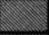 \\
\hline L. patella patella & & & & 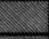 & & & 167 & 93 & & 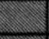 & & 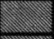 & & 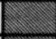 & & & & 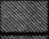 & & 10 \\
\hline Mytilina bisulcata & 667 & 03 & & & 333 & $\infty 8$ & 167 & 03 & & 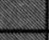 & & 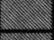 & & 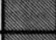 & & 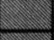 & 667 & 13 & 167 & 0,3 \\
\hline Platyias quadricomis & & & & & & 3 & 12. & 23 & & $=$ & & 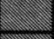 & & 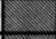 & & 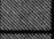 & & 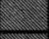 & & 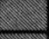 \\
\hline Polyarthra vulgaris & 21333 & 83 & 44 & 277 & 21. & 5,5 & 1695 & 354 & 61667 & 11,1 & 587 & 2 & 164 & 120 & 55 & 229 & 13 & 58 & 3 & 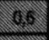 \\
\hline P. vulgaris $\mathrm{f}$ longiremis & & & 75 & 47 & & 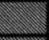 & & 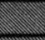 & & 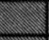 & & 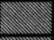 & & 3 & & $\mathbb{2}$ & & $x^{2}$ & & 2 \\
\hline Synchaeta pectinata & 148833 & 578 & 18667 & 107 & 54167 & 123 & 43. & 36 & & 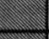 & & 3 & 14. & 20 & & 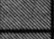 & 79333 & 13 & & 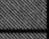 \\
\hline Testudinella petina petina & & $\mathbb{N}$ & & 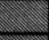 & & 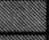 & & 3 & 667. & 0.7 & & 3 & 2. & 12 & & & 333 & lage & & \\
\hline Trichocerca capucina & & & & 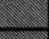 & & 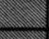 & & & & 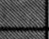 & 167 & 20 & & & & - & & ( & & 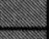 \\
\hline T. cylindrica & & & 2833 & 1,8 & 333 & 90 & & & 1667. & 0,3 & & 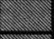 & & 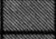 & & 3 & 2333 & 13 & & 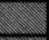 \\
\hline T. gracilis & 15 & 68 & 3. & 19 & & & & & & & & & & & & 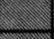 & & $n^{3}$ & 1833 & 63 \\
\hline T. pusilla & 15333 & 60 & 2333 & 1,5 & 8667 & 23 & & & 11. & 20 & 667 & 32 & 24. & 19 & 22333 & 83 & 16667 & 65 & 21. & 39 \\
\hline T. similis grandis & 2167 & 08 & & - & 167 & 0,4 & 167 & 83 & 7333 & 13 & 2 & 35 & 4. & 3.1 & & 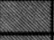 & & (3) & & 2 \\
\hline Bdelloidea & 3667 & 14 & 12. & 75 & 2167. & 0.5 & & & 167 & 0.3 & & 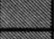 & 16 & 1,3 & & - & & - & 5 & 69 \\
\hline Subtotal & 2571 & 828 & 153667 & 967. & 311 & 78.5 & 49955 & 35,6 & 478265 & 86.4 & 16755 & 203 & 17 & 840 & 232335 & 96,3 & 253664 & 50 & 285834 & 58,4 \\
\hline
\end{tabular}


Tabela 6: Densidades numéricas (ind $/ \mathrm{m}^{3}$ ) dos crustáceos e outros organismos planctônicos presentes nos pesqueiros amostrados no periodo estiagem-frio.

\begin{tabular}{|c|c|c|c|c|c|c|c|c|c|c|c|c|c|c|c|c|c|c|}
\hline & 1 & & 2 & & 3 & & 4 & & 5 & & 6 & & 7 & & 8 & & 10 & \\
\hline & ind $\mathrm{m}^{3}$ & $x$ & \begin{tabular}{|l|}
$\mathrm{nd} . \mathrm{m} 3 \mathrm{3}$ \\
\end{tabular} & 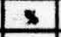 & ind.m3 & $x$ & ind.m3 & $*$ & ind.m3 & x & ind.m3 & $\star$ & $\mathrm{nod} / \mathrm{m} 3$ & $x$ & ind.m3 & $\mathbf{x}$ & $\mathrm{mo} / \mathrm{m} 3$ & 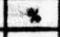 \\
\hline \multicolumn{19}{|l|}{ CLADOCERA } \\
\hline Alone of pappei & & & & & 400 & 0.5 & & & & & & & & & & & & \\
\hline Alonello sp & 4 & 0.6 & & & & & & & & & & & & & & & & \\
\hline Bosmine hegmenn & 713 & 1.0 & & & & & & & & & & & & & & & & \\
\hline Bosmme iongriostins & & & 83035 & 1,3 & 1640 & 0.2 & 23840 & 3,8 & 220 & 0.2 & 80 & 0.1 & 800 & 0,7 & 20 & 0.8 & 380 & 0.7 \\
\hline Bosmmopsis dotetersi & & & 522335 & $\mathbf{E}, \mathbf{7}$ & 280 & 0.3 & 12800 & 25 & & & & & & & & & & \\
\hline Depophie entigue & of & 0.8 & & & & & & & & & & & & & & & & \\
\hline Depomine gesesnen & 4 & 0.6 & & & 400 & 0.5 & & & & & & & & & & & & \\
\hline Diephenosome birge & 194 & 0.3 & 10000 & 20 & 320 & 0,4 & & & 1500 & 0.1 & & & 280 & 0,2 & & & & \\
\hline Diephenosome brevireme & & & & & 80 & 10 & 3820 & 0,6 & & & & 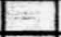 & & 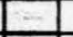 & & $E$ & & \\
\hline Disperacione dedey & & & 20 & 0,2 & & & & & 20 & 0,2 & & & & & & & & \\
\hline Moine micrure & & & & & & & 2320 & Q.4 & 1540 & 0.1 & 320 & 0.4 & & & & & & \\
\hline Mome minute & 8. & 0,1 & 11165 & 14 & 10640 & 13 & 6640 & 1.6 & & & & $\pi$ & 8240 & 7.2 & 60 & 0.2 & 2540 & 0.5 \\
\hline Simocepholus of ildirosths & & & & & & & 20 & 0.3 & & & & $E=$ & & 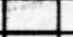 & & \begin{tabular}{|l|l} 
& 1 \\
\end{tabular} & & \\
\hline Chidondere (NI) & 28 & 0,4 & & $E$ & 10) & 0.1 & & & & & & $E$ & & - & & E & & - \\
\hline Irvoconptus spiniter & & & & & 10 & 0.1 & & & 40 & 0,4 & & & & 2 & & & & \\
\hline \multirow[t]{2}{*}{ Sublotal } & 1016 & 0.1 & 632055 & $\mathrm{~ns}$ & 13780 & 1.7 & 49440 & 7,0 & 3380 & 0,3 & 400 & 0.5 & 9320 & 21 & 80 & 22 & 2820 & 0.5 \\
\hline & & & & & & 1 & & 1 & & & & 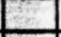 & & 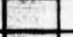 & & 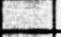 & & 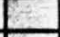 \\
\hline \multicolumn{19}{|l|}{ COPEPODA CYCLOPOIDA } \\
\hline nnuplos & 112551 & 36.7 & & 0,6 & 260 & 0.3 & 2032 & 0.4 & 280 & 23. & 3780 & 80 & 560 & 0.5 & 40 & $\infty 0.1$ & 400 & -8 \\
\hline copopoctios & 748000 & 24 & 115 & $-0,1$ & 150 & 02 & 606 & as & 1600 & 02 & 720 & $a$ & 280 & (2) & 20 & 0.8 & 560 & 0.1 \\
\hline Acenthogrobps sp mechos & & & & E & & - & 520 & 0.8 & & 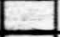 & & - & & 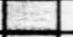 & - & 5 & & \\
\hline Acerthogolops ap fillmoes & & - & & E & & E & 140 & 02 & & E & & 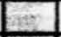 & & sate & & Ex & & F \\
\hline Eucydops pseudoensilor mechos & & & & 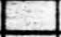 & & E & & Ex & & 2 & & 5 & & Ext & 20 & 50 & 100 & 02 \\
\hline E. psecudoensitur fimmeas & & & & 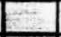 & & 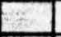 & & E & & 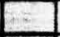 & & $=$ & & $E$ & & $x=1$ & 40 & 07 \\
\hline Mosocychops longontus finmeas & & & & 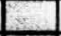 & & E & & 5 & & . & & 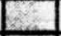 & & Winas & & Ei] & 40 & 0,7 \\
\hline M. longinetus filmoes avedes & & & & . & & . & & 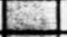 & & a & & E & & $E$ & & Eas & 20 & 500 \\
\hline Alorogoclops sp finmess & & & & Z1 & & 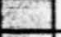 & & 5 & & 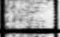 & & E & & 5 & & E & 200 & 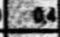 \\
\hline Thermogectops decipiens mectios & 1457) & 02 & 15 & 502 & & & & E & & 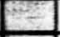 & & $E$ & 201 & 02 & & 5 & & (2) \\
\hline T. docipiens fimpers & 842 & 0.1 & 50 & 20,7 & 201 & 0.2 & & $E$ & & E & & 5 & & & & Wing & & 5 \\
\hline T. docipiens filimeas ovedas & 130. & 0.2 & & 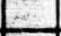 & & w & & E & & 5 & & 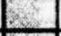 & & 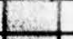 & & 5 & & - \\
\hline Thermogydops inversus mechos & 2124 & 0.3 & 5 & 0,6 & 50 & 0.7 & & $\square$ & 660 & 0.6 & & 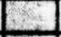 & & 2 & & E2: & & 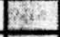 \\
\hline T. miversus fomeas & 2364 & a.3 & & D. & 10) & 0.1 & & 国 & 480 & 2.55 & & 5 & & 5 & & EI & & $E$ \\
\hline T. nuversus fimeas ovedas & 1336 & 0.2 & & E & & $=$ & & E & 40 & Q.4. & & Z & & E & & 6 & & 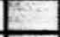 \\
\hline Tropogropose prasinus mectios & & & & 5 & 20] & 02 & & $5=1$ & & \pm & & 5 & & E. & & 20 & & E. \\
\hline T. prasinus fimmess & & & & $1=$ & 10 & 21 & & Ein & & E. & & ED & & Exgs & & ma & & $E$ \\
\hline \multirow[t]{2}{*}{ Sublotal } & 195703 & 2.2 & 196 & 0.2 & 520 & 0.6 & 3988 & 0.6 & 3140 & 0,3 & 4480 & 5.0 & 840 & 0,7 & 80 & 0.2 & 1220 & 0.2 \\
\hline & & $\square$ & & & & 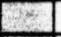 & & E & & 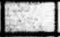 & & 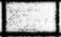 & & - & & Cas & & 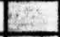 \\
\hline COPEPODA CALANOIDA & & 20 & & E & & 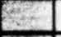 & & 21 & & 5 & & 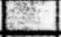 & & Ex & & 52 & & 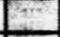 \\
\hline namplios & & 5 & & 22 & 70 & 400 & & EIII & 100 & 02 & 4320 & 567 & 100 & 150 & & HA & 3200 & 0.6 \\
\hline copepoditios & & 5 & & 2 & 40) & 0.5 & 40 & Es & & 잉 & & 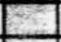 & & एव: & & 殒 & 140 & 0,3 \\
\hline \multirow[t]{2}{*}{ Subleal } & & . & & Esis & 110 & 202 & 40) & 26 & 100 & 8 & 4320 & 57 & & 5 & & nes & 460 & 08 \\
\hline & & Ple & & Ex & & 5 & & Tis & & Exis & & 19] & & reat & & Ee: & & Wo: \\
\hline \multicolumn{2}{|l|}{ COPEPODA POECILOSTOMATOIDA } & 5 & & - & & E & & 20 & & 프. & & एक्ष & & E.1 & & Eखा & & D. \\
\hline ntuplos & & $=$ & & $E$ & 2000 & 02 & & {$[1$} & & 5 & & Eहा & & Ining & & REI & 200 & 206 \\
\hline \multirow{2}{*}{ coppepodihos } & & 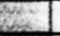 & & Eing & & Ext & & Ex & & In: & & 5 & & - & & स्र & & 5 \\
\hline & & the & & E] & & Ex & & WI & & 8 & & Ex & & III] & & $x$ & & 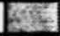 \\
\hline CHAOBORIDAE & 1555 & 02 & & 3.9 & & - & & 1 & & Eal & & E & 20 & 152 & 20 & ines & & 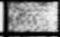 \\
\hline CHIRONOMIDAE & & 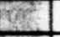 & 20 & 20 & 80 & 1,0 & & Bis & & 21 & 20. & 503 & & Fe. & & खूमा & & 5 \\
\hline PLECOPTERA & & $E$ & & 0.6 & & $E$ & & 5 & & 역 & & 5 & & Fin & & 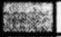 & & 팔 \\
\hline OLIGOCHAETA & & 5a & & $E$ & & W & & 1 & & E- & & 5 & & Ea & & (2) & 120 & 02 \\
\hline NEMATODA & & 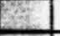 & & 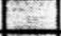 & & $E$ & & $E$ & & 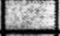 & & [8] & 20 & Q2 & & 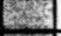 & & 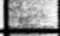 \\
\hline Totai de orgenismos ns amoetra & 718758 & 1000 & 807075 & 1000 & 823150 & 1000 & 624768 & Hese & 1040580 & 1000 & 76340 & 4000 & 114500 & 1000 & 358200 & 100 & 552540 & $2+1000$ \\
\hline
\end{tabular}


Tabela 6: Densidades numéricas (ind $/ \mathrm{m}^{3}$ ) dos crustáceos e outros organismos planctônicos presentes nos pesqueiros amostrados no periodo estiagem-frio (contin.).

\begin{tabular}{|c|c|c|c|c|c|c|c|c|c|c|c|c|c|c|c|c|c|c|c|c|}
\hline & 11 & & 12 & & 13 & & 14 & & 15 & & 16 & & 17 & & 18 & & 19 & & 20 & \\
\hline & ind.m3 & $\$$ & \begin{tabular}{l|l}
$\mathrm{nd} . \mathrm{m} 3$ & \\
\end{tabular} & * & $\mathrm{md} / \mathrm{m} 3$ & 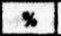 & $\mathrm{md} \cdot \mathrm{m} 3$ & x & ind.m3 & * & ind.m3 & $\%$ & ind.m3 & $\%$ & ind.m3 & $\%$ & ind.m3 & s & ind.m3 & \% \\
\hline \multicolumn{21}{|l|}{ CLADOCERA } \\
\hline Bosmine longrostins & & 8 & & & & & & & 9900 & 12 & & 39 & & 0,2 & 1 & 0.5 & & 0,3 & & 0,3 \\
\hline Bosminopsis deterti & & & & & & & & 2 & & - & & $E$ & 16A & 0,8 & 2 & 02 & & 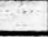 & & \\
\hline Daphnie jovem & & & & 5 & & & & & & 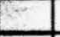 & & 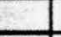 & 2 & \begin{tabular}{|l|}
0,1 \\
\end{tabular} & & 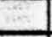 & & & & \\
\hline Dephnie gessnen & & & 20) & 0.1 & & & & a & & $F$ & & 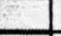 & & a & & 02 & & - & & \\
\hline Diephenosoma birgei & & & & & & & & & 180 & 0,2 & 228 & 1,3 & 12. & 0.7 & & - & & 0,1 & & \\
\hline Diephenosoma brewreme & & & 240 & 02 & & & & & 460 & 0.5 & & & & $\square$ & & 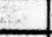 & & 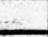 & & \\
\hline Mecothrix latcomis & & & & & & & & & & & & & & & 2 & 02 & & & & \\
\hline Mana minuta & 640 & 09 & $20 \mid$ & 0.1 & 40 & 0.2 & $20 \mid$ & 02 & 3940 & 0,4 & & & 56) & 0,3 & 12 & 0.7 & & - & 3696 & 1.4 \\
\hline thoconplus spiniter & 20 & 0,3 & & 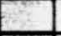 & & & & 5 & & E. & & 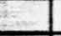 & & $\square$ & 2 & 02 & & tz & & - \\
\hline \multirow[t]{2}{*}{ Subtotal } & 600 & 1.0 & 280 & Q2 & 40 & Q2 & $20 \mid$ & 02 & 14080 & 15 & 928 & 6.1 & 238. & 1,3 & 12) & 0.7 & 12 & 0,4 & 392 & 1,4 \\
\hline & & & & 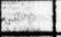 & & $\square$ & & $\square$ & & & & 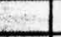 & & 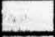 & & $\square$ & & 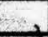 & & - \\
\hline \multicolumn{21}{|l|}{ COPEPODA CYCLOPOIDA } \\
\hline nauplios & 20 & 0,3 & 4780 & 3,1 & & $\square$ & 201 & 0.2 & 2520 & as & 2306 & 44,0 & 2 & 0,1 & & 02 & & $n, 4$ & 96 & 0.3 \\
\hline copepoditios & & $\square$ & 740 & 0,5 & & - & & 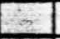 & 1720 & 02 & 1934 & 1,7 & & 2 & & 02 & 32 & 1.1 & 116 & 0,4 \\
\hline Eucycleps pseudionsitior machos & 20 & 03 & & 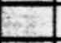 & & $=$ & & Ex & 40 & 24 & & 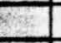 & & 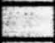 & & 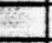 & & $=$ & & \\
\hline Mesoconclops longiselus machos & & 5 & & E & & 5 & & 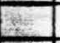 & & 2 & & 29 & & a & & -1 & & 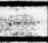 & & 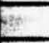 \\
\hline Mertacyctops mendocinus machos & & 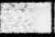 & & $E$ & & Es & & $\square$ & & E. & & 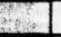 & & $\square$ & & $\square$ & & 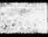 & 24 & 0,8 \\
\hline M. mandocinus femeas & & & & E & & $\square$ & & E & & E & & - & & D & & $\square$ & & a & & 0,3 \\
\hline M. mendocinus fimeas ovadas & & 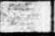 & & 5 & & $\square$ & & 5 & & $\Rightarrow$ & & 5 & & $E$ & & 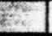 & & 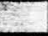 & 2 & 0,7 \\
\hline Thermocyctops docipiens machos & & 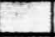 & & 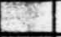 & & $\square$ & & E & & 5 & & 0,1 & & E & & 6 & & 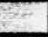 & & \\
\hline Thermocyctops inversus machos & & & & 5 & & $E$ & & 3 & & 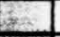 & 6 & 0,3 & & E & & 3 & & - & & E \\
\hline Thermocyctops minueus machos & & 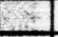 & 20 & Qs & & $E$ & & $E$ & & $E$ & & 0 & & $E$ & & $\Leftrightarrow$ & & 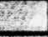 & & $E$ \\
\hline \multirow[t]{2}{*}{ Sublotel } & 40 & 0,6 & 5520 & 36 & 0 & $\square$ & 20) & 02 & 4280 & 04 & 431 & 208 & 6] & 0,3 & & 0,3 & 72 & 26 & 248 & 0.9 \\
\hline & & & & 2 & & 0 & & E] & & E. & & 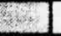 & & $\square$ & & 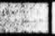 & & 2 & & - \\
\hline COPEPODA CALANOIDA & & E & & 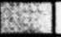 & & 2 & & स्य & & 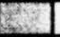 & & Ix) & & $\square$ & & $\mathrm{Em}$ & & Et & & 2 \\
\hline natuplos & 20] & es & 1200 & e. & & 2 & & 8 & & 50 & 3666 & 23 & & Es & & 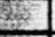 & & 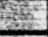 & & $E$ \\
\hline \multirow[t]{4}{*}{ copepoditios } & & - & & a & & E. & & 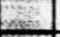 & & 5 & 1534 & 85 & & $i$ & & 3in & & - & & 0.7 \\
\hline & & & & 5 & & E. & & $\ldots$ & & E & 38 & (62) & & $\square$ & & +1 & & 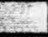 & & $E$ \\
\hline & & & & 5 & & $\square$ & & \pm & & Eate & 54 & 03 & & 5 & & 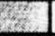 & & 5 & & E \\
\hline & & -4 & & Wa & & $\square$ & & 2 & & 52 & 7 & 0,1 & & $\ldots$ & & 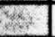 & & 5 & & E \\
\hline \multirow[t]{2}{*}{ Sublotal } & 20 & 0.3 & 1280 & $\infty$ & 0 & 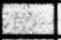 & of & 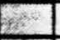 & & 5 & 52 & 28 & & $\square$ & & $\square$ & & + & & 0,7 \\
\hline & & 5 & & $E$ & & का & & 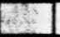 & & 5 & & 2 & & 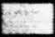 & & $\square$ & & $E$ & & $E$ \\
\hline COPEPOOA HARPACTICOIDA & & {[} & & E. & & 2 & & 28 & & E. & & \pm 1 & & $\square$ & & $\rightarrow$ & & $E$ & & . \\
\hline \multirow[t]{2}{*}{ copepoditios } & & $\square$ & & 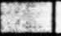 & & 2 & & 2 & & Ex & & 5 & & 2 & & 02 & & 07 & & E \\
\hline & & & & 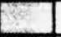 & & 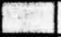 & & $\square$ & & E & & $E$ & & $\square$ & $L$ & $\square$ & & 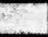 & & \\
\hline \multicolumn{2}{|l|}{ COPEPODA POECILOSTOMATOIDA } & & & Fin & & Eis & & $E$ & & $E$ & & I & & E & & 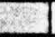 & & 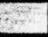 & & 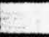 \\
\hline ntuphos & & 5 & & $x=1$ & 280 & 01 & 100 & a & 40 & a) & & 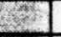 & & E & & $e^{2}$ & & 2.3 & 4) & 0.4 \\
\hline copepoditos & & $\Rightarrow$ & 20) & [0s] & & Eat & & Eस] & & 2 & & 3 & & $E$ & & 然 & & 43 & & 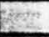 \\
\hline \multirow[t]{2}{*}{ adulios machos } & & 용 & & 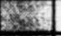 & & Exis & & ast & & 5 & & as & & 01 & & (4) & & है। & & 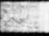 \\
\hline & & 58 & & 5 & & 20 & & 5 & & Eस] & & (73) & & 25 & & सा & & $x$ & & Ex: \\
\hline CHAOBORIDAE & & 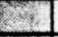 & & Wes & & Eas & & 8 & 60) & 3 & & (2) & & 20 & & (x) & & 28 & & Exest \\
\hline CHIRONOMIDAE & & De & & - & & Fat & & 8 & & 201 & & 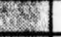 & & En & $2]$ & 02 & & 8 & 2 & 0.7 \\
\hline OUGOCHAETA & & - & & $E$ & & En & 40) & 65 & 80 & 02 & & 21 & & 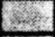 & & 2 & & 38 & & 0,7 \\
\hline Total de organismos na amostra & 678280 & $\infty$ & 151280 & $\operatorname{mos}$ & 200300 & Leal & 87820 & 1000 & 969000 & 1000 & 1874 & 46 & 19716 & 10 & 18396 & 60 & 2878 & in & 286562 & 10 \\
\hline
\end{tabular}


Tabela 6: Densidades numéricas (ind $/ \mathrm{m}^{3}$ ) dos crustáceos e outros organismos planctônicos presentes nos pesqueiros amostrados no periodo estiagem-frio.

\begin{tabular}{|c|c|c|c|c|c|c|c|c|c|c|c|c|c|c|c|c|c|c|c|c|}
\hline & 21 & & 22 & & 23 & & 24 & & 25 & & 26 & & 27 & & 28 & & 29 & & 30 & \\
\hline & ind./m3 & $\%$ & ind $/ \mathrm{m} 3$ & * & $\mathrm{mod} / \mathrm{m}^{3}$ & $\%$ & ind $/ \mathrm{m}^{3}$ & \% & ind $/ \mathrm{m} 3$ & $\%$ & ind. $/ \mathrm{m} 3$ & $\boldsymbol{x}$ & ind./m3 & $\%$ & ind. $/ \mathrm{m}^{3}$ & $\%$ & ind $/ \mathrm{m}^{3}$ & $\mathbf{x}$ & ind $/ \mathrm{m}^{3}$ & $\$$ \\
\hline \multicolumn{21}{|l|}{ CLADOCERA } \\
\hline Bosmina iongroserens & & & 506 & 35 & & & 1584 & 1,4 & 56 & 0,2 & 22934 & 12,3 & 152 & 52,6 & 3 & 3,1 & 54 & 9,6 & 6566 & 4,9 \\
\hline Bosmine longirostis (machos) & & & & +1 & & & & & & & & & & & & & & & 46 & 0,3 \\
\hline Bosminopesis detersi & 2 & 0.3 & & 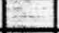 & & & 6 & 0.5 & & & & & & & 2 & 0,3 & & & & \\
\hline Dephnie jovem & & $E$ & & $E$ & & 5 & & 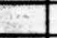 & & - & & $=$ & & 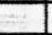 & & se & & 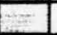 & & \\
\hline \multicolumn{21}{|l|}{ Dephnia gessneri } \\
\hline Dienphenosome brgei & & & 2 & 12 & & & & 0,9 & 24 & 0.9 & 228 & 0,1 & & & & & 4 & 0.7 & 16 & 0.8 \\
\hline Dimphenosome brevireme & & & 48 & 60,3 & & & & & 4 & 0.2 & 48 & a. & 6 & 0,3 & & & & & & \\
\hline \multicolumn{21}{|l|}{ Mocrothrix hebcomis } \\
\hline Nome minete & 96 & 1,5 & 1 & 26 & 916 & a.6 & 15 & 0,1 & 152 & 0,6 & 1 & 0.5 & 6 & 0.3 & & & 666 & 1,2 & 6 & 0,4 \\
\hline \multicolumn{21}{|l|}{ Hoconptus spinitor } \\
\hline \multirow[t]{2}{*}{ Subtotal } & 98 & 1.6 & 850 & 55,0 & 916 & 3.6 & 184 & 1.6 & 272 & 0.2 & 2322 & 22.5 & 1532 & 50.9 & 32 & 3,3 & 616 & 1,9 & 6724 & 5,9 \\
\hline & & & & 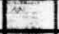 & & & & & & 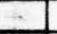 & & 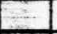 & & & & 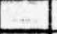 & & & & \\
\hline \multicolumn{21}{|l|}{ COPEPODA CYCLOPOIDA } \\
\hline nituplios & 18 & 0.3 & 8 & 205 & 1 & Q,4 & 293 & 25,4 & 36666 & u.5. & 2 & 0.2 & 12 & 3,5 & 4 & 0,4 & 1434 & 80.5 & 8634 & 6,4 \\
\hline copepoditos & 32 & 0.5 & 12 & 0.7 & 68 & 0,3 & 966 & 0,8 & 8534 & 3.4 & 44 & 0.2 & 22 & 0.8 & 4 & 0,4 & 21 & 3,5 & 2266 & 1,7 \\
\hline \multicolumn{21}{|l|}{ Eucyclops pseudoensiter machos } \\
\hline \multicolumn{21}{|l|}{ E. pseudioensilior theas } \\
\hline \multicolumn{21}{|l|}{ E. poncutoenselfor fitmeas ovadas } \\
\hline \multicolumn{21}{|l|}{ Mosocyctops ionglestus machos } \\
\hline Mulocyctops mendocanus machos & & E & & $E$ & & $=$ & & $E$ & 216 & 29 & 2 & 0.2 & & + & & - & 1166 & 28 & 2 & 0,2 \\
\hline M mandocinus temeas & & 8 & & 8 & & $\mathrm{E}$ & & 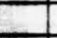 & 72 & 0.3 & 2 & 0.2 & & - & & E & 9 & 1,7 & 4 & 0.3 \\
\hline M mendocinus theas ovadas & & 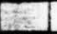 & & E: & & 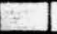 & & 5 & 24 & 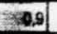 & & E- & & - & & E & 74 & 0.1 & 2 & 0,1 \\
\hline Thermocyciops decipiens machos & & 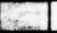 & & D. & & 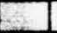 & 6 & 0.5 & 136 & 0.5 & & Enitis & & 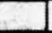 & & 5 & & 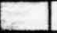 & & \\
\hline \multicolumn{21}{|l|}{ T. decipiens fomeas } \\
\hline Thermocyclops inversus machos & 2 & 0.3 & & Ee? & & 5 & & 5 & & 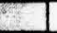 & & $D^{2}$ & & 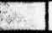 & & Ses & & 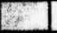 & & \\
\hline Tropocyctops prasinus machos & & & & WM: & & $\square$ & 12 & 0.1 & & ?11 & & 3 & & 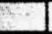 & & $x^{2}$ & & 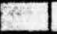 & & \\
\hline T. prosenus timeas & & $E$ & & E. & & E & 1 & and & & 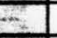 & & 5 & & 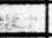 & & 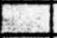 & & 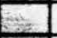 & & 5 \\
\hline T. prosinus fitmeas ovadas & & 3 & & sis & & 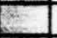 & 12 & 0.1 & & 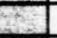 & & 28 & & 5 & & 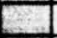 & & 5 & & 6 \\
\hline Subtotal & 52 & 0,8 & 2 & inas & 92 & $0 A$ & 3296 & 86,3 & 45648 & 28 & 5 & as & 124 & 4 & 8 & 208 & 14674 & 522 & 1928 & Ins \\
\hline & & E & & 15e & & 5 & & 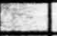 & & $z^{2}$ & & 5 & & 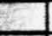 & & 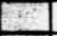 & & 3 & & 2 \\
\hline COPEPODA CALANOIDA & & 2 & & Exis & & 2y: & & 5 & & 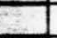 & & 5 & & 6 & & z. & & 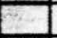 & & \\
\hline ntuphos & & 0,3 & 232 & 243 & & . & 6 & 0.6 & 24 & 0,0 & & $\square$ & & 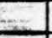 & & E. & & 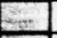 & & $\square$ \\
\hline copepoditos & & 5 & 28 & Fing & & $\Rightarrow$ & & 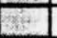 & 16 & 208 & & Ex & & 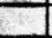 & 4 & 30 & & $\sqrt{8}$ & & Fक्ष \\
\hline Notodleptomus ap machos & & & & 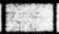 & & E & & 5 & & E & & ins & & E & & $\cos$ & & 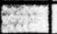 & & 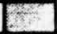 \\
\hline Notodieptomus sp itimeas & & - & & Din & & wh & & 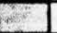 & & we & & $=$ & & 5 & & 5 & & $\sqrt{2}$ & & 20: \\
\hline Notodieptomus sp timeas ovadas & & है: & & 2 & & 5 & & Exis & & 5 & & wis & & $x=$ & & 5 & & + & & 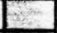 \\
\hline Subtotal & & 0,3 & 2 & $\sqrt{205}$ & & sin & 66 & 0,6 & 256 & 20, & & in & & 5 & 4 & $20 \mathrm{~A}$ & & and & & W. \\
\hline & & 更 & & 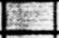 & & 5 & & 5 & & Fe & & Fi: & & 8 & & 2 & & 2 & & $\square$ \\
\hline COPEPODA HARPACTICOIDA & & & & : & & 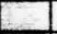 & & - & & & & 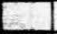 & & E & & - & & E & & \\
\hline copepoditos & & S & & 2 & & $E$ & & $E$ & & - & & 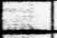 & & 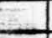 & & 5 & & 5 & & E \\
\hline & & Dis & & Inas & & Ex & & 6 & & Ea & & ias & & Cat & & E & & $E$ & & 5 \\
\hline COPEPODA POECIL OSTOMATOID & & Ex: & & Sel & & 5 & & 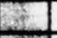 & & 5 & & 2at & & 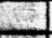 & & 5 & & 2 & & E \\
\hline ntauplios & & 202 & 6 & 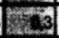 & & 102 & & 8 & & 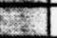 & & 25 & & 6 & & reag & & Fo: & & \\
\hline copepocititos & & Fin & & .2] & & $2 \times 8$ & & ए2] & & 9 & & E. & & 5 & & 8 & & 피 & & 5 \\
\hline adullos machos & & 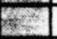 & & stat & & - & & tit & & xy & & 2 & & $x$ & & Dis & & कint & & 2 \\
\hline & & Ex=- & & in: & & $\square$ & & 28: & & D. & & (a) & & Wa] & & एक & & War & & E \\
\hline CMAOBOFIDAE & & $x$ & 2 & at & & E & & El: & & 5 & & 2 & & 5 & & S: & & 5 & & 5 \\
\hline CHIIRONOMDAE & & an & 2 & Ea & & 201 & 6 & -2.5 & & Es & & E: & 6 & $\infty$ & & 52 & & 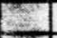 & & 2 \\
\hline OUEOCHAETA & & 8 & & (2) & 6 & 202 & & aㅏㄹ & & 8 & & 2 & & Ex & 2 & 203 & & 25 & & S1 \\
\hline NEMATODA & & 5 & & (2) & & Es & & 2 & & se & & 2 & & 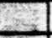 & & 0 & & $E$ & & 5 \\
\hline OSTRACOOA & & 20 & & ing & 6 & 202 & & $\$$ & & 2 & & - & & 2 & & 6 & & 5 & & 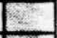 \\
\hline Total de organismos na amosta & 62204 & 10 & 17214 & 10 & 26134 & 1,0 & 115198 & 10 & 253246 & 10 & 185878 & 10 & 289 & 1.0 & $\overline{963}$ & 1,0 & 565 & 62,0 & 13624 & 1,0 \\
\hline
\end{tabular}


Tabela 7: Densidades numéricas (ind $/ \mathrm{m}^{3}$ ) dos crustáceos e outros organismos planctônicos presentes nos pesqueiros amostrados no período chuvoso-quente.

\begin{tabular}{|c|c|c|c|c|c|c|c|c|c|c|c|c|c|c|c|c|c|c|c|c|}
\hline & 1 & & 2 & & 3 & & 4 & & 5 & & 6 & & 7 & & 8 & & 9 & & 10 & \\
\hline & ind. $/ \mathrm{m} 3$ & *) & ind. $/ \mathrm{m} 3$ & $\mathbf{x}$ & ind./m3 & \%) & ind. $/ \mathrm{m} 3$ & $x$ & ind. $/ \mathrm{m} 3$ & $\%$ & ind./m3 & 3 & & * & ind./m3 & $*$ & ind./m3 & x) & ind./m3 & $\%$ \\
\hline \multicolumn{21}{|l|}{ CLADOCERA } \\
\hline Alona cf poppei & & & & 0.2 & 3 & 0,2 & & & & & & & & & & & & & & \\
\hline Alona of retengula & & L & & & & & 8 & 1,0 & & & & & & & & & & & & \\
\hline Bosmina longrostris & 14 & 0,2 & 2196 & 1,2 & 1948 & 12,2 & 65 & 0.8 & & & & & & & & & 612 & 1,3 & 2 & 0.9 \\
\hline Bosminopsis deitersi & 1 & 0.1 & 54 & 0,3 & & & & & & & & & & & & & 256 & 0.5 & & \\
\hline Ceriodaphnie comuta nigaudi & & & & 1 & & & & & & & & & & & 4. & 0,5 & & - & & \\
\hline Dephnia gassnen & & & & & 4. & 0.2 & & & & 5 & & & & & & 5 & & - & & \\
\hline Diaphenosome birget & 3 & 0,4 & 292 & 0.2 & 14 & 0.6 & 147. & 1,8 & 32 & 0,9 & & & 1. & 0.3 & & $E$ & 876 & $1,1,8$ & 6. & 0,3 \\
\hline Diaphenosoma brevireme & & & 28 & 0,2 & & & & & & - & & & & & & 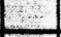 & 28. & 0.6 & & \\
\hline Disperatona deday & & & & & & c. & & - & & & & & 7) & 0.2 & & & & L & & \\
\hline Macrothnx SP & 2 & 0,3 & & & & & & & & & & & & & & D & & $E$ & & \\
\hline Macrothrix trisenelis & & & & & & 5 & 6] & 0.7 & & 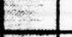 & & & & & & & & - & & \\
\hline Mone minuta & & & 28 & 0.2 & 244 & 1,5 & 55 & 0.7 & 76 & 0,2 & 536 & 3,8 & 13 & 0.3 & 1 & 0,1 & 676 & 1,4 & 124 & 0.5 \\
\hline Simocephelus ef lectirostins & & & & & 2 & 0,1 & & 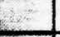 & & $\square$ & & & & & & $\mathrm{L}$ & & A. & & \\
\hline Iyocyptus spintifer & & & & E & 24 & 0,1 & 3. & 0.4 & & 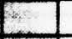 & 4. & 0,3 & & & & 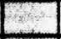 & & It & & \\
\hline \multirow[t]{2}{*}{ Subtotal } & 2 & 0,3 & 333 & 1.8 & 2365 & 14,8 & 284 & 3,4 & 18 & 0,3 & 54 & 3.9 & 138 & 0.4 & 14 & 0,2 & 27 & 3.5 & 132 & 0,6 \\
\hline & & & & 3 & & & & 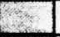 & & 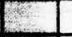 & & 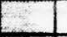 & & E & & 5 & & E & & 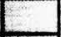 \\
\hline COPEPODA CYCLOPOIDA & & & & 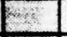 & & 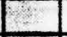 & & Wh & & Fis & & 5 & & E & & D. & & & & $E$ \\
\hline natuplios & 74 & 100,0 & 6 & 83 & 28 & $a_{2}$ & 79 & 0 & & E. & 1588 & $\mathbf{1 1 , 4}$ & 23 & 0,6 & 11 & 0.1 & 232 & 0,5 & 27 & 0.1 \\
\hline copepoditos & 36 & 5.1 & 24 & 0,1 & 2 & 0.9 & 83) & 1.0 & 3 & 0,8 & 1224 & 8,8 & 13 & 0,3 & 9 & 0,1 & 388 & 0,8 & 63 & 0.3 \\
\hline \multicolumn{2}{|c|}{ Eucyclopos psevudoensifer machos } & & & 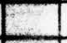 & 1 & 0.6 & 3 & 0.4 & & 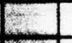 & 5 & 0.4 & 1 & 0.3 & 2 & 0.3 & & $E$ & 1 & 0,4 \\
\hline E. pseudoensifer fommeas & & $E$ & & 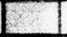 & & E & & 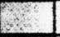 & & 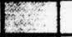 & 8. & 0,6 & 1 & 0,3 & & - & & L & 2 & 0,9 \\
\hline Mesocyctiops Iongisotus mach & 1 & 0.1 & & 5 & & E & & E & & Ex: & & E & & L & & Di. & & E & & $\square$ \\
\hline M. longisetus fomeas & 6 & 0.9 & & 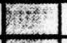 & & 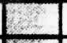 & & 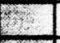 & & 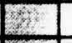 & & $E$ & & E & & 5 & & 5 & & 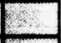 \\
\hline Thermocyctips decipiens med & 5 & 0,7 & 2 & 0,2 & & 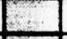 & & 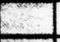 & 1 & 0.3 & & $E$ & & $\mathrm{z}_{\mathrm{B}}$ & & 10 & 152 & 0,3 & & 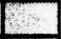 \\
\hline T. decipiens fomeas & 7 & 1.0 & & 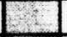 & & E. & & E & & 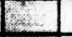 & & L & & & & La & 32 & 207 & & 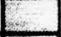 \\
\hline T. decipiens fomeas ovadas & & 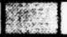 & & [at & & Ext & & 5 & & ". & & $E$ & & 5 & & No & 1 & {$[102]$} & & $E$ \\
\hline Thermocyctips inversus mach & 5 & 0.7 & & E춤 & & Ei: & & 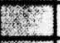 & & 5 & & $E$ & & $E$ & & 10 & 1 & 5 & & 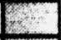 \\
\hline \multirow[t]{2}{*}{ Subtotal } & 188 & 6.5 & 86 & 6 & 58 & 20 & 165 & 20 & 4 & 0.1 & 2825 & 23 & 362 & 0.8 & 22 & 203 & 85 & 5 & 93 & 80,4 \\
\hline & & $E$ & & 5: & & E. & & 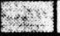 & & $=$ & & Da & & 5 & & 1 & & 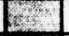 & & E.: \\
\hline COPEPODA CALANOIDA & & E & & $E=1$ & & $1=$ & & 5 & & 15 & & D & & E & & $\square$ & I & 1 & & 5 \\
\hline náuplios & & 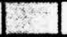 & 68 & 04 & 116 & 0.7 & & 6 & 1) & 0,3 & & 5 & & .. & & ER: & 48 & 120 & 67 & 0.3 \\
\hline copepoditos & & - & 16 & 0.9 & & E & & $\square$ & 8 & 0.2 & & E & & D & & D. & 16 & 0,3 & 12 & 0.5 \\
\hline Notodiaptomus sp machos & & E & & 205 & & 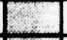 & & 6 & & 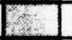 & & E. & & E & & III & & 12 & & $\square$ \\
\hline Notodiaptomus kiefen machos & & 5 & & $E$ & & $E$ & & 2 & & : & & 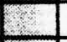 & & 5 & & Win & 7 & I. & 1 & 04 \\
\hline \multirow[t]{2}{*}{ Subtotal } & & 5 & 85 & 56 & 116 & 10.7 & & $\Leftrightarrow$ & 18) & 0 & & $x^{2}$ & & 5 & & 2 & 64 & [en & 8 & 03 \\
\hline & & L & & E. & & $\square$ & & $\infty$ & & L & & 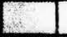 & & L & & 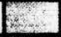 & & ए1 & & I \\
\hline \multicolumn{2}{|l|}{ COPEPODA HARPACTICOIDA } & L & & E- & & E. & & Ea & & E & & L & & 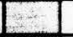 & & Ex & & E & & 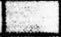 \\
\hline \multirow[t]{2}{*}{ copepoditios } & & E. & & DI & & $\square$ & & [-2 & & W: & & E & & E. & & 0.1 & & Ead & & L \\
\hline & & T". & & 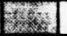 & & I.] & & [a] & & 1.5x & & E & & To & & [X? & & E.2I & & Ex \\
\hline \multicolumn{2}{|c|}{ COPEPODA POECILOSTOMATOIDA } & E: & & Divi & & 102 & & C2 & & Ex & & 3. & & $=0$ & & 18-2 & & 1. & & 2.: \\
\hline nauplios & & -21 & & - & 1 & 105 & & 21 & & (3) & 2 & (2) & 5 & (E) & 48 & Wos & & 26a & & 5 \\
\hline Copepoditos & & 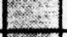 & & 102 & & 10 & 3 & 04 & & Diu & 1 & 207 & & [a] & & 2.2 & & 120 & & 0 \\
\hline \multirow[t]{2}{*}{ adultos machos } & & 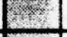 & & 12 & & $E$ & & 201 & & 8 & & 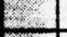 & & 2003 & & Con & & $E$ & & 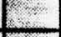 \\
\hline & & 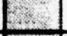 & & 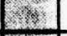 & & E. & & 2 & & 10 & & L & & 101 & & E: & & 1 & & 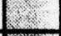 \\
\hline CHAOBORIDAE & & 2 & 1 & Les & & D. & & 2 & & E⿰氵 & & E. & & 10 & & 62: & & $E=1$ & & 50 \\
\hline CHIRONOMIDAE & & 04 & & +1 & 12 & 0.7 & 9 & 002 & & 10.6 & 4 & 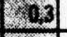 & 4 & 80 & & 12 & & 10 & 2 & 109 \\
\hline OLGOCHAETA & & 12: & & 8 & & 18 & & . & & 20: & & 10 & & 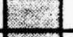 & & 20 & & 102 & & 1 \\
\hline NEMATODA & & +1 & & 121 & & 12 & & 2 & & 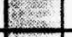 & 1 & $\mid 0,7$ & & 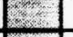 & & 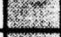 & & 10 & & 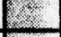 \\
\hline Total de organismos na amost & 7417 & 100 & 1863121 & {$[1000$} & 1622 & 100 & 83793 & 100 & 36655 & $|100|$ & 139397 & 1000 & 383398| & $1500 \mid$ & 74937 & 1200 & 488188 & 1.100 & 2347] & 100 \\
\hline
\end{tabular}


Tabela 7: Densidades numéricas (ind $/ \mathrm{m}^{3}$ ) dos crustáceos e outros organismos planctônicos presentes nos pesqueiros amostrados no periodo chuvoso-quente (contin. ).

\begin{tabular}{|c|c|c|c|c|c|c|c|c|c|c|c|c|c|c|c|c|c|c|c|c|}
\hline & $\mathrm{CH} 11$ & & $\mathrm{CH} 12$ & & $\mathrm{CH}_{13}$ & & $\mathrm{CH} 14$ & & $\mathrm{CH} 15$ & & $\mathrm{CH} 16$ & & \begin{tabular}{|l|l|}
$\mathrm{CH} 17$ \\
\end{tabular} & & $\mathrm{CH} 18$ & & \begin{tabular}{|l|}
$\mathrm{CH} 19$ \\
\end{tabular} & & $\mathrm{CH} 20$ & \\
\hline & ind.. $\mathrm{m} 3$ & * & ind/m3 & 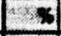 & ind/m3 & $\%$ & ind/m3 & \$) & ind $/ \mathrm{m} 3$ & $\$$ & ind./m3 & . & ind./m3 & * & ind Jm3 & 4 & \begin{tabular}{|l|l|} 
ind $/ \mathrm{m} 3$ \\
\end{tabular} & 3 & ind $/ \mathrm{m} 3$ & $*$ \\
\hline \multicolumn{21}{|l|}{ CLADOCERA } \\
\hline Alone of devidy & 2 & 0,7 & & & & & & & & & & & & & & & & & & \\
\hline Alone of guttate & & & & & & & & & & & & & & & & 0,5 & & & & \\
\hline Bosmine longrostris & & $E$ & & & 1 & 0.2 & 242 & 0,5 & 23 & 0.0 & & & 82 & 0,7 & 4 & 0,2 & & 0,1 & & \\
\hline Bosminopsis detitersi & & & & 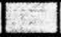 & & & & - & & 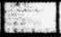 & & & 1 & का & & 0.5 & & 0,3 & & \\
\hline Diephenosome birge & 2 & 0,7 & & 0,1 & 2 & 0,4 & & & 21 & 0.8 & & & 4 & 0,4 & & 0,5 & & 0.2 & & \\
\hline Disperdione dedey & & & & & & & & & & & & & & & & - & 112 & 0,0 & & \\
\hline Mecrothix thserieds & & & 5 & 0,2 & & & & & 2 & 0,8 & & & & & & & & 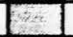 & & \\
\hline Mona minute & 22 & 0.8 & 18 & 20 & 56 & a.1 & & & 21 & 0.8 & & & 4 & 0.4 & 4 & 02 & 1236 & 0 & 127 & 0,4 \\
\hline Iyocryptus spiniter & 1 & 0.3 & & - & & & & & & & & & & & & & & F. & & \\
\hline \multirow[t]{2}{*}{ Subtotal } & 25 & 0,9 & 26 & 0.1 & 59 & 0.1 & 242 & 0,5 & 274 & 1,6 & & & 91 & 0,8 & 1 & 2,5 & 1357 & 100 & 127 & 0,4 \\
\hline & & & & \pm & & & & & & $\square$ & & & & & & 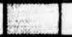 & & 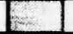 & & \\
\hline \multicolumn{21}{|l|}{ COPEPODA CYCLOPOIDA } \\
\hline neuphos & & & & anes & 41) & 0,023 & 512 & 1,650 & & 0,154 & 12633 & 32,4 & 14167 & 12,62 & 16 & 0,796 & 36) & 3000 & 23 & 30,868 \\
\hline copepootios & & 0,3 & & 05 & 27) & 0,8 & 16 & 0.3 & 3 & 0.1 & & 0,7 & 2 & 0,2 & & 0,3 & 84 & $1-26$ & & 0.6 \\
\hline Acanthogyolops sp mectios & & 1 & & 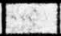 & & & T & 0,3 & & 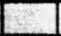 & & & & L & & T & & E & & \\
\hline Acenthrogrobops ap itimeas & & & & 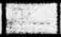 & & & & 0.3 & & E. & & & & E. & & $\square$ & & 5 & & \\
\hline \multicolumn{2}{|l|}{ Eucydopos psoudionsilier mechos } & & & Ex & & E & 1 & 0,3 & & 5 & & & & 5 & & D & & 0,0 & & \\
\hline \multirow[t]{2}{*}{ E. psevudoensilier timeas } & & & & L & & E & & - & & 5 & & & & E & & L & & 02 & & \\
\hline & & & & $x=5$ & & Z & & E & & 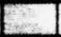 & & 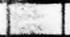 & & E: & & E. & & 0,1 & & E \\
\hline \multicolumn{2}{|l|}{ 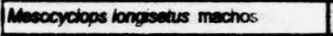 } & & & E & & L & & 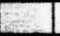 & & $\infty$ & & 0,4 & & 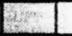 & & E & & I & & \\
\hline \multicolumn{2}{|l|}{ Mulacyctops mendocanus machos } & & & 5 & & $E$ & & E. & 4 & 0.2 & & C. & & E. & & E. & & 1 & & 0.2 \\
\hline M mendocinus tomeas & & 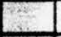 & & E & & E & 1 & 0.3 & 2 & 0,8 & & - & & $E$ & & 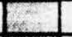 & & $E$ & & \\
\hline \multicolumn{2}{|l|}{ Thermograbos decipiens machos } & 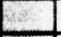 & & D. & & L & 1 & 0,3 & & $\square$ & & 0,5 & & 20 & & L & & 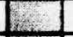 & & \\
\hline T. decipiens fomeas & & 5 & & E2: & & ER & & 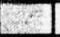 & & 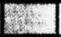 & & 035 & & $0=0$ & & 5.1. & & Tex & & 2 \\
\hline \multicolumn{2}{|l|}{ Thermocyolops inversus mechos } & & & 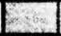 & & 5 & & 5 & & 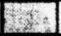 & & ER & & E & & 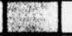 & & 2019 & & 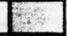 \\
\hline T. prasinus timoess & & Ec & & 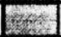 & & Evect & & 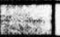 & & $\square$ & & E. & & Ex & & $=2$ & & 50 & & 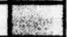 \\
\hline T. prasinus timees ovadas & & $E$ & & $E$ & & II & & E. & & (2) & & Im & & Wentan & & 27. & & (5n & & 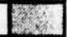 \\
\hline \multirow[t]{2}{*}{ Subtom a } & & 0,3 & & 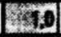 & 68) & 0,1 & 533 & 20 & 13 & 0.5 & 13373 & सx, & 14197 & 126 & 23 & 120.1 & 13. & $3 \times 20$ & 32 & 20.0 \\
\hline & & & & 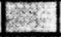 & & E. & & 2 & & 2 & & E: & & Ez: & & Whar & & 15 & & 2 \\
\hline COPEPODA CALANOIDA & & & & Be & & Ein & & Min & & Ext & & I & & Dim & & 12 & & Wan & & 5 \\
\hline neuphos & & $\mathrm{E}$ & & 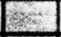 & 15 & 0 & & E & & E & 25 & 24 & 4333 & 30 & & 5 & & Wint & 126 & $3=0$ \\
\hline copepoditos & & & & L & 3 & (2.7) & & E & & Z & 2 & 0,4 & & E. & & E.a. & & 10 & 3 [ & 30 \\
\hline Natodiaptomus sp mechos & & & & E & & & & - & & L & 4 & a.2 & & & & $\square$ & & Fi: & & -1 \\
\hline \multirow[t]{2}{*}{ Subtocal } & & & & Z & 18 & 0,4 & & Ex & & Fin & 253 & 4,5 & 4303 & 39 & & 8 & & 12 & 120 & 0,4 \\
\hline & & 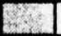 & & 221] & & m & & Ex & & Whe & & t1: & & E. & & W.2 & & 5 & & 2 \\
\hline \multicolumn{2}{|c|}{ COPEPODA POECILOSTOMATOIDA } & & & 2 & & $E$ & & E & & Ex & & 1 & & 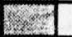 & & 5 & & 12 & & 5 \\
\hline ntuphos & & & & 85 & & 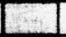 & 32 & 0.059 & & 077 & & $E$ & & $\square$ & & L & & TE & & \\
\hline \multirow[t]{2}{*}{ copepoditos } & & & & 0 & & L. & & D. & & $E^{2}$ & & men & & Sin & & . & & E. & & \\
\hline & & Ex & & 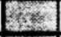 & & 5 & & E. & & Ea] & & E & & 5 & & 10 & & Es: & & 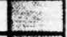 \\
\hline CHAOBORIDAE & & E: & & Did & & 5 & & E2I & & Ex: & & B. & & Dix & & 205 & & 1 & & 2 \\
\hline GHIRONOMIDAE & & $E$ & & 5 & & हa्य & 56. & (2) & & Eext & & $\ln 2$ & & E. & 1 & 105 & & 3 & & 103 \\
\hline OLIGOCHAETA & & Cist: & & Ees] & 3 & [थ] & & एक्षा & & 15: & & 2 & & Exid & & 13 & & $1-2$ & & 6i: \\
\hline NEMATODA & & क- & & 2 & & 인 & & 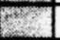 & & $m$ & & Ex & & Int & & 2 & & 15 & & $E$ \\
\hline Tothe de orgeniemos na amostrts & 28773 & 100 & 26476 & 100 & 454374 & 100 & 485798 & 100 & 25965 & 500 & 56328 & 700 & 112242 & 100 & 23872 & 100 & 13591 & 100 & 344388 & $\begin{array}{l}300 \\
100\end{array}$ \\
\hline
\end{tabular}


Tabela 7: Densidades numéricas (ind $/ \mathrm{m}^{3}$ ) dos crustáceos e outros organismos planctônicos presentes nos pesqueiros amostrados no período chuvoso-quente (contin.).

\begin{tabular}{|c|c|c|c|c|c|c|c|c|c|c|c|c|c|c|c|c|c|c|c|c|}
\hline & 21 & & 22 & & 23 & & 24 & & 25 & & 26 & & 27 & & 28 & & 29 & & 30 & \\
\hline & ind. $/ \mathrm{m} 3$ & $\%$ & $\mathrm{nd} / \mathrm{m} 3$ & 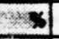 & ind. $/ \mathrm{m} 3$ & \% & & \%) & ind. $/ \mathrm{m} 3$ & 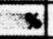 & ind $/ \mathrm{m}^{3}$ & * & ind $/ \mathrm{m} 3$ & \% & ind./m3 & $\mathbf{3}$ & ind $/ \mathrm{m}^{3}$ & $\%$ & ind $/ \mathrm{m} 3$ & $\%$ \\
\hline \multicolumn{21}{|l|}{ CLADOCERA } \\
\hline \multicolumn{21}{|l|}{ Alone di devidy } \\
\hline \multicolumn{21}{|l|}{ Alone of retangule } \\
\hline \multicolumn{21}{|l|}{ Bosmine longirostins } \\
\hline \multicolumn{21}{|l|}{ Bosminopsis doitersi } \\
\hline \multicolumn{21}{|l|}{ Ceriodephnie comuta ngaudi } \\
\hline Diephenosome burgei & & & 29 & 02 & & & & & 13 & 0.2 & 924 & 25 & 84 & 0,7 & & - & 24 & 0.0 & 4 & 0,7 \\
\hline Mecrothrix lebicomis & $3 \mid$ & 0.1 & & 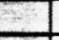 & & & & & & & & & & & & & & 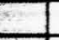 & & \\
\hline \multicolumn{21}{|l|}{ Mecrothrix trisenielis } \\
\hline Noine minute & 7) & $-0,3$ & 411. & 20 & 18 & 2,6 & 2664 & 6,6 & 6) & 0.2 & 376 & 1,3 & 48 & 0,4 & 24 & 100 & 6 & 0,2 & 1 & 0.2 \\
\hline \multicolumn{21}{|l|}{ Simocephelus semulatus } \\
\hline \multicolumn{21}{|l|}{ Mocryphes spiniter } \\
\hline \multirow[t]{2}{*}{ Subtotal } & 1 & 0.4 & 517 & 3,3 & 18 & 2,6 & 2692 & 5.6 & 111 & 0,3 & 2378 & 2.5 & 209 & 23 & 25 & 0,1 & 92 & 0,4 & 5 & 0,9 \\
\hline & & & & $\pi$ & & & & & & & & & & & & - & & & & \\
\hline \multicolumn{21}{|l|}{ COPEPOOA CYCLOPOIDA } \\
\hline ntuplios & 17 & $\therefore 0.7$ & 3. & 82 & 5628 & $\mathbf{4 , 7}$ & 158 & 3.3 & 612 & 110 & 282 & $\$ 7.5$ & 244 & 7.5 & 34) & 1,4 & 112 & 0,4 & 1755 & 32,8 \\
\hline copepocitios & 2 & .08 & 4 & 93 & 1468 & -38 & 2468 & 6,2 & 1128 & 24 & 1988 & 6.4 & 796 & 62 & 124 & 0.5 & 72 & 0,3 & 96 & 1,8 \\
\hline \multicolumn{2}{|l|}{ Eucyclopos peeudoensifier $m$} & {[} & & 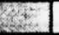 & 2 & 0.5 & & 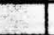 & & 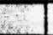 & & 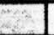 & 1 & 0.8 & & 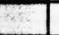 & & 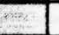 & 1) & 0,2 \\
\hline E. percudoensiler tomees & & E & & 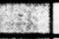 & & 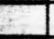 & 2 & 0.4 & & 3 & & - & 6 & 0.5 & & 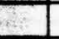 & & sn & & 5 \\
\hline \multicolumn{2}{|l|}{ E. previdoenaitor timeas ovedas } & 5 & & 5 & & $=$ & & & & 5 & & 5 & 1 & 0.8 & & 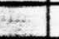 & & $\overline{2}$ & & \\
\hline \multicolumn{2}{|l|}{ Nonteyclops mendocanus mechos } & Es & & at: & 78 & 02 & & 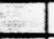 & & - & & + & & 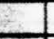 & & 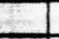 & & - & & \\
\hline M mencocinus temees & & Eeste. & & 201 & 7 & +2 & & 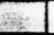 & & 5 & & +2 & & $\therefore$ & & . & & - & & 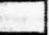 \\
\hline \multicolumn{2}{|l|}{ Thermocyclops decipiens mechos } & 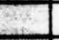 & & 2 & 5 & 0.9 & 14] & 02 & 96 & 0,2 & 58 & 21,4 & & - & & - & 1 & a.4. & 46 & 0,9 \\
\hline T. decopiens themeas & & 25 & & 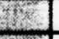 & & 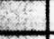 & 28 & 0.8 & 4) & 0,7 & 84 & 02 & & 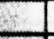 & 1 & 0,4 & 1 & 0.4 & 31 & 0,6 \\
\hline T. decipiens Himeas ovedes & & $5=$ & & S3x & & $x^{2}$ & & 2 & & 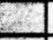 & 24) & 07 & & 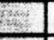 & & $x^{2}$ & & 2 & 13 & 2,2 \\
\hline \multicolumn{2}{|l|}{ Tropocyctops presinus machos } & 0,4 & & 64 & & 5 & & 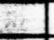 & & - & & $\infty$ & & - & & 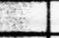 & & 5 & & 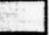 \\
\hline \multicolumn{2}{|l|}{ T. prasinus timeas } & 5 & 3 & 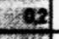 & & sets & & -3 & & 1 & & 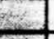 & & Ex: & & 5 & & 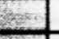 & & 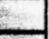 \\
\hline \multicolumn{2}{|l|}{ T. provinus timeess ovedes } & $\sqrt{3 x}$ & 1 & 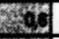 & & (1) & & 7 & & $m$ & & $m$ & & sen & & 2 & & thens: & & $\square$ \\
\hline Sublotal & 37 & 0.1 & 7 & 101 & 7186 & 18 & 4182 & 6.7 & 7348 & 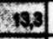 & 23424 & 042 & 1748 & 73,7 & 465 & 1,0 & 186 & $\operatorname{an}$ & 18591 & 32,7 \\
\hline & & x & & s. & & 3 & & 2 & & 2 & & 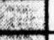 & & 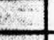 & & 8 & & 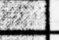 & & 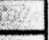 \\
\hline COPEPODA CALANOIDA & & res: & & W. & & 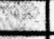 & & 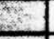 & & 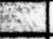 & & 2 & & 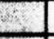 & & 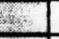 & & 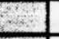 & & 2 \\
\hline ntuplios & & 5 & & 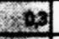 & & 3 & 28 & 0.8 & 56 & 0.9 & & $\therefore$ & & 5 & 264 & 20 & & 8 & 635 & 112 \\
\hline coppepoditios & & 2 & & 5 & & 3 & & 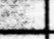 & & 1 & & 1 & & $=$ & 8 & 03 & & + & 3 & 0,6 \\
\hline Subtotal & & 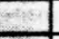 & 5 & 03 & & 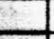 & 28 & 0,6 & 56 & 0.1 & & 5 & & 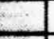 & 272 & 1,1 & & 2 & 6353 & 11,0 \\
\hline & & 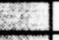 & & 8 & & 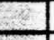 & & - & & & & 2 & & 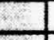 & & 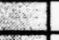 & & 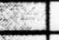 & & 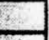 \\
\hline CHAOBORIDAE & & 2 & & sest & & -3 & & 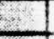 & & 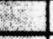 & & 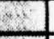 & & 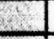 & & 3 & & 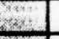 & & 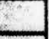 \\
\hline CHIRONOMIDAE & & 0,1 & & 42 & 3 & 0.8 & 12. & 03 & 12 & 02 & 16 & 8 & 5) & 204 & 3 & 81 & & 6 & 2 & 00 \\
\hline PLECOPTERA & & 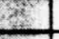 & & 8 & & $\square$ & & -1 & & 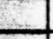 & & -1 & & + & & 4 & & 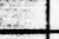 & 2 & Q.4. \\
\hline OLIGOCHAETA & 1 & 204 & & 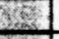 & 4 & 0.1 & & 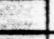 & 1 & 02 & 3 & 0.8 & & 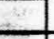 & 5 & 03 & 2 & 0,8 & & 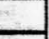 \\
\hline Total de orgenismos na amostral & 257511 & 300 & 15697 & 100 & 38311 & 100 & 47995 & 100 & 553545 & 100 & 364965 & 100 & 12742 & 100 & 2435 & 100 & 256464 & 100 & 535344 & 100 \\
\hline
\end{tabular}


Tabela 8: Táxons da comunidade zooplanctônica presentes nas amostras coletadas nos dois periodos estudados (+ presença: - ausência)

\begin{tabular}{|c|c|c|}
\hline & Estiagem/Frio & Chuvoso/quente \\
\hline $\begin{array}{l}\text { ROTIFERA } \\
\text { Anureeopsis fissa (Gosse, 1851) }\end{array}$ & + & + \\
\hline Ascomorpha sp & $\rightarrow$ & - \\
\hline Ascomorpha ecaudis (Perty. 1859) & + & + \\
\hline Asplanchna sieboldi (Leydig, 1954) & + & + \\
\hline Brachionus angularis Gosse, 1851 & + & + \\
\hline Brachionus angularis chelonis (Ahlstrom. 1940) & + & + \\
\hline Brachionus angularis psoudolabratus (Ahlistrom, 1940) & + & - \\
\hline Brechionus bidentatus Anderson 1889 & + & - \\
\hline Brechionus budapestinensis Daday 1885 & + & - \\
\hline Brachionus calyciliorus calycilionus (Pallas, 1766) & + & + \\
\hline Brachionus calycilions amphiceros (Ehrb., 1838) & + & + \\
\hline Brachionus calycifiorus enureeiformis (Brehm, 1909) & + & - \\
\hline Brachionus caudatus Barrois \& Daday 1884 & + & + \\
\hline Brechionus caudatus austrogenitus Anlstrom. 1940 & + & \pm \\
\hline Brachionus caudatus personatus Ahlstrom, 1940 & + & + \\
\hline Brachionus caudatus vulgatus Ahlstrom. 1940 & + & - \\
\hline Brachionus dolabratus Harring 1915 & + & + \\
\hline Brachionus falcatus falcatus Zacharias 1898 & + & + \\
\hline Brechionus havanaonsis Rousselet 1911 & + & + \\
\hline Brachionus mirus mirus Daday 1905 & + & + \\
\hline Brachionus mirus angustus (Koste, 1972) & - & - \\
\hline Brachionus minus laticaudatus Paggi 1973 & + & - \\
\hline Brechionus palulus patulus (O. F. Muller. 1786) & + & + \\
\hline Brachionus quadridontatus quadridentatus Hermann 1783 & + & + \\
\hline Brachionus quadridontatus brevispinus (Ehrb, 1832) & + & - \\
\hline Brachionus quadridentatus cluniorbicularis (Skorikov, 1894) & + & + \\
\hline Brachionus quedridentatus melheni (Barrois \& Daday, 1894) & + & - \\
\hline Cephalódolla sp & + & - \\
\hline Cephalodella qibba qibba (Ehrb, 1832) & + & + \\
\hline Cephalodella tonuiseta H. \& M. 1924 & + & - \\
\hline Collotheca sp & + & + \\
\hline Conochilus coenobasis Skorikov 1914 & + & + \\
\hline Conochilus dossuarius dossuarius (Hudson, 1875) & + & + \\
\hline Conochilus unicomis Rousselet, 1892 & + & + \\
\hline Diplouchlanis propatula (Gosse, 1886) & + & - \\
\hline Epiphanes macrourus (Barrois \& Daday, 1894) & + & + \\
\hline Filinia comuta brachiate (Rousselet, 1901) & + & + \\
\hline Filinia lonoisoto limnetica (Zacharias, 1893) & + & + \\
\hline Filinia longisota longiseta (Ehrb., 1834) & + & + \\
\hline Filinia opolionsis opoliensis (Zacharias, 1981) & + & + \\
\hline Gastropus cf. minor (Rousselet, 1892) & - & + \\
\hline Hoxerthre intormedia intermedia (Wiesniewski, 1929) & + & + \\
\hline Hoxerthre mire mire (Hudson, 1871) & + & + \\
\hline Kollicoltia bostonionsis (Rousselet, 1908) & + & + \\
\hline Keratolla amoricana Carlin, 1943 & + & + \\
\hline Keratalla cochloaris tocta (Laterborn, 1900) & + & + \\
\hline Koratolla lonzi lonzi (Hauer, 1953) & + & - \\
\hline Keratalla tropica tropica (Apstein 1907) & + & + \\
\hline Lecane (M.) sp & + & - \\
\hline Lecano bulla bulla (Gosse 1886) & + & + \\
\hline Lecane bulla styrax (H. \& M., 1926) & + & - \\
\hline Lecane lunaris lunaris (Ehrb., 1892) & + & + \\
\hline Lecane of scutate (H. \& M., 1926) & + & - \\
\hline Lecane (s. str.) sp & - & + \\
\hline Lecane acubata aculoata (Jakubski, 1912) & + & - \\
\hline Lecane curvicomis (Murray, 1913) & + & - \\
\hline Locano hamate (Stockes, 1896) & - & + \\
\hline Locane loystib loystila (Olofsson, 1917) & + & + \\
\hline Locane luna luna (Muller, 1776) & + & - \\
\hline Lecane quadridentate (Ehrb 1892) & - & + \\
\hline
\end{tabular}




\begin{tabular}{|c|c|c|}
\hline Lecane unquitata unguitata (Fadeew, 1925) & + & - \\
\hline Lecane proiecta Hauer 1956 & - & + \\
\hline Lecane stichaea stichaea Harring 1913 & + & - \\
\hline Lepedalla cf latusinus (Hilgendorf, 1899) & - & + \\
\hline Lepedella patella oblonga (Ehrb., 1834) & + & + \\
\hline Lepedella patella petella (O. F. Muller, 1786) & + & + \\
\hline Monommata lonqiseta (O. F. Muller, 1786) & + & + \\
\hline Mydiline bisulcate (Lucks, 1912) & + & + \\
\hline Platyias quadricomis quadricomis (Ehrb., 1832) & + & + \\
\hline Polyarthra vulgaris vulgaris Carlin, 1943 & + & + \\
\hline Polyarthra vulgaris f longiremis (Carlin, 1943) & + & + \\
\hline Pompholix sp & + & + \\
\hline Pompholix complanata Gosse 1851 & + & - \\
\hline Syncheota oblonga Ehrenberg 1831 & + & + \\
\hline Synchaete poctinate Ehrenberg 1832 & + & + \\
\hline Synchaeta stydata Wiezejski 1839 & - & + \\
\hline Testudinella patina intermedia Anderson 1898 & + & - \\
\hline Testudinolla patina patina (Hermann, 1783) & - & + \\
\hline Trichocorca bicristate (Gosse. 1887) & + & - \\
\hline Trichocerca capuccina Wierzejki \& Zachanias 1893 & - & + \\
\hline Trichocerca cylindrice (im Holf. 1891) & + & + \\
\hline Trichocerca cylindrica chattoni (Beauchamp, 1907) & + & + \\
\hline Trichocerca dixon-nutelli Jennings 1903 & + & + \\
\hline Trichocerca grecilis (Tessin, 1890) & + & + \\
\hline Trichocerce pusilla (Lauterborn, 1898) & + & + \\
\hline Trichocerca similis similis (Wierzejski, 1893) & + & + \\
\hline Trichocerca similis grandis (Hauer, 1965) & + & + \\
\hline Trichocerca stylate (Gosse, 1851) & + & + \\
\hline Bdolloidea & + & \pm \\
\hline $\begin{array}{l}\text { PROTOZOA } \\
\text { Thecamoeba }\end{array}$ & + & + \\
\hline Ciliophora & - & + \\
\hline GASTROTRICHA & - & + \\
\hline $\begin{array}{l}\text { CLADOCERA } \\
\text { Alona sp }\end{array}$ & - & + \\
\hline Alona of quttata (Sars, 1901) & - & + \\
\hline Alona cf poppoi Richard, 1897 & + & + \\
\hline Aona cf rectangula Sars, 1861 & - & + \\
\hline Alonelle sp & + & - \\
\hline Bosmine hermanni (Stingelin, 1904) & + & - \\
\hline Bosmina longirostris (O. F. Müller, 1785) & + & + \\
\hline Bosminopsis deiters (Richard, 1895) & + & + \\
\hline Coriodaphnia comuta nigaudi (Richard, 1894) & + & + \\
\hline Daphnia ambioue (Scourfield, 1947) & + & - \\
\hline Daphnia gassnori (Hersbst, 1967) & + & + \\
\hline Diaphanosoma birgai (Korineck, 1981) & + & + \\
\hline Diaphanosoma brovireme Sars, 1901 & + & + \\
\hline Disparalona daday (Birge, 1910) & + & + \\
\hline Ihocryptus spinifor (Herrich, 1884) & + & + \\
\hline Macrothrix sp & - & + \\
\hline Macrothrix laticomis (Jurine, 1820) & + & + \\
\hline Macrothrix triserialis & - & + \\
\hline Moina micrura (Kurz, 1874) & + & - \\
\hline Moina minuta (Hansen, 1899) & + & + \\
\hline Simocephalus of latirostris (Brady, 1866) & + & + \\
\hline Chydoridae (NI) & + & - \\
\hline $\begin{array}{l}\text { COPEPODA CYCLOPOIDA } \\
\text { Náuplios }\end{array}$ & + & + \\
\hline Copepoditos & + & + \\
\hline Acanthocyclops robustus (Sars, 1863) & + & + \\
\hline Eucyclopos pseudoensifor (Dussart, 1984) & + & + \\
\hline Mosocyctops longisetus (Thiébaud, 1914) & + & + \\
\hline Metacyclops mendocinus (Wierzejski, 1892) & + & + \\
\hline
\end{tabular}




\begin{tabular}{|c|c|c|}
\hline Microcyclops sp & + & - \\
\hline Thermocyciops decipiens (Kiefer, 1929) & + & + \\
\hline Thermocyctops inversus(Kiefer. 1936 & + & + \\
\hline Thermocyclops minutus (Lowndes. 1934) & + & - \\
\hline Tropocyctops prosinus (Fisher, 1860) & + & - \\
\hline $\begin{array}{l}\text { COPEPODA CALANOIDA } \\
\text { Nauplios }\end{array}$ & + & + \\
\hline Copepoditos & + & + \\
\hline Notodiaptomus cf henseni (Dahl. 1894) & + & + \\
\hline Notodiaptomus Sp & - & + \\
\hline $\begin{array}{l}\text { COPEPODA HARPACTICOIDA } \\
\text { Copepoditos }\end{array}$ & + & + \\
\hline $\begin{array}{l}\text { COPEPODA POECILOSTOMATOIDA } \\
\text { Náuplios }\end{array}$ & + & + \\
\hline Copepoditos & + & + \\
\hline adultos & + & + \\
\hline CHAOBORIDAE & + & + \\
\hline CHIRONOMIDAE & + & + \\
\hline PLECOPTERA & + & - \\
\hline OLIGOCHAETA & + & + \\
\hline NEMATODA & + & + \\
\hline OSTRACODA & + & - \\
\hline TOTAL & 122 & 104 \\
\hline
\end{tabular}


Tabela 9: Valores de riqueza. diversidade e equitatividade da comunidade zooplanctônica pesqueiros amostrados durante o período estiagem-frio.

\begin{tabular}{|c|c|c|c|}
\hline PESQUEIRO & RIQUEZA & DIVERSIDADE & EQUITATIVIDADE \\
\hline 1 & 24 & 2.73 & 0.14 \\
\hline 2 & 27 & 1.87 & 0.10 \\
\hline 3 & 31 & 2.27 & 0.12 \\
\hline 4 & 25 & 2.97 & 0.15 \\
\hline 5 & 35 & 3,40 & 0,17 \\
\hline 6 & 27 & 3.12 & 0.19 \\
\hline 7 & 28 & 3.74 & 0.22 \\
\hline 8 & 23 & 1.51 & 0.08 \\
\hline 10 & 30 & 2.90 & 0.15 \\
\hline 11 & 29 & 3.18 & 0.16 \\
\hline 12 & 30 & 2.41 & 0.14 \\
\hline 13 & 24 & 3.06 & 0.17 \\
\hline 14 & 21 & 3.10 & 0.19 \\
\hline 15 & 30 & 2.67 & 0.13 \\
\hline 16 & 21 & 3.24 & 0,19 \\
\hline 17 & 25 & 2.35 & 0.13 \\
\hline 18 & 28 & 3.09 & 0,18 \\
\hline 19 & 30 & 3.77 & 0.25 \\
\hline 20 & 32 & 3,12 & 0,15 \\
\hline 21 & 22 & 2.54 & 0,16 \\
\hline 22 & 28 & 3,09 & 0,18 \\
\hline 23 & 33 & 3.57 & 0,20 \\
\hline 24 & 32 & 2.99 & 0,15 \\
\hline 25 & 33 & 3,45 & 0,16 \\
\hline 26 & 23 & 1.94 & 0.09 \\
\hline 27 & 22 & 2.06 & 0.14 \\
\hline 28 & 21 & 2,69 & 0.20 \\
\hline 29 & 25 & 3,36 & 0,18 \\
\hline 30 & 27 & 2,71 & 0,13 \\
\hline
\end{tabular}


Tabela 10: Valores de riqueza. diversidade e equitatividade da comunidade zooplanctônica pesqueiros amostrados durante o periodo chuvoso-quente.

\begin{tabular}{|c|c|c|c|}
\hline PESQUEIRO & RIQUEZA & DIVERSIDADE & EQUITATIVIDADE \\
\hline 1 & 29 & 3.70 & 0.23 \\
\hline 2 & 34 & 2,11 & 0.10 \\
\hline 3 & 43 & 4.03 & 0.23 \\
\hline 4 & 29 & 2.42 & 0.15 \\
\hline 5 & 31 & 2.62 & 0,14 \\
\hline 6 & 24 & 3.22 & 0.19 \\
\hline 7 & 38 & 3.99 & 0.22 \\
\hline 8 & 28 & 3.24 & 0.20 \\
\hline 9 & 37 & 3.37 & 0.18 \\
\hline 10 & 33 & 3.26 & 0.18 \\
\hline 11 & 29 & 2.95 & 0.16 \\
\hline 12 & 27 & 3.38 & 0.19 \\
\hline 13 & 38 & 3.34 & 0.18 \\
\hline 14 & 36 & 3.21 & 0,17 \\
\hline 15 & 32 & 2.93 & 0.16 \\
\hline 16 & 24 & 3.17 & 0.20 \\
\hline 17 & 32 & 3,35 & 0.20 \\
\hline 18 & 36 & 3.30 & 0.19 \\
\hline 19 & 35 & 3.52 & 0.21 \\
\hline 20 & 39 & 3.68 & 0.20 \\
\hline 21 & 35 & 2.54 & 0.14 \\
\hline 22 & 30 & 3,34 & 0.19 \\
\hline 23 & 26 & 2.52 & 0.14 \\
\hline 24 & 31 & 2.89 & 0.15 \\
\hline 25 & 37 & 3.58 & 0.19 \\
\hline 26 & 26 & 2.25 & 0.12 \\
\hline 27 & 31 & 3.95 & 0.23 \\
\hline 28 & 26 & 3.29 & 0.18 \\
\hline 29 & 33 & 3,42 & 0.19 \\
\hline 30 & 26 & 1.97 & 0.10 \\
\hline
\end{tabular}


Tabela 11: Correlações das variáveis físicas, químicas e clorofila a com os eixos 1 e 2. correspondentes ao periodo estiagem-frio

\begin{tabular}{|l|c|c|}
\hline VARIÁVEIS & EIXO 1 & EIXO 2 \\
\hline Temperatura (TEMP) & -0.068 & 0.167 \\
\hline Condutividade (COND) & -0.388 & 0.083 \\
\hline pH & 0.023 & 0.561 \\
\hline Oxigénio dissolvido (OD) & -0.038 & 0.570 \\
\hline transparência (TRANSP) & 0.306 & 0.455 \\
\hline Sólidos totais em suspensão (STS) & -0.465 & -0.023 \\
\hline Nitrogênio inorgânico (Ninorg) & -0.363 & -0.208 \\
\hline Fósforo total (PT) & -0.471 & 0.198 \\
\hline Clorofila a (CHL) & -0.423 & 0.190 \\
\hline Variância explicada & $\mathbf{3 4 , 0 0 \%}$ & $\mathbf{2 1 , 8 0 \%}$ \\
\hline
\end{tabular}

Tabela 12: Correlações das variáveis físicas, quimicas e clorofila a com os eixos 1 e 2 , correspondentes ao periodo chuvoso-quente

\begin{tabular}{|l|c|c|}
\hline VARIÁVEIS & EIXO 1 & EIXO 2 \\
\hline Temperatura (TEMP) & 0.036 & 0.347 \\
\hline Condutividade (COND) & 0.407 & -0.165 \\
\hline pH & 0.367 & 0.350 \\
\hline Oxigênio dissolvido (OD) & -0.013 & 0.614 \\
\hline transparência (TRANSP) & -0.442 & 0.109 \\
\hline Sólidos totais em suspensão (STS) & 0.435 & -0.075 \\
\hline Nitrogênio inorgánico (Ninorg) & 0.289 & -0.363 \\
\hline Fósforo total (PT) & 0.434 & 0.067 \\
\hline Clorofila a (CHL) & 0.204 & 0.446 \\
\hline Variância explicada & $\mathbf{3 7 , 6 0 \%}$ & $\mathbf{2 1 , 6 0 \%}$ \\
\hline
\end{tabular}


Tabeia 13: Correiações dos taxons de rotiferos com os eixos 1 e 2. correspondentes ao periodo estiagem-frio

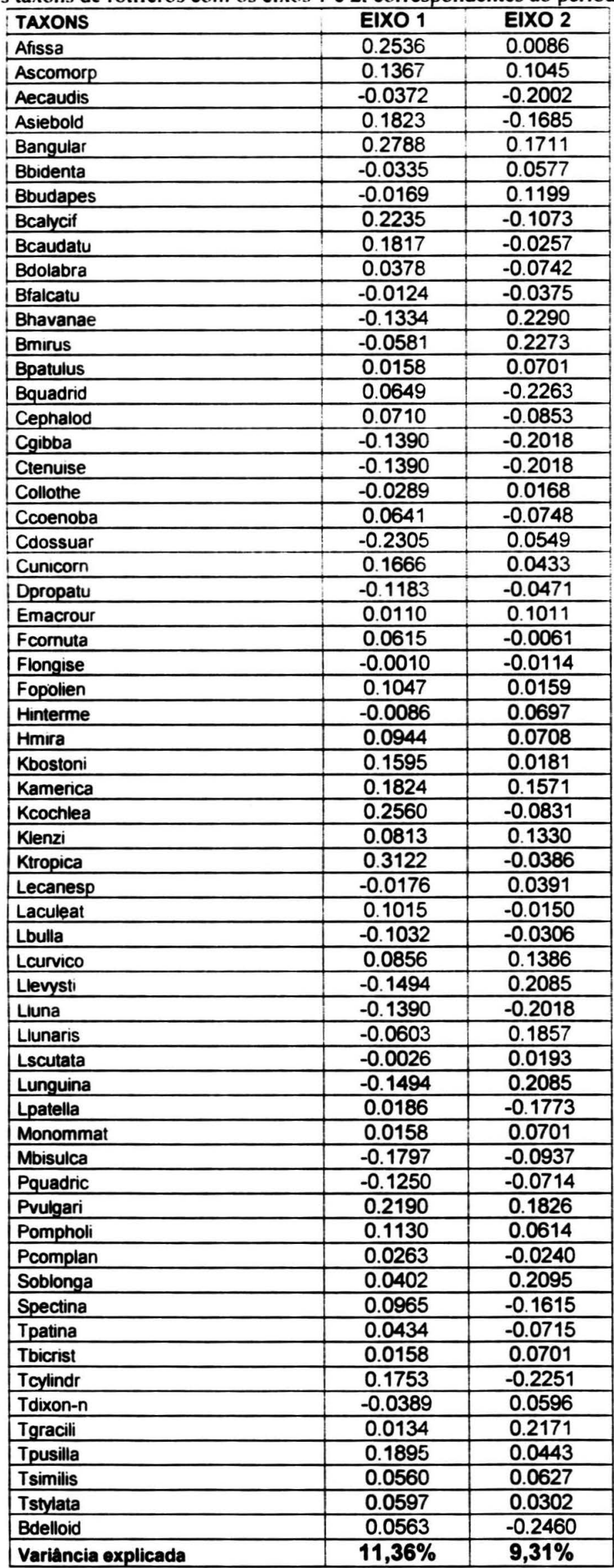


Tabela 14: Correlaçòes dos táxons de crustáceos com os eixos 1 e 2. correspondentes ao periodo chuvoso-quente

\begin{tabular}{|c|c|c|}
\hline TAXONS & EIXO 1 & EIXO 2 \\
\hline Afissa & -0.1280 & -0.2136 \\
\hline Aecaudis & -0.0582 & 0.0338 \\
\hline Asiebold & -0.1717 & -0.1400 \\
\hline Bangular & -0.1412 & -0.0020 \\
\hline Bbidenta & -0.0388 & 0.0594 \\
\hline Bbudapes & 0.0331 & 0.0184 \\
\hline Bcalycif & -0.2676 & -0.0744 \\
\hline Bcaudatu & -0.2297 & 0.0098 \\
\hline Bdolabra & 0.0719 & 0.0683 \\
\hline Bfalcatu & -0.0723 & 0.0960 \\
\hline Bhavanae & -0.0785 & 0.1568 \\
\hline Bmirus & 0.2529 & -0.1770 \\
\hline Bpatulus & -0.0340 & 0.1222 \\
\hline Bquadrid & -0.2798 & -0.0005 \\
\hline Cgibba & 0.1046 & -0.2691 \\
\hline Collothe & 0.2798 & -0.1369 \\
\hline Ccoenoba & 0.1257 & -0.0555 \\
\hline Cdossuar & 0.1028 & -0.1729 \\
\hline Cunicorn & 0.0488 & 0.0736 \\
\hline Emacrour & -0.1288 & -0.1056 \\
\hline Fcornuta & -0.1366 & 0.0100 \\
\hline Flongise & -0.0560 & -0.0411 \\
\hline Fopolien & -0.0815 & -0.1072 \\
\hline Gminor & -0.1221 & -0.0706 \\
\hline Hinterme & 0.0946 & 0.0440 \\
\hline Hmira & -0.1373 & -0.1653 \\
\hline Kbostoni & 0.1974 & -0.1752 \\
\hline Kamerica & 0.0559 & -0.0179 \\
\hline Kcoclear & -0.1172 & 0.1653 \\
\hline Klenzi & -0.0393 & -0.0132 \\
\hline Ktropica & -0.2572 & 0.1363 \\
\hline Laculeat & -0.0232 & 0.0368 \\
\hline Lbulla & -0.0861 & -0.1385 \\
\hline Lhamata & 0.1084 & 0.1084 \\
\hline Llevysti & 0.1108 & 0.0034 \\
\hline Llunaris & -0.0209 & 0.0878 \\
\hline Lecane & -0.0565 & 0.0165 \\
\hline Lpapuana & 0.0237 & -0.1026 \\
\hline Lquadrid & 0.1046 & -0.2691 \\
\hline Lremanei & -0.0476 & -0.0352 \\
\hline Lrotunda & 0.0331 & 0.0184 \\
\hline Lstiaea & 0.0272 & -0.0363 \\
\hline Ltriloba & 0.1033 & -0.0144 \\
\hline Llatusin & 0.2279 & 0.1281 \\
\hline Lpatella & 0.0264 & 0.1066 \\
\hline Mlongise & -0.0304 & 0.0071 \\
\hline Mbisulca & -0.0959 & 0.0853 \\
\hline Pquadric & 0.1946 & 0.1898 \\
\hline Pvulgari & -0.1966 & -0.0824 \\
\hline Pompholi & -0.0770 & 0.0454 \\
\hline Soblonga & -0.0350 & -0.2934 \\
\hline Spectina & -0.0601 & -0.0631 \\
\hline Sstylata & -0.0980 & -0.1814 \\
\hline Tpatina & 0.0800 & 0.1216 \\
\hline Tcapucin & 0.0675 & 0.0866 \\
\hline Tcylindr & -0.0954 & -0.0967 \\
\hline Tdixon-n & -0.0445 & -0.0506 \\
\hline Tgracili & 0.1341 & $\begin{array}{l}-0.1992 \\
\end{array}$ \\
\hline Tpusilla & -0.2162 & -0.1809 \\
\hline Tsimilis & -0.0395 & -0.0691 \\
\hline Tstylata & 0.0687 & -0.3233 \\
\hline Bdelloid & -0.0065 & -0.1699 \\
\hline Variância explicada & $10,60 \%$ & $9,12 \%$ \\
\hline
\end{tabular}


Tabela 15: Correlaçôes dos táxons de crustáceos com os eixos 1 e 2. correspondentes ao periodo estiagem-frio

\begin{tabular}{|l|r|r|}
\hline TAXONS & ElXO 1 & EIXO 2 \\
\hline Apoppei & -0.0642 & 0.0271 \\
\hline Alonella & -0.3834 & -0.2076 \\
\hline Bnagmani & -0.3834 & -0.2076 \\
\hline Blongiro & -0.0104 & 0.3503 \\
\hline Bdeiters & 0.0315 & 0.0710 \\
\hline Dambigua & -0.3834 & -0.2076 \\
\hline Dgessner & -0.1090 & -0.0831 \\
\hline Dbirgei & -0.2222 & 0.2047 \\
\hline Dbrevire & 0.0154 & 0.2203 \\
\hline Ddaday & -0.0355 & -0.0343 \\
\hline Mlaticor & 0.0623 & -0.1174 \\
\hline Mmicrura & 0.0207 & 0.0786 \\
\hline Mminuta & 0.0721 & 0.1134 \\
\hline Slatiros & 0.0612 & 0.1720 \\
\hline Ispinife & 0.0216 & -0.1450 \\
\hline nauplioC & -0.2823 & 0.2531 \\
\hline copepodi & -0.3106 & 0.2667 \\
\hline Acanthoc & 0.0612 & 0.1720 \\
\hline Epseudoe & 0.1273 & -0.0479 \\
\hline Mlongise & -0.0174 & 0.2182 \\
\hline Mmendoci & -0.0587 & 0.1804 \\
\hline Microcyc & 0.0482 & 0.0890 \\
\hline Tdecipie & -0.3707 & 0.0992 \\
\hline Variáncia explicada & $16,26 \%$ & $13,09 \%$ \\
\hline & & \\
\hline
\end{tabular}

